\title{
Nordic Management-Labour Relations and Internationalization
}

Converging and Diverging Tendencies

Edited by Daniel Fleming and Christer Thörnqvist

Nord 2003:015 


\section{Nordic Management-Labour Relations and Internationalization Converging and Diverging Tendencies}

Nord 2003:015

(C) Nordic Council of Ministers, Copenhagen 2003

ISBN 92-893-0954-7

ISSN 0903-7004

Print: Aka-print A/S, Århus 2003

Cover: dorte $\mathrm{p}$ grafisk design

Copies: 600

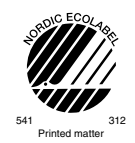

Printed on paper approved by the Nordic Environmental Labelling.

This publication may be purchased from any of the agents listed on the last page.

Printed in Denmark

\author{
Nordic Council of Ministers \\ Store Strandstræde 18 \\ DK-1255 Copenhagen K \\ Phone (+45) 33960200 \\ Fax (+45) 33960202
}

Website: www.norden.org

\author{
Nordic Council \\ Store Strandstræde 18 \\ DK-1255 Copenhagen K \\ Phone (+45) 33960400 \\ Fax (+45) 33111870
}

\section{Nordic Labour Market Cooperation}

is regulated via separate agreements and conventions. The Nordic Council of Ministers (the Ministers of Labour) draws up the political guidelines for cooperation in this area, which also covers general working conditions, legal aspects of industrial relations and the migration of workers in the Nordic region. The Nordic Council of Ministers is assisted by the Nordic Committee of Senior Officials for Labour Market and Working Environment Policy. The secretariat of the Council of Ministers is located in Copenhagen.

\section{The Nordic Council of Ministers}

was established in 1971. It submits proposals on cooperation between the governments of the five Nordic countries to the Nordic Council, implements the Council's recommendations and reports on results, while directing the work carried out in the targeted areas. The Prime Ministers of the five Nordic countries assume overall responsibility for the cooperation measures, which are co-ordinated by the ministers for cooperation and the Nordic Cooperation committee. The composition of the Council of Ministers varies, depending on the nature of the issue to be treated.

\section{The Nordic Council}

was formed in 1952 to promote cooperation between the parliaments and governments of Denmark, Iceland, Norway and Sweden. Finland joined in 1955. At the sessions held by the Council, representatives from the Faroe Islands and Greenland form part of the Danish delegation, while Åland is represented on the Finnish delegation. The Council consists of 87 elected members - all of whom are members of parliament. The Nordic Council takes initiatives, acts in a consultative capacity and monitors cooperation measures. The Council operates via its institutions: the Plenary Assembly, the Presidium and standing committees. 


\section{Contents}

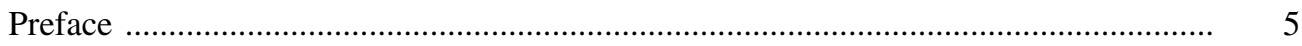

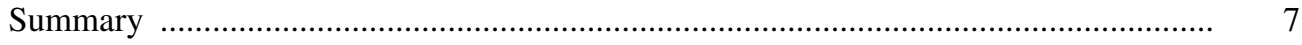

Sammanfattning (summary in Swedish) ……………………………………...... 8

1. Nordic Management-Labour Relations and Internationalization -

Converging and Diverging Tendencies

Daniel Fleming and Christer Thörnqvist

2. Towards Reflexive Governance of Management-Labour Relations?

Corporate Culture and Human Resource Management in Malaysia and Singapore ...

Daniel Fleming and Henrik Søborg

3. Between the Local and the Global - Representing Employee Interests in European Works Councils of Multinational Companies

Herman Knudsen

4. The Making of EWCs: A Comparison of European Works Councils in Four Scandinavian Transnationals

Monica Andersson and Christer Thörnqvist

5. International Management Strategies and Models of Industrial Relations -

A Norwegian Experience

Jan Heiret

6. Flexible Times: Dynamics and Consequences of Company Strategies for Flexibility

Kristina Håkansson and Tommy Isidorsson

7. Decentralized Pay in the Danish Public Sector......

Kirsten Bregn

8. From Centralized Self-regulation to Organized Decentralization:

Occupational Health and Safety (OHS) in Sweden 1940-2002.

Annette Thörnquist

9. Gender-specific Strategies for Industrial Action: The Swedish Case

in Historical Perspective

Susanne Fransson and Christer Thörnqvist

10. Research and Politics - The NordFram Group 1989-2003

Bernt Schiller

Contributors 



\section{Preface}

Ever since the mid-1980s, the inter-disciplinary research group NordFram (the Future of the Nordic Model) has written widely on labour-management relations in the Nordic countries from different perspectives. The theme for the last project, which we wish to present in this book, has been convergence and divergence of Nordic management-labour relations.

The teams have always consisted of researchers from all the five independent Nordic countries. A majority of the scholars over the years have been sociologists and historians, but also economists, political scientists, philosophers and student of labour law. The main results are published in three anthologies (see chapter 10 of this volume) of which this book is the last one.

Since this book is seemingly also the last one from the research group, at least for a long time, we wish to thank all the people who have taken part in research and meetings or in other ways contributed to the NordFram group over the years. To name them all is impossible, so our gratitude to them for their support goes to the anonymous collective - maybe a legitimate omission considering that many of our studies have focused on anonymous collectives, such as trade unions, employees in transnational groups in East Asia and European Works Councils.

Like the former projects, the latest project team, NordFram III, has involved researchers from all the Nordic countries. Yet, due to too heavy workload, some scholars had to leave the team before the project was finished; thus the present publication do not contain any studies of Iceland or Finland. Regrettably there is nothing to do about it; we hope this lack is somewhat compensated by our previous reports. However, the people, not presented in this publication, who have taken part in meetings and seminars during the running of this last project and by that helped improve the book a lot by giving ideas and comments on chapter drafts deserve a specially warm thanks. We would therefore in particular wish to thank Pauli Kettunen, Anders Kjellberg, Thor Indridasson and Torgeir Aarvaag Stokke. Torgeir Aarvaag Stokke has also published within the frames of the project, though not in this book (Torgeir Aarvaag Stokke and Christer Thörnqvist (2001), 'Strikes and Collective Bargaining in the Nordic Countries', European Journal of Industrial Relations, vol. 7, pp. 245-67). We are also very grateful for the English language assistance and corrections made by Roger Leys and Linda Lane, and for the kind administrative and publishing services of the nice people at the Nordic Council of Ministers - especially for their patience with broken deadlines. Finally, we wish to thank the Nordic Council of Ministers for eco- 
nomically supporting all meetings within the NordFram III network, and for making this publication possible.

Roskilde and Gothenburg, September 2003

Daniel Fleming and Christer Thörnqvist 


\section{Summary}

The chapters in this book all - in one way or another - deal with the issue of how international influences on work organization and labour market developments affect Nordic models of industrial relations. The main stress is on managementlabour relations; the book studies both 'social partners' in national industrial relations systems and the impact of transnational groups' HRM policies. An important question is whether such relations - industrial relations and HRM policies converge or diverge due to the international pressure. A sub-theme for some of the chapters is the strong resilience of Nordic industrial relations and trade union participation, contrary to the almost universal reversal due to decades of neoliberal pressure, a global convergence working in the other direction. All the chapters presented here are however also independent pieces and can thus be read separately, depending on which aspects of Nordic industrial relations the reader is interested in. Accordingly, the book neither gives any 'final answer' to the query of convergence or divergence; it just discusses different aspects of the issue.

The first chapter of the book, by Fleming and Thörnqvist, gives a brief overview of the theoretical background for the project. The following three chapters all bring up aspects of the relations between transnational HRM policies and national industrial relations systems: Fleming and Søborg (Ch. 2) in three Danish multinationals and two IR systems in Malaysia and Singapore; Knudsen (Ch. 3) and Andersson and Thörnqvist (Ch. 4) in European Works Councils. The somewhat peculiar Norwegian case of simultaneous strengthening of national industrial relations systems and international management strategies is the theme for chapter 5 by Heiret, while Håkansson and Isidorsson (Ch. 6) focus on the use of different flexibility strategies and its consequences. Kirsten Bregn (Ch. 7) discusses the decentralization and individualization of bargaining and salary agreements in the Danish public sector. The subject of chapter 8, by Annette Thörnquist, is the connection between overall industrial relations trends and the handling of occupational health and safety issues. The main puzzle of chapter 9 , by Fransson and Thörnqvist, is why there are so big differences between maledominated and female-dominated occupational groups when it comes to industrial conflict patterns and negotiating strategies. Finally, Bernt Schiller (Ch. 10) concludes the book with an overview of the history and development of the NordFram network. 


\section{Sammanfattning}

Temat för den här boken är hur den s.k. Nordiska modellen för arbetsmarknadsrelationer påverkas av globaliseringen. Bokens fokus ligger på förhållandet mellan företag och anställda, både vad gäller arbetsmarknadens parter (dvs. fackföreningar och arbetsgivarorganisationer) och betydelsen av multinationella företags HRM-policy. En viktig fråga är om sådana förhållanden konvergerar eller divergerar mellan olika länder när de utsätts för internationellt ekonomiskt tryck. Flera kapitel tar också upp de nordiska arbetsmarknadernas relativa motståndskraft mot den nyliberala vågen under 1980- och 1990-talen. Alla kapitel i boken är dock självständiga bidrag som kan läsas var för sig, beroende på vilka intressen läsaren har. Följaktligen ger boken inte heller några sammanhållna svar på de frågor som diskuteras, utan behandlar bara så mångsidigt som möjligt olika aspekter av utvecklingen.

I bokens inledningskapitel anger Fleming och Thörnqvist projektets teoretiska ramar. Därefter följer tre kapitel som alla behandlar förhållandet mellan multinationella företags HRM-policy och nationella arbetsmarknadssystem: Fleming och Søborg (kap. 2) i tre danska företag i Malaysia och Singapore, och Knudsen (kap. 3) respektive Andersson och Thörnqvist (kap. 4) i Europeiska företagsråd, European Works Councils. Den något speciella norska utvecklingen, där både det nationella arbetsmarknadssystemet och inflytandet av internationella management-strategier stärkts samtidigt, tas upp i kapitel 5, av Jan Heiret. Håkansson och Isidorsson (kap. 6) behandlar olika flexibilitetsstrategier och deras konsekvenser, medan Kirsten Bregn (kap. 7) diskuterar decentraliseringen och individualiseringen av lönebildningen i den danska offentliga sektorn. I kapitel 8 tar Annette Thörnquist upp förhållandet mellan generella trender i arbetslivet, framför allt decentraliseringen, och arbetsmiljöfrågor, medan huvudfrågan i kapitel 9 , av Fransson och Thörnqvist, är varför förhandlings- och konfliktmönster skiljer så mycket mellan kvinnligt och manligt dominerade yrkesgrupper. I kapitel 10, slutligen, ger Bernt Schiller, som själv var med och skapade projektgruppen (Nordfram) i mitten av 1980-talet en historisk översikt över gruppens historia och utveckling. 


\section{Nordic Management-Labour Relations and Internationalization - Converging and Diverging Tendencies: A Theoretical Framework}

\section{Daniel Fleming and Christer Thörnqvist}

\subsection{Introduction}

How do globalization and international influences on work organization and labour market developments affect Nordic models of industrial relations? Before giving a theoretical framework for this discussion, a brief example can illustrate some new global tendencies.

Ericsson, like others companies in electronics, has out-sourced much of its manufacturing production chain to Flextronics, a US-owned specialist in Fordist mass production in the electronics industry. Some production goes to China. In China the plants have no unions and the working life of young countryside girls is organized patriarchally - like modern textile mills but with the same machines and technical competence as in other countries. Similarly, production chains in other industries can be divided into new networks, out-sourced and internationally split up with competing management-labour relations as one of the results. How do these and other global tendencies influence Nordic labour relations?

The theoretical discussion presented here will focus on international changes that challenge traditional Nordic management-labour relations in three interconnected areas. Section 2 deals with work organization and division of labour; section 3 discusses industrial relations (IR) and human resource management (HRM), while section 4 stresses the influence of international discourses and practices in international organizations. Finally, section 5 gives the outline of the book.

\subsubsection{What Do we Understand by Management-Labour Relations?}

The shift from Fordism to decentralized networks has led to more complex relations of power and decision-making in companies, organizations and labour relations. To analyse the changes in these relationships, the concept of governance is used broadly to include both formal and informal power relations, decisionmaking and cooperation. Changes in work relations can take place on the plant 
and company level, internally or externally on the labour market, in legislation or in the process of collective bargaining. Thus the rules or patterns of governance can be externally determined in the industrial relations system (IRS) or internally determined by company management in human resource management (HRM). The main object of IRS is industrial conflict resolution and the main object of HRM the development of skills, competence and work organization. We distinguish between IRS and HRM in order to discuss and analyse different tendencies of convergence and divergence in work relations. The concept 'managementlabour relations' is in the following used in a broad sense. It includes regulation, decision-making, conflicts and cooperation in both IRS and HRM on different levels - at company, industry, national, regional (e.g. EU directives) and international level (e.g. ILO conventions). The governance of post-Fordist managementlabour relations has changed from predominantly collective to more direct and individual forms (e.g. regarding salaries and participation) and from predominantly industry-based to company-based forms (e.g. negotiations, skills and training). Changes of IRS and HRM may be complementary and influence each other.

However, the distinction is important because IR systems may play a dominant role in some cases, as in traditional Nordic management-labour relations with its strong central and local union influence but a rather insignificant role in many other countries with weak unions. A thorough study of industrial relations in the OECD countries by Traxler et al. (2001) shows convincingly that the main trend is a divergence in two directions: neo-liberalism with uncoordinated bargaining and 'lean corporatism' with coordinated bargaining. Which road a country takes is largely a matter of path-dependency. Countries with strong corporatist traditions have moved towards 'organized' decentralization of IR, which, together with a non-accommodating monetary policy, constitutes 'lean corporatism'. In many ways this is a better response to monetary signals than neo-liberal approaches, since coordinated bargaining directly relates to monetary policy, in stark contrast to uncoordinated bargaining. (Traxler et al. 2001: 300-01). Industrial reorganization in Europe in the 1980s also followed a pattern of divergence (Lane 1991).

\subsection{Work Organization and the Division of Labour}

When analysing new tendencies in service industries Frenkel et al. (1999: 14) distinguish between regimented and empowered forms of work relations. They set up a model of three ideal types of work organization: bureaucratic, entrepreneurial and knowledge-intensive (ibid.: 23-31). In the bureaucratic type hierarchical and regimented work relations predominate; in the entrepreneurial type customer-work relations predominate and in the knowledge-intensive type empowered or network-oriented work relations predominate. The first type can be compared to Fordist and the third to post-Fordist work relations. Empirically, job 
and work functions in service and manufacturing are often mixed types of work organizations. Complex sales work may consist of both entrepreneurial and knowledge-intensive ideal types and simple retail work consist of both bureaucratic and entrepreneurial types.

Thus Fordist and large-scale forms of production can increase and be most effective in some industries and knowledge-intensive networking in others. Consequently work organization and levels of competence, education and training differ greatly. Yet there is a tendency for knowledge-intensive work (KIW) to increase more. High-skill autonomous work systems, or KIW, dominate the 'new economy' (Hertzenberg et al. 1998). To develop this type of work and optimize its value-added production become the dominant converging philosophy or ideology, at least in human resource management and influences education and training of the work force, also of the non-KIW employees. These changes in work organization lay the foundation for new forms of governance in management-labour relations.

Information technology and more KIW increase the demand for competence development in companies and society, especially in so-called network organizations (Castells 1998). Most countries concentrate on knowledge-intensive competencies and worry about a shortage of them (Carnoy and Castells 2001). Educational policies become strategic. Aston et al. (1999) define human resource development (HRD) strategies as both educational and skill development strategies. Analyzing certain Newly Industrialized Countries in Asia they consider the state to be a main actor in the development of these skills and that these states have used HRD to catch up with the West. Thus, HRD here is understood as mainly the macro-level skills and the educational policies of the state, but also involves the meso- and micro level policies of private organizations and companies. HRD as defined by Ashton et al. (1999) is a broader concept than HRM as defined above in which HRM is limited to the level of organizations and companies. According to Ashton et al. (1999), the different industrial stages of the four Tigers have been supported by strong interventionist and competent state-governed HRD strategies. The development of the Tigers was not left to market forces as in the Anglo-Saxon model. Partly building on the experience of these proactive and successful HRD models, ILO, the World Bank and other international agencies recommend tripartite HRD strategies for High Performance Working (Stern and Sommerland 1999). High Performance Work Systems have long been discussed in the US as a high value-added strategy. However this value-added strategy entails that market value alone defines the value of labour, not the use value or competence of labour.

The difficulties in definitions also illustrate difficulties in being proactive in HRD strategies and selecting the right core competence and basic skills in educational policy. What are the industries of the future? The focus on HRD can improve working conditions in the future. A very promising situation for HRD poli- 
cies is the emergence of competition between employers on being a good and attractive workplace for their staff. Recent investigations of 'Best employers in Asia' (Far Eastern Economic Review 13 Sep. 2001), and 'Best employer in Europe' (Børsens Nyhedmagasin 3 Dec. 2001) confirm US survey results of Fortune's 'Best company to work for' (Investor's Business Daily 9 July 2001). An attractive employer with good work relations and a good work environment is often also a more profitable employer these surveys conclude.

There are two possible consequences of changes in work organization that could be relevant for industrial relations. One is the increase in knowledgeintensive and service-oriented work. The other is post-Fordist tendencies such as the complexity, specialization and variety of work organization. As discussed above, the theoretical concepts are based on ideal types that correspond to hybrids or less pronounced tendencies in reality. More knowledge-intensive work the type of work increasing most rapidly - requires in many countries more participation, networking and empowerment. Do employees in KIW organizations feel the need for unions to support these policies? Or is 'democracy at work' a natural practice and routine in empowered work organizations? If so, are unions, especially in countries and industries where unions are weak or excluded on the plant level, identified as outsiders? Among IT employees for instance, unions have often been seen as unnecessary. Yet there are still many issues such as salaries, mergers, shareholder intervention and larger organizational restructuring that may be felt to be necessary for both unions and works councils to handle not to mention current unemployment among IT-workers. Such issues need to be resolved within the IR system - at least within a European framework, where social partnership is an essential principle (Hyman 2001).

The other consequence is due to post-Fordist production: that is, less technical determination and standardization of work, less machine-structuring of work relations forming workplaces and the collective worker; in other words both more individualization and interdependence in work relations. Work may be more related to different types of problem solving and customers' service needs - and also different cultural traditions and institutions handling that type of work. In many service jobs there is today rather a customer-labour than a managementlabour relation that shapes work conditions. The complexity of post-Fordist work organizations could also improve conditions for unions to organize and identify common interest for collective action. There are more heterogeneous and diffuse options for union activity due to global restructuring of labour relations through internal and external flexibilization. The traditional principle of industrial unionism - one plant, one union - is in many countries on the decline. Companies and the collective worker - are split up globally in modular production networks with different business and working cultures. The industry where the change is most marked is electronics (Sturgeon 2002: 451-96). At least initially, modular production networks seem to have diverging effects on labour relations when the 
production chain is divided between different companies (e. g. Ericsson - Flextronics), countries and IR systems. Still, unions may find other areas than common industry or plant level conditions at work to organize around; for instance, demands for equal treatment and for labour rights - against gender or race discrimination, professional demand for competence development and so on. In the long run skills, competencies and work relations may at a global level become more similar for each type of production in the chain due to specialization in modular production networks.

\subsection{Industrial Relations and Human Resource Management}

There are several different analytical approaches to management-labour relations. We consider the French regulation school as a good starting-point for a more general theoretical framework for the governance of capitalism. Based on US experience, Aglietta (1979) describes this form of capitalist mass-production as Fordist accumulation, a special regime of capitalist accumulation that will be followed by post-Fordist forms of accumulation regimes. The concept of Fordism assumes a high degree of convergence of the governance of the production system and work organization - and Marx made a similar assumption in his analysis of capitalism. Harry Braverman, in his influential study Labour and Monopoly Capital (1974) points to such a convergence that also includes the supervisory control and de-skilling of manual industrial labour.

The convergence thesis is revisited and juxtaposed to globalization and different national and industrial systems in an anthology by Susanne Berger and Ronald Dore (1996). The complexity of the issue is likewise underlined by Westwood (1991). Other studies have concentrated on the control and political power relations in production using a theory of labour regimes (Burawoy 1985) or defining more specific national or regional labour systems or labour regime forms (Deyo 1989). These studies have, however, not explicitly used the concept 'industrial relations' or 'management-labour relations'.

Although manual labour often has been the victim of both over-exploitation and de-skilling during Fordism, the convergence of suppression and governance formed the basis for collective action, solidarity and for organizing the working class. Such collective action promoted social and welfare reforms. Most importantly, it made it necessary for the state to form industrial relation systems for social partnership and conflict resolution. The IR systems have developed in different directions. Despite many similarities IR systems diverge depending on different national, political, legislative and labour market traditions. If Fordism made it natural for research to focus on converging tendencies of managementlabour relations, post-Fordism makes it natural to focus on differences and dissolving tendencies of IR systems. 


\subsubsection{World-wide Decline in Union Density}

In a special issue of The British Journal of Industrial Relations (September 2002) Verma et al. find a dramatic world-wide decline in the organizing degree of trade unions since 1980. The rate of decline from 1980 to 1995 varies from between 40 and 65 per cent (France, the UK, the USA, Mexico, Australia) to 1-7 per cent (Sweden and Norway). Among the few countries with increases were South Africa, Chile, Taiwan, China, Hong Kong and India. Globalization and economic competition are seen as one reason for the decline, types of jobs in small firms and the growing service sector another. Individualization and less social pressure on young worker to join unions as a third factor that contributes to the decline in union density.

Contrary to this decline in organizing degree of trade unions multinational companies (MNCs) have often been more successful in their organizing strategies. They have used human resource management (HRM) to develop direct participation schemes, quality circles and performance based salaries that either keep unions out or make collective bargaining and union representation less relevant. Yet union busting, for long a predominant tendency in the US, does not seem to be the main purpose of HRM any longer. The primary function of HRM is rather to develop skills and competencies of employees and enhance similar management-labour relations and work organizations in the whole group that is, in all departments and subsidiaries of an MNC. In this way HRM influences business culture and management-labour relations in a convergent direction, at least within the same MNC.

Compared to industrial relations the role of the state is less important for HRM. MNCs can act rather independently in forming their global HRM strategies. Still, the support and cooperation - or lack of support and cooperation - of the state has a major impact on companies: the educational system, vocational schools, training institutes, and legal or economic incentives for skill upgrading and training provided by companies. As mentioned above, the state can have a crucial role in proactive HRD strategies in research and education. Moreover, the state may promote synergies between the IR system and HRM, especially if state legislation prescribes tripartite relations (state-unions-employers). As discussed above, companies in more knowledge intensive and high-skill sectors might, for example, compete in being 'good employers' in order to be able to recruit and keep the best employees. The reason for this competition can be due to a shortage of professionals in their particular field or because the education and knowledge invested in are costly and hard to replace.

Multinationals develop global HRM strategies in order to have the same standards and quality of products in different subsidiaries - based on similar skills and competence in work organizations. Performance systems also tend to converge. In particular, company training and education use standard modules and homogenizing discourses. In summary, HRM practices in MNC subsidiaries tend 
therefore to converge within the group. Another MNC in another industry may follow a different practice in HRM, although consultancy firms usually recommend a type of HRM within the same paradigm or the same line of thinking. Globalization, network orientation and empowerment constitute necessary elements of post-Fordism, but also possible tendencies of divergence and threats to coherence of a MNC organization. To counter these tendencies three theoretical reasons for convergence strategies in international corporations can be pointed out: (1) common concepts and modes of cognition are necessary, due to intensified network communication at different levels, both nationally and internationally; (2) decision-making needs to follow similar standard rules and patterns (often codified in ISO certification) to obtain the same quality of products and of services; (3) divergence in work organization and differences in subsidiary culture world-wide need to be bridged and narrowed in HRM and company culture to be able to use network organisation - even if company values are to some extent symbolic or superficial.

The reason why HRM makes inroads in the traditional field of industrial relations is often due to trade union weakness. If unions organize less than 5 or 10 per cent of the workforce there may be no collective bargaining. Another possibility is that collective negotiations take place as part of HRM organized procedures; negotiations may be run by an in-house or company union. Performance related individual salary systems tend to eliminate part of the collective bargaining interest of workers.

Furthermore, the informal sector is often the largest in developing countries and not possible to unionize. In the formal sector professionals, high-skill or managerial workers are in most countries not allowed to organize: either because they handle 'classified information' or because they have a privileged position and thus do not want to organize. Finally, in some of the main European countries (Germany, France, Italy, the Netherlands) at shop floor or company level unions are not allowed to negotiate remuneration.

\subsection{International Discourses and Practices in International Organizations}

There are several international influences on IR systems that could affect Nordic IR. To what extent do ILO standards, the European social dimension or neoliberal discourses change condition for Nordic management-labour relations? Although in most countries IR are to some extent influenced by ILO conventions and ILO core labour standards ('universal rights'), there is strong pressure, especially from trade unions, to use the IR system as a defensive framework for national protection against the negative impact of globalization. This contrasts with the predominant neo-liberal discourse that gives primacy to a global economy without social balances and safety nets. The world market is the prime mover in 
this neo-liberal globalization discourse, eliminating or supplanting all-important political and social regulations - including IR and social partnership. According to this discourse, all other dimensions of globalization, be they ecological, cultural and political, are secondary to the economy, or calculated as a cost to a single, economic dimension. Moreover, the dependence on the world market is constantly escalating; hence obstacles such as national IR systems must, as far as possible, be eliminated. By extension, neo-liberal ideology implies that a nation can and should be run in the way that a company is run (Beck 2000: 9, 118-19).

Some commentators argue that apologists within big business, universities and the media have for decades paved the way for this neo-liberal conception of the world. As a result, neo-liberal solutions seem to be the only ones acceptable to meet the challenges of globalization (Beck 1998: 25; Bourdieu 1998). Neoliberalism, of course, undermines the defence of national or regional IR systems and promotes global HRM strategies.

For instance, a widening wage gap is often seen as necessary for the creation of new jobs or, at least, to prevent existing production jobs from moving to Asian or other low-wage countries. This is sometimes termed 'the race to the bottom' and seen as an economic law - just as Marxists long explained the level of minimum of existence as 'the iron law of wages' - but now within a neo-liberal determinism. Hence, it is often argued that when it comes to the combination of employment and macro-economic performance, the UK and the USA both perform very well. They are both 'high employment economies with large low-wage sectors' (Casey and Gold 2000: 97). Yet, according to the OECD's 1996 Employment Outlook, increased wage-spread has not created a type of new jobs that are possible to earn a living from either in the UK or the US. Increasing the wage-spread only increases the poverty of low-paid workers. Nor has the large wage-spread given low-paid employees an opportunity to work their way up to better paid jobs. The low-paid have stayed at the bottom and are often forced to take two or three casual jobs to make a living.

Moreover, in the mid-1990s, the percentage of fully employed people, capable of gainful employment was, for example, twice as high in Germany as in the UK (60 per cent and 30 per cent respectively), because Germany largely maintained a traditional welfare state with a corporatist labour market regime. Twenty years earlier the percentage was above 80 per cent in both countries (Beck 2000: 5859). With flexibility in employment contracts, part time and casual jobs have increased in most countries, including the Nordic countries, and hence a large group of employees are without unemployment and pension benefits - and often outside the purview of unions and the IR system. This is a diverging labour market tendency of which we have not yet seen the end.

Anthony Giddens (2000) has argued that after the peak of the Asian crisis in the late 1990s there is no longer any room for conservative or neo-liberal solutions. Yet Giddens also states that the 'energies of many on the political left have 
long been preoccupied with resisting neo-liberal claims, or with a defensive reworking of leftist thought in the face of them' (ibid.: vi). In other words, the discourse is still very powerful and has a strong impact on policies on the ground. An alternative strategy by trade unions and left-oriented parties seems far away.

Employer and state elite interests may also try to prevent international labour rights in their countries or industries - especially in less developed countries. Hence there is a decreased level of ratification of new ILO conventions (Hanami 2001). However, established labour market practices and traditions, whether codified in labour legislation and collective agreements or not, are strongly rooted. All the main social partners - employers, unions and the state - may for different reasons want to maintain a national IR system, often as a defence to neo-liberal globalization, despite the fact that this might impede co-ordinated action on an international or European level. It is interesting to note the discrepancies between the Nordic countries. During the 1980s and 1990s, the Swedish employers' associations have often been very hostile to social partnership and the strong IR system, while the Danish employers have accepted the system without any conflicts with their union counterparts (Due and Madsen 2000).

In the Nordic countries there seem to be rather little conflict between HRM and IR practice. For instance, most Swedish employers now agree that the 1976 Codetermination Act (giving employees the right to take part in workplace and company decisions) is, in practice, compatible with their interest in participation (Levinson 2000). This position of the employers is quite contrary to their hostility to the legislation when it was enacted. Partly as a consequence of this conflict the Swedish Employers' Confederation (SAF) wanted to reorganize the whole IR system and some Swedish multinationals tried to set up company specific agreements (Schiller 1988; Mahon 1994). This was a clear divergence from the Nordic model.

Since employers' associations and trade unions are very much part of the political process in each country, variation and divergence is natural. However, just as, for decades, the common Nordic labour market has helped to co-ordinate the Nordic IR systems, a common economic and labour market in Europe may tend to homogenize legislative and structural features of labour market systems. For instance, at European company level some unions are trying to establish a common framework for agreements on future labour standards, sometimes including non-EU countries. Co-operation between European Works Councils may help unions to learn from each other and co-ordinate 'best organizing practices'.

All in all there is no simple conclusion to the issue of convergence or divergence of HRM and IR, although it can be a methodological tool for analysing globalizing tendencies in different areas. Socio-economic convergence at the European macro-level may not correspond to more divergent socio-economic developments in Asia, Africa or Latin America and changes of IR systems there. A convergence of HRM in a multinational company may just be a strategy to 
coordinate activities bridging these different socio-economic tendencies and divergence in culture, institutions and systems of industrial relations.

\subsection{The Outline of this Book}

For about a decade-and-a-half, the so-called NordFram (the Future of the Nordic model) network has been studying and comparing features of participatory and democratic reforms of industrial relations in the Nordic countries. Difficulties in realizing democratic influence in IR due to globalization have also very much been in focus: for instance in Nordic multinationals, conflicts leading to coordination of union-management collaboration, and finally to European Work Councils. NordFram has also analysed this development in Nordic companies when it comes to the increasing demand for development of competence and participation in post-Fordist work organization.

The final chapter of this book - written by Bernt Schiller who was one of the persons who started the network some 14-15 years ago - gives an overview of the research NordFram has produced over the years. The other chapters all discuss different features of the changes in the Nordic model due to internationalization, either at a cross-national level or in national contexts. Accordingly, the book rather brings together different case studies dealing with convergence-divergence than tries to give an overall analysis from an uniform starting-point.

The next chapter, chapter 2 by Daniel Fleming and Henrik Søborg, studies the role of corporate culture in bridging the gap between HRM principles in three Danish multinationals and two IR systems far from the Nordic ones, namely in Malaysia and Singapore. In both countries, but particularly in Malaysia, management-labour relations to a large extent depend on a traditional educational system, authoritarian work relations and ethnic division. However, both countries are undergoing a 'westernization' of HRM and a transformation to more knowledge intensive and networking forms of work. Several multinational companies, including the Danish ones, have no doubt promoted this change by presenting alternatives to the authoritarian patriarchal traditions in management-labour relations, especially in Malaysia, where the tripartite tradition is very weak.

The following two chapters, chapter 3 and 4, both address one of the most important recent features in European management-labour relations: the introduction of European Works Councils (EWCs). In chapter 3, Herman Knudsen discusses the opportunities for EWCs to acquire influence on corporate decisions in multinationals. Based largely on a survey and interviews of Danish EWC representatives and a survey of managers in Danish-based MNCs, Knudsen concludes that with the EWCs a new form for genuine employee representation at a transnational level has actually been created. He concludes that contact between EWC representatives and the ensuing greater trade union contact might contribute to a more European, even global, outlook in the labour movement, even though there 
are still many obstacles to this development. If this influence is to be effective, the EWC representatives have to integrate local, national, European and global perspectives, and work out formulæ for transnational worker solidarity. Monica Andersson and Christer Thörnqvist (chapter 4) present findings from a survey of communication and expectations in EWCs in four multinational groups of Scandinavian origin. The main findings are the importance of informal contacts between the representatives in order to make the EWC work in practice, and the problematic situations that occur when the members do not have any common language but must rely on interpreters - even for informal contacts!

Chapter 5, by Jan Heiret, brings up the interesting and rather peculiar Norwegian case. Unlike in other countries both national IR systems and international management strategies have become stronger. The Norwegian labour market became more centralized in the 1980s and 1990s, while most other Western countries moved in the other direction, but still the influence of international management ideas has been very strong. Heiret finds the answer in the long historical traditions of cooperation between employers' associations and trade unions on issues of productivity.

In chapter 6, Kristina Håkansson and Tommy Isidorsson present results from their studies of the use of three kinds of so-called capacity flexibility in the Swedish labour market with focus on retail trade and engineering: functional flexibility, numerical flexibility and flexible working hours. The use of flexibility strategies, according to Håkansson and Isidorsson, affect IR systems in different ways. At company or shop floor level, both numerical and functional flexibility may weaken the employee collective and trade unions since both strategies may promote a division into core and periphery workers with different levels of security of employment. In addition, the use of functional flexibility may reduce the core workers' need for a union, since these workers acquire favourable working conditions just by being core workers.

The decentralization and individualization of agreements on pay in the Danish public sector is the topic of chapter 7 by Kirsten Bregn. Since 1997, as Bregn argues, there has been "nearly a revolution in the pay systems of the public sector'. New features are extra clauses related to functions, qualifications and results, based on agreements between the employers' and the employees' organization/the employee's representative. One of the most important aspects of the new pay system has been the introduction of pay clauses based on individual assessments. On the one hand, the new system gives the individual employee better opportunities for influencing her/his salary but on the other hand, subjective performance assessments also mean that the employees are subject to the risk of favouritism and biased assessments. Highly educated professionals would prefer to do the negotiating themselves, without the interference of a trade union. One effect is a move towards this system in the private sector and more generally a weakening of the trade unions. 
In chapter 8, Annette Thörnquist focuses on an often forgotten aspect of industrial relations, namely occupational health and safety. On health and safety issues a general consensus between the social partners is assumed. Yet, based on empirical evidence from the Swedish private sector 1940-2002, Thörnquist shows that changes in occupational health and safety practices to a large extent follow the overall trends in the IR transformation, as do the ideological frictions between the main social partners. Since a main trend in the 1980s and 1990s has been a move towards decentralization of IR, the responsibility for, and handling of, occupational health and safety issues has also been decentralized. As regards the tripartite talks in 2002, the question is whether or not this governmental initiative will help restore the 'classical' Swedish tripartite model.

Conflicts and frictions are also the topic of chapter 9, by Susanne Fransson and Christer Thörnqvist. The main puzzle is why there are so big differences between male-dominated and female-dominated occupational groups when it comes to industrial conflict patterns and negotiating strategies. Fransson and Thörnqvist highlight the Swedish model and the so-called solidarity wage-policy, which gave the workers in the male-dominated export industries the chance to combat wage-drift by wildcat strikes, but also guaranteed female-dominated occupations in domestic market-oriented industries real wage increases. With the decline of the Swedish model this situation has changed and the new trend is that female-dominated unions have began to use the new legislation against discriminatory wage-setting as a collective means of achieving higher pay.

Finally, in chapter 10, Bernt Schiller gives an overview of the NordFram network. There are also other people, not presented in this book, who have taken part in meetings and seminars and helped improve the book a lot by giving ideas and comments on chapter drafts. We would in particular wish to thank Pauli Kettunen, Anders Kjellberg, Thor Indridasson and Torgeir Aarvaag Stokke.

\section{References}

Aglietta, Michel (1979), A Theory of Capitalist Regulation: The US Experience, London: New Left Books.

Ashton, D., F. Green, D. James and J. Sung (1999), Education and Training for Development in East Asia: The Political Economy of Skill Formation in East Asian Newly Industrialised Economies, London: Routledge.

Beck, Ulrich (1998), 'Wie wird Demokratie im Zeitalter der Globalisierung möglich? Eine Einleitung', in Ulrich Beck (ed.), Politik der Globalisierung, Frankfurt am Main: Suhrkamp, pp. 7-66.

Beck, Ulrich (2000), What is Globalisation?, Cambridge: Polity Press.
Berger, Susanne and Ronald Dore (1996), National Diversity and Global Capitalism, Ithaca and London: Cornell University Press. Bourdieu, Pierre (1998), Contre-feux: Propos pour servir à la résistance contre l'invasion néo-libérale, Paris: Liber-Raisons d'agir.

Braverman, Harry (1974), Labour and Monopoly Capital, New York: Monthly Review Press.

Burawoy, Michael (1985), The Politics of Production, London: Verso.

Børsens Nyhedmagasin, 3 Dec. 2001.

Casey, Bernard and Michael Gold (2000), Social Partnership and Economic Performance: The Case of Europe, Cheltenham and Northampton, MA: Edward Elgar.

Carnoy, Martin and Manuel Castells (2001), 'Globalization, the Knowledge Society, and 
the Network State: Poulantzas at the Millenium', Global Networks vol. 1, pp. 1-18.

Castells, Manuel (1998), The Rise of Network Society, Oxford: Blackwell Publisher.

Deyo, Frederic (1989), Beneath the Miracle: Labour Subordination in the New Asian Industrialism, Berkeley: University of California Press.

Due, Jesper and Jørgen Steen Madsen (2000), 'Varför är den danska avtalsmodellen annorlunda än den svenska?', in Stig Tegle (ed.), Har den svenska modellen överlevt krisen?: Utvecklingstendenser $i$ arbetslivet inför 2000-talet, Stockholm: Arbetslivsinstitutet pp. 13-32.

Far Eastern Economic Review, 13 Sep. 2001

Frenkel, Stephen J., Marek Korczynski, Karen A. Shire and May Tam (1999), On the Front Line: Organization of Work in the Information Economy, Ithaca and London: Cornell University Press.

Giddens, Anthony (2000), The Third Way and its Critics, Cambridge: Polity Press.

Hanami, Tadashi (2001), 'International Labor Standards from Asian Perspective', Paper to the 4th Asian Regional Congress, International Industrial Relations Association, Manila: University of the Philippines, UP-SOLAIR.

Hertzenberg, S., J. Alic and H. Wia (1998), New Rules for a New Economy, Ithaca: Cornell University Press.

Hyman, Richard (2001), 'Theorising Industrial Relations: Anglo-Saxon Individualism versus the European Social Model', Paper to the 6th Regional European Congress, International Industrial Relations Association, Oslo 25-29 June 2001.

Investor's Business Daily, 9 July 2001.
Lane, Christel (1991), 'Industrial Reorganization in Europe: Patterns of Convergence and Divergence in Germany, France and Britain', Work, Employment and Society, vol. 5, pp. 515-39.

Levinson, Klas (2000), 'Codetermination in Sweden: Myth and Reality', Economic and Industrial Democracy, vol. 21, pp. 457-73.

Mahon, Rianne (1994), 'Wage-earners and/or Co-workers? Contested Identities', Economic and Industrial Democracy, vol. 15, pp. 355-83.

Schiller, Bernt (1988), 'Det förödande 70talet'": SAF och medbestämmandet 19651982, Stockholm: Allmänna förlaget.

Stern, Elliot and Elisabeth Sommerland (1999), Workplace Learning, Culture and Performance, London: Cromwell Press.

OECD (1996), Employment Outlook, Paris: OECD.

Sturgeon, Timoty J. (2002), Modular Production Networks: a New American Model of Industrial Organisation, Industrial and Corporate Change, vol. 11, pp. 451-96.

Traxler, Franz, Sabine Blaschke and Benhard Kittel (2001), National Labour Relations in Internationalized Markets. A Comparative Study of Institutions, Change and Performance, Oxford: Oxford University Press.

Verma, Anil, Thomas Kochan and Stephen Wood (2002), 'Union Decline and Prospects for Revival: Editors' Introduction' British Journal of Industrial Relations, Vol 40, pp. 373-84.

Westwood, Robert Ian (1991), 'Managerial Values and Practices: Convergent or Divergent Trends?', Malaysian Management Review, vol. 26, pp. 13-36. 



\title{
2. Towards Reflexive Governance of Management-Labour Relations? Corporate Culture and Human Resource Management in Malaysia and Singapore
}

\author{
Daniel Fleming and Henrik Søborg
}

In many multinational companies (MNCs), strategic thinking concentrates on attempts to lower costs, improve quality and shorten delivery times by streamlining organizational structure globally and strengthening competence building locally (Tregaskis, Heraty and Morley 2001; UNCTAD 2001). This strategic agenda reflects the problem of coping with flexible demands on globalised markets and rapid technological changes and, at the same time, building a corporate culture and company identity that can equip employees to cope with these demands. In this double faceted agenda, organizational streamlining cannot stand alone but requires human resource development (HRD). The right combination of these two elements - organizational and HR development - is the key to productivity gains and competitive differentiation between companies (Best 2001). Strategy papers in Danish MNCs such as Danfoss, Grundfos and ISS illustrate this double faceted agenda (company home pages 2001-2002). In pursuit of this agenda in the last two decades we have seen management spend a lot of money and time in building a globally integrated corporate culture, common values, aims and standards with the purpose of creating a corporate "us" that is motivated and committed to change and flexibility. Some of the key mechanisms in establishing this corporate culture are direct participation, delegation of responsibility and emphasis on commitment.

This new strategic agenda of MNCs which, in the 1990s has become widespread in Danish companies - especially in knowledge-intensive and service developing companies, is developing a different management-labour relationship than the traditional relationship in the industrial era of Fordism, with its close control and precisely described subordination. Compared to the hierarchical control and supervision of Fordism, management discourses under the new strategic agenda are based on a different, more reflexive form of governance of management-labour relations. We identify the new management discourses as the dominant paradigm in human resource management (HRM) and use the term HRM 
with this 'positive' connotation. Although it is often used in a generic sense and not intended to imply one particular style or approach (Storey 2000) we find it appropriate to use the term with this connotation. We focus on HRM's perception of learning and control. In contrast to management discourses of traditional hierarchical forms of work organization HRM emphasizes employees' continuous learning and their own responsibility of job tasks, decisions and information. HRM's aim is the development and use of the creative potential of every individual (Schumann 2000).

The perception of learning and control in the new management discourses is double faceted or relational in its character and reflects the sophistication of the HRM discourse compared to management discourses under previous production systems: particularly the significance of the corporate "us" as an integrative mechanism. Thus in these discourses, the demand for change and flexibility is embedded in a governance and power structure in which management seeks to eliminate the potential contradictions between the interests of employers and employees. In HRM-oriented companies it is not unusual for management to expect employees to continuously acquire knowledge of new technology and organization and employees tend to regard this competence building as an individual requirement that, as workers, they have to fulfil in order to maintain their market value. This reflexivity or dual requirement becomes an important means of governance in a HRM-oriented company, new methods of "controlling" power relations and increasing productivity in a non-conflictual manner (Sennett 1998). Reflexive self-control is difficult to evolve without comparable learning structures in the institutional environment. An increasing number of MNCs face this problem when transferring their new strategic agenda to work and business cultures that are different from that of their home base (Unctad 2001).

Our focus is on the problem of implementing this new strategic agenda in Danish HRM-oriented subsidiaries in Malaysia and Singapore. These companies, together with other HRM-oriented companies, represent a small but growing business culture in the new industrial environment in Southeast Asia. What we have been especially interested in analysing is how these companies try to form new discourses for corporate culture and HRM in work and business environments with weak trade union traditions and strong paternalist or patriarchal management-labour relations. The question is how internal stakeholders in the Danish companies promote or hamper the implementation of HRM strategies and local work and business cultures and institutions influence their implementation.

With their high degree of foreign direct investments Malaysia and Singapore are excellent case study countries for analysing problems connected to transfer of new management-labour governance mechanisms to foreign work and business cultures. Both countries claim in their national visions of the future which describe their roads to high-developed country status, that they want to promote conditions for developing knowledge-based societies with more direct participa- 
tion, delegation of responsibility and self-directed learning. We consider it a challenge for Danish HRM-oriented companies to implement their strategies in these two countries, because they meet strong influence from other foreign business cultures, especially American and Japanese and to a lesser extent European and local business cultures.

Our information on the Danish companies ${ }^{1}$ is mainly obtained by interviews with management and a survey of HRM practices. Our impression is that Danish companies in Malaysia and Singapore is closely connected to their parent companies and to international HRM discourses. But in the subsidiaries management is also influenced by the local institutional environment and business culture. In the first part of this paper we focus on a broader conceptual framework and the international and Danish company context in order to outline how the corporate culture and HRM agenda have been set.

\subsection{Conceptual Framework and Preliminary Definitions}

As regards some fundamental relations of power and decision-making, management-labour relations under the new strategic HRM agenda do not differ from those of previous periods. Management still has the prerogative to decide on company strategy, recruitment and dismissal policy. However, on the ground in factories and offices, the relationship has changed towards direct participation, delegation of responsibility and an emphasis on commitment. Compared to scientific management under Fordism, with clearly demarcated decision-making competence in a hierarchical organizational structure, the focus in human resource management policy is on setting up less hierarchical ('flatter') organizational structures with greater decision making competence both for the individual employee and for the team group. Power relations and decision-making become more complex in the flatter organizational structure. We need concepts and terms that describe this complex structure and that emphasize own control and cooperation in team groups. We need concepts and terms that catch the doublefaceted and relational character of this structure. Castells' analysis of the shift from Fordism to decentralised networks is useful in identifying the organizational transformation process that many companies are currently going through (Castells 1998). But Castells' analysis does not fully conceptualize the complex power relations between management and labour in decentralised network-

${ }^{1}$ Carlsberg, International Service Systems (ISS), East Asiatic Company (EAC), Jebsen \& Jessen, Danfoss, Grundfos and Hempel. The sample covers different sectors: Trading companies with licensed or own production, sales or services: EAC and Jebsen \& Jessen; brewery: Carlsberg; cleaning and specialised service: ISS; manufacturing of load-sensing hydraulics, refrigeration control, radiator thermostats, compressors etc.: Danfoss; high-technology pumps: Grundfos; marine painting: Hempel. However in this article examples are mainly limited to Danfoss, Grundfos and ISS. We have used questionnaires and interviews with personnel or HR-departments in headquarters and subsidiaries, company booklets, papers and other written information; and usually also interviews with local top managers and middle management in sales, service or production. We have also interviewed other companies to make a broader comparison possible. 
oriented organizations. We will try to capture these relations by combining Foucault's concept of governance and Giddens' concept of reflexivity in the term reflexive governance. Governance of management-labour relations broadly describes both formal and informal power relations, decision-making and cooperation.Reflexive governance describes the tendency to two-way communication, networking and the sharing of information and responsibility in management-labour relations. The inherently relational and cognitive nature of all power relations stressed by Foucault (1978/91) and the general concept of modern reflexivity elaborated by Giddens (1994) have strongly influenced how social science and management theory understand new tendencies in relations between management and labour. Thus some management theorists consider that the consequences of modern reflexivity in network organization and more open and democratic management-labour relations are very far-reaching. Reflective democracy becomes the dominant and only legitimate form of modern governance (Larsen 2000). Often, these authors lack a discussion of the level at which these changes in company practice occur. Other, more critical authors such as trade unionists, claim that HRM and the new corporate responses to consumer and trade union criticism are mainly cosmetic; forms of political correctness. In their view, only trade unions, organizations that represent the interests of labour, can protect workers' rights. Management cannot. The code of conduct, introduced in many multinationals, or the Social Accountability certificate (SA 8000) for good governance and fair labour practice does not, in their view, change corporate power relations vis-à-vis labour. According to these critics, HRM and this new corporate agenda may simply privatise labour legislation and side step explicit industrial relation regulation to avoid unions (Gallin 2000: 23-26).

\subsection{External IRS versus Internal HRM}

In most companies, industrial relation systems (IRS) for the labour market and human resource management (HRM) within the organization determine rules or patterns of governance in management-labour relations. In the following, the concept 'management-labour relations' is used in a broad sense to include regulation, decision-making, conflicts and cooperation in both IRS and HRM at different levels - at company, industry, national, regional (e.g. EU-directives) and international level(e.g. ILO-conventions).

How can we conceptualise the difference between HRM and IRS? In more reflexive forms of governance of management-labour relations this may be even more difficult. One difference seems to be that IRS is predominantly determined by national regulation of industries and labour markets (through state and collective agreements) that are external to the company. By contrast, HRM is mainly determined internally in the corporation or organization at plant, sectoral or global level. International IR standards exist, such as ILO conventions regarding 
equal rights for men and women, ban of child and slave labour etc. But they still need national IR implementation to be effective. In most countries and especially at the international level, labour's organizational weakness means that there is little if any trade union demand for coordinated regulation of industrial relations. This weakness permits great diversity in IRS. By contrast, multinational corporations often try to establish a single global corporate HRM under which internal management-labour relations converge. Thus, while the freedom of manoeuvre of unions is mainly determined by national IRS, that of corporate managers is determined by global HRM strategies. This process undercuts the traditional international solidarity of the union movement. Our hypothesis is that management increasingly uses HRM as a strategic global instrument for forging new management-labour relations and that this tendency often erodes the IRS as an instrument for unions and employees.

For management HRM can be seen as a more flexible and effective instrument to utilize and develop labour resources because it is not impeded by legal regulation of management-labour relations as is the IR-system based on employers' and employees' rights (or restrictions on rights) as citizens. Thus IRS has a broader public and civil society dimension involving the state that is absent in HRM. HRM regulation is mainly internal to a global company. Very little is open to public scrutiny and debate and, in the view of management, this may give more flexibility and freedom. The typical contractual regulation in IRS is not dynamic enough an instrument for management to maximise productivity, competence development and the creativity of labour.

The Nordic model of voluntary collective agreement presupposes strong unions both for establishing new agreements on individual and collective rights for workers and to implement these rights. However, non-union employees generally enjoy the same rights as union members. So the Nordic model tends to apply to the whole national labour market. In Nordic countries, the scope of HRM is circumscribed by legal and collective agreement rights in the IR-system: for instance by co-determinant regulation of many management-labour relations. Interestingly enough, this usually works to the satisfaction of management (Levinson 2000). Actually, Nordic IR regulation and practice can be seen as a further push for human resource development involving the unions. The legal and collective agreement framework gives to some extent unions and employees the status of equal partners to management. This is much less the case in Malaysia and Singapore, where Nordic companies lack the participatory push from unions, a push that has been incorporated in the Nordic business culture.

\subsection{Business Culture, Corporate Culture and HRM}

In many MNCs, Corporate culture is often formulated as a set of value statements and determined by management or top-management. However, it is not 
only internal relations that affect corporate culture but also external relations. Given the reflexive nature of communication and governance the local and global business milieu shape corporate culture strategies. Thus, corporate culture develops within a business culture and within the international management community. Business culture is here used as the broader concept, denoting a national, historical or ethnic element in a business system. Regardless of pressure for global HRM convergence, the American business culture is still quite different from the Japanese that does not have the same market and share holder orientation (Dore 2000). European business cultures put greater value on labour relations and social policy (Visser 2000). We understand corporate culture in a MNC as a dynamic process in which the parent company tries to integrate the different units. The degree of convergence or diversity differ in different companies depending on how much emphasis the parent company places on corporate culture integration and harmonization. But in every MNC the corporate culture is a melting pot because subsidiaries often operate in business and working cultures that are different from the parent company. So a process of transformation is taking place, usually leading to the emergence of a new cultural outcome, which might be call a third culture (Featherstone 1990).

In the context of corporate and company culture we cannot omit a discussion of the concept of working life culture. Working life culture is a broader concept determined by the social and cultural embeddedness and historical development of the firm, the business system, the labour movement and management-labour relations i.e. social relations such as trust, solidarity, authority, gender, ethnicity, class, status and power relations are formative. Working life culture also differs from country to country, depending on class, ethnicity, gender, profession and geographical region. The national working life culture of trishaw drivers, mine workers, maids, sales officers, teachers, engineers and bank managers is probably as different as, for example, autoworkers' culture differs internationally. Globally, for most jobs and workplaces (including the informal sector, small and medium sized firms) there is no deliberate company strategy to develop a corporate culture or human resource policy. Thus the strategic scope of corporate culture is limited and differentiated.

However, three important factors influence corporate culture in a reflexive way: 1) Consumer values influence corporate culture but management also wants to influence consumers by its corporate culture. The strong focus on brand names, design or quality features to influence consumers sometimes have the reflexive effect of rebounding since consumer and public criticism force on to the corporate agenda issues of environmental standards, labour rights and political correctness.2) Corporate culture is affected and influenced by ownership and shareholder values. One aim is to integrate employees (and consumers) in the corporation, either as individual or institutional shareholders in pension funds etc. Corporate pension funds, stock options etc. lead employees to become involved 
in the stock market. 3) Corporate culture is influenced and affected by management-labour relations and human resource development. High performance and competitiveness are directly linked to good working relations and continuous learning.

\subsection{The Corporate Culture Agenda and Direct Participation}

In our sample of companies, the concept of corporate culture as a strategic operational concept is rather new. Previously, management considered company culture an outcome of the special relationships between employer and employees in their company, referring in annual reports and special events to the special norms and traditions that constituted these relationships. In the 1980s, management in our sample of companies began to focus on company culture not as this cumulative process but as an operational agenda in the organization.

Why, at the beginning of the $80 \mathrm{~s}$, did management begin to focus on corporate culture values and direct participation as a way of improving competitiveness? It is always difficult to point to one reason as the most important. Yet, undoubtedly, an important factor was the economic downturn in the western economy. Many managers were looking for new ideas and inspiration to speed up the economy again. They began to take an interest in Japan and its economic success. This success was to a large extent associated with the organizational and managerial business system in Japanese companies. The characteristic features of Japanese business culture were delegation of responsibility, consensus in decision-making and, above all, employee identification with the company and its corporate values. Western consultancy companies such as McKinsey began to advise their customers to improve performance by learning from the Japanese way of organising work. There were great productivity gains to be made in many companies by changing their work organization so that employees had better opportunies to use their creative potential (Nonaka and Takeuchi 1995). McKinsey also pointed to the advantages that could accrue by learning from Japanese production systems: for instance, by implementing Just in Time Systems and Lean Production Strategies (Watson 1995). It is clear that the influence on Western business culture of Japanese work organization and production systems was tremendous in the 80s. The growing interest among managers in new management ideas is in many ways a reflection of the discovery of the Japanese route to economic success (Storey 1998).

Tom Peters and Bob Waterman, two authors and consultants with McKinsey, captured this growing interest among managers in new concepts and ideas that could revitalise company organizational and managerial systems. In "In Search of Excellence" (1982) they launched an attack on what they called the extremely rationalist and analytical approach to management in the Western world. They claimed that Western managers, from their corporate ivory towers, had lost sight 
of that which is basic to managing a company (1982: 40). Number-crunching analyses had blinded managers to what is crucial to company success, people and values. The two authors claim that it is rare to find organizations in which management has a people- and value-related approach. Yet in "excellent" organizations they found this people- and value-oriented approach. "Strong cultures" are characteristic of these organizations and employees are directed more by shared values than by rulebooks, commands or formal procedures. The message of Peters and Bob Waterman is very clear and simple and its impact on management thinking in larger companies has been great. Many of the book's key concepts have become catchwords in the international discourses of HRM.

In the Nordic countries too, this rediscovery of the cultural dimension in management has had a great impact on management thinking and practice. The focus in the literature, particularly in reports from consulting firms and business schools on culture and people-related approaches to management, has been on breaking down hierarchies and building up flatter organizational structures that should pave the way for more participation and delegation of responsibility. The former SAS chief executive, Jan Carlzon, became very famous in the 1980s for his slogan "breaking down the pyramids in companies" (Carlzon 1985). His advice to companies builds on the same assumptions as Tom Peters and Bob Waterman. They conceive of culture not as a result of a long process anchored in the traditions and norms of the companies but as an operational strategic concept by which management can change the organizational structure. As Jan Carlzon claimed it is possible to break down the pyramids in a company by a kind of culture revolution whereby new values and objectives are established.

The focal point in this organizational restructuring is not on the individual person in the company and his or her background, biography and specific affiliation to the company. On the contrary, the focus is on the firm as an entity, not on conflicts of interest between employer and employees but on common interests and, consequently, on an entity in which it is possible to break down old norms and insert new corporate norms. Often in management literature this norm building process is compared to the team building process in team sport. The focus is not on the employees, but on management. This is because, according to Peter Senge, the success of this team building process depends on management's capability to install and execute this process (Senge 1995). It is management that has the task of inspiring and encouraging but also controlling employees. For this reason management is the key actor in the literature on corporate culture and employees are often regarded just as building blocks in management's hands. The criticism of this perception of the norm building process in management literature has been precisely on the emphasis on management as the driving force for a non-conflictual corporate culture and hereby ignoring employees' role in the firm. We find this criticism in other approaches to organizational restructuring and human resource development (Storey 1998; Schumann 2000). 


\subsection{Corporate Culture and the Problem of Change}

Interestingly, all companies in our sample have a written document on corporate culture or company culture. We regard this as a reflection of the fact that value formulation and goal setting have become a central part of management thinking in the last 10-20 years. International management philosophy has no doubt a great influence on corporate culture in these companies. Several of them have used some of the bigger international consultancy firms, especially McKinsey, to help them to set up guidelines for corporate culture. The question is why they invest money in developing corporate culture. We do not think this is because they want to be well equipped to take part in the international management discourse at conferences and seminars. We regard the increasing interest in value formulation and goal setting as an expression of a growing awareness of the problems of change.

All companies in our sample confront increased competition. As a response they set up ever more demanding change programmes to differentiate themselves from their competitors. A recent investigation of the 'change barriers' that stand in way of implementing these programmes emphasises that the barriers are mainly people-related, both at the management level and further down in the organization (Price Waterhouse 1997). Undoubtedly, management's interest in corporate culture strategies is intended to break down these barriers and motivate employees to adapt to a life long learning process and an ever-changing work organization. Contrary to working conditions 40-50 years ago there is now permanent demand for change. Global competition as well as local pressure forces companies to be innovative and ready to change. At every level in the company employees are confronted with rapid renewal of technologies, such as new computer systems and new forms of communication: for instance, e-mail, internet and intranet.

The implementation of these new technologies has, of course, increased management's interest in programmes of change. On the other hand, putting technological change programmes on the agenda is not a new managerial task. In the twentieth century management has pretty much demanded permanent change, given the need for rationalisation and increased productivity. Employees have never been enthusiastic about these demands because they have historical experience of redundancy and deterioration in their working conditions in the wake of these processes of change (Kogut 1993). Therefore, the introduction of new technology and new work organization have often been issues of conflict between management and employees. This conflictual background is important to bear in mind when analysing management's efforts in the 80s and 90s to set up a new agenda for change. In this new agenda management are very focused on eliminating employee resistance to processes of change. The main task is to eliminate the link between change and rationalisation processes so as to eliminate these negative connotations. In the new agenda change is connected to learning processes 
and the firm is conceived of as a learning organization. In this new organization values such as 'change readiness' and flexibility rank very high (Sennett 1998) and personal and organizational barriers to change are targets of corporate culture strategies. Management's task is to set up an organization that eliminates these change barriers (Peter Senge 1993).

\subsection{Coherence and Change}

In our sample of companies the impact of the new management discourse has led to a change in some of the companies' focus on values and activities that aim to strengthen company coherence. Previously, corporate culture mainly emphasised stability and traditions. For example, in some companies the trainee period was mainly concentrated on job functions, employee discipline and sometimes learning the meaning of the company value system if this was explicit. Trainees dedicated themselves to carry on this traditional value system. The content and perspective in such a corporate culture were not to manage change but to secure stability and coherence. The cultural outlook was linked to technological development and production strategies. In the overseas subsidiaries there was a greater tendency to stress stability and traditions, not training, because technological development was not as advanced as at headquarters.

With this description of new corporate culture, we do not want to argue that company technological development and strategic thinking was, prior to 1980 , under no pressure for change. On the contrary, the twentieth century is characterised by an enormous stream of technological changes, not only in headquarters but also in overseas subsidiaries. However, what distinguishes the period after 1980 is the pace of technological change, and particularly, the impact of these changes on work organization and development of skills and competencies. Up to the beginning of the $80 \mathrm{~s}$, in both manufacturing and service industries, technological development and the rationalisation of production had not, in general, disproved Braverman's thesis that the development trend in monopoly capitalism was towards further de-skilling of employees (Braverman 1974). But from the 80 s on, the emphasis has been more and more on re-qualification and upgrading of employee skills.

This shift in the demand for qualification has been conceptualised in different ways. Martin Baethge and Herbert Oberbeck talk about systemic change as a result of the computerisation of production (Baethge and Oberbeck 1986). Contrary to previous technological changes the introduction of information technology not only changes the individual's work functions but also interconnections between these functions. This is the reason why many authors talk about the need for requalification in the wake of the introduction of computers and information technology. 
In the 1980s Horst Kern and Michael Schumann saw many cases in which management could only increase efficiency by relaxing the division of labour and by utilising the work force within a more complex and highly integrated work organization. As a result of new technology and new ways of organising work, they saw a strong tendency to abolish the old Taylorist link between increased efficiency, on the one hand, and downgrading and de-qualification on the other hand (Kern and Schumann 1984). Michael Piore and Charles Sabel saw the same tendencies as Kern and Schumann in their analysis of industrial development in Northern Italy. They found a new industrial organization with flexible specialisation and a need for re-qualification of the work force. Yet they point out that it is not the whole company work force that requires upgrading. It is the core workers that need to change their qualifications and prepare themselves for life long learning if they want to keep their jobs. The groups of part-time and contractual employees, who go in and out of companies, are not exposed to the same pressure for re-qualification as are the core work force.

These analyses from the 1980s about pressure for change and demand for new knowledge highlight issues of competitiveness in a new way. The old competitive environment was characterised by more stability - durable products over a longer period, less changing customer needs and more clearly defined national and regional markets (M. Best 1990). In such a world the key competitive advantage was where a company chose to compete. In today's business environment shaped by fragmented markets, accelerated product life cycles and global competition, the competitive advantage is less where a company competes than how it competes (P. Docherty and B. Nyhan 1996). Therefore, to a large extent, competitiveness is nowadays dependent on up to date knowledge among the core employees and the right organizational structure to meet internal and external requirements. The intensified flow of new information and knowledge forces these employees not to stick to old norms and work procedures but to be ready to acquire and use new knowledge in a reflexive way.

According to Anthony Giddens characteristic of the period of modernization and particularly the age of intensified information and globalisation is that we are forced to be reflexive in our social activities, not only at the workplace but everywhere. In Giddens' definition reflexivity refers "to the use of information about conditions of activity as a means of regularly reordering and redefining what that activity is. It concerns a universe of action where social observers are themselves socially observed; and it is today truly global in scope" (Giddens 1994). We understand Giddens' definition of reflexivity as an attempt to conceptualise how permanent change more and more becomes a general human condition, influencing our thinking and actions, explaining why the capability continuously to learn seems to be a crucial competence among the employees. In many multinational companies a high degree of reflexivity in their different units all over the world is necessary for dissemination of new technologies and work organizations and, 
most importantly, for shaping a corporate culture of change. The need for coherence in companies can only be met by the participation in, and understanding of, fairly simultaneous change processes by employees.

From this perspective it is not surprising that, as indicated earlier, management wants to restructure their companies as learning organizations. In our sample of companies, management regards corporate culture strategies as guidelines to encourage employees to participate in building learning organizations. A learning organization is not an outcome of employer prerogatives, but of complex incentive structures emphasising both participation and loyalty. On the one hand, management needs to formulate corporate culture strategies that encourage employees to participate in breaking down barriers that stand in the way of change processes. These barriers include employees' opposition to change, middle management resistance and inappropriate leadership. On the other hand, management needs to encourage employees to work hard work and be loyal. These demands do not have to be in conflict with management's concept of the learning organization. On the contrary, these two strategic objectives need to fit together if management wants to create a company 'us' that demarcates a competitive position vis-à-vis other companies (Kettunen 1998).

However, employee interest may be articulated in different ways. Compared to Nordic business and work culture, labour interest is articulated less selfreflexive in Malaysia and Singapore. Thus, subsidiary corporate culture may be more top-down and homogenous, at least on the surface, with little independent voice for employee criticisms ${ }^{2}$

\subsection{Danish Human Resource Management in the Southeast Asian Context}

Fifteen to twenty ago, the headquarters in our sample did not set up corporate culture strategies for tying together the companies in their groups. Instead, they emphasised the existence of traditional company values among the upper echelons in their subsidiaries. These traditional values were often tacit and nourished by Danish expatriates who transferred them to the subsidiaries. However, the focus on Danish company values was not strong in most of the subsidiaries. Normally, management was more interested in adapting their organization to local business and work culture. In organization manuals and newsletters, which some of the larger subsidiaries published, the focus was not on parent company spirit, but on the local culture and values. Compared to the strong corporate culture in American and Japanese subsidiaries it is remarkable that the parent company culture was so insignificant marked in the Danish subsidiaries. Probably, this was due to a cautious approach - not only among Danish but also other Nor-

\footnotetext{
${ }^{2}$ This is actually taken up by the Singaporean government as a competitive weakness that will now be remedied in schools and higher education.
} 
dic managers - to transferring Nordic management-labour traditions to Malaysia and Singapore. In manuals and newsletters the emphasis was on technical quality and safety standards, not on Nordic management-labour traditions. In so far as the manuals and newsletters focused on management-labour relations they underscored mutual commitment and the family-like relations in the subsidiaries. Unlike the Nordic countries, management in Malaysia and Singapore did not have strong trade unions as partners, setting the agenda for cooperation. Trade unions are not mentioned as partners in manuals and newsletters. Nor have we found any reference to government regulation of industrial relations or to regulations regarding employees' rights. Both in Malaysia and Singapore there are rather detailed laws and regulations about the industrial relations but, in our sources, there are no references to these. Probably, this is because the subsidiaries have not experienced severe conflicts between management and labour. Nevertheless, it indicates that Nordic management-labour relations and local IRregulations are not important in setting the corporate culture agenda in Danish subsidiaries.

The limited emphasis on corporate values in the subsidiaries in our sample reflects the division of tasks between parent companies and subsidiaries. Finance and $R \& D$ were concentrated in the parent companies and, through transfer of budget systems and technology, the parent companies exercised overall governance of the subsidiaries. The more detail governance of production and sales was in the hands of the subsidiaries. So the subsidiaries became relatively independent of headquarters and this is why the strategic relationship between headquarters and subsidiaries in this period has been described as a stand-alone strategy (Unctad 1994). In this period, managers who were in charge of subsidiaries in this period emphasised in interviews with us that too close surveillance from the headquarters was a bad sign, while relative autonomy was a kind of recognition by headquarters that the subsidiary was well run. The stand-alone strategy is nowadays very rare in subsidiaries because of the change in production strategy governing relationships between parent company and subsidiaries.

In our sample, the change in production strategy with its stronger emphasis on corporate culture and closer ties between parent companies and subsidiaries is characterised by streamlining sales, administration and production channels in order to improve costumers relationship and increase profits through growth and productivity. It is particularly the bigger costumers who are in focus when companies set their agenda for new production strategy. They demand the same high quality in products and services all over the world. Jørgen M. Clausen, the CEO in Danfoss, emphasised this in his presentation of Danfoss' organizational changes since January 2001:

We must mirror our costumers. They are demanding more than quality components. They want our products, but they also want us to demonstrate our understanding of their business. They want applications expertise and they want solutions. They want to 
work without geographical limits; and to know that their suppliers have the global network for fast responses anywhere, at any time (Danfoss people 2000).

As already indicated it is in this context that we analyse corporate culture strategies and we consider them as an attempt to provide a common perception in the company group about quality and high performance standards. Almost all companies in our sample seek to nurture this corporate "us" spirit on quality and performance standards by programmes for increasing participation and involvement. Although we have not investigated the attitudes of employees towards participation and involvement in detail, it is our impression that employees are not hostile to these programmes.

The historical background in which these new strategies are established by the parent companies varies in our sample of companies. There are three main groups of companies in this sample. The first is a group of older companies with roots in patriarchal management-labour traditions. The second is a group characterised by new patriarchal management-labour relations. Thirdly, one company with roots in modern management philosophy.

The business and work culture in the older companies has been under the sway of patriarchal management-labour traditions which are fundamentally characterised by a quid pro quo relationship whereby the employer promises job security and the employee promises loyalty and commitment to the company. These companies built up this relation first through their apprenticeship systems in which the employers taught young employees their expectations as to loyalty and commitment and then through the career system, which selected employees that fitted the company traditions. Although patriarchal management-labour relations were predominant in these companies for many years they have not been reluctant to adopt new management strategies. As we suggest later, human resource management strategies have gained a footing in these companies because they not only emphasise individual initiative and participation, but they also stick to loyalty and commitment as fundamental elements in the management-labour relation. Jebsen and Jessen, as representative of the older companies in our sample, in their Corporate Commitment and Philosophy from the late 1990s, formulate this dual dimension in human resource management thinking. "We shall encourage individual initiative and promote active participation at all levels in fulfilment of corporate goals and objectives". And "We want to foster relationships based on mutual respect, trust and confidence at all levels within the organization and externally" (Jebsen and Jessen p. 8, no date).

\subsubsection{Danfoss and Grundfos}

Relatively newly established companies such as Danfoss and Grundfos have also had patriarchal management-labour traditions, but not in the same style and manner as the older ones. The two companies specific historical background as entre- 
preneurial companies were greatly influenced by the founders' engineer and high technology-oriented spirit; rooted in rural environments in Denmark and employing first generation labour and highly educated engineers and technicians. These factors laid the foundation for a new patriarchalism characterised by a nonconflictual interaction between management and employees, a comprehensive internal training system and many social benefit arrangements and leisure activities in the companies. Both Danfoss and Grundfos are now owned by familydominated foundations. This ownership structure has given the two companies greater stability than many stock-owned companies, which are highly influenced by fluctuations on the stock markets around the world. They have also been very R\&D-oriented because the foundations determine that a great part of their profits have to be channelled to R\&D activities. This ownership structure underpins the two companies' new patriarchal management-labour relations. Both companies today have bonus programmes with shares and the effect of this arrangement is that management-labour relations are less confrontational and the employees are more loyal and committed to the companies. Grundfos has decided that in 2001 all employees worldwide will have the option of buying shares in the company at a special price.

With their background and the way the two companies set up their participatory policies by emphasising identity and commitment to company values, Malaysian and Singaporean work and business cultures do not impede the two companies' subsidiaries implementing corporate human resource management strategies. The family-oriented attitude of local employees to their work places certainly differs from the more independent and reflexive participatory attitude among employees in the parent companies. But this attitude fits well into the new patriarchalism as Danfoss and Grundfos practise it in their subsidiaries in Malaysia and Singapore. They encourage employees to use initiative and to participate in the development of HRM objectives. But they emphasise that HRM is not a break with the family-oriented approach. 'Danfoss Asean Mission' illustrates this combination of HRM objectives of encouraging learning and participation and company respect for old values:

We believe in reaching our vision and goals through:

- Empowerment and development of people with commitment to learn

- Mutual trust, respect and care

- Teamwork and open communication

- Recognising the importance of harmony between working and family life (Danfoss homepage).

\subsubsection{ISS}

One company in our sample does not fit into this picture of patriarchalism: International Service Systems, ISS whose main activity is cleaning. It has become the world's leading cleaning company by acquisition of other companies. Until now, 
its success is due to the ability of top management to integrate the new companies into ISS' financial reporting system, operational systems and organization. In recent years, the pace of acquisition has speeded up and the question is whether top management can also accelerate the integration of the corporate culture of different new companies. Until now ISS has succeeded in integrating the new companies because top management has given priority to human resource and organizational development. It seems as if the new top management prioritises differently than it did under the leadership of Poul Andreassen, the founder of ISS' modern business and HR development culture. There is greater emphasis on shareholder values and quantitative expansion and less on HR development and consequently less on integration of the new companies in the corporate culture. However, the priority assigned to shareholder value by the new top management in their strategic thinking is ambiguous. In the new five years plan 'Create 2005' - the top management points to six priority areas in which HR development does no have the highest priority. But, on the other hand, HR development is not asssigned low priority (ISS homepage 2002). In Malaysian and Singaporean subsidiaries we have noticed that the HR departments were uncertain about the priority of HR development in the new five years plan. But the HR managers did not face constraints from headquarters in assigning priority to HR development. They have room for manoeuvre; for independent initiative in the field of HR development but they would like to know what priority is assigned to HR development by headquarters since they have acquired a big Asian cleaning company and have got many new contracts and new employees.

This is an interesting situation in the history of ISS because the company has previously always given a clear message to employees and shareholders about the high priority of HR and organizational development. We want to stress that these tendencies are rather new and it too early to conclude that they represent a break with ISS's historical background. Something that suggests that the new top management want to come back on the old track is their plan to re-establish ISS Service University as a centre for HR development.

However, if we look at ISS's history it is a company with a modern work culture inspired by American human relation philosophy already in the 1960s. Management laid great emphasis on non-conflictual management-labour relations and on upgrading cleaning work by training and quality standards. ISS was one of the first companies in Denmark to introduce "The employee of the month" and a training programme where the participants get a five stars award after passing the examination. HRM thinking in ISS has therefore not been a matter of implementing a new corporate culture. It has rather been to develop the existent human relation philosophy. The strategic management level has been the main agent in developing the corporate culture agenda, while the lower management level (the supervisors) has been the main agent in implementing and maintaining this 
agenda in daily work practices. Normally, the cleaners do not stay long enough in the company to get familiarised with the corporate culture.

The smooth introduction of HRM in ISS has not meant that the company has been ahead of the more patriarchal companies in our sample. We must admit that we had expected that these companies lagged behind ISS but we have realised through our interviews that their historical background has not meant a more hesitant attitude towards introducing HRM strategies (Fleming et al. 1998). The most likely explanation of this open attitude towards HRM strategies is that these strategies aim to set up the same close relationship between management and labour as in the patriarchal system but with a new form and style. As in the old system, management-labour relations in HRM strategies lay great emphasis on a non-conflictual company culture. But unlike the old system HRM strategies focus on participation and involvement and the incentive structure is closely linked to these strategic objectives.

\subsubsection{Training and Learning Practice}

In our analysis of the Danish subsidiaries in Malaysia and Singapore we have not tried to measure the degree of involvement of employees in the subsidiaries but we have conducted a survey on the dissemination of training in HRM practices. We categorised employees in the following five strata:

a. Management/Professionals

b. Supervisors, Sales reps. and Technicians

c. Skilled workers

d. Clerical

e. Semi-skilled/un-skilled workers.

The $\mathrm{a}$ and $\mathrm{b}$ strata, not surprisingly, have participated in most training courses with elements of HRM, for instance in new technology, team work and participation, IT-courses, leadership and HR development. Typically, the lower strata have participated in teamwork and participation courses. It is interesting to notice that most of the companies find that they have increased the degree of delegation of responsibility in the last five years. No one could point to a specific reason for this change but the managers and supervisors we interviewed mentioned some of the following reasons:

1. To find methods and techniques to improve the use of employees' skills and competence.

2. To increase employees' interest and awareness of product quality and improvement.

3. To find methods and techniques to enhance motivation for learning, change and flexibility. 
In annual appraisal schemes in our sample of companies the focus is on these three areas and particularly on how the individual employee can improve quality, costumer service and productivity. Management and supervisors consider these appraisals useful tools to improve the interest among the employees for learning and participation. But at the same time they admit that it is more difficult to implement participation among the lower strata than among other strata. We will deal with this problem later; a problem that is partly connected to different social and cultural conditions and partly to learning and ranking in the company hierarchy.

As mentioned earlier, the management-labour relation in such participatory work organization rests on a complex power relation involving both governance of Other and Self-governance (Foucault [1978] 1991). We find this dual power relation in management's efforts to install corporate culture values, which motivate the individual employee to work and learn and at the same time optimize operational procedures in the company. Is this power relation an emerging reflexive governance of management-labour relations? In our sample of companies in Malaysia and Singapore we have seen, among the upper strata of employees, a growing consensus between the economic interests of the company and the interests of the employees in more motivating and attractive work conditions. In the lower strata the working conditions necessary for establishing this consensus are not present. Although semi-skilled and un-skilled workers experience a pressure to learn new work procedures and the demand for flexibility, their working conditions have not changed to such an extent that it is reasonable to talk about a change in management-labour relations.

\subsubsection{Unions and External Relations}

Until now our focus has been on corporate culture strategies in the companies. But the implementation of these strategies is not only dependent on the internal relationships in the companies. The work and business culture in the surrounding society has also a significant impact on the implementation of these strategies. Although in recent years HRM strategies have had more and more impact on management-labour relations in Malaysia and especially in Singapore, the fundamental feature of these relations is still marked by patriarchal structures and traditions. In Singapore and to a lesser extent in Malaysia, governments act politically within a new patriarchal framework characterised by controlled and supervised participation. Trade unions are weak compared to Nordic trade unions and theirs influence on management-labour relations is very limited. In Malaysia, Malaysian Trade Union Congress, MTUC, is primarily focused on wage negotiations and its main goal is to achieve minimum wage agreements in every industry. MTUC does not organize a very high percentage of the workers partly because many companies do not allow workers to be members of a union and partly because several companies only allow in-house unions that are not affiliated to 
MTUC. In Singapore, the National Trade Union Congress, NTUC is closely connected to the government. NTUC's Secretary General is also Minister Without Portfolio and he is member of the tripartite system by which the partners make agreements on wages, training, participation, heath and safety conditions etc. NTUC is more involved in regulation of management-labour relations than MTUC but, as in Malaysia, many employees are not organized in a union.

For the Danish companies in this environment, conditions for implementing HRM policies do not provide a democratic pressure from below on industrial relations. On the other hand, the patriarchal traditions provide non-conflictual relations between management and labour and a high degree of company loyalty that many companies consider to be a good starting point for HR development. In addition, in Malaysia and especially in Singapore, the attitudes of employees to learning are very positive. The patriarchal traditions and the weak position of the trade unions have therefore created a very co-operative attitude among employees in the two countries. Some commentators consider increasing job-hopping in the last decade to be a protest against patriarchal management-labour relations and authoritarian government policies. But until now this protest can only be considered as individual protests and there is no evidence that it has caused serious cracks in the fundamentally co-operative attitude among employees towards the companies.

However, the co-operative attitude that Danish headquarters wants to develop in the subsidiaries through corporate culture and competence strategies is not the same as the attitude that we meet in local companies of the old Asian patriarchal tradition, nor in many other foreign companies. American and Japanese companies tend to ignore the local work culture in implementation of their HR strategies by having corporate manuals for every procedure and, in Japanese companies, employ a lot of expatriates to install these strategies. However, the Danish companies are more reluctant to break down local work culture. Their strategies are a compromise between international HRM objectives and local values. As we mentioned earlier, Danfoss' 'Asian Mission' is an illustration of this compromise. Typically for the companies in our sample, the human resource manager who set up this Mission in Danfoss, is a manager with local background bridging international management and local cultural values. In the Danish companies, it seems that, in implementing HRM policies, management has taking into consideration the barriers posed by the old authoritarian and patriarchal work culture. In our interviews with managers, they all emphasised that, in implementing the delegation of responsibility to team work groups they have take into account that most of the employees are not trained to carry out independent work tasks or to make decisions by themselves. Employees work under employers' prerogatives without criticism. It is not easy to break with this work culture and this is why we refer to a third culture in the Danish subsidiaries at this stage of the implementation of HRM policies. They have not reached the same level of delegation of 
responsibility and decision-making as their sister companies in Denmark but, on the other hand, they differ from many local companies in which management has not begun to break down the old authoritarian and patriarchal work culture. The barriers that both local managers and employees have to break down in order to carry out HRM policies are not only an outcome of historically determined management-labour relations but are deeply rooted in the surrounding society. Most of the students in the educational system and employees in government institutions are also brought up within the authoritarian and patriarchal tradition. The aim of the educational system has not been to develop an independent and reflexive attitude among students. The governments in the two countries are aware of the problems that these barriers cause in implementing participatory management strategies. They have initiated experiments in the educational system to train students in critical thinking and more self-directed learning methods. We will later return to this.

We consider both Malaysia and Singapore as countries in transition from old patriarchal work cultures with strong authoritarian traditions to more modern work cultures with participation and involvement. The pace of transition varies in the different sectors of the two societies and within the sectors there are also variation in pace. In our sample we have seen a variation between the upper and the lower strata of managers and employees in their adaptation to corporate culture strategies. The upper strata are more familiar with the corporate cultural values of headquarters than the lower strata. Western middle class values usually have more influence on the daily lives of the upper strata than on the lower strata and before their employment in the Danish subsidiaries they usually have had jobs in other international companies. Consequently, in the transfer of corporate culture and competence strategies to the subsidiaries, headquarters concentrate their efforts on this stratum. Often, these core employee groups come to the corporate training centres where trainers from headquarters or consultancy firms introduce them to the company's strategies. At these sessions the participants from different subsidiaries in the group have an opportunity to meet and share experience. Undoubtedly, the companies consider these informal meetings as the best way to build up corporate culture. They consider this competence building in the upper strata as a trickle down strategy according to which they expect that the upper strata transfer corporate cultural strategies to the lower strata.

In our interviews with managers in the subsidiaries we have not met any explicit critique of the headquarters policy of transferring corporate culture, HRM and competence strategies to the subsidiaries. But among managers there is some scepticism about the trickle down effect to the lower strata in the subsidiaries. As we mentioned earlier, there is no explicit resistance among these lower employee groups to competence building and participation. But the authoritarian and patriarchal tradition in working life create some barriers to implementing participation and devolution of responsibility. Although these barriers have their roots in cul- 
ture traditions we hesitate to explain everything on the basis of Asian culture and values. In the sister companies in Denmark too it has been hard to implement participation and delegation of responsibility in teamwork groups. But in Denmark there is another tradition of critique and dialogue in management-labour relation than in the two Southeast Asian countries. A participatory work environment presupposes that the participants are open to critique and dialogue. The mindset among many employees in our sample is according to several managers not prepared to face faults and critique in front of other workers in a team. Cultural barriers can explain some things, for instance the fear of losing face in front of others if one has committed a fault or is not able to carry out a task. However, we do not find this cultural explanation sufficient. As mentioned earlier, it has also been hard to establish teamwork in sister companies in Denmark - and the same cultural explanation cannot be used to explain Danish employees' attitude to teamwork. Lack of training in teamwork is in our opinion a more likely explanation of the problem.

Unlike in Denmark trade unions in Malaysia are not much involved in implementation of teamwork and participatory work organization. Even when they do organize in a factory they normally concentrate on negotiating salaries and health and safety rules with the employers. But it is rare that they are involved in training issues at the work place level. MTUC has recently begun to participate in tripartite meetings with the Human Resource Development Council (under the Ministry of Human Resources) and the Federation of Employers on training programmes for un-skilled and skilled workers and vocational training programmes. In Singapore, NTUC is more involved in providing training courses for unskilled and skilled workers. Its activities are mostly on the national level, not so much on the company level. Unlike in Denmark NTUC is not involved in negotiating training issues with management. It is management that sets the agenda for implementing teamwork organization. For instance, supervisors in ISS said that the members of their teams had no wish to involve trade unions in negotiating the training issues. Of course, the team-leaders version could be wrong or they could be unwilling to involve unions. But this is not our impression. ISS does not want to exclude trade unions from their companies. However, trade unions are weak in Malaysia and Singapore because of strong and restrictive government regulation of union activities and a lack of traditions among the employees of membership of trade unions. This is especially the case for low status cleaners. In ISS, management builds their HRM strategies mainly on supervisors and management strata because cleaners are not so linked to the company. As already mentioned, the turnover rate is very high among cleaners and it is absolutely critical to management's attempt to set up an agenda for teamwork and participatory work organization. However, the high turnover rate does not seem to weaken the organization. A strong corporate 'us' spirit is spreading down from the supervisors and above. In Malaysia and Singapore a growing number of cleaners want to join ISS 
training programmes and get the chance to be upgraded and get a better-paid job. It shows that HR development programmes not only provide mobility in a company but they also pave the way for integrating wider groups in the corporate culture.

\subsection{Concluding Remarks}

We have above explored some of the reasons why Danish companies focus on corporate culture and competence development in their subsidiaries in Malaysia and Singapore. Generally speaking, the parent companies have been interested in streamlining the organizational structures globally and locally and at the same time strengthening local competence building. Global competition between leading MNCs globally has set the tune for their strategy. They have seen that the most successful MNCs have gained competitive advantages by setting up a flatter network-oriented organization that can provide rapid and competent responses anywhere, at any time. They have recognized that the Achilles heel in this strategy is local competence building: partly because of lack of skilled labour, partly because of working cultures that are unfamiliar with participation and selfdirected learning. In order to improve competence building, most of the companies have focused on the following three areas:

a. Improving the use of employees' skills and competence.

b. Increasing employees' interest and awareness of product quality and improvement.

c. Enhancing motivation for learning, change and flexibility.

The companies did not encounter strong resistance to this policy, particularly the upper strata have been supportive to learning and participation. The open attitude among employees to the human resource development policy is probably due to the Danish companies' compromise between old work values and new management policies. Management placed emphasis on loyalty and family-like relations, but at the same time they sought to transform these values into a participatory work context. Although we have not found any strong resistance to management's competence development policy we are hesitant to conclude that the companies have succeeded in building up the intended competence among all strata. It is primarily among the upper strata that the companies have found a potential to build up a capacity for reflexive learning that underpins the new network organizational structure. The other strata are still influenced by the old traditions of management-labour relations, family traditions and the educational system. However, the companies do not consider these barriers as insurmountable. They believe in a trickle down strategy. They identify transformation capacity mainly within their plants but also in intermediary institutions such as human resource management institutes and in supportive programmes of government departments 
and agencies. The majority of local managers have been exposed to modern network and human resource management theories and they have often higher education and degrees from abroad. This pull of supportive forces towards implementation of HRM policies has become the driving force in the process of breaking down the old management-labour relations. In the absence of trade unions as sparring partners in the workplace, management in Danish subsidiaries has to build corporate culture and competence development by focusing on the welleducated middle and upper strata of employees in their companies.

These strata belong to the new middle classes with a Westernized life style. Typically, they not only participate in HRM-courses in the companies but also in intermediary institutions that are promoting the HRM philosophy. In the 1990s, governments in both Malaysia and Singapore have been very engaged in projects that strengthen transformation from a labour-intensive industrialisation to a knowledge-based economy. In that transformation process they lay great emphasis on developing new self-directive competencies in the educational system. In Malaysia, for instance, the government has recently launched a Smart School project. Teaching in these schools is IT-oriented and the aim is to change teaching towards more self-directed learning. According to the plan all primary and secondary school will be converted to Smart Schools by 2010. It may be a too ambitious plan but the signal is important, especially in any discussion of the possibility of strengthening the transformation capacity of HRM-oriented companies.

Both in Malaysia and Singapore there are many institutions that support the transformation of authoritarian patriarchal traditions in management-labour relations. In Singapore there is a stronger tripartite tradition and there seems to be consensus about supporting reflexivity, new management and networking. In Malaysia the tripartite tradition is much weaker and although the government, by strong leadership, is promoting a knowledge-based economy, the transformation is not going so smoothly as in Singapore. The educational system is more difficult to change, the religious resistance towards change is stronger and ethnic divisions create greater conflicts in a change process.

\section{References}

Baethge, Martin and Herbert Oberbeck (1986), Zukunft der Angestellten: Neue Technologien und berufliche Perspektiven in Büro und Verwaltung, Frankfurt am Main: Campus.

Braverman, Harry (1974), Labour and Monopoly Capital: The Degradation of Work in the Twentieth Century, New York: Monthly Review Press.

Carlzon, Jan (1985), Riv pyramiderne ned! En bog om chefen, lederen og det nye menneske, København: Gyldendal.

Castells, Manuel (1998), The Rise of Network Society, Oxford: Blackwell Publisher.

Chan Kwok Bun (ed.) (2000), Cinese Business Networks: State, Economy and Culture, Singapore: Prentice Hall.

Docherty, Peter and Barry Nyhan (eds) (1996), 'Understanding Industry in Transition', Human Competence and Business Development, Berlin, Heidelberg and New York: Springer Verlag.

Danish company booklets and homepages 19962002. 
Dore; Ronald (2000), 'Will Global Capitalism be Anglo-Saxon Capitalism?', New Left Review, Nov-Dec pp. 101-19.

Featerstone, Mike (1990), Global Culture: An Introduction, London: Sage.

Fleming. Daniel and Henrik Søborg (1998), 'Strategies for Network Integration and Human Resource Development of Danish Companies in Malaysia and Singapore', in Daniel Fleming, Pauli Kettunen, Henrik Søborg and Christer Thörnqvist (eds), Global Redefining of Working Life A New Nordic Agenda for Competence and Participation?, Copenhagen: Nordic Council of Ministers., Nord 1998:12, pp. 121-70.

Foucault, Michel ([1978] 1991) 'Governmentality', in G. Burchell, C. Gordon and P. Miller (eds) The Foucault Effect - Studies in Governmentality, London: Harvester Wheatsheaf.

Gallin, Dan (2000), Trade Unions and NGOs: A Necessary Partnership for Social Development, Geneva: Paper No 1, Civil Society and Social Movements. UNRIDS.

Giddens, Anthony (1994). Living in a PostTraditional Society, in Ulrich Beck, Anthony Giddens and Scott Lash, Reflexive Modernization: Politics, Tradition and Aesthetics in the Modern Social Order, Oxford: Polity Press.

Gomez, Edmund Terrence and K. S. Jomo (1997), Malaysia's Political Economy: Politics, Patronage and Profits, Cambridge: Cambridge University Press.

Kern, Horst and Michael Schumann (1984), Das Ende der Arbeitsteilung? Rationalisierung in der industriellen Produktion: Bestandsaufnahme, Trendbestimmung, München: Verlag Beck.

Investor's Business Daily, 9 July 2001.

Kettunen, Pauli (1998), 'Globalisation and the Criteria of "Us" - A Historical Perspective on the Discussion of the Nordic Model and New Challenges', in Daniel Fleming, Pauli Kettunen, Henrik Søborg and Christer
Thörnqvist (eds), Global Redefining of Working Life - A New Nordic Agenda for Competence and Participation?, Copenhagen: Nordic Council of Ministers., Nord 1998:12, pp. 3380

Kogut, Bruce (ed.) (1993), Country Competitiveness: Technology and the Organizing of Work., New York:. Oxford Univ. Press.

Levinson, Klas (2000), 'Codetermination in Sweden: Myth and Reality', Economic and Industrial Democracy, vol. 21, pp. 457-73.

Peters, Thomas J. and Robert H. Waterman, Jr. (1982), In Search of Excellence: Lessons from America's Best-run Companies, New York: Harper \& Row.

Piore, Michael J., and Charles F. Sabel (1984), The Second Industrial Divide: Possibilities for Prosperity, New York: Basic Books.

Price Waterhouse (1997', 'Without Change there is no Progress', A global survey by Price Waterhouse.

Senge, Peter (1983), Fifth Ddiscipline: The Art and Practice of the Learning Organization, London: Century Business.

Sennett, Richard (1998), The Corrosion of Character:The Personal Consequences of Work in the New Capitalism, New York: W.W. Norton.

Shamsul, A. B. (1999), 'From Orang Kaya Baru to Melaya Baru: Cultural Construction of the Malay "New Rich"'. in Michael Pinches (ed.), Culture and Privilege in Capitalist Asia, London and New York: Routledge, pp. ??

Unctad (1994), World Investment Report 1994, Geneva.

Unctad (2001), World Investment Report 2001, Geneva.

Visser, Jelle (2000), 'From Keynesianism to the Third Way: Labour Relations and Social Policy in Postwar Western Europe', Economic and Industrial Democracy, vol. 21, pp. 421-56.

Watson, Tony J. (1995), Sociology, Work and Industry, London: Routledge. 


\title{
3. Between the Local and the Global - Representing Employee Interests in European Works Councils of Multinational Companies
}

\author{
Herman Knudsen
}

\subsection{Introduction}

This chapter addresses the opportunities for European Works Councils (EWCs) of gaining influence on corporate decisions in multinational companies (MNCs). The first part establishes a frame of reference for investigating the issue by analyzing and discussing the power relations between management and labour in MNCs. The second part introduces the European Union Directive on European Works Councils, previous research on EWCs, and the concept of transnational employee influence. In the third and main part of the article findings from own research are presented and analyzed in the context of opportunities for employee influence. The research is based on a survey and interviews among Danish EWC representatives as well as on a survey among managers in Danish based MNCs. Finally, the last section discusses the EWC as a new arena for European industrial relations and its links and possible compatibility with national, including Nordic, industrial relations traditions.

\subsection{Growing Imbalance Between Capital and Labour}

According to Guy Standing's well documented book Global Labour Flexibility (Standing 1999) the last two decades have witnessed increasing insecurity for people as far as income, employment and job security is concerned. In Standing's words there has been a global shift from an era of statutory regulation to the era of market regulation. The partial removal of statutory regulation, the deterioration of welfare services, and the privatization of public companies are among the factors that have secured companies a greater freedom to exploit the opportunities of the market. Many have greeted these changes with enthusiasm as the way

${ }^{3}$ Acknowledgements: This article is based on research funded by the Danish Social Science Research Council. It was written during a stay at the Department of Economics, University of Wollongong. I thank the colleagues there for inviting me and providing me with good working conditions. I also thank my Nordfram colleauges for stimulating discussions and comments to the first drafts. 
not just to boost profits, but also as the one and only model able to ensure social and economic progress. Trade unions have often attempted to resist this development, but rarely successfully.

What about other models of social and economic progress? The Nordic model? The German model? The continuation of these models in a European model as propagated by the European Union? The predominant discourse in European Union politics and in the 'new' Labour Parties advocating a third way, seems to be that we can have the best of all worlds, that we can combine a new, more dynamic form of market regulation with social security and welfare for all. Indeed, it is claimed that the former is a necessary condition for the latter. It may be so, but it all depends on the balance between the two. Some countries have obviously gone so far in accommodating to the demands from big capital that not much is left to the welfare state. In particular large sections of unskilled workers have been hit by poverty because of unemployment or underemployment taking the form of low paid casual and often part-time jobs (Beck 2000).

The new market regulation regime is not just saying that nation states should step down and leave more leeway to capital. It is also part of the receipt that trade unions and worker representatives should be curbed - at least to the degree that they subsume their goals and interests under the interests of capitalist companies. This means that the pluralism of earlier eras, the acknowledgement that labour has legitimate, independent interests and that capital has to seek and build on compromises with these and other non-profit oriented interests, has disappeared. Not everywhere, but certainly in the predominant political discourse on the development of economy and society.

Besides the decrease in income and employment security Guy Standing also notes a decline in representational security (Standing 1999: 194-205). In many countries trade unions have been weakened, partly because of a hostile political and ideological climate, and partly because increasingly people are employed in jobs or types of work where there is little tradition for unionism. Representation in the workplace, whether through trade union representatives or works councils, is almost exclusively a European (and Japanese) phenomenon. Globally, the trend has been away from collective representation and towards an individualized employment relationship.

Looking at the Nordic countries - and the whole of Western Europe for that matter - these trends have not had a revolutionizing strength. Apart maybe from Britain and Ireland, the collective representation of workers' interests at the workplace is still the norm. Although trade union membership has declined significantly in many countries, at the workplace level work councils or similar bodies, usually dominated by trade unionists, persist (Ferner and Hyman 1998; Gill and Krieger 2000; Knudsen 1995). However, as I argue below, although representation is still intact, its efficiency tends to be weakened by the internationalization of capital. 
A rapidly increasing part of total economic activities are organized by multinational companies (MNCs). In the developed countries about one in five employees are directly employed by such companies. The share rises to about two in five if we include subcontracted and franchised operations of MNCs (Edwards 1999; UN 1998).

A great part of the growth in MNCs in recent years is due to cross-border mergers and acquisitions. In particular in Europe this process was speeded up throughout the 1990s - connected to, first the introduction of the Single Market, and then the European Monetary Union. In 1995-97 almost half the purchases of firms taking place worldwide were in Western Europe; in 1997 cross-border acquisitions of EU companies amounted to $\$ 138$ billion (Edwards 1999).

\subsubsection{Management and Labour in MNCs}

How does this growing internationalisation affect employees and the possibilities for an effective interest representation? According to Edwards (1999) three different effects can be discerned. First, there is what he terms the general 'acquisition effect'. Mergers and takeovers may be followed by new investment, or result in a redeployment of and an intensified use of already existing assets. They may also lead to a slimming or even a closure of production. In fact, it is not unusual for mergers and takeovers to be followed by redundancies.

The second effect mentioned by Edwards is the 'multinational effect'. By becoming multinational and by acquiring additional plants, a company increases its ability to apply 'divide and rule' tactics and practices in its dealings with the workforce (Cowling and Sugden 1994). In particular, such tactics can be applied by companies that produce similar, and movable, products at different locations. Through bench-marking and similar techniques management collects comparative information on productivity, quality and performance in general. On the basis of this, investments tend to be placed where performance is highest whereas the lower performing plants may experience disinvestment or outright closure.

As pointed out by Coller and Marginson (1998) and Mueller (1996) this is not just a technical, 'objective' process. Differences between plants regarding performance and profitability are exploited by management in its negotiations with employee representatives and trade unions. This has led to concepts such as 'concession bargaining' and 'coercive comparisons' (Coller and Marginson 1998). By threatening to reduce the activities of a plant or to close it altogether management brings the workforce on the defensive. This then typically results in deals where the continuation of employment is only upheld on the condition that workers make concessions as for example increased working time flexibility, intensification of work and pay restraint. Not least the car industry is abound in examples of this type of bargaining based on the logic of divide and rule (Ardiles 1999; Hancké 2000). 
The third effect of internationalisation mentioned by Edwards is the "nationality effect', or the export of institutional features from the country of the company headquarter to subsidiaries in other countries. The effect of this may be changes in what Whitley (1992) has termed 'national business systems'. More concretely, Edwards relates his findings to Albert's (1993) notion of two capitalisms with distinct characteristics - the Anglo-Saxon and the Rhine model. Between these models corporate governance differs because of different national regulations, cultures and traditions. In the Anglo-Saxon model companies are almost exclusively responsible to the shareholders, rendering high short-term profits the main concern. Contrary to this, in the Rhine model companies also have obligations towards the wider society and the employees, leading to an emphasis on longterm development and profitability. These differences imply different types of pressure on management, and this again leads to differences in managers' approaches to human resource management and industrial relations (Edwards 1999).

In an attempt to evaluate the impact of the nationality effect on industrial relations in European establishments that have been taken over by or merged with other companies Edwards (1999: 324) concludes that

takeovers by Anglo-Saxon MNCs pose significant challenges to employees and their representatives. The system of corporate governance in Anglo-Saxon countries, notably Britain and America, pressurises management into a 'cost-minimisation' approach to managing labour, involving the monitoring of short-term labour costs, greater numerical flexibility and hostility to employee representation structures.

In other words, when Anglo-Saxon companies take over continental European ones they tend to an important extent to export Anglo-Saxon HR and IR traditions to the acquired establishments on the European continent. According to Edwards there is not much export of continental IR-practices in the opposite direction, i.e. when continental European companies take over British or American establishments. Instead, they tend to actually import back some of the AngloSaxon practices to the continental home countries (Edwards 1999: 336-37), the net result being an erosion of continental IR systems, i.e. the systems in which employee representation and participation have been strongest.

It should be added that Edwards views this trend as being in its initial stages and only visible in the most internationalised MNCs. His observations conflict with traditional wisdom concerning the decision-making locus for HRM and IR issues. A number of studies have concluded that in MNCs such issues are usually decided not by the corporate headquarter, but locally in the individual subsidiaries, and very much influenced by the regulations, cultures and traditions in the particular country in which the subsidiary is located (Hamill 1983). This is also the conclusion reached by Tayeb (2000: 120): 
the so-called 'soft' aspects of management, such as interpersonal relationships and communication, HRM and industrial relations issues, were influenced by the local culture and handled according to locally accepted norms and traditions, even though in some cases the parent company was unhappy with the outcome.

The trend found by Edwards, however, may represent an important present and future development. Evolving practices such as increasing international networking within the HRM field (Fleming and Søborg 1998) and the application of 'coercive comparisons' mean that management at the corporate level is now better equipped to reshape local industrial relations and HRM practices.

To the three effects of internationalisation identified by Edwards, a fourth, more formal one, must not be forgotten. In MNCs the possibilities for employee representatives to be in contact with the 'real' management are reduced. According to national legislation or collective agreements in most European countries, employee representatives enjoy certain rights to be informed and consulted by management, in some countries even rights to take part in management decisions through codetermination procedures. These rights to some degree become illusory if an establishment becomes a subsidiary of a foreign based MNC. It is of little use to discuss matters with the local management if decisions are actually taken by a corporate management abroad, and national legislation cannot oblige a management located in another country (Knudsen 1995; Kolvenbach and Hanau).

All these four effects point to a relatively clear conclusion: The increasing internationalization of the ownership and management of workplaces weakens the representation of labour vis-á-vis capital. And together with the downward trend in employment and income security it changes the balance of power between capital and labour in favour of capital. ${ }^{4}$

Notwithstanding this representation deficit and power imbalance, one could expect that the European Works Councils, established according to the 1994 European Union directive, will make a difference; after all, this directive grants employee representatives in MNCs the right to be informed and consulted by corporate management. Let us therefore turn to this theme, first by taking a closer

\footnotetext{
${ }^{4}$ Some other global trends have also affected the balance of power between capital and labour. Thus, the growing use of outsourcing intensifies competition between workforces and constitutes a further obstacle to a joint coordination of employee interests. Outsourcing implies an increasing discrepancy between formal and real structures in production and business, between the firm defined as a legal unit and the firm seen as the conglomerate of activities and organizations that participate in the production and sale of a specific product (Cowling and Sugden 1994). However, other trends at play tend to promote the power of labour, at least potentially. The use of just-in-time principles makes companies extremely vulnerable to disruptions and delays in the different stages of production. It is therefore central for employers to prevent strikes and other forms of industrial action, and this may be exploited by employee representatives in their negotiations with management. Also, it is increasingly important for companies to gain and maintain a good public image. When companies adopt mission statements saying that they will live up to high ethical, environmental and social standards, it is probably mainly motivated by considerations about market positioning and sales. But the standards do provide a normative platform which critical journalists as well as trade unions and employee representatives can use as a yardstick in their evaluations of the actual practice of the companies. For instance, recently MacDonalds, Nike and GAP have been exposed by the media for their use of child labour and sweatshop labour practices in some of their outsourced production in Asia (BBC 2000).
} 
look at the provisions and mechanisms of the directive, and later by examining the functioning of EWCs.

\subsection{European Works Councils - \\ A Platform for Transnational Employee Representation}

The growing inequality between capital and labour and in society in general does not correspond well with the self-image that the European Union likes to propagate. Here concepts as 'Social Europe' and the 'European Social Model' are plus words that pop up again and again. The concepts are used in a highly ideological manner alongside economic policies that increasingly build on liberalist receipts prescribing more power to markets and managers. When the European Single Market project was launched in the mid-1980s, leading EU spokespeople such as the President of the Commission, Jacques Delors, were keen on stressing that this essentially liberalist project should be accompanied and balanced by a 'Social Dimension' firmly securing employee rights at the Community level (Knudsen 1995: 116).

Although often used ideologically, the notions of 'Social Europe', a 'European Social Model' and the 'Social Dimension' are not without substance. It is true that the EU member states - in general, but some clearly more than others are more 'social' in terms of welfare provisions, employee rights and social and economic equality than are the two countries which the EU usually compares itself with, the US and Japan. It is probably also true that if the EU is to secure continuing popular support, especially from the Nordic countries and Germany, it will essentially have to generalize the social standards obtained in the North to the whole community of countries, rather than contributing to a lowering of these standards.

However, historically it has proven difficult to give flesh and blood to the European Social Model. The construction of this model as a material reality would involve the translation of the various social traditions of the member states into EU policies and institutions (thus forcing some member states to change their institutions and standards considerably) and a consolidation through new legislation at the European level. The ideas for this have been there, the political will has also been there in most member states, but often one or two countries have felt that they stood to loose to much from European legislation. In the social and industrial relations area it has usually been Britain and Denmark that have dragged out, watered down or outright prevented legislation. While the British opposition to EU legislation during the years 1979-97 was evidently political, for both countries it has also been a matter of defending strongly voluntarist national IR traditions against statutory EU regulation. 
With this background outlined, we can now look more closely at European Union initiatives attempting specifically to redress the balance between capital and labour in MNCs.

At the political level in the EU there was awareness at an early stage of the changes in industrial relations driven by the internationalization of companies. In 1973, a report from the European Commission identified some of the problems posed by the transnational companies. The report (CEC 1975) specifically mentioned

the need for appropriate representation of employee interests vis-à-vis a company which no longer takes its decisions independently but complies with those of the group in which it forms part.

The discussions on the issue led the Commission to put forward the so-called Vredeling Directive in 1980. The directive would introduce an obligation for employers in 'complex' undertakings to inform and consult the employees' representatives. It was met by a storm of protests from multinational business interests, including American and Japanese based MNCs, and was taken off the agenda in 1986. By that time it was evident that it could not be adopted because of the British Thatcher government's determination to veto it (Knudsen 1995: 126-29).

However, four years later the Commission issued a new proposal, the draft directive on European Works Councils. This proposal was justified in general by the promise made by European policy-makers of adding a social dimension to the single market. More specifically, it was argued that employees in one country "affected by decisions taken elsewhere by the parent undertaking...could be unequally treated" which again "is bound to have a direct effect on the operation of the internal market" (CEC1990). The European Commission further argued that the dialogue between EWCs and management would be likely to increase worker involvement and commitment, and thus productivity ('Impact Assessment...', printed in Kolvenbach and Hanau).

In spite of strong opposition from business interests and the Conservative British government the European Works Councils Directive was adopted in September 1994. The adoption was only made possible by the 1993 Maastricht Treaty in which the attached 'Social Protocol' introduced qualified majority voting on some industrial relations issues. Britain did not sign the protocol and was also exempted from the EWC Directive. The British position changed after Labour's election victory in 1997, and a special extension directive ensured that British workplaces became covered from 1999.

The EWC Directive applies to companies or groups of companies with more than 1,000 employees (and at least 150 employees in two different countries) within the area of the European Economic Agreement $(E E A=E U+$ Norway, Iceland and Liechtenstein). Such companies, no matter whether they are based in 
EEA countries or in for instance the US or Japan, are obliged to set up an EWC if requested to do so by the employee representatives. The EWC may be an employee-only body or a joint body for management and employee representatives. ${ }^{5}$ It is entitled to be informed and consulted by the central management on strategic issues as well as employment issues involving employees in more than one country; thus typically restructuring involving the relocation of jobs has to be taken up with the EWC.

The normal procedure for instituting an EWC is an agreement based on prior negotiations between employee representatives and the central management of the company (or its appointed representatives in the case of MNCs based outside the EEA). This procedure is in line with the increasing influence of the subsidiarity principle on EU social regulation (Schiller 1998). However, although flexible and open to national as well as company-specific interpretations, the directive does include elements of 'hard regulation': If management refuses to negotiate, or if negotiations do not lead to an agreement within three years, the company is still obliged to finance some basic activities of an EWC and to meet with it at least once a year.

The so-called subsidiary requirements of the directive define the minimum employee rights that apply directly in such situations. Of course, they thereby also provide a norm for the company-specific negotiations. Analyses of EWC agreements have usually compared the content of agreements with the subsidiary requirements of the directive. So-called voluntary agreements under the directive's article 13 could be concluded until 22 September 1996 (the deadline for the transposition of the directive into national legislation). While the content of these agreements often fell below the subsidiary requirements as far as explicit employee rights are concerned, agreements signed later under article 6 generally have improved in this respect (Knudsen and Lund 1997; Marginson et al. 1998; Marginson 1999). Some agreements include rights that are not mandated by the directive, for instance two ordinary meetings per year, resources for training or for communication and contact on the employee side also between ordinary meetings.

By October 2002 there existed 739 EWCs according to Waddington and Kerckhofs (2001), based on the database of the European Trade Union Institute ${ }^{6}$ ). With on average 18 employee representatives on each EWC (Marginson 1999) this amounted to more than 13,000 employee representatives with tasks at the transnational level. Although it is not likely that all MNCs covered by the direc-

\footnotetext{
${ }^{5}$ In this article the concept EWC either denotes an employee-only body or the employee side of a joint body. The rights granted in the directive are in any event given to employee representatives. In practice, there may be little difference between an employee-only body entitled to meet with management, and the employee side of a joint body; most EWC agreements allow the employee side to have their own meetings besides the joint meetings with management.

${ }^{6}$ From my research on Nordic and in particular Danish based EWCs it is my experience that the list of EWC agreements registered by the ETUI database is far from complete. Thus, the number of EWCs calculated by Kerckhofs (2001) is most likely underestimated.
} 
tive (estimated to 1,865 by the ETUI) will actually establish EWCs, the number of European representatives will probably have risen to about 20,000 in a few years. Thus, at least numerically this new tier in European industrial relations is certainly not insignificant.

\subsubsection{Research on European Works Councils}

With the adoption of the EWC Directive and a number of other industrial relations directives (Falkner 2000), concepts such as the European Social Model or Social Europe are not completely without substance. These regulations do signal a different path than the ones pursued in other parts of the world.

However, evidently one can question the strength and real significance of these European regulations of industrial relations. Here, Euro-pessimists and Euro-optimists (Dølvik 1997) are divided. An important reason for the division is that optimists and pessimists tend to place EWCs within different frames of reference. The pessimists tend to stress the weakness and incompleteness of European regulation compared to more labour-friendly regulation found in some of the member states. Streeck (1997), judging from a critical German perspective, thus has claimed that EWCs are neither works councils nor European. Further he has argued that because of their weak foundation they may actually - through the mechanism of regime competition - help to undermine national representation systems and rights.

British observers, for their part, have been more prone to compare with British institutions, and in that perspective even modest European regulations have given rise to optimism (see for instance Wills (2000) for a list of 'great expectations' which, by the way, are challenged by her own research).

Perhaps more fruitful than the polar pessimist-optimist positions is a more open and wait-and-see attitude towards the possible long-term outcomes of EWCs (as held by among others Beaupain et al. 2001; Knudsen 1999; Lecher et al. 1999; Marginson 2000). New opportunities have been opened, and it still remains to be seen how they are seized and exploited by various groups of social actors.

The optimism-pessimism divide is not only related to frameworks inspired by national institutions and discourses. Observers also diverge as to how much they expect EWCs to achieve in terms of effective and solidaristic interest representation. Some seem to expect from them nothing less than genuine international worker solidarity - certainly a high expectation as worker solidarity across different workplaces is hardly the norm even in the best organized national systems. Others have more modest expectations, such as that EWCs should be able to organize a dialogue, with management and internally between employee representatives, which may be advantageous to both sides.

High expectations tend to lead to pessimist research results. An example of this are these concluding remarks from a case study (Wills 2000: 103): 
The EWC studied indicates that, as yet, these new European structures for international trade unionism have not facilitated widespread collective action, mass protest or even an embryonic collective consciousness at this level.

No wonder that this new body in industrial relations comes out as a manifest failure, when all the aspirations that the labour movement has hitherto failed to accomplish are projected on to it! By this remark I do not suggest that we as researchers should try to eradicate any hopes and 'great expectations' from our research agenda. But we must be aware of which hopes and expectations research findings are measured against and maybe coloured by.

Research on EWCs has moved from dealing with the expectations arising from the formal rules of the directive (e.g. Knutsen 1997; Streeck 1997) or the formal texts of EWC agreements (Marginson et al. 1998; Marginson 1999) to focussing on the actual functioning and practice of EWCs. In particular, since 1999 a large number of articles and a few books have reported on the latter. Most of the studies have been case studies (e.g. Hancké 2000; Lecher et al. 1999; Lucio and Weston 2000; Whittall 2000; Wills 2000), but a few studies based on surveys/questionnaires have also been conducted (Knudsen and Sørensen 2000; Miller 1999; Nakano 1999; Veersma 1999).

In a recent paper (Beldam and Knudsen 2001) a colleague and I attempted to compare the original expectations attached to the EWC Directive by the main social actors involved, with the available research findings on the actual practice of EWCs so far. In brief, we found that employer expectations of a number of harmful effects of EWCs had not been confirmed; on the contrary, many MNCs seem to use its contact with the EWC as a meaningful and useful management instrument. We also found evidence tending to substantiate the expectations of EU policy-makers - of the EWC as a step towards more harmonious industrial relations in MNCs. However, it was difficult to find strong evidence supporting the trade union expectations of EWCs as instruments for increased influence to employees in MNCs. On this point, research is still rather inconclusive; findings from case studies often point in different directions (see for instance Hancké 2000 versus Whittall 2000).

Still, the question of employee influence is extremely central in the debate on EWCs. The rest of this chapter will deal with this question, first by discussing the concept of employee influence at the transnational level, and then by presenting and discussing some findings from Danish research on EWCs.

\subsubsection{Employee Influence in MNCs: A Conceptual Framework}

The EWC Directive is not a strong statutory base for employee influence. It contains no provisions granting employee representatives the right to negotiate with or to take decisions jointly with management (codetermination). Formally, opportunities for influence exclusively rests on the obligation of the central management to inform and consult the employee representatives on the EWC. The latter 
may exploit the information given as a source for constructing a more precise picture of the company and its strategy and plans, something which again may lead to the formulation of more precise demands and tactics. Consultation and dialogue with management have the potential of employee proposals and ideas being considered by management and being integrated into management decisions, wholly or partly. In cases where both sides are interested, consultations may lead to informal negotiations and the conclusion of informal or formal agreements (examples of this are given in Knudsen and Sørensen 2000; and Lecher et al. 1999).

Influence on decision-making may be defined as the achievement of certain outcomes or effects which would not have been achieved without an effort to intervene in the decision-making process; at the same time the outcomes achieved must be deemed favorable or advantageous by the influence-seeking person or group. The latter part of the definition is necessary because an influence-seeking effort does not always lead to either a positive or neutral result; it may in fact result in a negative outcome.

One example, based on a conversation with an EWC member, may illustrate this: An American MNC with operations in Britain, Denmark and other European countries informed its EWC that it intended to move some of its operations from Britain to Denmark; this would entail job losses in Britain and increased employment in Denmark. The chairman of the EWC, a Dane, consulted with his British colleagues and urged management to call off the planned relocations. To this a corporate management representative replied: 'If you don't want the jobs in Denmark we can move them to the US'. Had this become the outcome, the influence achieved by the EWC would have been negative. The intervention of the chairman would have resulted in a net loss of jobs for the workforces represented on the EWC, whereas the original management proposal only involved a relocation of jobs within the European area. (To the curious reader: In the end management implemented its original plan, and the EWC chairman never found out whether the proposal to move the jobs to the US was a realistic option or just a threat).

At this stage we can sum up that efforts to gain influence through EWCs may result in positive, neutral as well as negative outcomes.

Because of the multi-plant and multi-national character of the EWC it is relevant to distinguish whether influence gained favours the whole constituency of the EWC or only a part of the constituency, located at one particular workplace or in one particular country. In the first instance, the influence can be said to express international solidarity and also a changed balance of power between corporate management and the workforces employed by it. In the latter instance, the influence may also be an expression of solidarity (as in the example above where the Danish EWC chairman supported the British workforce). 
Typically, EWC members will compare conditions and standards across the plants and countries they represent. On this basis, it is possible that demands are developed which aim at improving conditions in the worst off plants/countries 'lift the floor' has always been a central principle in trade union activity. As an example of this mechanism, redundancy payments to Danish workers in subsidiaries that were closed down were increased through the intervention of the EWC. (Knudsen 1999: 74-75). Danish legislation and collective agreements do not entitle laid off workers to redundancy pay contrary to what is the case in most other European countries. By putting pressure on corporate management, the EWCs in these cases improved the conditions somewhat for the laid off Danish workers.

However, in other cases influence that only favours workers in one plant or country may express the opposite of solidarity. This primarily occurs if employee representatives see themselves as representing only their own, local constituency, and interpret interest representation in a parochial way. By doing so they may pursue influence in competition with and possibly at the expense of other workforces within the MNC. Thus, Hancké (2000: 55) concludes from his case studies of EWCs in the car industry that:

Not only are EWCs relatively unimportant in building up international union strength; local trade unionists seem to use the EWCs to do the opposite: to obtain information that can be used in the competition for production capacity with other plants in the same company.

In this example the positive influence gained through the EWC by the representative from one plant actually results in negative influence for the totality of workforces represented on the EWC. Hancké explains in some detail how management exploits the competition between workforces through rounds of concession bargaining where concessions given by workers in one plant (for example on working time flexibility) become arguments for management when it starts negotiations in the next plant. Such inter-plant competition may be promoted and exploited by management irrespective of the existence of an EWC, but to the extent that Hancké's observations hold true, the EWC may actually help to strengthen rather than weaken this oppressive mechanism.

To the type of negative influence mentioned above - caused by management responding in a 'punishing' mode to demands from the employee side - we may thus add another type of negative influence, namely the one resulting from EWC members narrow-mindedly pursuing local interests at the expense of workforces in other plants and countries. While such parochial forms of seeking influence seen from a local or even national perspective appear as helping to increase employee influence, from a perspective focussing on the need for organizing and empowering workers transnationally they have mainly negative consequences. The task of securing that locally based interest representation develops into forms 
which are not just effective in the local context, but also coordinated with the collective interests of all workforces within the particular MNC, is no doubt the biggest challenge that EWCs are confronted with. It is the moment of truth for international solidarity.

One particular type of parochialism that has been discussed by several observers, is the 'unholy' alliance that may exist between corporate management and employee representatives from the mother-company or generally from the home country of the MNC (Elvander and Elvander 1995; Knudsen and Bruun 1998; Lecher et al. 1999). Lecher et al. (1999: 222-23) describe the 'home advantage' in this way:

As a rule, EWC representatives from the home country form the single largest contingent - a dominant position which endows a feeling of security. They also usually have recourse to national structures of representation to obtain information and influence on group-level decisions...And finally, the fact that the meetings are held in their mother tongues and in their own countries offers benefits which should not be underestimated.

Elvander and Elvander (1995) describe a situation where Volvo had to cut down production. The influential employee representatives at the main plant in Gothenburg managed to obtain a promise from management that no jobs would be lost there. Instead job losses were 'passed on' to the Uddevalla factory located elsewhere in Sweden as well as to a foreign subsidiary. Although these events took place before the establishment of an EWC at Volvo, the example demonstrates a type of practice that can easily continue, in spite of the existence of an EWC. To avoid such internal struggles between representatives from different plants, a close communication between EWC colleagues from all countries involved is necessary. A conscious effort by the home country representatives not to use the privileged position in a plant-egoistic way is also required.

From the examples and arguments above it follows that the important distinction is not between representation which exerts influence in favour of all employees in the MNC versus influence which only brings advantages to a few. What is important is rather whether the perspective of EWC representatives is inclusive, i.e. aiming to further the interest of all employees, or exclusive, i.e. aiming at furthering only local interests, perhaps at the expense of other employees in the group.

The opportunities of gaining influence of an inclusive nature are contingent on a number of preconditions. One is, as just mentioned, that the employee representatives have a sufficient degree of internal communication, allowing them to exchange knowledge and experience, to develop trust and mutual understanding

\footnotetext{
${ }^{7}$ As a point of reservation: Language and place of meetings do not always follow the location of the headquarter. For example, many Scandinavian MNCs have chosen English as their official language, and in some EWC agreements it is determined that meetings alternate between company locations in different countries.
} 
and to formulate common goals for the activities of the EWC. The development of an inclusive perspective is not likely without a feeling of collective identity. Another precondition is that the EWC representatives have recourse to a power base that can be mobilized in critical situations. This power base is not given by the statutory provisions of the EWC Directive which as already mentioned are weak regarding employee rights. Neither is it realistic that the EWC as such is able to mobilize employees for collective action; except perhaps for extraordinary situations, for example closures or other drastic restructuring. Only the trade unions, at local, national and European level, can to some extent supply the EWCs with a sense of power. They can give advice on complex issues, back up demands raised by the EWCs, and mobilize workers in support of EWC demands if this is found necessary. Therefore, close links to the relevant trade union organizations provide the most important power base that the EWC can draw on.

A third precondition for inclusive influence is that corporate management is prepared to engage in a dialogue with the EWC, consider the proposals put forward by employee representatives, and accept informal, if not formal, bargaining as a part of the exercise. It seems that management in most MNCs have realized that a close cooperation with the EWC may bring benefits to the company, such as less resistance to change among employees and a greater understanding for management goals in general (Beldam and Knudsen 2001). If managers are to obtain these benefits, they must display good will and accept some of the proposals and wishes put forward by the employee representatives.

Of course, influence can also be obtained through more confrontational tactics. Yet, in such cases the EWC is unlikely to be the main protagonist. When Renault in 1998 closed down its plant in Vilvorde in Belgium, the Renault-EWC strongly protested for not having been consulted. But the strikes that followed in Belgium, France and Spain were called by the trade unions, not the EWC. Moreover, the action organized by the unions later contributed to more respect being paid to the EWC by the Renault corporate management (Kerckhofs 2001).

Through the above discussion of opportunities and preconditions for influence based on cross-national solidarity in EWCs, a frame of reference has been established. The next section will put some empirical findings into this frame.

\subsection{Employee Influence through EWCs - Some Findings from Danish Research}

A study of practices and attitudes of EWC representatives and managers involved with EWCs was carried out by a colleague and myself in 1999-2000. Survey data were collected during the summer and autumn of 1999 through a questionnaire sent to all Danish EWC members (111 of whom 85 responded). Another questionnaire was sent to top managers in the 27 Danish MNCs which at that time had established an EWC; here 17 responded. The survey on the employee side 
was supplemented by five individual and one group interview with EWC representatives. The findings from the study was published in Danish in 2000 (Knudsen and Sørensen 2000). Conclusions from the study appeared in English in EIRR (2000).

In the following the data collected for the study will be analyzed specifically with regard to the question of opportunities for employee influence through the EWC. However, before data are presented and discussed one point has to be made clear: More or less, the respondents were all beginners and learners! The study dealt with novel and often experimenting institutions rather than 'ripe' institutions rooted in traditions and routines. Among respondents in the employee survey about two out of three had been EWC representatives for less than three years, and had only taken part in three or less EWC meetings with management. A few recently elected respondents ( 7 per cent) had actually not taken part in any many meetings at all. As pointed out by Lecher et al (1999: 213) EWCs must go through several stages, from their formal creation, through processes of mutual interaction and recognition between the parties involved, to where they

acquire the status of an industrial relations actor (that)...represents interests and put forward demands which have been collectively elaborated within the EWC itself, functioning as an institution and with its own views on employment and corporate issues.

The reader must bear this novelty of the EWC institution in mind when judging the findings from the Danish study presented below.

\subsubsection{EWC Representatives in Denmark - A Brief Profile}

Among the 85 employee representatives 25 (29 per cent) were women. All but one were members of a trade union -86 per cent were members of trade unions affiliated to the LO while the rest belonged to unions organizing for example engineers, salespeople and foremen. At least three out of four served as local trade union delegates (shop stewards) and also held seats on local cooperation committees (the Danish equivalent to works councils). 30 per cent were joint shop stewards, 35 per cent member of a group cooperation committee in Denmark, and 42 per cent held a position as employee elected representative on the company board. Thus, generally the EWC representatives were highly experienced local trade union delegates.

Just under half of the EWC representatives served on EWCs in Danish based MNCs, while just over half were in EWCs belonging to MNCs based in other countries, notably Swedish, British, Swiss and German based groups. 13 per cent of the representatives held a position as president or vice-president of the EWC, and 22 per cent were member of the EWC's executive committee or steering group. 
The most common motives given for accepting the task as an EWC member were 'to represent my colleagues' and 'to strengthen union cooperation across borders,' both ticked by over 60 per cent of the respondents. 13 per cent stated to have been 'urged by management,' indicating that local trade union bodies had perhaps not everywhere been able to control the selection of representatives.

The following sections focus on different factors that affect the opportunities for employee influence through EWCs: management attitudes; the activity of EWC representatives; barriers from differences in culture, language and interest; and resources available for EWCs.

\subsubsection{Is Management Prepared to Concede Influence to EWCs?}

Among the statements we confronted employee representatives with one maintained that, 'Group management takes the proposals and ideas we have put forward into account'. 27 per cent totally agreed with the statement, 41 per cent partly agreed, while the rest either disagreed or did not know. Remarkably the share of those who totally agreed was higher among representatives in Danish based MNCs (38 per cent) than in MNCs based abroad (19 per cent). This no doubt reflects the short distance, physically as well culturally, between the representatives in the home country and the group management, as well as the fact that relations between the two sides existed already prior to the establishment of the EWC.

We also formulated the negative statement that 'Group management does not want a genuine cooperation' (with the EWC). 10 per cent totally agreed, and 29 per cent partly agreed with this statement. From this and other data in the survey can be concluded that about to out of three EWC members do not consider management to be an obstacle to forms of cooperation that involve conceding some influence to the EWC.

The evidence from the interviews was somewhat more pessimistic. A typical complaint was that management only informed about decisions after they had been taken. In the words of a representative in an American owned group in the food industry (interview 1):

We ask every time if any kind of closures or relocations are expected, but we never get a reply. We always get the reply too late, when the decisions have been taken.

From two Danish based MNCs, in the textile and manufacturing industry respectively, we get similar stories (interview 6):

One of the big themes we have had is relocation of work from Portugal (to Russia, HK). We had a meeting with management in February last year. In April we were told that one of the factories, with 251 employees, would be totally closed down.

Shortly after we had had an (EWC) meeting they decided to move a part of the production from here to England instead of building a new factory here. They had actu- 
ally decided to build a factory here, but because of a number of things they found out that they would move a part of it to England ... It came as a chock both in England and here. They ought to have called a meeting with the English and Danish representatives in the steering group. We were offered and had a steering group meeting afterwards, but then the decision had already been taken. 15 persons were fired ..., there will probably be more in the future.

In this company the EWC representatives had taken a direct discussion with management on participation in decision making, arguing that management decisions would cause less friction and be more acceptable to the workforce if they are taken with the active involvement of the EWC. But (interview 6):

We got a clear message back that they would decide themselves, because we were 46 shop stewards, and not all could be trusted.

In other MNCs it appears that management does not want to invest too much energy in the dialogue with the EWC. An employee representative in a Swiss based MNC in manufacturing had this impression (interview 6):

There are no results as yet. I can feel that they listen in a more positive way than they did the very first time. Perhaps there is hope, but I think it is a long process. At the moment they don't know how much they dare tell us. Usually, they tell us the things when everything has been decided, sometimes even carried out in practice. To me it appears as inferior work on the part of management. It is something they have in order to make things look nice. They have not understood the extent to which they can use it.

However, an example can also be found of a management pursuing a more active strategy. The top management of a German MNC in manufacturing called a meeting with the EWC on company strategy and the future division of labour between the different subsidiaries. They asked the EWC representatives to work out their own coherent proposal. An overall aim of the project was a 25 per cent market increase in Europe making it possible to maintain the existing workforce. The Danish EWC representative saw this as an important chance for the EWC to influence company strategy (interview 3).

In the employer side survey, managers were asked whether the contact with the EWC had had any impact so far on company decisions in various areas. Most of the 16 managers responding to this question reported that there had been no impact. Yet, on issues such as personnel policy, training, health and safety, relocation of jobs, redundancies, and closure of plants, between three and five replied that the EWC had to a certain extent had an impact on decisions. More generally, managers were divided on the value they ascribed to the EWC. Eight found it to be an overall advantage, four held the opposite view, while five were undecided. Over half found that the contact with the EWC had positive consequences for the company in one or more respects (cooperation (10), exchange of information (9), 
employee acceptance of company decisions (7), company loyalty among employee representatives (6)). Only one respondent found the EWC to have resulted in any negative consequences.

Most managers, however, did not find the EWC to be very 'competent to conduct a dialogue with corporate management on the development of the group'. Eleven found it competent only to 'a small extent', six 'to some extent', while none found it to be competent 'to a great extent'. Neither did most managers want to support measures that may render the EWC more competent. Out of the 17 respondents only six answered affirmatively to the question, 'Should the employee representatives on the EWC receive training in order to become more competent for the EWC task?' And only one and three were in favour of allowing trade union officers or external experts to take part in meetings between the EWC and management. Thus, it seems that most Danish managers, although positive towards the EWC as such, are very keen on keeping it as an in-house arrangement, detached from national and international trade unionism.

In both surveys we asked whether any agreements had been concluded between the EWC and management. Agreements can be seen as relatively manifest signs of employee influence, clearly transcending the powers formally included in the directive. No managers found that agreements had been made; however, two of the 17 responding managers would like to enter into agreements with the EWC on certain issues in the future. Among the employee representatives 17 per cent reported that agreements had been concluded. Some of these had to do with the operations of the EWC itself, others dealt with such issues as relocation of production or jobs, personnel policy, the adoption of a company social charter, and training.

To sum up, there are indications that management in many MNCs attempt, more or less consciously, to prevent EWCs from getting influence on company decisions. Rather than promoting joint decision-making, managers want to develop their contact with the EWC into a human resource instrument whereby employee loyalty and understanding of company decisions may be enhanced. However, there are also indications that some MNCs accept, or even promote, EWC involvement in certain types of decisions.

\subsubsection{EWC Members: Own Efforts and Perception of the Significance of the EWC}

A low level or a lack of influence may also result from employee representatives themselves being too passive or giving low priority to the EWC. In the survey we confronted the employee representatives with the statement 'The employee side has not done enough to achieve influence'. 58 per cent totally or partly agreed with that, whereas only 14 per cent totally disagreed. Again responses varied substantially between representatives in Danish based MNCs, where 67 per cent agreed, and foreign based MNCs, where the share was only 50 per cent. This is 
an understandable difference in as much as the representatives in the home country have other channels of access to corporate management, in particular the cooperation committee and the employee representatives on the company board, whereas those employed in foreign MNCs have no other channels than the EWC; therefore they are likely to put more effort into EWC activities. More surprisingly - and certainly quite alarmingly for the trade union movement - we also found that the tendency to agree with the statement rises proportionally with seniority as EWC representative. Among members with less than one year's seniority 38 per cent agreed, but among members who had served on the EWC for more than three years as many as 71 per cent agreed that they had not done enough to achieve influence. Also, members with special functions in the EWC, such as presidents and executive committee members, were more prone to agree with this self-critical statement than were lay EWC members. It is difficult to interpret these results. They may indicate that the longer you have been on an EWC and the more centrally placed you are, the more aware you are of the uncertain and insignificant role ascribed to it by the trade unions, cf. the discussion on union policies later in this chapter.

Other data suggest that the critical assessment of own effort is probably quite realistic. 85 per cent spend less than ten hours per month on work related to the EWC, including meetings, and 41 per cent spend even less than five hours per month. 35 per cent are only in contact with other employee representatives from their EWC in connection with meetings, i.e. in most cases once a year, and other 45 per cent only have such contacts approximately once a month. Obviously, such a low level of time consumption and internal contact between EWC representatives does not constitute an effective basis for the formulation of common policies and demands.

One reason for the relatively low level of activity seems to be that the EWC by many is not seen as important as are other channels for influence. The statement 'The work of the EWC plays a very little role compared to the work carried out by shop stewards in Denmark' aimed to measure attitudes in respect to this. 61 per cent agreed totally or partly with the statement, and only 16 per cent expressed their total disagreement. Also, it is difficult to make the shop-floor colleagues interested in participation at the European level. Two out of three representatives agreed that 'Most colleagues show no interest in the work of the EWC', and four out of five agreed that it is difficult for the colleagues to understand what goes on in the EWC. Contrary to this, the vast majority of representatives found good support from other local trade union delegates. 82 per cent agreed that 'my shop steward colleagues find that the work of the EWC is an important part of trade union work'.

It is also important to employee representatives how the national trade unions seem to be valuing their tasks as EWC members. Here, two out of three representatives totally or partly found that the national trade union organisations 'provide 
the support that I need'. However, there was also a majority who found that the national unions had not put enough resources into supporting the EWCs. In particular, this majority wanted the unions to supply more information about the nature of the tasks involved in being an EWC member, to help make the EWCs more visible, and to arrange training for people interested in being elected to an EWC.

Until now it has been argued that low employee influence through the EWCs may be due to opposition from employers as well as a low level of effort from employee representatives themselves. The latter may be related to the low status given to the EWC by employees in general and to some extent also by the national trade unions. However, other difficulties stem from the multinational character of the EWC.

\subsubsection{Differences in Language, Culture and Interests as Barriers}

Danish EWC representatives saw differences in language, culture and interests as quite serious obstacles to a joint, cross-border interest representation through the EWC.

17 per cent totally and 30 per cent partly agreed with the statement, that 'Language difficulties make effective cooperation impossible'. And over half of the respondents disagreed with the statement, 'If only the EWC members know each other well, language is not so important.' So, language was seen as a major problem, and consequently the vast majority of the representatives insisted on translation to all relevant languages during EWC meetings as well as the provision of language training by the company. Yet, some had also experienced that language problems can be worked with, also in the short run (interview 1):

Of course it gives difficulties, because the most important is what goes on in the 'corridors', the social events, that is where contacts are knitted together and where trust develops. I have tried it in Amsterdam where we were nine different nationalities that walked about in the streets. We made it work in spite of that. There were Scandinavians, Spaniards, Germans ... and a Belgian who speaks French and German. We learned it. But it is important that everybody learns the company language so that we can communicate. It should be paid by the company, not at the expense of, but as a supplement to translation.

Another barrier is 'cultural' differences, or perhaps more precisely differences related to the fact that the European countries have differing industrial relations systems. Not just formal rules are vastly different, so are formal as well as informal practices, for example in relation to meetings between managers and employee representatives. Yet, most of the employee representatives rejected that 'Differences in the way of thinking/ culture make an effective cooperation impossible'; actually, although 36 per cent partially agreed, only six per cent agreed totally with the statement. However, a strong need is felt to learn more about the rules and customs of other countries. When asked about training needs, 68 per 
cent ticked the option 'knowledge about industrial relations in other countries', as compared to 57 per cent 'voting for' language training, and 50 per cent for training in companies' financial matters.

Cultural and language differences may result in prejudice and suspicion towards EWC representatives from other countries. Such suspicion is perhaps not always unwarranted as this quote from a representative in a Danish MNC tells (interview 6):

It is a bit of a problem, for the Italian representative is the personnel manager. It is a bit critical what we should talk to her about. We cannot talk with her for she speaks only Italian; English is incredibly difficult for her. We can't communicate with her outside of meetings about these things (why she has been chosen as employee representative, HK).

On the same EWC the workers in a subsidiary in Poland are 'represented' by a foreman. This is clearly an example of management having picked the 'wrong' persons as employee representatives, probably because the relevant workers and unions in Italy and Poland have not been informed about the EWC. As pointed out by Royle (1999) in his study of the MacDonald EWC, such 'elections' manipulated by management evidently makes it difficult for the employee representatives to develop a common perspective and to function as a channel for collective employee interests.

In other cases, prejudice based on culture turns out to be - just prejudice (interview 1):

It surprises one what they think and do in other countries. One had expected Italy to be an underdeveloped country. One has attitudes like that. Then we have discussed what the Italians do when threatened by factory closure. They demand that a new factory be built in the neighborhood where everybody can get a job! That is their first demand. If that cannot be done, then they get redundancy pay for up to one year and six months! In Denmark you can only get it for 52 days.

Some statements in the survey particularly attempted to measure whether EWC representatives perceived that they have different interests to such an extent that a common pursuit of influence becomes meaningless. 38 per cent agreed, partly or totally, that 'It is difficult for us to agree because we have different interests'; however, only four per cent agreed totally compared to a share of 20 per cent who totally disagreed. Even less support was given to the statement 'The employees in the home country of the company play their own game together with the group management'. Only 29 per cent agreed more or less with this statement whereas 37 per cent disagreed totally.

It may sound surprising, then, that a majority of seven out of ten agreed with the proposition that 'Some (EWC representatives) think more about their own workplace than a common line towards the group management'. To interpret this as a sign of a workplace egoism that excludes cross-border solidarity would 
hardly be correct. For 92 per cent of the same population agree with the statement that, 'The climate (in the EWC) is marked by trust and cooperation', and 71 per cent agree that 'As EWC members we have already developed common points of view'. It seems that for most EWC representatives there is no contradiction between representing the interests of one's own workplace and being part of a group which aims to represent the interest in a coordinated way at the European level. So, a fair conclusion as to the question of how potential differences of interest are perceived by EWC members, is that only a relatively small minority view such differences as a serious obstacle to a joint European interest representation.

Also here learning processes leading to changing perceptions can be found. The following story from a Dutch-British MNC in the food industry gives an example of common positions being developed in spite of an objective situation of competition between workforces in different countries. The background was that management had threatened to close a factory in Belgium. However, a closure was avoided on the basis of concessions given by Belgian employee representatives in local bargaining. The EWC representatives believed that this local agreement was undercutting Belgian legislation regarding payment for night shift work, and they saw it as a type of concession to management that should be avoided in the future. Therefore (interview 2):

On our last meeting we adopted a code of conduct where we oblige each other to inform if there are rumors or knowledge about relocations of plants etc. In such situations we oblige each other not to conclude any local agreements before it has been discussed in the EWC.

\subsubsection{Resources Available for the EWC}

An important precondition for a common interest representation through the EWC is that resources are available for facilitating communication between EWC representatives. Such resources include time off for meetings and ongoing communication, translation facilities, training, access to external experts, and independent office, telephone, fax and e-mail facilities. Management's obligation to provide and finance these resources is laid down in the individual EWC agreements at company level, but to a widely varying extent (Marginson 1999).

Most of the Danish EWC representatives found that they have sufficient resources at their disposal. However, a considerable minority reported that some resources were not available or not available to a satisfactory degree: Computer/e-mail ( 24 per cent), fax (14 per cent), office facilities (14 per cent), paid time off (11 per cent), translation (25 per cent), assistance from secretary (37 per cent), funding of preparatory meetings ( 21 per cent), telephone ( 7 per cent). Only 40 per cent had received training related to their EWC tasks, and most of the training had been financed by trade unions rather than the employers. 
The opportunity for EWC representatives of being together during a longer period at a conference or seminar is an essential part of constituting an EWC successfully. Representatives must learn to know each other and exchange experiences and viewpoints as a precondition for building up trust and a common perspective on the role of the EWC. We found that exactly half of the Danish EWC representatives had taken part in such an activity (the most frequent duration being two, three or four days), whereas the other half had not.

In the survey we found relatively clear attitudinal differences between these two groups. The following list shows a number of statements concerning relations between employee representatives, and the share within each of the two groups that agreed with the statements (the first figure shown is for the 'havebeen-togethers'):

- 'As EWC members we have already developed common viewpoints': $86 \%$ versus $57 \%$

- 'Some think more about their own workplace than a common line towards the group management': $62 \%$ versus $80 \%$

- 'Differences in the way of thinking/culture make an effective cooperation impossible': $36 \%$ versus $49 \%$

- 'Difficulties with language make an effective cooperation impossible': $39 \%$ versus $57 \%$.

The difference in the replies from the two groups clearly indicates the importance of (resources for) communication on the employee side. The qualitative significance of being able to get together is also witnessed by the following stories from EWC representatives (interview 1 and 2 respectively):

\begin{abstract}
I was so lucky to be able to participate in a seminar in Lisbon for a week, paid by European trade union organizations, where I was together with colleagues from my own EWC. A week together where we were together exclusively on the employee side has helped incredibly, because a project like this is a question of trust and mutual trust, and you don't get that by meeting for two days once a year where you have a very pressed program. Our colleagues can really feel the result of that seminar.
\end{abstract}

Last year we got an agreement with them (management, HK) that the company would pay for four days. We were together in Brussels for four days with all facilities, interpreters and everything ... That is the first time ever we have been together alone. It was a course arranged by among others the Dutch trade union, and it was very European, for we had teachers from four different countries. It was really good and we had a lot of talk with each other.

\title{
3.4.6. Prospects of Influence at the European Level
}

In the sections above some barriers and constraints to the unfolding of European level employee influence in MNCs have been presented. At the same time, examples have been given of how constraints have been transcended. To use the 
metaphor of Lecher et al. (1999) it seems obvious that not all EWCs have reached the take-off phase where corporate management is met by an independent and coordinated employee side. It is also likely that a number of EWCs will never reach this phase (as it is also the case with some of the national works councils [cf. Kotthoff 1994 and Agervold 2002]).

Practically as well politically it is a quite demanding task to reach and maintain the level at which the EWC functions as a collective. Factors as divisive MNC strategies and language and cultural barriers make the attainment of unity considerably more difficult than is the case for works councils at the national level.

To transcend the limitations discussed above, in particular two actors external to the EWCs themselves are central. The first one is the European Union. If the EU wants the EWCs to form part of a genuine European Social Model it will have to revise the EWC directive so that independent employee rights are strengthened. It must give trade unions a formal role in the establishment and running of EWCs, and it must guarantee a more secure resource base for EWCs. Otherwise, it is likely that many EWCs will merely be insignificant appendices to corporate management.

The other important actor is the trade union movement. Trade unions welcomed the EWC directive, but their practice towards the EWCs is marked by ambivalence. On the one hand national as well as European trade union organizations have put a lot of resources into organizing employee representatives across borders and enabling and supporting them, so that EWC agreements could be negotiated and concluded with management. They have also provided training, expert assistance, and - rarely in the Nordic countries but often in southern Europe - national trade union officials as full members of EWCs.

On the other hand national as well as European union organizations have been slow in developing strategies for the EWCs. There have been no clear messages from the union movement as to what EWCs should attempt to achieve and with what means. This relative passivity is related partly to the diversity of viewpoints held by unions in the different European countries (Lecher et al 1999: 248-55), making a common strategy at European level difficult to work out. Partly, it also reflects that some of the less enthusiastic unions fear that EWCs, formally nonunion organizations, may take over some of the functions now fulfilled mainly by unions at local and national level, collective bargaining not least (Beaupain et al 2001). The skepticism and lack of strategy was summed up like this in an article by a Danish trade union officer responsible for support to EWCs (Odgaard 2000):

During the last 5-6 years we have contributed to the establishment of European Works Councils. During this period we have, at the Nordic as well as the European level, mainly been preoccupied with the procedure for the establishment of these EWCs... When on rare occasions we have taken an interest in the activities and tasks 
of the EWCs, the starting point has been to contain the activities of the EWCs. We have been good at telling what the EWCs shall not deal with, and we have been bad at telling what they shall deal with. We have never attempted to draw up a proper trade union strategy defining the tasks and issues that EWCs must try to promote (my translation, HK).

This fear of putting a real content into the EWCs is evidently not stimulating EWC representatives to be enthusiastic about fighting for influence at the European level through the EWC. On the contrary, the wavering attitudes among trade unions are likely to have a demoralizing effect on EWC representatives who are used to find guidelines for their work in national trade union policies.

In spite of the various limitations to EWC influence there are also examples that show the potentials for inclusive forms of influence at the European level. Simply good communication between EWC representatives and a readiness to back each other up may give results as told by this representative in an American based MNC (interview 1):

We had an example where some shop stewards in Spain were dismissed because of some confidential letters that had been opened. Then all EWC representatives wrote a letter to management saying that we did not understand that it could be normal management policy to open the letters of shop stewards. We could not accept that, and we demanded that the dismissals were withdrawn. Then they did that. That was done in the context of the EWC.

A further basis for influence is the drawing up of comparisons of employment and working conditions in the different subsidiaries of the MNC. EWCs may attempt to exploit such comparisons in similar ways as management uses benchmarking and 'coercive comparisons'. Parallel to management initiatives, the EWC as a collective can attempt to spread 'best practice' to countries where employment and working conditions are lagging behind. By doing so, however, EWCs enter areas normally regulated by national legislation and/or collective bargaining. Consequently, the dynamics inherent in the formulation of demands based on comparisons may be constrained by opposition from national trade unions.

A third source of influence is the awareness of EWCs of the importance for companies of a good image. A representative from a Dutch-British MNC explains (interview 2):

They (management, HK) have always known that the press and public opinion could spoil many things. That's why the company already many years ago when they shut down productions bought people to be silent ... You had people at the age of 50 or so who were queeing up to get the sack, because they could get more money in redundancy pay than they could earn for the rest of their life.

In the same MNC the EWC representatives called a press conference at which they explained their protests to the company's paying out of extra dividends to 
shareholders. The dividends were allegedly based on profits gained from plants that had been sold off or closed. The EWC instead demanded the introduction of a profit share scheme at the European level.

In at least two Danish based MNCs the EWC has taken company image as a point of departure for their activities. In one case the EWC has invited management to formulate a code of conduct with high standards on ethical, environmental and social issues. These high standards shall also apply to plants that are acquired for instance in Eastern Europe (interview 4):

If there is a hidden agenda, it is about helping the colleagues in Eastern Europe to get a better working environment, and it is of course also about preventing social dumping. But of course we neither can nor shall compete with their pay levels.

Finally, influence may be achieved through joint European development projects with management. Typical areas for such projects appear to be training, environmental protection and occupational health and safety (Knudsen 1999: 74; Lecher et al 1999: 217). As pointed out by Lecher and colleagues there is however a risk that such projects in 'soft' areas come to dominate the agenda of EWCmanagement meetings at the expense of strategic issues.

To conclude: EWCs have potentials for being bodies able to achieve influence and thus to some extent strengthen the power of European labour vis-a-vis the MNCs. The low degree of influence reported so far may be explained by in particular these five factors:

1. the novelty of the institution

2. opposition among employers

3. the lack of well defined employee rights in the directive and in individual agreements

4. the lack of trade union strategies for EWCs and hesitation among EWC representatives

5. cultural and linguistic barriers to cross-border employee communication.

One could add a sixth factor: the lack of interest among ordinary employees where there seems to be an almost fatalist attitude towards capital's globalisation. None of these factors are rocks that cannot be moved, but for the time being it remains true that there is a serious imbalance between international capital on the one hand and on the other labour forces that are primarily oriented towards local and national perspectives. 


\subsection{EWCs between the Local, National, Nordic, and the Global}

Some observers as for example Streeck (1997) have argued that EWCs would become extensions of national representation systems rather than genuinely European bodies. Research presented in this article and by others (Lecher et al 1999; Whittal 2000) indicate that this is hardly the general trend, although there is also research that lends support to Streeck's hypothesis (Hancké 2000; Wills 2000). As opposed to Streeck, Paul Marginson has argued that the EWC is an important seed to a new European industrial relations playground, in particular because it is linked with a wider process of Europeanisation in which MNCs develop a sub-global, European identity. According to his observations (Marginson 2000: 29):

... MNCs have developed, to an extent which varies according to sector and market
segment, a European dimension to the international organization of production and
market servicing and the management structures which coordinate them. This has
given rise to the Eurocompany.

Marginson stresses that the EWC Directive as well as other legislation at the European Union level have been active in promoting industrial relations which are neither global nor national in their scope, but European. Partly because of these regulations MNCs now tend to develop coherent human resources and industrial relations approaches for specifically the European area.

However, even if the 'Eurocompany' is a growing trend, national diversity still makes its way to the European level. There are still marked differences between the IR approaches of say British based and German based MNCs (Edwards 1999). As to the employee side, EWCs are usually coloured by the industrial relations of the home country of the MNC. In particular, this is the case if most of the MNC's employment is located in the home country, and if employee representatives from this country dominate the EWC numerically. And typically, negotiations with management on the conclusion of an EWC agreement are coordinated by a trade union officer from the home country.

An attempt to show the diversity of the relations and the division of labour between EWCs and national representation systems, is given by Lecher et al (1999) who studied the functioning of EWCs in Germany, France, Britain and Italy. For Denmark it is also possible to identify some EWC characteristics which are connected with the national IR traditions (Knudsen 1999; Knudsen and Sørensen 2000). First of all, among trade unionists EWCs have very much been seen as a European extension of the Danish 'works councils'. The Danish word for these samarbejdsudvalg - is also used for the new European bodies - europaiske samarbejdsudvalg. This may appear logical. However, by doing so an essential difference between the national body and the European one is played down. 
Whilst the national bodies (which are joint management-employee bodies) are intended for discussions of 'tactical' matters such as principles for personnel policies, work organization, training, payment systems, and the introduction of new technology, the EWCs are mainly intended to deal with 'strategic' issues and their impact on employment. The tasks of the EWC are thus more similar to the functions performed by employee representatives on company boards. The tendency to identify EWCs with national works councils rather than with employee representation on the company board has probably meant that Danish EWC members have been less prepared to formulate policies in response to strategic initiatives from management.

The lack of strong powers to EWCs may also play a role in the Danish 'reception' of EWCs. As shown above EWC activities are considered clearly less important than local shop steward activities, especially among representatives in Danish based MNCs, and relatively little effort is spent on EWC activities. This can be interpreted as supporting Streek's (1997) pessimist contention that EWCs will fail to become important industrial relations players because their powers are too weak compared to national institutions. For Danish employee representatives who already have several open doors to corporate management it may seem unnecessarily complicated and difficult to go through the EWC as a way of seeking influence. They take the easy way - at the expense of the inclusive type of influence defined earlier in this chapter? At least this could be a hypothesis for further research.

A further aspect is the Danish tradition of a great extent of informality in workplace industrial relations. In this tradition formal agreements and agendas are often put aside, and real results may often appear after talks during a dinner or over a beer. One of the Danish EWC representatives told that as he found that some important matters were not on the agenda, he took them up with management outside the agenda or outside the formal meeting. However, for the German EWC colleagues this was not the correct way to communicate with management: "They are deeply offended by our openness" (interview 3 ).

If we extend the perspective to the Nordic countries in general we will find that Nordic employee representatives typically are not only informal, but also (Gudmundsson 1995; Knudsen and Bruun 1998)

1. almost exclusively trade union members,

2. experienced with participation in management decisions at various levels

3. experienced with gaining influence through close cooperation with management

4. usually functioning relatively independent of national trade unions.

These characteristics in many respects fit well with the intentions of the EWC Directive and, in a wider perspective, the idea of a European Social Model. One 
the one hand, this is not surprising, as it is the cooperative industrial relations of Germany, the Netherlands and the Nordic countries that are the main sources of inspiration of EU policy-makers.

One the other hand, the Nordic model will hardly become the European model. To the extent that EWCs will take on a European character, the 'Europeanness' will most likely be based on mergers of distinct features from different national traditions as well as the development of new features. In fact, a new dynamism may develop when a flexible and cooperative Nordic approach is mixed with a German insistence on strong formal rights and the British and southern European tradition for independent interest representation and perhaps confrontation. Such encounters may function as greenhouses for a broadening of horizons and the development of more reflexive relations and practices. Some of the interviews in our Danish research certainly point in that direction.

With the European Works Councils a new layer of employee representation, operating at a transnational level, has been created. In the course of time, the contact between EWC representatives and the ensuing greater trade union contact across borders will inevitably contribute to a more European, if not global, outlook in the labour movement. The EWC representatives are forced to try to integrate local, national, European and global perspectives, and work out formulas for transnational worker solidarity. Not a small task, but still the task has always been at the heart of international trade unionism!

\section{References}

Agervold, Mogens (2002), 'Arbejdet i samarbejdsudvalg: En empirisk undersøgelse af arbejdsformer, indhold og tilfredshed med SU-arbejdet', Tidsskrift for Arbejdsliv, vol. 4, pp. 81-98.

Albert, Michel (1993), Capitalism against Capitalism, London: Whurr Publishers.

Ardiles, Antonio M. (1999), 'Working for Big Brother Ford: Limits to the Effectiveness of the European Works Councils?' Transfer, vol. 5, pp. 394-99.

BBC (2000): 'GAP and Nike - No Sweat'.

Beaupain, Thérèse, Steve Jefferys and Rachel Annand (2001), 'Early Days: Belgian and UK Experiences of European Works Councils', paper to 6th European IIRA Congress, Oslo, June.

Beldam, Camilla and Herman Knudsen (2001), 'European Works Councils: The Visions and the Emerging Realities', paper to 6th European IIRA Congress, Oslo, June.

CEC (1975), 'Multinational Undertakings and Community Regulations', Bulletin of the European Communities, Supplement 8/75,
Brussels: Commission of the European Communities.

CEC (1990), Proposal for a Council Directive on the Establishment of a European Works Council in Community-scale Undertakings or Groups of Undertakings for the Purposes of Informing and Consulting Employees, (COM (90) 581 final), Brussels: Commission of the European Communities.

Edwards, Tony (1999), 'Cross-border Mergers and Acquisitions: The Implications for Labour', Transfer, vol. 5, pp. 320-43.

Beck, Ulrich (2000), The Brave New World of Work, Cambridge: Polity Press.

Coller, Xavier and Paul Marginson (1998), 'Transnational Management Influence over Changing Employment Practice: A Case from the Food Industry', Industrial Relations Journal, vol. 29, pp. 4-17.

Cowling, Keith and Roger Sugden (1994), Beyond Capitalism. Towards a New World Economic Order, London: Pinter Publishers.

Dølvik, Jon Erik (1997): Redrawing the Boundaries of Solidarity? ETUC, Social Dialogue and the Europeanisation of Trade 
Unions in the 1990s, Oslo: Arena Report 5/97.

EIRR (2000), European Industrial Relations Review, no. 318, July.

Elvander, Nils and Anita Elvander (1995), Gränslös samverkan. Fackets svar paa företagens internationalisering, Stockholm: SNS Förlag.

Falkner, Gerda. (2000), 'The Institutional Framework of Labour Relations at the EUlevel: Provisions and Historical Background', in Rainer Hoffmann, Otto Jacobi, Berndt Keller and Manfred Weiss (eds), Transnational Industrial Relations, Düsseldorf: Hans Böckler Stiftung, pp. 11-28.

Ferner, Anthony and Richard Hyman (1998), Changing Industrial Relations in Europe, Oxford: Blackwell.

Fleming, Daniel and Henrik Søborg (1998), 'Strategies for Network Integration and Human Resource Development of Danish Companies in Malaysia and Singapore', in Daniel Fleming, Pauli Kettunen, Henrik Søborg and Christer Thörnqvist (eds), Global Redefining of Working Life A New Nordic Agenda for Competence and Participation?, Nord 1998: 12, Copenhagen: Nordic Council of Ministers, pp. 121-170.

Gill, Colin and Hubert Krieger (2000), 'Recent Survey Evidence on Participation in Europe: Towards a European Model?', European Journal of Industrial Relations, vol. 6, pp. 109-32.

Gudmundsson, Gestur (1995), 'The Nordic Model: Definitions and Dimensions', $P+$. European Participation Monitor, no. 10, (Dublin, European Foundation for the Improvement of Living and Working Conditions).

Hamill, J. (1984), 'Labour Relations Decision Making in Multinational Corporations', Industrial Relations Journal, vol. 15, pp. 30-34.

Hancké, Bob (2000), ‘European Works Councils and Industrial Restructuring in the European Motor Industry', European Journal of Industrial Relations, vol. 6, pp. 35-60.

Interview 1: with Danish EWC representative in US based MNC in the food industry (24/8 1999).

Interview 2: with Danish EWC representative in Dutch-British based MNC in the food industry (24/8 1999).
Interview 3: with Danish EWC representative in German based MNC in the manufacturing industry (24/8 1999).

Interview 4: with Danish EWC representative in Danish based MNC in the manufacturing industry (24/8 1999).

Interview 5: with Danish EWC representative in Danish based MNC in the manufacturing sector (24/8 1999).

Interview 6: group interview with three Danish EWC representatives from a) a Danish based MNC in the manufacturing industry, b) a Danish based MNC in the textile industry, and c) a Swiss based MNC in the manufacturing industry (24/8 1999).

Kerckhofs, Peter (2001), '20 Years of European Works Council Dynamics', paper to 6th European IIRA Congress, Oslo, June.

Knudsen, Herman (1995), Employee Participation in Europe, London: Sage.

Knudsen, Herman (1999), Europaske samarbejdsudvalg opstår-aktører, forhandlinger og strategier, Aalborg: Department of Development and Planning, Aalborg University.

Knudsen, Herman and Niklas Bruun (1998), 'European Works Councils in the Nordic Countries: An Opportunity and a Challenge for Trade Unionism', European Journal of Industrial Relations, vol. 4, pp. 131-55.

Knudsen, Herman and Anna Gitte Lund (1997), Europaske samarbejdsudvalg i Danmarkanalyse af 'artikel 13' aftaler, Aalborg: Department of Development and Planning, Aalborg University.

Knudsen, Herman and Ole Ravnholt Sørensen (2000), Multinationale lonmodtagere Erfaringer med europaske samarbejdsudvalg, Aalborg: Aalborg University Publishers.

Knutsen, Paul (1997), 'Corporatist Tendencies in the Euro-Polity: The EU Directive of 22 September 1994 on European Works Councils', Economic and Industrial Democracy, vol. 18, pp. 289-323.

Kolvenbach, Walter and Peter Hanau, Handbook on European Employee Co-Management (looseleaf publication), Deventer: Kluwer.

Kotthof, Hermann (1994), Betriebsräte und Bürgerstatus: Wandel und Kontinuität in betrieblicher Mittbestimmung, Munich: Rainer Hampp Verlag.

Lecher, Wolfgang, Bernhard Nagel and HansWolfgang Platzer (1999), The Establisment of European Works Councils: From Information Committee to Social Actor, Aldershot: Ashgate. 
Lucio, Miguel Martínes and Syd Weston (2000), 'European Works Councils and "Flexible Regulation": The Politics of Intervention', European Journal of Industrial Relations, vol. 6, pp. 203-16.

Marginson, Paul (1999), 'EWC Agreements under Review: Arrangements in Companies Based in Four Countries Compared', Transfer, vol. 5, pp. 256-77.

Marginson, Paul (2000), 'The Eurocompany and Euro Industrial Relations', European Journal of Industrial Relations, vol. 6, pp. 9-34.

Marginson, Paul, Mark Gilman, Otto Jacobi and Hubert Krieger (1998), Negotiating European Works Councils: An Analysis of Agreements under article 13, Report for the European Foundation for the Improvement of Living and Working Conditions and the European Commission, Luxembourg, Office for Official Publications of the European Communities.

Miller, Doug (1999), 'Towards a "European" Works Council', Transfer, vol. 5, pp. 344-65.

Mueller, Frank (1996), 'National Stakeholders in the Global Contest for Corporate Investment', European Journal of Industrial Relations, vol. 2, pp. 345-68.

Nakano, Satoshi (1999), 'Management Views of European Works Councils: A Preliminary Survey of Japanese Multinationals', European Journal of Industrial Relations, vol. 5, pp. 307-26.

Odgaard, Gunde (2000), 'Det europæske samarbejdsudvalgs placering', Copenhagen: BAT-nyt, no. 9, pp. 10-12.

Royle, Tony (1999), 'Where's the Beef? MacDonald's and its European Works Council', European Journal of Industrial Relations, vol. 5, pp. 327-47.
Schiller, Bernt (1998), 'Victory of Subsidiarity? The Case of the European Works Councils: A Comparative Study of Voluntary Agreements in the Nordic Countries and in the EU', in Daniel Fleming, Pauli Kettunen, Henrik Søborg and Christer Thörnqvist (eds), Global Redefining of Working Life - A New Nordic Agenda for Competence and Participation?, Copenhagen: Nordic Council of Ministers, Nord 1998:12, pp. 323-61.

Standing, Guy (1999), Global Labour Flexibility, London: Macmillan Press.

Streeck, Wolfgang (1997), 'Neither European nor Works Councils: A Reply to Paul Knutsen', Economic and Industrial Democracy, vol. 18, pp. 325-37.

Tayeb, Monir H. (2000), The Management of International Enterprises: A Socio-political View, London: Macmillan Press.

UN (1998), World Investment Report, New York: United Nations.

Veersma, Ulke (1999), 'Last Best: Experiences of Dutch European Works Councils', Transfer, vol. 5, pp. 302-19.

Waddington, Jeremy and Peter Kerckhofs (2003), 'European Works Counsils: What is the Current State of Play?', Transfer, vol. 9, pp. 322-39.

Whitley, Richard (ed.) (1992), European Business Systems: Firms and Markets in their National Contexts, London: Sage.

Whittall, Michael (2000), 'The BMW European Works Council: A Cause for European Industrial Relations Optimism?', European Journal of Industrial Relations, vol. 6, pp. 61-84.

Wills, Jane (2000), 'Great Expectations: Three Years in the Life of a European Works Council', European Journal of Industrial Relations, vol. 6, pp. 85-107. 



\title{
4. The Making of EWCs: A Comparison of European Works Councils in Four Scandinavian Transnationals
}

\author{
Monica Andersson and Christer Thörnqvist
}

\subsection{Introduction}

This chapter presents results from an ongoing, extensive study of European Works Councils (EWCs) in four multinational companies of Scandinavian origin - SCA, Trelleborg, Danfoss and ISS. ${ }^{8}$ The focus is both on employee representatives and management's expectations on the EWC, as well as on prerequisites of solving problems arising in daily EWC work. The extended study especially emphasizes communication within the EWCs. If an EWC shall function in line with the intentions in the 94/45/EC Directive - that is, as a channel for consultation and information between management and employees as well as between workers in different countries - it requires well working forms of communication (cf. Knudsen and Bruun 1998). Different languages, national industrial relations systems and labour market traditions, gender structures, and company cultures/HRM systems stress the need for new communication channels.

Furthermore, the extended study also stresses the importance of some 'outside' actors, which are only briefly addressed here. The maybe most important of these outside actors are the European Industry Federations (EIFs), which bring together national unions by industrial sectors at European level. The EIFs are significant actors for European industrial relations at large, and they have also helped companies negotiating and concluding EWC agreements. One of their head strategies of today is to select major EWCs and get them to work effectively as consultation mechanisms (Annand 2001).

The study is based on semi-structured interviews with all the EWC members in the four groups and a sample of management representatives - in total some 150 people. ${ }^{9}$ In this chapter, however, we largely focus on analysing the compa-

\footnotetext{
${ }^{8}$ Besides the other participants in the Nordfram research group, we wish to thank all the EWC representatives, both management and employees, who have helped us to improve this chapter.

${ }^{9}$ The interviews were made face-to-face with the individual respondee, over the phone, or in a few cases by letter. All respondees were contacted about a week before the interview, when they also received a written questionnaire. The interviews were made in Scandinavian languages, English, French, German, and - with the help from interpret-
} 
nies' written EWC agreements, together with a selection of questions from the extended study, especially those that address practical problems in settling the agreements or making them work in practice.

The next section gives the international background and preconditions for European Works Councils; section 3 sorts out some mainlines in previous research on EWCs; section 4 presents and compares the involved multinationals and their business areas; section 5 presents the social partners involved and their expectations on the EWCs; section 6, on which the main stress lies, discusses the key features of EWC agreements, how they were settled and also some of the major problems in the everyday EWC work; and in section 7 finally, we sum up our conclusions.

\subsection{Why EWCs?}

The 1990s was a decade of great changes for many European industrial relations systems. Some major changes were the dramatic collapse of the regimes behind the Iron Curtain which opened Eastern Europe to western capital; the deepening political and financial integration in the European Union; the weakening of national economies caused by internationalization; the dissolving of traditional post-war corporatism and with that the decentralization of collective bargaining; and the continuing move from a Taylorist/Fordist ideal towards lean production, Kaizen, just-in-time and so on (Ferner and Hyman 1998; Traxler et al. 2001).

Politically, the decade started in a highly neo-liberal manner. The Treaty of Maastricht in 1993 opened up for adaptation of a common neo-liberal economic policy in Europe. Yet, for the purpose of counterbalancing negative social effects of a European Single market, the Treaty was accompanied by a 'Social Dimension'. ${ }^{10}$ In 1997 an additional step was taken to create a 'Social Europe' and an 'European Social Model', through the Amsterdam Treaty. The 'Social Dimension' aimed at securing employee rights at the community level, and stressed the importance of social partnership. If the Maastricht is seen as the high point of the adoption of neo-liberal economic policy by the EU, then Amsterdam can be viewed as an attempt to mitigate its effects (Guerrero et al., 2001: 57-58). Moreover, according to several students of European industrial relations, social partnership is today a very important precondition for macroeconomic performance (Casey and Gold 2000).

The meaning of the term 'social partnership' varies widely between countries. As Casey and Gold (2000: 51) exemplifies, in Austria, corporatism - and with

ers - in Spanish. Most interviews took about one hour, though some were considerably longer, even more than three hours. This chapter draws on interviews with about 80 of the 150 representatives; that is, as many as we had finished in September 2002. The emphasis is, due to practical reasons, on SCA and ISS and the four EWCs' executive committees (see below). Since some 70 interviews remains to be done, we are purposely vague with figures; instead of giving exact numbers, we usually prefer to talk of 'a majority of our respondees...', many representatives said...', and so on.

${ }^{10}$ Actually, the 'Social Protocol' was inaugurated already in 1991. 
that social partnership - is often associated with economic success and thus has a positive ring, while for many people in the UK 'the term social partnership is at best an alien term and at worst a synonym for inefficiency and failure'. In the Nordic countries, the term 'labour market parties' is more common than 'social partnership'. Talking of 'labour market parties' might be a bit limiting though, since the idea of social partnership involves three aspects. First, it means a social recognition of different interests of workers and employers; second, an acceptance, and even more, an encouragement of the collective representation of these interests; and third, an aspiration of organized accommodation between representatives for capital, labour and the state to provide an effective base for regulation of work and labour market (Ferner and Hyman 1998: xv).

One important aspect of social partnership in the EU - with the potential of even becoming the most important one due to the ongoing internationalization and the increasing economic importance of multinational companies - is the introduction of European Works Councils (EWCs). European Works Councils have gradually been established ever since the 94/45/EC Directive was adopted by the EU Council in 1994; also, several agreements were even settled before 1994 on a voluntary basis (so-called Article 13 agreements ${ }^{11}$ ). The directive of 1994 aims at improving the employees' right to information and consultation in communityscale undertakings or groups of undertakings within the Union. Hence, an EWC should be established in every company with at least 1,000 employees within the EU and at least 150 employees in each of two member states. The central management of a company is obliged to create the conditions and means necessary for setting up the EWCs and appropriate procedures. Although the Directive is very modest in its requirements, it is regarded as an important step towards the development of industrial relations at European level. By the end of 1999, about 600 EWCs was formed all over Europe (cf. Knudsen, this volume).

One of our informants - the head of UNI Property Services, an international trade union confederation - pointed out that the introduction of EWCs creates a new problem for unions and other bodies for employee representation. In just a few years, more than 20,000, maybe up to 30,000, new employee representatives must be found in Europe. To find that many people with former experience of representing organized labour and good language skills is of course very hard, which underlines the need for a well developed framework to make an EWC work smoothly.

Finding EWC representatives might be very hard in countries with weak trade union traditions, but it might even be a problem in the Nordic countries, despite their long and strong corporative traditions and comparatively very high union density. Actually, the strong Nordic trade unions might be a problem itself; why involve in EWCs, when there already exist well functioning organizations for

\footnotetext{
${ }^{11}$ The two forms of agreements partly overlapped in time; hence between 1994 and 1996 it was possible to settle either 'old voluntary' article 13 agreements or 'new mandatory' so-called article 6 agreements.
} 
employee representation? Some Swedish unionists, engaged in international issues, have complained that the 'traditional' Swedish unions neglect the EWC question and that the debate of employee influence in transnationals is far too silent (Kärrlander 2000). In other words, strong corporatist traditions might be a problem for - corporatism (cf. Engstrand 1994).

\subsection{Some Mainlines in Previous Research}

Despite its short history, EWCs have already been much noticed in scholarly research. Three principal approaches can be observed.

The oldest line has analyzed the content of the EWC agreements - both the voluntary ones which preceded the 1994 Directive (Article 13 agreements, which could be settled till 1996), and the later, mandatory agreements (Article 6 agreements). Of particular note is the research and overall activities of the Foundation for the Improvement of Working and Living Conditions in Dublin, and the Industrial Relations Research Unit (IRRU) at the University of Warwick. Comparisons have been made between MNCs with various national origins, of different sizes and belonging to different sectors (Krieger and Bonneton 1995; Marginson 2000; Marginson and Clarey 2001; Marginson et al. 2001).

A second line has dealt with the EWCs' role for the architecture of European industrial relations. Two stands can be distinguished: one 'Euro-optimistic', seeing EWCs as a potential and major means for increased employee and trade union influence (cf. Martinez 2000; Whittall 2000); and one 'Euro-sceptic', challenging this assessment (cf. Willis 2000).

The third line of research is concerned with the 'inner life' of the EWC; that is, studies of structures and processes of communication and patterns of internal interaction. According to Lecher and Rüb (1999), some case studies have been carried out of single companies' EWCs and others dealing with earlier initiatives on information and consultation processes in MNCs (for instance, Gold and Hall 1992). Yet there are surprisingly few publications reporting qualitative comparative research on EWCs. Moreover, most of these studies were conducted in the first half of the 1990s, treating the voluntary Article 13 agreements under the options set out by the Directive, while more recent research has been preoccupied with structuring and charting the quantitative growth of this rapidly expanding field.

The Nordic countries are a bit specific. Not much research has been undertaken regarding EWCs; yet there is a rather strong tradition of both cross-country trade union collaboration and research about those attempts. Long before the EWC Directive, several Nordic MNCs had developed networks of collaboration across the Nordic boarders, and some of them had even extended globally (Schiller 1993: 45-47). Considering the corporative tradition, the Nordic countries may have a lot to contribute to the development of European Works Coun- 
cils. Still, though, the Nordic debate on EWCs is remarkably silent. A Swedish trade union delegate in Brussels has argued that Swedish trade unions are not only too anonymous in the European debate, but they also neglect the issue of EWCs. According to him, this involves a great risk for conflict between central organizations and local representatives, as the latter can not sit and wait, while nothings happens at national level (Kärrlander 2000).

\subsection{The Studied Companies and their Business Areas}

\subsubsection{Basic Differences and Similarities}

As mentioned, our study considers four groups of Scandinavian origin: SCA, Trelleborg, Danfoss and ISS. SCA is a manufacturer of absorbent hygiene products, tissue and fluff products, packaging solutions, publication papers and wood products. Trelleborg belongs to the chemical sector, with focus on polymer technology, with a larger part in automotive. Danfoss's focus is on producing different technical solutions, for instance in refrigeration and air conditioning, industrial controls, and heating and water, while ISS is into services, mainly cleaning.

Accordingly, the companies all represent different sectors of the economy. Yet there are also fundamental differences between being into services, like ISS, and into manufacturing, like the other three groups. In 1998, some 80 per cent of the existing EWC agreements were settled in manufacturing, compared to 13 per cent in the services sectors. The discrepancy largely depended on the very different levels of union density and organization (Marginson et al. 1998: 9-11). Moreover, the manufacturing sector is generally more capital- and knowledgeintensive, which implies more participation, networking and empowerment in many organizations. Another major difference is that services are produced at the same place as they are consumed; hence, there is less threat that a cleaning service will be moved to another country (social dumping). Closures and transfers are hardly issues at transnational level as the production is local, and a situation of deficit is more likely to present a risk of closing down or been bought up by competitors. Some other, in our case important, characteristics differ the cleaning industry and ISS from the other three groups. Services are in general small-scale and adapted to the local need of the customers, the local employees do not usually need any formal education to perform the job, the workers do seldom develop any professional identity or feelings for their jobs and there is a high labour turnover, as employees move between different jobs within the sector or to other sectors (Venneslan and Ågotnes 1994: 112; interview with ISS's HR manager, Oct. 2001).

Of course there are important differences between the three groups based in manufacturing too, and also within the single groups: between different business areas, and even within the business areas. The clearest example is SCA, which 
operates in three different business areas. ${ }^{12}$ The business area 'Hygiene Products' faces similar internal and external production conditions and is highly integrated across national boarders. One part of the business area 'Packaging' - the paper production - does require large industrial systems (heavy investments in machines, technology transportation and distribution are of major concern), while the second part - the corrugated cardboard - is based on small units, whose technology is less advanced and requires more simple processes. Finally, the third business area within SCA, the 'Forest Products', is concentrated to Sweden and Austria.

ISS's organization also reflects the simultaneous presence of country-based operations focusing on the need of the local consumer, and a business area with operations highly integrated across boarders. The cleaning business is fragmented into many small local providers of single services. A critical factor for ISS is therefore to offer integrated service solutions to important business-to-business customers. Different prerequisites for the cleaning area and the health care area within ISS represent equally large variations, when it comes to the qualification level of the employees.

Also the Danfoss and Trelleborg operations are to a rather high degree integrated across boarders. Trelleborg is selling to consumers in manufacturing, mainly from the automotive industry, but also to other industries, for example within the building sector. The different kinds of industries of course imply different types of problems. Yet Trelleborg's business concept focuses on offering functional solutions through integration over business areas and across boarders. Danfoss is in a similar way a business-to-business actor with technologically advanced products requiring complex production and lot of emphasis on innovation and product development, especially in the areas where Danfoss reclaims leading market positions. Moreover, SCA, Danfoss and Trelleborg all strongly stress Research and Development (R\&D). The R\&D departments differ from the general production units requiring employees with a high qualification level, which underlines the qualification level between the three manufacturing companies and ISS.

It should also be noted that all the four groups are examples of rather old companies. SCA is the oldest, with precursors already in the 17th century, while Danfoss with its 70 years in business is the youngest. Hence all the companies are highly integrated in Danish or Swedish society and have been so since before they turned multinational. Moreover, all groups have since long developed welldefined cross-country organizational cultures and HRM policies.

\footnotetext{
${ }^{12}$ In fact, there are four areas, since North America constitutes a business area of its own, which, howevewr, is less important for this study of the EWCs.
} 


\subsubsection{Size and Acquisitions}

ISS is the largest group by size (some 265,000 employees world-wide in spring 2003) but has in comparison the least number of employees in the home country (6.7 per cent). Moreover, the company has experienced a major reorganization under the motto 'add new business fast' since the conclusion of the EWC agreement in 1994, a time when Denmark was still the most important country of the group and 60 per cent of the employees were Danes. The reorganization peaked between 1998 and 2002; in that period more than 100 new companies were acquired, which brought more than 150,000 new employees to the group. The 265,000 employees in ISS are however spread over about 75,000 workplaces all over the world. This means that the average number of ISS employees per workplace is about 3.5, certainly nothing that facilitates EWC organization. Moreover, only 53 per cent of the employees are hired on full-time contracts.

Trelleborg has perhaps not the same growing rate, but has however doubled its number of employees through a restructuring process in only three years; in summer 2002 there were about 15,500 employees in 40 countries. The change also totally restructured Trelleborg's businesses and core segments. Consequently the Swedish part of the group has decreased to 15 per cent.

The other Swedish group, SCA, has about the same employee size in its home country (16 per cent) but is with its 42,000 employees in all more than twice as big as Trelleborg (or Danfoss). SCA also expresses a further concentration on Eastern and Southern Europe. Further, major acquisitions in North America witness of that market's increasing importance. One of SCA's business areas, Hygiene Products, also underwent a major change in 1995 - the same year the EWC agreement was settled - as its headquarters moved to Germany in connection with an amalgamation with a large German company.

Danfoss has totally 17,000 employees and compared with the other companies the largest relative number of employees in the home country (39 per cent). Danfoss is also the only of the four groups still not introduced on the stock market. How not being exposed to the pressure of the international stock market affects Danfoss is hard to tell. Yet it is most likely that a stock market introduction accompanied with the need to satisfy external share-holders should have a great impact on Danfoss in the future and bring more pressure to bear for short-term results. The recent changes within Danfoss include a trend of moving production units to Eastern and Southern Europe, and a reorganization of distribution towards one common centre, situated in Denmark, for the whole EU market.

To conclude, no matter their size, all the companies have expanded substantially through organic growth and acquisitions in recent years. 


\subsubsection{The Companies' National Origin and}

Headquarters of the Mother-Company

As mentioned, SCA and Trelleborg are Swedish, while Danfoss and ISS are Danish. Although one could talk about a 'Nordic model', Danish and Swedish industrial relations differ in some matters. For instance, the Danish model is more focused on consensus than the Swedish one; the Danes are thought of as more informal in their labour market relations and more eager to collaborate. To some extent the differences can be explained by how the labour market institutions have developed historically, with the inauguration of several new labour market laws in Sweden in the 1970s as an important dividing line. Also, Sweden has a higher concentration of large groups, which has an influential impact on Swedish industrial relations (Due and Steen Madsen 2000).

The mother companies are all situated in Scandinavia. Danfoss and Trelleborg are strongly integrated in the regions were they are founded; Danfoss is held by a Danish family fund, and Trelleborg by a fund located in southern Sweden. Trelleborg's headquarters is located in the south of Sweden too, in the city of Trelleborg, but two business areas' headquarters are located outside the national borders, in Italy and the USA respectively. SCA has its headquarters in Sweden as well as the business area Forest Products. The other business areas are managed from outside Scandinavia - Hygiene Products from Germany, Packaging from Belgium and the North America from Philadelphia USA.

From a trade union point of view, the location of the headquarters is important. The labour market legislation in Sweden guarantee board representation and information about important decisions by the Codetermination Act (MBL). The legislation includes organizational changes in companies belonging to the group situated in other countries. Denmark is not regulated in the same way, but the labour market tradition gives the employees about the same influence in practice. One immediate effect of the headquarters moving abroad is lost representation in the board of directors (and the board is not necessarily Scandinavian any longer). An indirect effect is weakening of the possibilities to use the formal right to collaboration within the whole group. In the long run this means that employee participation risks cementing on local level. Another part of the picture is the tendencies of increasing and unequal power balance between employees and employer in an internationalized world. (Interview with Christer Larsson, head of EWC related issues for the Swedish Paper Workers' Union, Oct. 2001).

\subsubsection{Strategies of Business and HRM}

The four companies studied have all developed HRM strategies common for the whole group, no matter the country or the kind of production. Aiming at global growth and market presence/leading positions the companies have intensified HRM activities and branding (reputation and image management), programmes for training and management development, projects on cultural and behavioural 
values and so on. This reflects an increased focus on the outside world as well as strategies to create internal networks and promote a corporal culture unifying employees across boarders and occupations. Also in this sense ISS stands out, as 80 per cent of the business has a local character, and strategies towards the whole sector and the business globally are estimated as important as creating a common company culture.

\subsection{The Social Partners and their Expectations}

This section deals with the social partners and their expectations of the EWCs. The formal side of social partner representation, that is, how EWC representatives are appointed and so on, are dealt with in the next section, though.

\subsubsection{Employee Side Representation}

EWC members do not have to belong to a union; yet trade unions and international trade union confederations are no doubt powerful actors. Unnecessarily to say, however, unions and their traditions vary considerably across Europe. There are sometimes big differences between, for instance, traditionally militant trade union confederations such as the French CGT and consensus-based unions such as the Swedish confederations for salaried employees and professionals, the TCO and SACO respectively. Also, a few of our respondees, who thought of themselves more as 'middle-management' than as 'workers', made a point of honour in not belonging to a trade union at all.

Despite the many differences, we have not found any serious conflicts between different trade unions in any of the four groups. When settling the agreements there were diverging ideas of whether trade union representatives not belonging to the EWC - sometimes not even employed by the company - should get permission to attend the EWC meetings or not. The problems were however seemingly solved without any disruptive conflicts and left no negative impact on the EWC work. (The union representatives not belonging to the EWC did not get access to the meetings, if not especially invited as guests.) No matter if there are frictions below the surface or not, the representatives in all the four studied EWCs seem to respect each other's different trade union traditions enough to make the EWC work.

A clear majority of the employee representatives in our survey have or have had trade union positions of trust; several of them are full time trade union officers and have long experience of trade union work. Some of them also were or had been members of a board of directors, chairmen of a union or of a lo$\mathrm{cal} /$ national works council. The high median age and the male dominance of the respondents are thus not surprising. The results are in line with findings from a Danish study, describing the typical EWC representative as a male, 45-54 years, employed in the company for more than 15 years, having only basic education 
(seven to ten years) and with solid experience of trade union work (Knudsen and Ravnholt Sørensen 2000: 27).

The most obvious example of the close connections between EWC work and traditional trade unions is Trelleborg, where the EWC chairman is also president of the second largest Swedish blue-collar union in manufacturing, Industrifacket. Moreover, interviews with the EWC representatives revealed that many of them have attended conferences for exchange of experiences arranged by trade unions at different levels - which, on the other hand, goes for many representatives in the other three groups too.

ISS is the only company of the four studied that has fully integrated an international trade union confederation (UNI) and allocated seats in the EWC and the executive committee for it. The Danish cross-occupational union for unskilled women workers, Kvindeligt Arbejderforbund (KAD) ${ }^{13}$ is also represented in the EWC. On the other hand, ISS shows a low level of union membership compared to the other companies, which reflects the service sector in general in Europe.

Already before the EWC agreement was settled Venneslan and Ågotnes (1994: 114) commented on the joint interests of management and the trade unions in ISS. From the company's perspective it was important to strengthen the employees' competence and professional pride, thereby improving productivity and the quality of cleaning services, and thus also reducing turnover. From a trade union point of view, it was essential to strengthen organized cooperation, in order to facilitate the improvement of working conditions, employment security and so on.

Still, though, EWC members at ISS generally find their group management less supportive than the EWC representatives in the other three groups do. During the EWC's first years the HRM director was, according to a vast majority of our respondees, very personally motivated in making the EWC work. Other management representatives showed only little or no interest in the EWC work, though. It seems rather clear that one of the main reasons for the difference between ISS and the other three groups is that the ISS group management cannot use the EWC to spread information in the same way as management in the other three groups can. The ISS employees are spread over a tremendous number of workplaces all over Europe (in fact all over the world) and the national EWC representatives have no possibilities to keep in touch with all of them. In the three manufacturing companies, on the other hand, production is more concentrated to large plants. The EWCs might thus function as a means for the group management to - without any extra costs - spread information about important crossnational decisions to the employees in all the European countries were the company has undertakings. It is rather telling that the EWC representatives also feel

\footnotetext{
${ }^{13}$ Kvindeligt Arbejderforbund is the only union left in Euorpe that only organize women. No salaried employees are organized though, but only unskilled women. The organization reaches over all kind of industries, such as cleaning and other services, manufacturing and health care.
} 
less support from the employees they represent than the EWC members in the other three groups do. ${ }^{14}$

\subsubsection{Employee Side Expectations from the EWC}

According to our interviews, the employee representatives' expectations follow some rather distinct mainlines. One is to create networks, to exchange information and knowledge among the employees in different countries. A second one, following from the first one, is to develop cross-national policies for acting; that is, to create similar 'guidelines' for all representatives in the group. The idea is to improve the conditions for everybody in the company independent of working country; to get the same information from, and possibilities to communicate with management; to be able to return feedback from the shop-floor or the customers; to achieve 'real' influence on management decisions; and in the long run to be a counterpoise to social dumping. As one representative expressed it, the "EWCs role is not once and for all given; it is something that should be developed, and to become a personal sparring partner is one of the aims' (Scandinavian member of the SCA Pan EWC, Oct. 2001). Another member expected the EWC in due time to get negotiation rights and to gain influence on issues such as work environment and carrier opportunities (Southern European member of the SCA Hygiene's executive committee, Oct. 2001). Yet, only few of the respondees expressed hope of negotiation rights in the foreseeable future, as they did not see EWC mature enough for such a responsibility.

On the other hand, even if the EWC does not achieve the right to negotiate, it might still mean an improvement in the contacts with the group management. One of our respondees explained that he wished the EWC to be a channel for discussions with top management 'beyond the company hierarchies'. In other words, the EWC should be a means for its members, especially outside the group's home country, to get in touch with top management directly without having to go through all levels of plant management, national management, and so on. Such a channel for getting and giving information could be very valuable, even without any negotiating rights (Scandianvian member of the executive committee, Danfoss, Oct. 2001). Another respondee touched the same subject when he said that he wished the EWC to be a forum where the representatives could meet and discuss with top management on more equal terms, without 'feeling' the hierarchy every time they said something (Benelux representative, Trelleborg, Jan. 2002).

\footnotetext{
${ }^{14}$ It must be noted, though, that when this is written, the results from Danfoss rest on a too limited number of interviews to make any positive conclusion. The picture of the Danfoss representatives' opinions about the support they get from both management and the employees they represent might change slightly when more interviews are made and should thus only be regarded as trend which seems to be in line with the (reliable) results from the other two manufacturing transnationals.
} 


\subsubsection{Management Expectations from the EWC}

Following Lamers's (1999) study of 18 EWCs, the group management can benefit in several ways from an EWC. First, the EWC can facilitate management's overview of the group, support group internationalization, and the shift in decision-making towards the international level. Second, the EWC can promote European corporate identity among the employees and their representatives - a sense of belonging to an international company and not just a local firm. The EWC can also be used to spread information to all the representatives at the same time. If the central management is able to formulate a good and ambitious strategy vis-à-vis the local EWC representatives, it could be a way to motivate the employees and explain corporate strategies. Third, the EWC can be a means for solving problems in cases of reorganization, to prevent devastating conflicts. Finally, management can use the EWC to put out a feeler in preparation for corporate decision to be taken.

The SCA management focuses on almost all the points mentioned by Lamers, seeing EWC as a point of reference with transnational character, highly important for communication flows from management as well as between management, the EWC representatives and the employees.

At Danfoss the EWC representative's ideal role is the one of an ambassador. Although Danfoss was sceptical at the beginning and still views the EWC as a forum without power, the management side has hopes for a constructive dialogue in the future.

Trelleborg sees EWC as a forum for information regarding strategy and performance, which might contribute to the company's development, but the EWC also deals with social issues and communication. The EWC might contribute to a corporate view, a 'Trelleborg spirit', which would facilitate problem solving and prevent problems to arise and to bridge cultural differences.

ISS expects the EWC member to be active, motivated and engaged in the information given, and to give feedback and make comments, at least in the words of the former HRM director and his successor. As mentioned though, management at large seems to pay rather little attention to EWC issues, likely since it cannot see what to gain from the EWC. Accordingly, the workers' representatives have little confidence in ISS's intentions with the EWC. One of the representatives even claimed that the management's real intention with the EWC was likely to achieve employee quietness; the employees should discuss issues in the EWC instead of bringing them before the management and thus be kept passive (Central European representative, August 2002). Another example of the ISS's rather impassive attitude towards the EWC is when the representatives had to pay their own fares to the EWC meeting in Copenhagen in spring 2002. Despite several attempts, the group management could not get the local employees responsible for the EWC representatives' expenses to pay in due time. Of course the representatives got their expenses paid for afterwards, but for the single individual 
an international flight ticket is a rather considerable amount of money to wait for, especially with a cleaner's salary.

\subsection{The EWC Agreements: Basic Features and Problems}

Since SCA is divided into three different business areas, there are also three different EWCs. The three EWCs are summoned under an all-embracing Group EWC - the 'big', or Pan EWC. Danfoss has entitled its EWC the European Information and Consultation Forum (EICF) and the agreement includes an appendix with guidelines for how to settle disputes by arbitration. In Trelleborg the council is called TEWC.

The agreements of Danfoss and ISS specify a lot of routines. SCA's agreement is detailed, but also based on internal negotiations within the business area EWCs. Hence, SCA seems to handle variations within its different BAs in a better way than the three other companies.

The ISS and Danfoss agreements both presents long lists of issues to be covered by the EWC; still, in practice all the companies follow the requirements of the EWC Directive rather closely. In all the four groups the most important consequence of this is that all EWC issues should be of a transnational character; remuneration and compensation are considered national or local and therefore not a matter for the EWC. In other words, the understatement is that issues already handled in national or local contexts should be excluded. Since the EWCs are only permitted to information and consultation, none of them has the right to negotiate or to conclude agreements.

\subsubsection{The Constitution of the EWCs}

The EWC is purely an employee-side body in SCA, Trelleborg and Danfoss, while ISS has chosen a joint management and employee model. Trade union representatives may also be associated to ISS's EWC, even if they are not employed by the company. In the other three groups, full-time trade unionists may be appointed only if they are on leave from a position in the company.

According to the SCA agreement, the chairman of the pan EWC and her/his deputy should represent different business areas and different countries. Also at business area level it is recommended that the chairman and the deputy should be from different countries, if possible. At Trelleborg the chairman should be an EWC representative from the country where the group has its headquarters. Similar conditions are applied at ISS and Danfoss, except that the nationality of the chairman is not regulated.

The appointing of EWC representatives is carried through either by local works councils, central company works councils or similar employee representation bodies, or by direct elections. The differences are national and similar to all the four groups. Two main ways of election can be distinguished: one indirect, 
used for instance in the Nordic countries and France; and one direct way, based on workplace elections, applied in Germany, the UK, Spain, Italy and countries in the former Eastern Europe. Several of our informants with longer EWC experience stressed the problems - particularly in the early phases of the EWC formation - to elect delegates from countries with weak traditions of workplace representation. One example of a less common method was to draw votes of candidates from a hat (Swedish member of the Trelleborg EWC's executive committee, Oct. 2001). Another example, foredoomed to failure, occurred when the country's HR manager himself took the place as delegate (ibid.). In such cases the whole point with representation lost its meaning and the representative felt misplaced.

It could be noted that the Danish labour market legislation holds a special law on how an EWC's employee representatives should be elected. According to the law, the other EWC members should appoint the representatives. If the company does not have any EWC, the members should be elected by the local trade union representatives, and, if there is no union representation at the plant, by all employees. Further, if someone demands it, representatives for groups not covered by an existing EWC or a local union branch could be incorporated in the election process (Knudsen and Ravnholt Sørensen 2000: 103-04).

In all the four companies the responsibility for the EWC lies on the CEO or a person nominated by the CEO, normally the senior vice president of HRM. In the pan SCA EWC, the three SCA business areas' EWCs and Trelleborg, the vice president's secretary was appointed to assist the EWC in administrational matters, while ISS and Danfoss do not have any person designated, though support is given on demand. In both ISS and Trelleborg there have been changes in the management range; hence none of the managers who negotiated the original EWC agreement are present in the company today. Shifts at management level have also influenced business area level EWCs in SCA.

Continuous shifts of representatives as well as of managers cause problems for the EWCs. An EWC representative expressed that

\footnotetext{
it takes time before a new person has learnt about the duty and the special conditions for the forum, as well as it takes time to get to know the others involved. In the case of a new top manager taking office it usually means new perspectives, strategies and new ways of managing the body (Scandinavian member of the SCA Packaging executive committee, Apr. 2002).
}

Furthermore, costs in connection to the EWC meetings - such as meeting venues, translation and interpretation, English courses and training, and consultations of experts - are covered by the mother company in all the four groups. Yet, compensation for working time lost, travels and lodging, are usually covered by the single representative's local firm. How the costs should be covered - centrally or locally - is continuously a matter of discussion within the groups. An EWC rep- 
resentative means additional costs for the single unit and is thus sometimes questioned by the local employer.

Most generous concerning training is SCA Hygiene Products, inviting each representative to a week of English training per year. In general, SCA EWC representatives are offered a three weeks long English training course in the beginning of an EWC mandate period with follow-ups in accordance with individual needs and interests. On the other hand Trelleborg, Danfoss and ISS offer more interpretation services at the yearly EWC meeting, which is estimated as a high cost. Shortly after the agreement was settled, Trelleborg also organized a language course in England for all EWC members, paid by the company. Trelleborg has also sometimes invited all representatives to special pre-meetings held in English to brush-up the language before the ordinary EWC meeting. From a company perspective, the aim with these kinds of measures is in the long run to reduce the costs for interpretation and to support the communication between the delegates.

\subsubsection{Countries Covered by the EWC}

SCA and Trelleborg do not cover countries outside the EU and EEA, which Danfoss and ISS on the other hand do. Danfoss includes the Czech Republic, Poland and Russia, while ISS covers Slovenia. The SCA agreement states that 'if mutually agreed the agreement can be extended to cover SCA employees in other countries'. Consequently, at SCA there have been discussions about involving Eastern European countries in a next step and then open up for an even wider incorporation. An EWC representative describes SCA's EWC as a growing process first present in the Nordic countries, then covering the EU 'and soon it would be mature for including European neighbours' (Scandinavian member of the SCA Pan EWC, Oct. 2001). Yet, SCA has considered a 'mentor system' as a way of connecting operations in smaller countries (fewer than 150 employees) to the EWC. For example, if Sweden has an EWC representative but not the neighbour country Finland, the Swedish representative should establish a contact with a Finnish contact person, whom he should inform directly about actual and relevant issues treated within the network of EWC. In the Danfoss agreement the parties have signified their intention of widening the scope worldwide. However, after discussions on the issue in 2001 the plan was postponed.

SCA has chosen not to give any specifications in the agreement on the distributions of seats. Instead, the countries covered, the number of seats and how these are distributed are regulated by internal negotiation within each business area. In the opposite, in Trelleborg, Danfoss and ISS each EWC agreement specifies clear rules for composing the council and allocating the EWC seats. In Trelleborg the seats are first distributed between the countries covered, and second between the business areas. Trelleborg is the only company mentioning this in the EWC agreement. 


\subsubsection{Terms of Office, Eligibility and Number of Representatives}

In all the EWC agreements, the election of members is, as mentioned above, largely a national matter. The Trelleborg and ISS agreements also let national rules decide the mandate period. The SCA agreement, on the other hand, states the terms of office to four years, and the Danfoss one states it to three years. The 'normal' mandate period in Trelleborg and ISS, however, is three years at Trelleborg and four years at ISS. Continuity is however desired by all parties; hence reelection is both possible and mostly appreciated.

Moreover, the SCA agreement recommends that candidates should have at least three years of service within the company. The reason is, according to the agreement, that 'persons with longer experience are likely to have a wider internal network, which will enhance the communication process between the company and its employees'. At Danfoss an EWC candidate should have a period of service of nine months, and at ISS one of more than twelve months. Danfoss employees who are department managers or higher up in the company hierarchy are neither eligible nor have the right to vote.

Trelleborg's revised agreement states that each country with more than 150 employees should have at least two representatives. Countries with even more employees may have up to a maximum of four representatives. The total number of EWC representatives is 25 at Trelleborg as well as at Danfoss, and 34 at ISS. At SCA Hygiene Products the EWC consists of 14 members, at Packaging 13 members and at Forest Products nine members. 13 of the members are also representatives in the pan SCA EWC together with three board members, which make 39 members in all.

At SCA the EWC also have representatives from the parent company's Board of Directors, who are co-opted without voting rights to the pan SCA EWC. Similar arrangements are made for each business area EWCs in SCA.

\subsubsection{The Executive Committee}

All EWCs have a kind of board, a special committee. The committee can have many names, for example working, executive, selected, restricted or steering committee. To not confuse the reader, we use the term executive committee in the following, no matter the company. The committee is the heart of the EWC and also the main channel from management into the EWC. All the companies have a committee consisting of a chairman/president and between three and five members.

At SCA, each business area has its own executive committee. The nationalities of the members in the executive committee do in several cases correspond with the most important countries in the company, but in some cases not, since the members have been appointed due to special skills.

The main tasks for a executive committee are to prepare and carry out EWC meetings together with management and to function as a channel between man- 
agement and the employees. Danfoss's agreement also specify that if something extraordinary happens, the committee's role is to meet together with representatives from management and with the countries directly involved. In practice it is the same in the SCA EWCs, even though it is not regulated by the agreement.

In all the groups, the committee should meet as often as is reasonably required, but at least once or twice a year. The committees do however meet more frequently, and consequently the committees' members know each other and management much better than the rest of the EWC representatives do.

\subsubsection{Handling the Meetings}

In SCA, each business area management and EWC should together set a meeting agenda. It allows flexibility in combining meetings with business events or special activities. In the SCA agreement two meetings per year is recommended, of which one should be with the pan EWC. Yet, practice differs from the agreement; a meeting with all EWC members and the Swedish group board of directors is held only every second year. Still the executive committee of the pan EWC is meeting more frequently, normally three times per year. Business area EWCs meet up to three times a year, plus sometimes extraordinary meetings.

In the other groups, one EWC meeting a year is the normal. At Trelleborg and Danfoss even the location is specified; it should be held in a region nearby the headquarters. The EWC meetings in the pan SCA, ISS, Trelleborg and Danfoss are sometimes rather complicated arrangements with 25 to 39 EWC members, some manager representatives and interpreters for translations into several languages.

One problem in all the groups is that - mostly due to language problems - it takes time for many representatives to get acquaintance enough with the EWC work to ask questions and interact in the meetings. If the EWC meetings are characterized by two-way interaction or just one way presentations is also a matter of national traditions; some countries have high respect towards top managers, and there are also differences between 'corporatist' and 'conflictual' traditions.

\subsubsection{Strategies for Member and Employee Involvement}

It is often hard to find transnational issues that interest all the EWC members and the employees they represent. The EWCs studied have chosen different strategies. The EWCs at SCA have jointly suggested a corporate health and safety guideline. Trelleborg's EWC has also focused on health and safety issues as well as environmental problems in the production units. Danfoss's EWC initiated a corporate culture programme. Other actual issues have been 'value based management', 'career opportunities for women', 'HR planning processes' and guidelines for how to introduce and disseminate the IT system SAP R/3. Moreover, the EWCs at SCA and Trelleborg have been able to influence outsourcing and downsizing actions as well as social planning when operations are closed down. At ISS 
the EWC tries to deal with human resource policies and the esteem of the business. The main question concerns how to transform the sector's reputation of low quality/menial jobs.

When key persons were asked if the agreement differed from practice, the main argument was that the agreement constitutes a base, while reality is a living processes and has developed since the EWC was first settled. For many EWC representatives though, national or local problems make it hard to discuss and understand common transnational issues.

From a single member point of view, EWC work is not just a matter of reading documents, reporting them to the people who elected them, and attending a meeting once or twice a year. If the EWC work shall function in the long run, the members must also get personally acquainted with each other. The best opportunity to do so, according to a vast number of our respondees no matter the company, is to meet at coffee breaks and at the dinner the company usually throw for the members in the evening of the first day of the official EWC meeting. (In all the four groups, the EWC meetings are normally for two days; thus there is always a dinner for all members in the evening of the first day, when representatives may usually also meet with representatives of the group management.)

These informal contacts are invaluable, in the words of almost all our respondees. If the EWC shall have any practical importance, its members must have more frequent contacts than just at the official meetings, when the time is limited and the issues dealt with in a strictly formal way. However, if the members, at lest those who are not members of the executive committee, shall take such contacts, they must first know each other. The language barrier between, for instance, a representative from France and one from Germany can be extremely hard to force if they have never met in person; yet if they 'know' each other it is much easier to send an email or even give the other a ring. In the words of one of our respondees, the meetings are characterized by an 'official' atmosphere, but as soon as the members 'get outside' the atmosphere becomes really friendly (Central European member of SCA's pan EWC, Apr. 2002). Well functioning informal contacts also give the representatives the opportunity to exchange important experiences which there are no time for, or are hard to formulate as items on a meeting agenda.

The main obstacle even to informal contacts, though, is the language problem. Even if social events open up for new possibilities to meet across borders, it is still hard to discuss through an interpreter. Accordingly, there are often regional differences in communication: people from Northern Europe keep in touch with each other, as do people from Central and Southern Europe, while it is much more rare with contacts across these three geographical areas. This far, only two respondees have claimed that the social activities have no meaning at all. Not surprisingly, both of them were from Southern Europe and claimed both that they had very little knowledge of other languages, such as English. In other words, 
they are typical representatives for the kind of members who face the greatest risk to be excluded from the EWC work (both members of the ISS EWC; both interviews were made in May 2002).

\subsection{Concluding Reflections}

Not surprisingly, there is a common understanding among our respondees that the making of a functioning EWC is an on-going process, which must proceed slowly and safely, yet without interruptions. Setting up an EWC is actually just a first step; after that, the EWC has to form its role and evolve. Learning processes within the EWC are highly important.

In brief this means that the quality of an agreement and necessary material resources are an important, but not a sufficient precondition for a long-term working EWC. Actual development, strategies and performance of the EWC are likely to deviate downwards as well as upwards compared to the agreement. Further, the language problem is almost always underestimated. The fact that the companies provides interpretation at the EWC meetings does not solve the problem that members beside the official meeting usually only get acquainted to other representatives with whom they have some kind of functioning lingua franca, which is usually English, but sometimes also French or German. Since these lingua franca are to a large extent geographically bound - English in northern, German in central and French in Southern Europe - the common EWC member seldom or never get in touch with other representatives across the language borders, except at the official meetings. Almost all our respondees claim the informal contacts to be extremely important for a smoothly working EWC; therefore the language problem is at the moment much bigger than for instance cultural differences, different national industrial relations systems and HRM traditions, or different technical facilities.

The three manufacturing MNCs studied in this chapter have long traditions of cooperation. A study of SCA undertaken by Engstrand (1994) described a good spirit of cooperation both within the Swedish trade unions and towards management. Yet her findings also indicated an employee side fear that different national industrial relations together with language problem could jeopardize the EWC work and the good relations.

Moreover, there are other major differences between the three manufacturing companies and the service sector based group ISS. No doubt the 1994 EWC Directive suits MNCs with their focus in the manufacturing sphere best. Such companies are usually based on rather large production units with many employees in each, and many of them already have well established fora for employee organization and representation, such as local union branches or works councils. ISS, on the other hand, is spread over some 75,000 workplaces with an average of 3.5 employees per workplace and almost half of the workforce working less than full 
time. The ISS representatives also feel less support from both management and the employees they represent than do the members of the other three EWCs. Add to this the traditionally low organization rate in the service sector, and the question should not be why ISS have more difficulties in making their EWC work smoothly, but rather how they manage to get it working at all. It should be emphasized that this has little to do with the management's attitude. Both the previous and the present HRM director have been very positive to the EWC work, and even with a very EWC friendly management it would be extremely difficult to keep such an organization together, especially since only few of the ordinary cleaners can be reached by phone or email. The main problem is rather that the Directive does not cover for these kind of problems: the employees should elect representatives, the representatives should carry information between the employees and management, and management should pay for the process, but how is this to be done in a company organized like ISS? The Directive leaves us empty-handed on this point; what is needed is more comparative studies of other multinationals in services and retail trades, to see how they deal with the problem.

Even if the language question is the most burning one, it is of course also important that the EWC representatives know each other's traditions and experiences, and the basic elements and prerequisites of different industrial relations practices. An EWC is based on both multi-lingualism and multi-culturalism and thus needs solidarity, creativity, trust and respect between its members. How far the single EWC has reached in this matter might not be concluded here. But one important step is conquered, when the EWC in practice is more than one big meeting a year. Yet the EWC network and contacts outside official meetings together with the performance of the executive committee need to be further explored.

Training might have a least two purposes: first, to learn English in order to create a lingua franca; and second, to provide a common basis for teambuilding of the EWC. In Trelleborg and SCA, language training is seen as a proficient way of getting together and to know each other. At the language courses the EWC representatives discuss common matters of interest and even the Englishmen do participate. The EWC representatives take advantages of the Englishmen's language ability for writing minutes of internal meetings and communications.

Furthermore, Nordic EWC agreements do in general differ from other national agreements by the moderation of information. The greater moderation is likely the result of a strong tradition of informal influence in the Nordic industrial relations (Knudsen and Bruun 1998). Among the agreements presented - all of Scandinavian origin - the SCA EWCs are highly dependent on internal negotiation, while the others have rather specified details of the process. 
Why has SCA chosen this strategy of internal negotiations, no fixed seats and differentiated EWCs? One of the EWC representatives we interviewed, who was involved in the establishing of the agreement, gave three explanations

first, we realized that we were going to grow and therefore we needed to be flexible; second, by experience from the Swedish experiences of work with co-determination we have learnt that there is a danger that the big ones run over the small ones, since it is practically impossible to take decision with 30 persons without erasing the 'least powerful'; third, for us the important thing is that the representatives meet, discuss and establish a relation with the decision-makers, that is, the actual executive managers in each business area (Scandinavian member of the SCA Pan EWC, Oct. 2001).

In this sense SCA has not taken the road suggested by the EU Directive. The Directive stresses much more formalized relations; one company means one management and one employee side body. From a company perspective the most important is not channels to the head-of-the-board, but to the executive managers. The EU Directive is designed with inspiration from German and French industrial relations. One basic principle in German works councils (Betriebsrat) practices is that the bigger the EWC is, the more power it gains. Today, both the Directive and most European agreements are based on that principle.

One could say that the EWC Directive shares the same prerequisites as the Swedish Co-Determination Act (MBL), in the sense that the legal requirements on employers to negotiate contradict the recommendation to regulate codetermination by the law or the agreement. Although employee representatives have the right to participate in the decision-making process, employers are free to act as they think are best, provided that they first have informed the representative and given them an opportunity to present their views. The impact of the Swedish MBL as well as of the EU Directive finally depends on the attitude of the employers, and ultimately on societal and industrial power relations.

The relationship between the EWC and management is marked both by different and common interests, caused by environmental influences and the different objectives and perspective of the key actors. Regarding resources, the EWC depends on management. The EWC has to fight for or negotiate its resources - and the range of autonomy incorporated in it. Moreover, the question of controlling meetings is subject to an implicit or explicit negotiation process. Hence, it is hypothetical that the influence on the development of meetings also leads to potential influence on discussion topics and on the developmental direction of the EWC.

Finally, it is important to stress that the four groups studied in this chapter have themselves expressed a desire to participate in a research project in order to improve the EWC and its activities. This action could be understood as a belief in EWC and a will to improve its functioning. A further assumption might be that in companies expressing belief and willingness to improve EWC, their EWC become more developed than the average EWC. 
Yet, the EWC is still such a new feature that it is too early to tell which the main, remaining obstacles will be in the future; no doubt settling an EWC agreement is not always corresponding to the making of an EWC...

\section{References}

Annand, Rachel (2001), 'The European Industry Federations - Key Players in a European Industrial Relations System', in Steve Jefferys, Frederik Mispelblom Beyer and Christer Thörnqvist (eds), European Working Lifes: Continuities and Change Management and Industrial Relations in France, Scandinavia and the UK, Cheltenham and Northampton, MA: Edward Elgar, pp. 248-66.

Casey, Bernard and Michael Gold (2000), Social Partnership and Economic Performance: The Case of Europe, Cheltenham and Northampton, MA: Edward Elgar.

Due, Jesper and Jørgen Steen Madsen (2000), 'Varför är den danska avtalsmodellen annorlunda än den svenska?', in Stig Tegle (ed.), Har den svenska modellen överlevt krisen?, Stockholm: Arbetslivsinstitutet, pp. 13-32.

Ferner, Anthony and Richard Hyman (eds) (1998), Changing Industrial Relations in Europe, Oxford: Blackwell.

Gold, Michael and Mark Hall (1992), Report on European-level Information and Consultation in Multinational Undertakings - An evaluation of Practice, Dublin: The European Foundation for the Improvement of Living and Working Conditions.

Guerrero, Ana, Marinús Pires de Lima, Lesley Holly and Christer Thörnqvist (2001), 'Public Policies and Social Exclusion', in Pierre Desmarez et al., Employment and Exclusion: Thematic Network, Brussels: European Commission, SOE2-CT98-3064, pp. 53-65.

Engstrand, Åsa-Karin (1994), 'Från företagsnämnder till internationellt koncernfackligt samarbete', Göteborg: Internationalla Arbetslivstudier, BA thesis, Göteborgs University (mimeograph).

Kärrlander, Kent (2000), 'Svenskt fack försummar EU', Dagens Arbete, 15 May.

Knudsen, Herman and Niklas Bruun (1998), 'European Works Councils in the Nordic Countries - A Chance and a Challenge to Trade Unionism', European Journal of Industrial Relations, vol. 4, pp. 131-55.

Knudsen, Herman and Ole Ravnholt Sørensen (2000), Multinationale Lønmodtagere - erfaringer med europaiske samarbejdsudvalg, Aalborg: Aalborg Universitetsforlag.

Krieger, Hubert and Pascale Bonneton (1995), 'Analysis of Existing Voluntary Agreements on Information and Consultation in European Multinationals', Transfer, vol. 1, pp. 188-206.

Lamers, Josee (1999), The Added Value of European Works Councils, Haarleem: AWVN.

Lecher, Wolfgang and Stefan Rüb (1999), 'The Constitution of European Works Councils: From Information Forum to Social Actor?', European Journal of Industrial Relations, vol. 5, pp. 7-25.

Marginson, Paul (2000), 'The Eurocompany and Euro Industrial Relations', European Journal of Industrial Relations, vol. 6, pp. 9-34.

Marginson, Paul and Mark Carley (2001), Negotiating EWCs under the Directive: A Comparative Analysis of Article 6 and Article 13 Agreements, Dublin: The European Foundation for the Improvement of Living and Working Conditions.

Marginson, Paul, Mark Gilman, Otto Jacobi and Hubert Krieger (1998), Negotiating European Works Councils: An Analysis of Agreement under Article 13, Dublin: European Foundation for the Improvement of Living and Working Condition and the European Commission

Marginson, Paul, Mark Hall, Alice Hoffmann and Torsten Müller (2001), 'The Impact of European Works Councils on Management Decision-Making in Anglo-Saxon Multinationals: A Case Study Comparison', Warwick: Industrial Relations Research Unit, University of Warwick, paper for the conference 'Multinational Companies and Human Resource Management', De Montfort Univerisity, Leichester, 12-14 June.

Martinez Lucio, Miguel (2000), 'European Works Councils and "Flexible Regulation": The Politics of Intervention', European Journal of Industrial Relations, vol. 6 , pp. 203-16.

Schiller, Bernt (1993), Den nordiske demokratimodels tilkomst: Den skandinaviske model: Utvikling eller afvikling, København: Forlaget Sociologi. 
Traxler, Franz, Sabine Blaschke and Bernhard Kittel (2001), National Labour Relations in Internationalized Markets: A Comparative Study of Institutions, Change, and Performance, Oxford: Oxford University Press.

Venneslan, Knut and Hans J. Ågotnes (1994), 'Transnationalization and Participation', in Bernt Schiller, Knut Venneslan, Hans J.

Ågotnes, Niklas Bruun, Ruth Nielsen and Dennis Töllborg, The Future of the Nordic Model of Labour Relations - Three Reports on Internationalization and Industrial Rela- tions, Copenhagen: Nordic Council of Ministers, Nord 1993:36, pp. 93-164.

Whittall, Michael (2000), 'The BMW European Works Councils: A Cause for European Industrial Relations Optimism?' European Journal of Industrial Relations, vol 6, pp. 61-83.

Willis, Jane (2000), 'Great Expectations: Three Years in the Life of a European Works Council', European Journal of Industrial Relations, vol. 6, pp. 85-107. 



\title{
5. International Management Strategies and Models of Industrial Relations - A Norwegian Experience
}

\author{
Jan Heiret
}

\subsection{Historic Encounters in the Post-war Period: International Strategies and National Practice ${ }^{15}$}

A conspicuous development trend in Norwegian working life during the last decades has been that both the industrial relations system and various forms of international management strategies appear to have strengthened their position: the organized relationship between the parties has been maintained and extended in the large industrial company groups. Tripartite cooperation between the state, employers' associations and the trade unions continues to play a key role in the wage determination processes. And the professional organizations within the health and education sectors have been increasingly incorporated in the corporative bodies. Simultaneously, international management strategies, in which 'organized partners' is an unknown term, are to be found in profusion, astride a powerful global wave of IC-technology and market liberalism.

The predominant question in this chapter is what happens when these two worlds meet. Will management strategies be adopted as a tool for establishing relations between management and employees, undermining the established relationship between the parties? Or will national and local traditions governing organized working life stamp their mark on imported practices?

One answer to this question requires an historical approach, purely because this encounter between management strategies and organized relationships between the parties is far from being a new phenomenon in Norwegian working life. On the contrary, the development of the Norwegian system of managementlabour relations after 1945 can be understood as precisely a result of such encounters, embodied in the establishment of new practices at the workplace. And, in these encounters, we find international models, not only for management

${ }^{15}$ I wish to thank Herman Knudsen, Christer Thörnqvist, Bernt Schiller, Knut Grove, Martin Byrkjeland and Øyvind Bjørnson for constructive comments. 
strategies, but certainly also for the ideas of an industrial relations system based on organized parties. ${ }^{16}$

Rather than a unilateral focus on conflict situations, or struggles between national traditions and global strategies, I would therefore prefer to discuss how forms of mutual influence from different strategies and traditions have contributed to establishing and developing what we may call 'the Norwegian cooperative model'. ${ }^{17}$

In the course of the chapter I will examine the most influential management strategies' approaches to Norwegian industry and working life - from the American Taylorist strategies emergence during the 1950s, via the English sociotechnician's breakthrough of the 1960s, and on to the global total-quality movement that characterizes current working life. Thus, the interpretation and institutionalization of the management strategies will be analyzed in relation to certain reforms of the formalized Industrial Relations system. Important points of reference at the company level, are the two leading Norwegian-owned groups, Aker (ship building/offshore construction) and Norsk Hydro (Chemical and Metal industry) which may be regarded as exemplary cases of 'the Norwegian cooperative model'. These cases can also be linked to different and opposing management strategies. The point of departure is the 1950 s - a period which may be characterized as a decisive turning point in the development of managementlabour relations in Norwegian working life.

\subsection{Three International Strategies and a Norwegian Model: Experiences of the 1950s and 1960s}

\subsubsection{An American Productivity Movement}

After the Second World War, the Labour Party (Arbeiderpartiet) in Norway attempted to introduce a planned economic system. Working life was to be placed under the aegis of the state in order to ensure the party's overall political objective: modernization through industrialization. Economic growth, with industry as the driving force, was to ensure welfare for all. And at the national level, a collective bargaining system was established, based on what Hans Otto Frøland (1992) characterized as a 'corporate social contract'. The basis for wage negotiations was a 'contract' between the government, The Norwegian Confederation of Trades Unions (LO) and the Norwegian Employers' Confederation (NAF): moderation today should provide prosperity tomorrow. In order to achieve economic

\footnotetext{
${ }^{16}$ For a broader analysis of the development of the Norwegian system of management-labour relations/industrial relations after 1945 see Heiret 2003a and 2003b.

${ }^{17}$ My approach may as such be seen as a contribution to the international literature that views Management strategies and Industrial Relations traditions not as cases of transfer or diffusion of techniques, technology or organizational models between countries, sectors and companies, but as processes in which particular ideas and ideals of social organization are interpreted and institutionalized as elements of the historical construction of national systems of management-labour relations (cf. Zeitlin 2000; Kjær 2001; Røvik 1998).
} 
growth, the employers received guarantees of moderate wage claims while the employees had the benefit of an economic policy in which subsidized consumer goods and a redistribution policy played an important role. In contrast to the Swedish model of 'centralized self-regulation', which proposed that the parties would ensure a moderate wage level through negotiations without state intervention (See Kjellberg 1998: 79-80), the Norwegian state became a major actor in a tripartite system. Nevertheless, in contrast to the situation in both Sweden and Denmark, the local unions maintained not only an organizational autonomy but also a certain organizational strength that could undermine national agreements that did not have local support.

At the beginning of the 1950s, however, confidence in a state system was somewhat weakened. If company managers were to make a more active contribution to the modernization process, then market forces would require more freedom (Lange 1998). Furthermore, there were also pressures from abroad. In order to receive US Marshall Aid the economy had to be more internationalized. Norway was not merely to remove trade and customs barriers - the borders had to open to American management strategies.

An American strategy document - 'Planning for Productivity' - gave expression to the American viewpoint on the situation in Norwegian industry (Slagstad 1998: 271-72). Neither the employers the trade unions nor the government had managed to create an institutional framework for an increase in productivity. The state-regulated economy had created serious barriers to effective production and, according to the American productivity experts, Norwegian industrial leaders had 'developed a psychopathic fear for "socialism" 18 which, in matters of productivity, made cooperation between management and employees difficult. And the 'corporate social contract' that set its marks on the collective bargaining system, was a 'partnership of the top' (Bull 1982: 110-11). Although the production committees, which should function as arenas for joint productivity accords, had been established in an agreement between LO and NAF, distrust and suspicion continued to prevail on the shop floor.

According to Finn Olstad, the 1950s was the decade of class struggle within Norwegian industry. Local wage negotiations were linked to the prevailing piecework system, and Olstad understands the piece-rate bargaining between the individual worker or team and the foremen, as a daily manifestation of the clash of interests between labour and capital. There was '... a constant tug of war on the results of and the power over production. And the relatively tranquil labour situation was very largely an expression for the fact that the employers had resigned part of the control over production' (Olstad 1991: 152-53). In this perspective the local power of labour is seen as one of the major forces in post-war society and as a formidable obstacle to measures that the companies, the govern-

\footnotetext{
${ }^{18}$ The quote is from the Mutual Security Agency author of 'Planning for Productivity', the reference here from Terje Halvorsen 2000: 218.
} 
ment, and the leaders of the Labour Party wished to invoke to promote rationalization and increased work effort. At the same time, company management was scarcely interested in bestowing employees with power over the workplace, 'which they feared might leave an opening for a union takeover and thus intervention in so-called managerial prerogatives' (Byrkjeflot and Halvorsen 1996). In other words, it was more important to bank on the prerogative of management than to enter into an agreement with the employees, even though the ultimate aim was increased productivity.

It was in this situation that the American experts steadfastly maintained that a radical new and comprehensive programme for productivity increase had to be established if Norway was to receive dollar aid. According to the pattern of US industry, scientific work-studies were to provide the basis both for the determination of wage levels and for the manner in which the various work tasks were to be carried out. The piecework system was regarded as ineffective and a source of conflict. The engineers were now to take over the planning and leadership of the work, and the wage level was to be determined according to objective criteria (Ågotnes 1990: 184-85).

The idea that scientific studies could solve these problems was a classic Taylorist assumption. 'The aim was to realize the maximum benefit of the employees' mechanical performance - a form of human machine', Terje Halvorsen writes (2000: 221). And the scientific determination of optimal working methods and work tempo implied a 'monotonization and intensification of work, which denoted a control of working operations and thereby manpower output of the worker himself to the side of the management' (ibid).

Nevertheless, the leadership of the LO came to support the American specialists and in 1953 the Confederation adopted a programme which expressed its official view on the 'productivity problem'. This entailed 'securing the industrial basis of the nation, improving its competitiveness, strengthening its ability to cope with economic cycles, and to raise productivity' (ibid.). And in order to achieve this objective, the members of the confederation had to allow themselves to become 'Taylor-made'. However, this attempt to 'Taylorize' Norwegian workers encountered resistance. In his classic analysis of workers' collectives, Sverre Lysgaard showed how the workers established informal collectives that established their own standards for work tempo and performance. Lysgaard also showed that loyalty was stronger towards one's own work-team than towards the management's demands for increased input (1961). The support for productivity efforts and the work studies were also weakened in so far as the employers would not negotiate on the possible distribution of productivity gains (Terje Halvorsen 2000: 219). As long as the engagement in the 'productivity movement' was only going to serve the owners' profits, it was difficult to create any enthusiasm among employees. 
Further, it was not only the workers who were sceptical of American ideas. Norwegian engineers also lacked any hegemonic inspiration derived from the Taylorist management strategy, neither from the education system nor from the firms. Within Norwegian engineer tradition, as in the German tradition, considerable prestige was attached to practical experience (Byrkjeflot 2001 and 2002a), and leading representatives 'attempted to develop a qualifications policy which advanced knowledge at all levels in the firm' (Tor Halvorsen 1994: 575). This contrasted sharply with the Taylorist attempt to disseminate knowledge from the skilled worker and technicians to a professional stratum comprising leading engineers, united in their own piecework and rationalization divisions. As such, the majority of work-study engineers came to carry out their tasks as hired consultants, and not as a specialized work-group at a given management level within the companies. Nor were company owners especially supportive of the idea of increased productivity through union support. The idea of more effective employees was embraced, but productivity cooperation, which implied collaboration with a Labour-controlled state together with the trade union movement, was not in accordance with the employers' general conceptions (Terje Halvorsen 2000: 217).

The productivity movement was an international phenomenon, which became interpreted and institutionalized in many European countries. According to Peter Kjær, the situation in Sweden followed the same path as in Norway because the Swedish industrial leadership too regarded the interventionist labour initiatives as a 'fundamental challenge to private ownership of the means of production...' Denmark, in contrast, stands out as an early example of a more collaborative approach to productivity policy (2001: 317 ): the idea that productivity was a socio-economic problem that required responsible co-operation among various social actors became an 'ideal conception' that contributed to consensus. Hence productivity policy could be constituted as a field situated between political, ideological and technical issues. The actors then had to relate to each other in processes of ongoing co-operation in order to solve the problems. Therefore it was possible to establish a network of institutions around the National Productivity Council of the Ministry of Trade and Industry, whereby joint projects were developed and implemented through negotiations between the parties (ibid: 318). To some extent the Norwegian Productivity Institute (NPI) played a similar role by creating national and regional networks that were able to influence the American initiatives and shape the productivity effort (Amdam and Bjarnar 1998). Nevertheless, despite the fact that the LO supported the NPI and participated at the national level, the 'collaborative consensus' still had its limits on the company level, and a proposed legislation of co-determination, instead of paving the way for a joint conception of productivity, created additional problems. 


\subsubsection{Between Legislation, Agreements and Local Practices}

In the Labour party's election manifesto of 1954, the party promised to work for legal reforms; the employees in the large companies should achieve the right to elect representatives on the company boards (Bergh 1983: 95). But these proposals encountered resistance. The chairman of LO, Konrad Nordahl, was concerned that the clear demarcation between trade unions and company management would become diffuse and the employers were not willing to allow the employees' access, either to the board or to a general assembly: employee representatives without proper qualifications would render the board's activities less effective and, moreover, the board hardly ever handled matters that directly concerned the employees.

Neither the LO nor the leadership of the Labour Party desired a confrontation on this question. The main challenge was to encourage employers to cooperate on matters of productivity. Instead of proceeding along the lines of legislative reform, the issue was transferred to the agreement system. This lead to the Basic Agreement re-negotiation of 1957 between the LO and the NAF specifying extended responsibilities for company management concerning information dissemination. Management was now obliged to confer with the local union representatives 'on projected changes in activities'. On matters that concerned workers' terms of employment and working conditions, union representative should be able to express their opinion prior to the company's decisions being put into practice (ibid: 95-97). In the negotiations the employers had also agreed to cooperate in order to improve the well being of employees and to increase productivity. But if employers were to enter into such an agreement, the LO and Labour Party would have to give way on their demands for influence in matters concerning essential strategic questions. Furthermore, priority was to be given to negotiations rather than recourse to the law.

The agreement of 1957 had many features in common with the Danish collective agreement on cooperation committees (Samarbejdsutvalg) of 1947 which gave representatives of the workers at workplace and company level certain rights to be informed and consulted by employers (Knudsen 1995: 82). But the Norwegian cooperation was not institutionalized in committees as in Denmark and agreements had to be implemented without the Danish collaborative consensus. Furthermore, even though the parties had arrived at a common understanding at the national level, the way was not yet open for the American productivity movement. Taylorism's weak anchorage in the engineering profession and the strength of the local union system had the opposite result; namely that work studies became incorporated into the collective bargaining system.

In so far as works studies had become a theme of the negotiations, they also became a potential source of power for the local unions (Tor Halvorsen 1994: 585). In leading industrial companies the wages system was also on trial as well as new forms of cooperation that were to have considerable significance for the 
further development of relations between management, union and employees. In Norsk Hydro and Aker, both union representatives and management pointed to the piecework system as the main problem - not only for productivity but also for the working conditions (Andersen 1989; Grove and Heiret 1998; Heiret 2000). The piecework system favored the skilled negotiators, but not necessarily the skilled workers, and it did not encouraging further achievements. On the contrary, the pieceworkers kept the working tempo down in order to avoid demands for lower piece-rates. As such, the negotiations of piece-rates became a key source of dissatisfaction and distrust as well among the workers as between the workers and the management. But the solution was not to abandon the negotiation system and to transfer the determination of wages to engineers with 'objective criteria'. Rather, the position of the local union was fortified in collective wage negotiations in that the piecework system was displaced by fixed-wage rate agreements. In exchange for accepting work-studies, the union received the right to negotiate a fixed wage for the various work and job categories. Scientifically measured productivity increases should lead to wage increases for all employees. Moreover, in order to understand the broader significance of international management strategies, developments in Norsk Hydro and Aker are of particular interest in so far as the two Norwegian company groups were arenas for the two most popular strategies in Norwegian industry in the 1960s.

\subsubsection{Kenning and the Aker School}

One of the American Marshall advisors achieved a special position in Scandinavia. During the 1950s, George Kenning emerged as an important personal advisor for key figures both in Norwegian and Swedish economic life (cf. Kalleberg 1991; Quale 1995: 238; Sørhaug 1996: 7; Byrkjeflot 2001 and 2002b). Kenning's practical managerial experience came from General Motors and the Swedish mining company LKAB, and he was brought to Norway in 1955 by the US embassy and the Norwegian Productivity Institute. His management principles suited a traditional hierarchical mass-production organization. According to his principles, a manager's task was to formulate a permanent company policy, make decisions, delegate responsibility for specific tasks and communicate downwards in the hierarchy. Further, management should be a clearly defined profession. 'A leader can lead anything' became Kenning's most renowned proclamation, and those who are led should just follow orders: 'Most employees require to know what has to be done, and thus a leader to tell them as such' (Quale 1995: 240). Within the theory of organizations, Kenning may be seen as a pure child of Taylorism: his principles were based on an instrumental understanding of hierarchical control. As such it was regarded as a countermove against local labour power and the unions' claim for co-determination and Kenning's popularity has partly been explained by the managers' fear of the ideas of industrial democracy (Quale 1995: 238). Kenning himself, however, lost his battle with the unions. In the 
wildcat strike at LKAB in Kiruna, Northern Sweden, in 1969-1970, one of the demands of the strike committee was that the firm had to abandon Kenning's principles of management (Byrkjeflot 2002b). Hence his principles were brought to public attention and lack of support for them lead him to leave Sweden. In Norway, however, and especially in Aker, the 'Kenning-courses' were about to become a major theme in management.

In 1957 Kenning had turned up at a shipyard on the Island of Stord on the Norwegian West Coast (Grove and Heiret 1996: 84). In attempts to modernize the mode of production and the workforce, the local director was eager to import ideas from the USA. So foremen as well as middle management had to participate in the 'Kenning-course' where they were thought his principles of leadership. But the idea that a welder could be the foreman for the engineering workers and vice versa, did not appeal to this audience. However, one year before, the local shipyard had become part of the Aker company group, and the general director, Martin Siem, was another modernizer with American ideas and, in addition, connections to George Kenning. Thus during the sixties, Kenning became more and more involved in the management training courses of the company, now known as the 'Aker-School' (Kalleberg 1991: 228).

Nevertheless, in terms of what has happened to management-labour relations in Aker, Kennings ideas are hardly recognizable. As mentioned, Aker was a forerunner in the implementation of scientific work-studies and replacing piece-rates with a fixed wage. But the reforms did not lead to the expected results. It appeared difficult to find objective scientific standards for productivity growth and placement within a salary scale created new conflicts among employees. A solution to these problems was neither to be found within the rational scientific ideal nor in an authoritarian management theory, but rather in developing an atmosphere of trust between the parties (Grove and Heiret 1998: 133-34; Heiret 2000). Instead of solely stressing technological development, leadership, control and scientific measures, the question of productivity was now made dependent on a common understanding of interest between the owners, the management, the employees and the local union. In line with this, wage growth became linked to an expected increase in productivity. And it was here that the issue of trust entered into the picture. Rather than believing in inaccurate scientific goals, management chose to rely on a deal with the union. To safeguard the competitiveness of the company and achieve higher wages, employees were obliged to increase their efforts to reach the productivity goals. Moreover, productivity became an integral part of union activities, symbolized by the appointment of union representatives with especially responsibility for the productivity (produktivitetstillitsmenn) and regular productivity discussions.

I would maintain that this 'partnership' is an expression of a fundamental change in the normative foundation of management-labour relations - or, if one will, the so-called 'culture of the firm' - understood as the common interpretation 
of reality by employees, union representatives and management. At the same time it is important to ensure that the partnership did not replace the role of the organized parties. These relations of trust were based on established and recognized positions of power. Productivity gains were determined through negotiations, and even the actual cooperation was regularly used as an element in the bargaining (Grove and Heiret 1998: 135). The union at Aker Engineering (Akers mek.) in Oslo was recognized as having one of the country's strongest local organizations and at the shipyard at Stord, which during the 1960s became Aker's most important yard, it was only possible to establish this element of trust after the union had acquired a sufficient power base. A strong negotiating position visà-vis management and which would be manifest in the size of the wage-packet, was a necessary condition for ensuring the cooperation of the union and their members in productivity programmes. Furthermore, a strong position of the union among the workforce was also required so that management could rely on employees' adhering to the agreement that their representatives had endorsed.

What reinforced the significance of the partnership was that the agreement on the new wage system and the new relationship was established for the whole company group and not confined to the workplace. We thus see that Kenning's disciples contributed to change management-labour relations, giving the union a new power basis and creating a new interdependency between employees and managers. In other words a development not exactly in accordance with the lessons thought at the 'Aker-School'.

\subsubsection{Thorsrud and Socio-techniques}

The other influential management strategy in the 1960s was the socio-technique. In 1962, the so-called Cooperation Experiment between the LO and the NAF commenced (Bergh 1983; Venneslan 1991; Grove 1993; Reime 1997). Behind this project was the Norwegian psychologist, Einar Thorsrud, who had been inspired by the Tavistock Institute of Human Relations in England. At the organizational-theoretical level, the aim of the socio-technique was to increase productivity by combining knowledge of technological systems with insights in social systems. Thus it also challenged Kenning's theory. In keeping with the Human Relations tradition, 'joint decision-making' was a fundamental concept. But such co-determination would 'first become a reality if the alienation could be reduced and increased engagement among large groups of employees encouraged' (Gulowsen 1975: 11). By means of 'job extension' and 'partly selfgoverned working groups' employees should increase their control of own work situation and working practices. They would then achieve more interesting work and undoubtedly acquire a more satisfactory relationship within the workplace. Thereby the 'psychological requirements of the job' would be fulfilled, and satisfied workers would yield increased productivity. 
While traditional human relations theory was more solely concerned with the psychological job satisfaction and that employees had a sense of co-determination, Thorsrud and his English mentors were concerned with real co-determination. To a greater degree, the workers themselves should in fact have control over the workplace, and the technical system should be reformed to adapt to the social system within which the human task was performed. In addition, the sociotechnical solutions in the Norwegian version should be worked out in cooperation with the unions.

These cooperative experiments and socio-techniques established one of their most important bases in Norsk Hydro. Although the actual results varied, selfmanagement groups were established in several workplaces but this selfmanagement had a tendency to break down after the researchers withdrew, and the ideas did not spread widely into other activities as the researchers had predicted (Venneslan 1990: 14; Gulbrandsen 1993: 32-35). Thus, as was the case with the Kenning School in Aker, the practical consequences for managementlabour relations cannot be interpreted on the basis of the management-strategic doctrines and, as in Aker, the restructuring of the wage system had major consequences for the further development of the relationship between the parties.

Also in Hydro, the introduction of a fixed-wage system provided the basis of a new interdependency between the employees, the union and the management. Wages and productivity were to be increased through cooperation between the parties, both within the individual firm and the company group. But such cooperation assumed a completely different level of trust than had existed during the conflict period of piecework (Heiret 2000). However, by contrast with Aker, there was nevertheless a greater degree of conformity between the declared management strategy, the basis for the new wages system and in the establishment of an atmosphere of trust. The socio-technical cooperation experiments undoubtedly played a major role in this.

In addition, these experiments came to affect the further development of working-life relationships, not just in Hydro, but also throughout large parts of Norwegian industry. First, the significance of co-determination of the work process became generally accepted - both as a democratic principle and as a measure aimed at promoting productivity. Secondly, one of the researcher's conclusions became part of a permanent and essential feature of what came to be known as 'the Norwegian model of cooperation' (Karlsen and Munkeby 1998). Experiments that encouraged the employees to participate in the shaping of the work process required support of top management as well as a strong local trade union (Gulowsen 1975: 84).

But even though the socio-technical researchers attached importance to trust and cooperation between management and local union representatives, they were on a collision course with the LO in one respect. They did not share the LO's view of the importance of developing a representative approach to co-determi- 
nation. Having looked into experiences from Norway and other countries where there was union representation on company boards, the researchers steadfastly maintained that the employees' representation would not be an effective means of achieving industrial democracy (Thorsrud and Emery 1964: 11). Whether the worker had the right to choose representatives to the company board would be of little significance for a worker unless he had a certain minimum of selfdetermination at his own workplace. It was also pointed out that the employees' representatives might thereby distance themselves from those they represented (Gulowsen 1975: 12-13).

\subsubsection{A Norwegian Model of Cooperation}

The history of the effects of international management strategies during the 1960s cannot be concluded without outlining the history of the crucial legislative reforms and agreements during the same period (Heiret 2003a). Regarding the question of representative democracy, neither Thorsrud nor Kenning won the day. In 1966, 'company committees', which had their predecessors in the production committees and are comparable with their Danish counterparts, became part of the Basic Agreement. And now, the basis for the reform was cooperation on increased productivity. As long as it was based on a joint understanding on profitability, the employers were willing to extend the right to information and consultation. In other words: the 'ideal conception of productivity' had become widely accepted in Norway too. In 1972, one year ahead of the Danes, the Norwegian employees achieved the right to elect their own members of the board - a right that was further extended four years later to encompass the board at group level. Representation on the board was a further example of the extension of trust-based cooperation. The parliamentary proposal had received the support of both the right and the left wings of the Parliament (Stortinget) (Bergh 1983). Within the LO the will to influence strategic decisions had become stronger than the fear of becoming the hostage of the employers. The Employers' Confederation had also reversed its standpoint: if employees were willing to accept the responsibilities of management, which was implicit in representation on the board, then employers were willing to accept the changes in the law.

Thereby three of the pillars in 'the Norwegian model of cooperation' were established (Heiret 2003a). The right to negotiate, which hitherto had been the employee's most effective tool in restricting the role of management, was now supported by participatory as well as representative democratic arrangements. The fourth pillar was the tripartite collective bargaining system that during the sixties was further centralized and formalized. By means of technical calculations, carried out by a corporative committee, a consensus on the macro economic basis for social reforms and possible increases of wages was established. Furthermore, through a common pay scale in the public sector, the state had acquired a tool to coordinate and compare the wage level to the assumed competitiveness of the 
export industry. Thus, the Norwegian state took a stronger and more decisive part in the industrial relations system than did Sweden where the system could still be characterized as 'centralized self-regulation'. But the distinctive stamp on the Norwegian system, compared to both the Swedish and the Danish, was the combination, and the tension, between a centralized and state-dependent national system, and strong and well-organized local unions that were embedded in a broad set of institutionalised relations with employers.

The priority given to the local level was far from a new phenomenon in Norwegian industry - what was new was that the trust-based cooperation on increasing the profitability signified that management-labour relations were no longer solely based on conflict and diametrically opposed interests. Cooperation in matters of joint interest became increasingly more important.

\subsection{Efficiency and Competitiveness - Or Democracy? Experiences of the 1970s and 1980s}

During the 1970s and 1980s the Kenning and Thorsrud traditions continued to influence the development of management-labour relations in Norway. This was particularly evident in the way that socio-technical ideas made their impact in one of the most ambitious legal reforms in Norwegian working life - the Working Environment Act of 1977.

\subsubsection{Participation for Better Working Environment}

An important new feature of the act was that the workers' experience and involvement should be taken into account in a fundamentally different manner than hitherto (Bjørnson 1997). This was most clearly expressed in $\$ 12$ of the act that was designed to regulate the psycho-social working environment. The general requirement was that 'technology, organization of the work, execution of the work, working hours and pay systems shall be arranged in such a way that the employees are not exposed to adverse physical or mental strain'. Further, conditions 'shall be arranged so that employees are afforded reasonable opportunity for professional and personal development through their work' - and that work should be organized so that it gives 'opportunity for self-determination and professional responsibility /.../ for variation and for contact with others [and] for connection between individual job assignments'. ${ }^{19}$

In the preparation of the bill, researchers from the 'Cooperative Experiments' had played a major role not least in the change of direction concerning participation and direct democracy. Thus the profile of the act was in clear opposition to Taylorist productivity ideology. It could be said that the intention of the act was to improve the working environment by extending the right to participation, and that the basis of the act was the theoretical postulate that steadfastly maintained

\footnotetext{
${ }^{19}$ Quote from §12, sections 1 and 2 in the Working Environment Act of 1977.
} 
that the active participation of the employees was a prerequisite of functional industrial democracy and a defensible working environment (Hansen 2002). This profile contained both an expressive and an instrumental conception of democracy. In the expressive version there was an assumption that democratic influence has an intrinsic value and thereby is as important for the working environment as fresh air, less noise and a secure place of work. The instrumental understanding was more concerned with industrial democracy as a means of achieving better working conditions. Those who experience where the 'shoe pinches' are best able to suggest adequate improvements.

The 1970s stand out as a period of working life reform in all the Scandinavian countries. Regarding the question of encounters between international ideas and strategies, and national traditions and institutions, the similarities and differences between the three countries call for some reflections. Although the Danes got their Working Environment Acts in 1977 and the Swedes the year after, neither version had the same emphasis on participation and psycho-social and organizational matters. These acts had some general clauses but no specific measures dealing with psycho-social factors (Hydén 1992: 139; Lindøe et al. 2001: 25-27). One reason for this is probably that the socio-technique did not have the same direct impact on the legislative process in all three countries. But in an amendment in 1991, Sweden adapted the same rules and principles as stated in the Norwegian Law. According to Håkan Hydén (1992: 140), this is 'a strong evidence of the mutual influence among the Nordic countries', and, I would add, a sign of the socio-technical ideas that in the meantime had strengthen their positions through their Norwegian advocates.

In Sweden however, more than in both Denmark and Norway, the question of participation was in the 1970s linked to the issues of democratization, power and the prerogative of management (Johansen 1995). In a wave of political radicalization and wildcat strikes, the centralized 'self-regulation'-system of rationalization and modernization was challenged by demands for real co-determination at all levels, from the shop floor to the board. And the result was extensive labour legislation, including the Co-determination act of 1976, designed to increase union influence over employment and production matters (Kjellberg 1998: 85).

However, when the socio-technical ideas, imported by Norwegian researchers with experience in the Cooperative Experiments, became influential in Sweden in the 1980s and 1990s, they not only affected ideas about the working environment. They now became part of a new research offensive that again stressed the strong connection between participation, cooperation and competitiveness (Gustavsen et al. 1996).

\subsubsection{Participation for Increased Competitiveness}

In 1985, a Norwegian public committee issued a report that pointed out that codetermination was now more generally recognized as a means of improving effi- 
ciency and contributed to 'the development of the firm' (NOU 1985:1. See also NOU 1984:33). Cooperation between the parties was acclaimed as a national advantage in the increasingly competitive international environment and it was maintained that the ability of industry to adapt and to compete was to be of decisive significance for the type of co-determination, which was to be practised (Johansen 1995: 124). It was the employees' influence on day-to-day affairs that had to be strengthened and that could result in an increase of skills that, in turn, would yield increased competitive advantages. The formal representation arrangements, together with the union structure and collective bargaining system were, on the other hand, regarded as obstacles to the required adaptation. A further step in the democratization process should rather ensure effective leadership than to be a restriction on employers' management rights. And when the parties in the public sector finally signed their basic agreements on co-determination in the first half of the 1980s, the main goal was more efficient public services rather than the democratic rights of the employees (Lægreid 1983).

A key role in this change of focus was played by Bjørn Gustavsen and Per Engelstad of the Work Research Institute who had developed theories of "coordinated leadership' and 'dialogue-based adaptation programmes' that represented a continuation of the Cooperation Experiments of the1960s (Korsnes 1997: 2). Thus the normative basis of the industrial democracy was in the process of being transferred from 'participant democracy' to 'better management', and even though the organized parties continued to play important roles, the cooperation on joint interests, was tending to overshadow the acknowledgment of opposing interests.

A similar development occurred in Sweden. The Co-determination Act had to be followed by agreements signed by the parties, but when it came to implementation, the reform was overshadowed by an economic downturn and neo-liberal ideology. At the same time, the research focus in Sweden too, turned to the need for more competitive firms (Johansen 1995: 35 and 105-07). The result was that the power relations between the parties remained unchanged, and the idea of participation was once again linked to the concept of productivity and efficiency.

What more can we say about Kenning's Norwegian venture? In the 1970s and 1980s the 'Aker School' won a dominant position in Norwegian working life. Hundreds of young managers took the training which Kenning and his protégés advocated and many of these were later head-hunted by other large private and public organizations such as the Norcem (cement industry), the Storebrand (insurance), the DnC bank, and the state railways, NSB (Kalleberg 1991; Quale 1995: 239). In the formulation of the texts of the acts and the agreements, Kenning had, however, far less influence than Thorsrud and the socio-techniques. In addition there was open opposition between the two traditions. While the Aker group had systematically kept their managers away from the courses and programmes that were arranged in the aftermath of the Cooperation Experiments, a 
number of firms, led by Norsk Hydro, distanced themselves from Kenning's management philosophy.

It is nevertheless my opinion that we cannot find decisive differences between management-labour relations as practiced in these two leading Norwegian company groups. On the contrary, both contributed to the further development of 'the Norwegian model' in a direction that can neither be understood as a mirror image of the Human-Relations inspired socio-technique, nor of Kenning's Tayloristic doctrines.

In spite of the socio-technicians' focus on direct participation rather than representative arrangements - and in spite of the Kenning-tradition's original scepticism of the trade union movement, the local union representatives got an increasing number of roles to fulfil. This came to expression, not least in the Working Environment Act that beside stressing the direct participation of the employees also established a representative body: 'The Working Environment Committee' could require employers to commence measures aimed at improving the working environment. Furthermore, the safety overseer (hovedverneombud) was given authority to prohibit work processes that endangered employees' lives or health. Both the committee and the safety deputy were to represent all the employees, irrespective of whether or not they were members of the union. Nevertheless, the act provided a new opportunity for unions that comprised a majority of employees in the workplace. In large companies such as Aker and Norsk Hydro, the local organization was strengthened in as much as the safety overseer also became a full-time union representative (Grove and Heiret 1992, 1996).

\subsubsection{Participation for Strategic Firm Development}

During the course of the 1980s Norwegian industry underwent far-reaching internationalization and company restructuring. Those Norwegian company groups that emerged as the giants were all steeped in the tradition of organized parties. It was therefore those companies with the best-developed and longest experiences with industrial democracy that were now expanding. Further, the successful companies were those that, over the years, had developed a network of local union representatives within the framework of the company structure and had formalized the arenas wherein cooperation between the parties at the group level occurred (Venneslan and Ågotnes 1994; Berg, Grove and Heiret 1993).

Close cooperation within the companies ensured the further development of the relationship between the organized parties in a more internationalized and liberalized economic world order. A decisive trend was that strategic decisionmaking processes accompanied productivity as arenas for cooperation. The union representatives in the company - not just at Aker and Hydro but also at other major groups such as Nora, Orkla, Kværner and Statoil, no longer just took part in the development of the working place, but also contributed to the strategic positioning in new national and international markets where fusions and fissions 
had now become part of everyday life (Heiret 2000). And this was a positioning that also characterized Swedish union cooperation within the company groups (Brulin 1989; Elvander and Elvander 1995). But even though an explicit democratic understanding provided the basis for the local union representatives, it was the instrumental linkage to strategic company development that made this cooperation potent. This was a new situation in Aker. During the 1960s the union representatives had been excluded from strategic decision-making and, during the 1970s, Aker management had opposed the proposal for union board representation at the level of the firm as well as that of the company group (Grove and Heiret 1996: 147-48).

Apparently, the development of laws and agreements and the practice of management-labour relations all pointed away from Kenning's teachings - a development which is echoed among organization theorists who were certain that his ideas were out-dated even at the time of his arrival in Norway, and who have accorded him the blame for the fact that Norwegian management was not equipped to absorb new and more advanced ideas (Quale 1995: 245). Tian Sørhaug, however, suggests an alternative and more fruitful interpretation. Sørhaug does not find Kenning of interest as a theoretician and his doctrines have little meaning if read as purely scientific documents. He notes that Kenning's theories were directed towards personal conditions and the firm's internal circumstances and were not concerned with technology, the market nor the customer. But precisely the theories' 'lack of context, that which undermines their scientific claims is /.../ that which strengthens their credibility and thereby their potential as a basis for action' (Sørhaug 1996: 92). What Kenning mediated was an open moral legitimization of the role of management and a direct and explicit reference to 'the distaste accompanying formal management in an egalitarian and informal culture'. His significance lay first and foremost in the ability to create a Norwegian power-elite with an informally organized personal network' (ibid: 8788). In addition, Kennings influence had probably more to do with his charisma than with the content of his arguments (Kalleberg 1991).

Hence management as it was practised cannot be deduced from the theories. It was founded in the confrontation with an active stratum of union representatives and laws and agreements that were constantly undergoing change. Even though it may be possible to maintain that the Aker management initially represented a more authoritarian style than their colleagues in Norsk Hydro, the Aker firms were also drawn into a formalized structure of organized parties where cooperation in matters of productivity and strategic company development achieved an ever more central place.

Meanwhile, the triumvirate of the LO, the NAF (now named NHO) and the State ensured that a national framework of the industrial relation system was in place. In order to stabilize the national oil-dependent economy in an unstable international market, the three parties not only maintained but also strengthen the 
centralized state-conducted moderate collective bargaining system to such a degree that the system of the 90 s has been described as centralized concertation (Dølvik and Stokke 1998). A characterization that is still valid, in spite of tendencies to decentralization and even individualization in both private and public sector in recent years (Heiret 2003b).

In Sweden, the development of the collective bargaining system followed a path more in harmony with the hegemonic liberal ideology. During the 1980s, on the initiative of the Swedish Employers' Confederation (SAF), wage agreements were partly decentralized, national negotiations lost impact and the wage level was more strongly linked to the demands of local productivity and flexibility (Kjellberg 1998: 86-89). But, without a 'solidaristic wage policy', defined by the LO and the SAF, the competing organizations managed to increase the wage level, and when the parties failed to secure moderate wages settlements, the state was brought in. In the beginning of the 1990s, the state temporary proclaimed a wage freeze and suspended the right to strike, and a new institutional measure was implemented: if the parties failed to obtain a moderate wage level through decentralized negotiations, the state could intervene as mediator. Although SAF had been able to assert new ways of wage setting, employers were 'not strong enough to dismantle the old bargaining system' (Thörnqvist 1998: 287).

Still, in Sweden, the collective bargaining and wage adjustment system became highly decentralized and even individualized in the nineties, compared to the Norwegian situation. But traditional industrial relations in Norway also encountered other challenges while the processes of internationalization and globalization proceeded.

\subsection{The Quality Movement and the Norwegian Model - Experiences of the 1990s}

During the 1990s, an increasing number of attempts were made to implement international management strategies in the private as well as in the public sectors. Terms such as 'firm culture', 'leadership philosophy' and 'value leadership' became everyday concepts: but, if they were to have credibility, the culture, the philosophy and values had to be acquired from external sources - preferably from Japan or the USA. In this respect 'Management by Objectives', 'Business Process Re-engineering', 'Benchmarking' and 'Total Quality Management' have become part of everyday jargon in Norwegian working life too.

Internationalization of concepts was surely not a new phenomenon. However, the question is whether these new ideas and management tools have merged with 'the Norwegian cooperative model' and 'the Norwegian system of industrial relations', as did the Taylorist productivity ideology, the human relation-inspired socio-technique and the Kenning-oriented management concept. 


\subsubsection{TQM - A Strategy without Content?}

The identification of these 'institutional standards' as Kjell Arne Røvik has described them, is their general content. Ideas concerning leadership, organizational structure, firm culture, personnel policy and competitive strategy are phrased in such a manner that they can be readily identified as universal; applicable to every industry, geographical situation or problem area. As immaterial ideas they can travel 'over oceans and continents, nations and organizations /.../ rapidly and unhindered, frequently by fax or by plane' (Røvik 1998: 16). But it is also a characteristic trend that their 'life-time' has become increasingly shorter. While 'work-studies' and 'self-governing groups' could be effective for several decades, many employees in the 1990s gained the impression that every new director - or each new year - brought with it its own new concepts.

At the end of the 1990s it was 'Total quality management' that had the greatest impact. TQM was a part of a global 'quality movement' which should put the 'customer at the centre' and 'increase quality at every stage'. Important elements in the concept were to demolish hierarchies and give employees greater responsibility and influence, or stated in another way: 'Total quality management is a leadership concept which strives to satisfy customer expectations by ... involving the employees in a process of continual improvement' (Kvadsheim 1999: 232, with reference to Imai 1986).

While company managers explain the use of strategies and concepts as rational responses to actual challenges, neo-institutional organizational theorists have launched an alternative explanation. Concepts such as TQM are not introduced first and foremost to solve specific problems, but to function as symbols that the organization is adaptable to change and solution-oriented and in consequence 'modern'. 'The claim is that current popular organizational recipes have acquired their legitimacy and distributive power in as much as they have become symbols for basic rational values in modern society; like logic, efficiency, management, control, democracy and science i.e. a movement forward and upwards towards something increasingly better' (Røvik 1998: 16). The extent to which these concepts function in accordance with their rational objectives is less important. The symbols are nevertheless effective if they legitimize leadership as dynamic and forward-looking.

Such a development may challenge the 'Norwegian model of cooperation' if the managers in Norwegian companies, consciously or unconsciously, attempt to attain their legitimacy from such a global symbol world rather than referring to procedures for joint decision-making and participation. The use of symbols and values can be understood as one way of putting into practice that which Francis Sejersted terms 'hidden power' or 'manipulation' (1997: 35-36). Sejersted maintains that Norwegian society is characterized by particularly strong democratic norms. In order to achieve the required confidence of subordinates, it has been necessary for management in Norwegian working life to abide by industrial- 
democratic procedures. By replacing such procedures with symbols, leadership becomes based on manipulation rather than confidence, and is therefore in danger of rendering the legitimacy basis for management-functions in a precarious position (ibid).

Whether the use of international management strategies is an expression of a rational attempt at changing organizational structure, practice and culture, or may be understood, as symbolic manipulation is, however, an open question. Røvik himself is nevertheless sceptical of both assertions. Instead, he maintains that organizations 'translate and adapt ideas and recipes' in that these are 'interpreted and re-interpreted such that constantly new and different versions are established'. Even though these concepts have global coverage and virtually identical ideas and formulae, they do not contribute to a uniform or homogenized practice (Røvik 1998: 168-69).

\subsubsection{TQM in Norway}

In Norwegian industry we have observed an attempt to translate Total Quality Management. In Bedriftsutvikling 2000 (Company Development 2000) - a programme jointly financed by the Research Council of Norway and the business sector, Rogaland Research has developed their own versions of TQM and contributed to its installation in a number of small, medium and large companies. Henrik Kvadsheim sums up the intention as follows: 'The expressed intention was to inaugurate a systematic process for continual improvement /.../ based on elements from TQM, and under the assumption that the process should be based on partnership cooperation and broad participation.' Researchers should ensure the 'active participation and the engagement of all staff in the improvement process.' This implies that everyone should be granted the opportunity to present his or her viewpoint during the process and as such be an integral part of it. Further, the process should be based on 'arenas which will ensure sufficient democratic legitimacy' - something which in a Norwegian context meant following those 'laws and agreed rules-of-the-game for the manner in which the development of the company should be organized.' Finally, top management, middle management and the local union representatives were picked out as the key actors in the implementation of this strategy.

Rather than clarify the concept of TQM, Rogaland Research, in my view, demonstrates that their project has contributed to furthering 'the Norwegian cooperative model' by linking direct participation with the institutionalized joint decision-making system. ${ }^{20}$ This project is presented in a more refined form in Tor Claussen's $(1999,2000)$ analysis of TQM processes, which he presents in three cases.

\footnotetext{
${ }^{20} \mathrm{An}$ extensive use of so-called dialogue conferences is also included in this concept - a method developed by Bjørn Gustavsen, and which personifies the traditions of the Cooperative Experiments via the Working Environment Act's decision on participation to BU-2000. (See Kvadsheim 1999:239, with reference to Gustavsen 1990.)
} 
The first case, involving one of Norsk Hydros aluminum smelters, shows a process where TQM was implemented without any special consideration to the Norwegian system of organized parties. The programme retained much of its general form. It was largely regarded as uncontroversial and was prepared by members of the staff. The intention was to make the individual employee responsible by 'increasing the individual's awareness of his own work situation' and 'concerning the individual's place within the entire organization' (Claussen 1999: 162). Initially, the local union was not drawn into this work, but several of the representatives were gradually drawn in as 'internal consultants'. According to Claussen this resulted in a situation whereby 'a culture emerged where power and person-dependence provided the basis for the development of arbitrariness in decisions', and even though this created a certain engagement, particularly among the consultants and also among employees - the programme had few practical consequences.

The second example also comes from the metal industry. Here it was the management that prepared the version of the programme and in such detail that its application would result in comprehensive changes in organization and working conditions (ibid: 163). The union, which had no influence on this 'translation' regarded TQM as a covert efficiency programme, and the entire process came to a halt on account of massive opposition.

In the third example, from a company network in the engineering industry, employees were engaged via their representatives and the programme was implemented through the system of formalized cooperation (ibid: 168). Without doubt this is Claussen's exemplary case. Nevertheless, he has an important objection: 'Any well-defined critical perspectives of the programme activity were not articulated'. This arose from the fact that a focus on common interests contributed to a consensual orientation of viewpoints which counteracted a dynamic critical perspective (ibid: 165). Here is the core of Claussen's theoretical and normative errand, which is to strike a blow for a Norwegian cooperative model in which the conflictual parties have a constructive and critical role. ${ }^{21}$ The process of company development must be based on formal arenas comprising representatives of all parties such that management-initiated processes and strategic resolutions can be subjected to an organized 'critical skepticism'. With reference to Sejersted, we can state that this is Claussen's insurance against the TQMprogramme being taken into use as a form of symbolic manipulation, which

\footnotetext{
${ }^{21}$ The inheritance from the Cooperation Experiments and Thorsrud may also be found in Claussen's comprehensive democracy-theoretical ambitions: A successful TQM-process should contribute to a democratic development in the company group, in working life, and in society as a whole (2000: 204). This is an understanding of democracy in line with Thorsruds vision that co-determination at the workplace was to have a rub-off effect in that it provided the necessary training and motivation for participation in a broader political arena. Increased self-determination in the work situation would result in people finding a new and more democratic relationship to their children's education, to family life and to local society (Venneslan 1991: 61).
} 
would act both as a hindrance to real participation and to undermine the legitimacy of the management.

In their use of TQM, Rogaland Research illustrate the main point being made by Røvik. The programme in itself contains no specific message but must be given a content that gives meaning in a local and national context. In addition, we are given a demonstration of the fact that 'the Norwegian cooperative model' continues to be a strong theoretical and normative idea. In the Research Council, in research communities, and among management and employees' representatives, TQM-processes have be translated as 'cooperative experiments' - and a real combination of direct participation and representative mutual decisionmaking is regarded as a decisive criterion for success.

Kvadsheim's summary of the results of this action-oriented research is decidedly positive. Researchers appear to have come furthest in the establishing of procedures for negotiating and problem formulation. The economic-practical results are restricted to smaller adjustments of planning and operational routines, which nevertheless represent a potential for both economic and working environmental improvement. Similarly, the projects reveal 'a limitation associated with the staff's contribution to the development of the companies'. The focus was on internal circumstances, and conditions 'linked to the market, competitive situation, external relations' received little attention and remained solely the responsibility of management.

\subsubsection{Participation as Symbol and/or Reality?}

In a thesis on organizational studies, Monica Rydland has followed the implementation of 'Total Quality in Aker' (TQA) (2001). Her starting point is the former shipyard on the island of Stord (Aker Stord) - now a producer of offshore installations. (This production unit also figured in case three in the study by Claussen). Even though their conclusions coincide in many areas, there are interesting differences. In the electro subsidiary company (Aker Elektro), TQM was opposed by the employees' representatives and middle management and the operators were indifferent. The trade union representatives were not involved in the 'translation', and regarded the processes as a covert measure to improve efficiency. The result was that 'total quality management' scarcely affected the operators in this project-organized activity. In Aker Stord, the local union supported the process. It regarded TQA as a possibility to (re)vitalize both direct and indirect democracy, and the union took part in the development of the concept. But even here, the programme made little impact on the production process. Indeed, the further down Rydland came in the organizational hierarchy, the less people felt themselves to be associated with the concept of 'total quality' and the fewer the measurable results to be found. Rydland advanced the metaphor 'immunity' in order to explain the phenomenon. The normal worker has become accustomed to concepts which come and go, and after a while is no longer either involved or 
irritated by them. In addition, she found that neither the management nor the union had functioning routines or structures to promote active participation in dayto-day activities. Concepts and campaigns were thus not able to proceed any further than to the various information and discussion groups.

But it cannot be concluded that efficiency and rationalization campaigns were not put into practice. Simultaneous to the TQA process, an adaptation process was also being undertaken with considerably more quantifiable and practical significance for the company's profits as well as for the everyday life of the operators and the working environment. As a result of a public initiative to reduce oil production costs in the Norwegian sector in the North Sea, the offshore industry was obliged to make savings of some 50 per cent. In accordance with modern requirements, this so-called NORSOK process was naturally included and presented with the aid of concepts borrowed from the 'total quality movement'. But 'influence' and 'continual quality improvement' was far too time-consuming and had to yield to more prosaic and quantifiable measures that resulted in shorter project times as well as less time devoted to the individual tasks. In the opinion of both supervisors and operators, there was just not sufficient time to keep campaigns of the TQA-type alive. In the light of Kvadsheim's summary, it seems that TQA became an arena for small improvements while the major processes of change could continue simultaneously, with little relation to either 'joint decision-making' or 'continual quality improvement'.

In another thesis, Trond Søreide has analyzed a TQM process at Haukeland Regional Hospital (Søreide 1999). This process, called 'Continual Improvement (CI) failed due to the determined resistance of the health staff. CI was an initiative of the administrative leadership and the health profession saw the process as a sign that their traditional professional control was to be subordinated to an administrative hierarchy. In other words, the translated version of the international concept was understood to be a conscious attempt to dismantle the existing power structure.

In my view, Claussen and Rydland's case studies illustrate Sejersted's warning: where these initiatives are regarded as symbolism, the use of international management strategies can trigger opposition, which puts management's legitimacy at stake. But what is interesting in Claussen's analysis is that it is precisely this resistance that emerges as constructive and creative. The local union representatives that function as 'critical skeptics' can increase the possibility that international concepts be 'translated' in the form of specific measures for real participation. Alternatively, they can contribute to expose existing conflicts - as in the case of Haukeland Regional Hospital. Rather than attributing a crucial role to the underlying democratic norms in Norwegian society, as does Sejersted, my belief is that this critical skepticism is the result of 40 years of mutual confidence. It is the tradition of the 1960 s, to link cooperation on productivity to joint deci- 
sion-making and participation, which is fundamental both for the skeptics of today as well as the critical participants.

Rydland's survey points, however, to a weakness in this partnership. When cooperation on continual quality improvement functioned, it worked best in the formal arenas of the intermediate levels in the organization. In addition, the influence of the trade unions became weaker the further down in the organization that Rydland went. If TQM was to be regarded as symbolism, then also the trade union's legitimacy was in danger of being undermined by this concept.

Again, one is prompted to draw a parallel with the 1950s and 1960s: reactions to management concepts bear a similarity to the resistance to the 'technicaleconomic' system that Sverre Lysgaard recognized in the 'worker's collective' a collective which was also opposed to the unions (Lysgaard 1961). Following some forty years of cooperation efforts, it is still difficult to achieve genuine cooperation, even in the best-organized parts of Norwegian industry. Perhaps the organized, critical sceptics have neither the organizational apparatus nor the legitimacy to be the primus motor for the individual employee's participation in his own work situation. Perhaps the cooperative institutions that were established in the heyday of 'the industrial society' are not adequate tools to give the international concepts substance. Possibly these institutions are merely cooperative bodies with 'history and structure' but without any real substance. ${ }^{22}$ Nevertheless, and in line with Sejersted, it might be claimed that 'there is nothing remarkable about the fact that we live in a world of anachronisms. This is indeed the norm. Institutional change occurs but slowly, implying that today's problems must be solved with yesterday's institutions. Now and then this may be very successful (Sejersted 2000: 156)'. Perhaps the efforts of Norwegian researchers to integrate Total Quality Management as an element in the Norwegian cooperation model are examples of possible success. But they are taking a deep plunge. By linking the programmes to symbolism, researchers are also placing themselves in danger of losing legitimacy and credence unless the content is in harmony with the vision.

\subsection{Concluding Remarks}

Both international management strategies and imported models of industrial relations have made their mark on the development of the Norwegian system of Management-Labour Relations. But ideas based on Taylorism as Human Relation, Total Quality or different models of institutionalized co-determination and corporatism, have all been implemented in a national tradition with strong local unions and a centralized and state-dominated system of collective bargaining. Thus all such strategies may be regarded as expressions of globalization-

\footnotetext{
${ }^{22}$ See Olstad's claim that the Norwegian society had become 'a class society of history and structure, even though the
} class relationship had lost its significance (Olstad 1991: 63). 
processes. Globalization though, understood not as tendencies that are unequivocally convergent and able to conquer the globe, but as complex encounters between ideas and models on global journeys - and local and national institutionalized experiences. The peculiarity of the Norwegian experience is that both the national IR-system and the influences from international management strategies have become stronger during the 1980s and 1990s. But even though we may distinguish a divergent Norwegian System of Management Labour Relations when compared to other Nordic and European experience, a focus merely on uniqueness has its limits. The Norwegian collective bargaining system and its forms of representative democracy have been constantly linked to the same idea of strong connections between cooperation and competitiveness that we also find in different versions of Human Resource Management in the other Nordic systems of Mangement-Labour Relations. But neither the Nordic nor the other European labour market parties have yet found an ideal conception of productivity and efficiency, able to achieve competitiveness, participation, industrial democracy and high standards of working life environment.

\section{References}

Ågotnes, Hans-Jakob (1990), 100 år i kamp og samarbeid, Bergen: Jernarbeiderne i Bergen. Bergen Jern og Metall.

Amdam, Rolv Petter and Ove Bjarnar (1998), 'The Regional Dissemination of American Productivity Models in Norway in the 1950s and 1960s', in M. Kipping and O. Bjarnar (eds), The Americanisation of European Business, London: Routledge, pp. 91-111.

Andersen, Håkon With (1989), Fra det britiske til det amerikanske produksjonsideal. Forandringen av teknologi og arbeid ved Akers mek. verksted og i norsk skipsbyggingsindustri 1935 -1970, Trondheim: Tapir.

Berg, Nina, Knut Grove and Jan Heiret (1993), Medbestemmelse i flernasjonale konsern studier fra Hydro, Siemens og ABB. København: Nordiske Seminar- og arbeidsrapporter 1993:648.

Bergh, Trond (1983) 'Medbestemmelse eller opposisjon? Noen hovedtrekk ved den norske debatten siden 1945 om demokrati i arbeidslivet', i Trond Bergh (ed.) Deltakerdemokratiet: Teori og praksis. Oslo:

Universitetsforlaget 1983, pp. 84-125.

Bjørnson, Øyvind (1997), 'Perspektiver på arbeidsmiljøets historie' i Arbeiderhistorie 1997: Årbok for Arbeiderbevegelsens Arkiv og Bibliotek, Oslo: Årbok for Arbeiderbevegelsens Arkiv og Bibliotek, pp. 4-33.
Brulin, Gøran (1989), Från den 'svenska modellen' till företagskorporatism? Facket och den nya företagsledningsstrategien, Lund: Arkiv.

Bull, Edvard (1982), Norgeshistorien etter 1945, Oslo: Cappelen.

Byrkjeflot, Haldor and Tor Halvorsen (1996), 'The Institutionalization of Industrial Administration in Norway in 1950-90', in R.P. Amdam (ed.) Management Education and Competitiveness: Europe, Japan, and the United States, London: Routledge, pp. 171-193.

Byrkjeflot, Haldor (2001), 'The Nordic Model of Democracy and Management'. in Haldor Byrkjeflot et al (eds), The Democratic Challenge to Capitalism: Management and Democracy in the Nordic Countries, Bergen: Fagbokforlaget, pp. 19-50.

Byrkjeflot, Haldor (2002a), 'Ledelse på norsk: Motstridende tradisjoner og idealer?' in Anders Skogstad and Ståle Einarsen (eds), Ledelse på Godt og Vondt Bergen: Fagbokforlaget, pp. 41-60.

Byrkjeflot, Haldor (2002b), 'The Americanisation of Swedish and Norwegian Management', in Matthias Kipping and Nick Tiratsoo (eds), Americanisation in 20th Century Europe: Business, Culture, Politics, vol. 2, pp. 111-27.

Claussen, Tor (1999), 'Dynamisk demokratisk medvirkning i bedriftsutvikling: Be- 
driftsutvikling og demokratiseringsprosesser i virksomheter og arbeidsliv' in Eivind Falkum, Line Eldring and Tom Colbjørnsen (eds), Medbestemmelse og medvirkning: Bedriftsutvikling mot år 2000, Oslo: Faforapport 324, pp. 153-79.

Claussen, Tor (2000), Bedriftsutvikling, arbeidsmiljø og filosofi, Oslo: Unipub, Akademika.

Dølvik, Jon Erik and Torgeir Aarvaag Stokke (1998), 'Norway: The Revival of Centralized Concertation', in Anthony Ferner and Richard Hyman (eds), Changing Industrial Relations in Europe, Oxford and Malden, MA: Blackwell, pp. 118-45.

Elvander, Nils og Anita Seim Elvander (1995), Gränslös samverkan. Fackets svar på företagens internationalisering, Stockholm: SNS förlag.

Frøland, Hans Otto (1992), Korporativt kompromiss gjennom korporativ konsert. Tariff- og inntektspolitikk i LO-N.A.F. området 1950-1965, Trondheim: Historisk institutt, Universitetet i Trondheim.

Grove, Knut (1993), Mellom nasjonalstaten og Siemenskonsernet: Samarbeidsvilkår og samarbeidspraksis i elektrovarmefabrikken, Bergen: AHS-Serie A 1993-1.

Grove, Knut and Jan Heiret (1992), Gjennom brytningstider. Historien om en ung fagforening: Alnor Kjemiske Fagforening 25 år, Håvik: AKF.

Grove, Knut and Jan Heiret (1996), I stål og olje: Historia om jern- og metallarbeidarane på Stord, Stord: Stord Metall- og Bygningsarbeideres Fagforening.

Grove, Knut and Jan Heiret (1998), 'Ein utkant i sentrum: industribygging og arbeidarar på Stord og i Aker 1945-1990' i Arbeiderhistorie 1998: Arbok for Arbeiderbevegelsens Arkiv og Bibliotek. Oslo: Arbeiderbevegelsens Arkiv og Bibliotek, pp. 122-51.

Gulbrandsen, Trygve (1993), Norsk arbeidslivsforskning: En gjennomgang av forskning om arbeidslivet 1950-90, Oslo: Institutt for samfunnsforskning, Rapport 93:2.

Gulowsen, Jon (1975) i samarbeid med Jan Irgens Karlsen, Thoralf Ulrik Qvale og Ståle Seierstad, Arbeidervilkår: et tilbakeblikk på Samarbeidsprosjektet LO/NAF, Oslo: Tanum-Norli.

Gustavsen, Bjørn (1990), Strategier for utvikling $i$ arbeidslivet, Oslo: Tano.

Gustavsen, Bjørn et al. (1996), Concept-driven Development and the Organization of the Process of Change: An Evaluation of the
Swedish Working Life Fund, Amsterdam: John Benjamins Publishing Co.

Halvorsen, Terje (2000), 'Mobilisering for modernisering. $\mathrm{LO}$ og arbeidet for produktivitets $\varnothing$ kning i norsk industri etter 1945', in

Inger Bjørnhaug,, Øyvind Bjørnson, Terje Halvorsen and Hans-Jakob Agotnes (eds), I

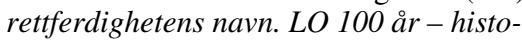
riske blikk på fagbevegelsens meningsbrytninger og veivalg, Oslo: Akribe, pp. 21340.

Halvorsen, Tor (1994), Profesjonalisering og profesjonspolitikk: Den sosiale konstruksjonen av tekniske yrker, Bergen: Institutt for administrasjon og organisasjonsvitenskap og Gruppe for flerfaglig arbeidslivsforskning, Universitetet i Bergen.

Hansen, Kåre (2002), 'Postulater om deltagelse, demokrati og arbeidsmilj $\varnothing$ - historien om et fors $\varnothing \mathrm{k}$ på å praktisere en teori' Tidsskrift for Arbeidsliv, no. 1, pp. 29-45.

Heiret, Jan (2000), 'Konsernfaglig samarbeid mellom demokratisering og ledelse', in Inger Bjørnhaug,, Øyvind Bjørnson, Terje Halvorsen and Hans-Jakob Ågotnes (eds), I rettferdighetens navn. LO 100 år - historiske blikk på fagbevegelsens meningsbrytninger og veivalg, Oslo: Akribe, pp. 279305.

Heiret, Jan (2003a), 'Samarbeid og statlig styring, 1945-1977', in Jan Heiret, Olav Korsnes, Knut Venneslan and Øyvind Bjørnson, Arbeidsliv - historie - samfunn: Norske

arbeidslivsrelasjoner $i$ historisk, sosiologisk og arbeidsrettslig perspektiv, Bergen: Fagbokforlaget, pp. 109-76.

Heiret, Jan (2003b) 'Et nasjonalt system i en internasjonal verden, 1978-2002', in Jan Heiret, Olav Korsnes, Knut Venneslan and Øyvind Bjørnson, Arbeidsliv - historie samfunn: Norske arbeidslivsrelasjoner $i$ historisk, sosiologisk og arbeidsrettslig perspektiv, Bergen: Fagbokforlaget, pp. 177-245.

Imai, Masaaki (1986), Kaizen (Ky'zen): The Key to Japan's Competitive Success, New York: McGraw-Hill.

Johansen, Tor Are (1995), Bedriftsdemokratisk utvikling i en фkonomisk krisetid: LO, DNA og bedriftsdemokratiet 1973-1985, Bergen: AHS-Serie A 1995-2.

Kalleberg, Ragnvald (1991), 'Kenningtradisjonen i norsk ledelse' Nytt Norsk Tidsskrift 3/1991.

Karlsen, Jan Irgens and Ida Munkeby (1998), 'Den norske samarbeidsmodellen - Vekst 
og fall eller fall og vekst?' in Tore Nilssen (ed.) Mot et bedre arbeidsliv, Bergen: Fagbokforlaget, pp. 37-58.

Kjellberg, Anders (1998), 'Sweden: Restoring the Model? in Anthony Ferner and Richard Hyman (eds), Changing Industrial Relations in Europe, Oxford and Malden, MA: Blackwell, pp. 74-117.

Kjær, Peter (2001), 'In the Name of Productivity: The Institutionalisation of Productivity Policy in Denmark 1945-1960' in Haldor Byrkjeflot et al. (eds), The Democratic Challenge to Capitalism: Management and Democracy in the Nordic Countries, Bergen: Fagbokforlaget, pp. 317-40.

Knudsen, Herman (1995), Employee Participation in Europe, London: Sage.

Korsnes, Olav (1997), Industri og samfunn: Framlegg til et program for studiet av norsk arbeidsliv, Bergen: Sosiologisk institutt, Universitetet i Bergen.

Kvadsheim, Henrik (1999), 'Organisering av utviklingsprosjekter. Økt innflytelse for ansatte gjennom bruk av møte- og medvirkningsarenaer i ledelsesinitierte utviklingsprosesser', in Eivind Falkum, Line Eldring and Tom Colbjørnsen (eds), Medbestemmelse og medvirkning: Bedriftsutvikling mot år 2000, Oslo: Faforapport 324, pp. 227-50.

Lange, Even (1998), Samling om felles mål: 1935-1970. Oslo: Aschehougs Norgeshistorie.

Lindøe, Preben, Jan Erik Karlsen and Terje Lie (2001), Et nordisk grep på arbeidsmilj $\phi$ regulering? Organisering og bruk av virkemidler i de nordiske land, Købehavn: Nordisk Ministerrråd, TemaNord 2001:535.

Lysgaard, Sverre (1961), Arbeiderkollektivet, Oslo: Universitetsforlaget.

Lægreid, Per (1983), 'Medbestemmingsretten i den offentlige sektor og det politiske demokrati', in Trond Bergh (ed.), Deltakerdemokratiet: Teori og praksis, Oslo: Universitetsforlaget, pp. 126-49.

NOU 1984:33 Politikk for arbeid.

NOU 1985:1 Videreutviklingen av bedriftsdemokratiet ('Brubakken-utvalget')

Olstad, Finn (1991), Arbeiderklassens vekst og fall: Hovedlinjer i 100 års norsk historie, Oslo: Universitetsforlaget.

Quale, Thoralf (1995), 'Ledelse - Fra administrasjon til omstilling', in Dag Olberg (ed.), Endringer $i$ arbeidslivets organisering, Oslo: FAFO-rapport 183, pp. 232-68.

Reime, Lisa Moi (1997), 'Samarbeidsprosjekstet LO/NAF og debatten om bedriftsdemokratiet', in Arbeiderhistorie 1997:
Årbok for Arbeiderbevegelsens Arkiv og Bibliotek, Oslo: Arbeiderbevegelsens Arkiv og Bibliotek, pp. 133-44.

Rydland, Monica (2001), Symbolisme og effektivitetskrav: Totalkvalitet i Aker, Bergen:

AHS-Serie A 2001-3.

Røvik, Kjell Arne (1998), Moderne organisasjoner: Trender i organisasjonstenkningen ved tusenårsskiftet, Bergen: Fagbokforlaget.

Sejersted, Francis (1997), 'Lederskap og demokratisk kapitalisme' in Haldor Byrkjeflot (ed.), Fra styring til ledelse, Bergen: Fagbokforlaget, pp. 33-52.

Sejersted, Francis (2000), Norsk idyll? Oslo: Pax.

Slagstad, Rune (1998), De nasjonale strateger, Oslo: Pax.

Søreide, Trond (1999), Vurdering og posisjon: Refleksjoner rundt organisatorisk motstand knyttet til et fors $\phi k$ på å innføre Total Kvalitetsledelse $i$ en i en helseinstitusjon, Bergen: Rapport nr 68, Institutt for administrasjon og organisasjonsvitenskap, Universitetet $\mathrm{i}$ Bergen 1999.

Sørhaug, Tian (1996), Om ledelse: Makt og tillit i moderne organisering, Oslo: Universitetsforlaget.

Thörnqvist, Christer (1998), 'The Swedish Discourse on Decentralisation of Labour Relations' in Daniel Fleming, Pauli Kettunen, Henrik Søborg and Christer Thörnqvist (eds), Global Redefining of Working Life - A New Nordic Agenda for Competence and Participation? Nordic Council of Ministers, Nord 1998:12, pp. 267-91.

Thorsrud, Einar and Fred Emery (1964), Industrielt demokrati: representasjon på styreplan i bedriftene? Oslo: Universitetsforlaget.

Venneslan, Knut (1990) 'Industrielt demokrati i Norden: Redogjørelse for det norske delprojektet, in Daniel Fleming (ed.), Industriell demokrati i Norden, Lund: Arkiv, pp. 9-22.

Venneslan, Knut (1991) Arbeidslivet som etterkrigshistorisk forskningsfelt, Bergen: AHS-Serie B 1991-5.

Venneslan, Knut and Hans-Jakob Ågotnes (1994), 'Transnationalization and Participation' in Bernt Schiller, Knut Venneslan, Hans-Jakob Ågotnes, Niklas Bruun, Ruth Nielsen and Dennis Töllborg, The Future of the Nordic Model of LabourRelations, Copenhagen: Nordic Council of Ministers, Nord 1993:36, pp. 93-163. 
Zeitlin, Jonathan (2000) 'Introduction' in Jonathan Zeitlin and Gary Herrigel (eds), Americanization and its Limits: Reworking
US Technology and Mangament in Postwar Europe and Japan Oxford: Oxford University Press 2000. 



\title{
6. Flexible Times: Dynamics and Consequences of Company Strategies for Flexibility
}

\author{
Kristina Håkansson and Tommy Isidorsson
}

\subsection{Introduction}

During the 1990s flexibility become a key concept on the labour market. In several European countries managers' and employers' organizations emphasized the need for flexibility.

The term flexibility is not well defined. Since it is a word with a lot of positive connotations it is used extensively and with several different definitions. In this chapter we will examine flexibility as a firm's or an organization's adaptation to temporary changes in demand. This could be called 'capacity flexibility' i.e. the ability to adjust production volume to demand.

Pressure on local unions to accept the demand for capacity flexibility also increased during the 1990s. The Swedish Employers' Confederation as well as European employers' organizations proposed a more deregulated labour market, for instance the use of agency workers as a way of achieving capacity flexibility (UNICE 2000; SAF 1996). The use of agency workers or temporarily employed workers might be one solution to increase flexibility. However, we will stress that companies can attain capacity flexibility in several different ways. We distinguish three principally different ways of achieving this flexibility. One way is by numerical flexibility e.g. variation in the number of employees; a second way is by working time flexibility e.g. variable working hours; and a third is by functional flexibility e.g. designing the work organization so that employees can vary the work tasks. When discussing ways to attain this flexibility it is important to be aware of all three strategies since they imply different organizational settings. Our distinctions are inspired by, but differ from those of Atkinson and Meager (1986) presented below.

\subsubsection{Purpose}

The purpose of this chapter is to:

- present a theoretical framework that facilitates the understanding of the mechanisms that influence the development towards the use of strategies for capacity flexibility on a company level;

- describe different strategies to achieve flexibility; 
- analyse the prerequisites for using different company strategies for flexibility;

- analyse their consequences on a macro level, company level and the level of the individual worker.

\subsubsection{Methods and Sources of Information}

This chapter is based on results derived from several articles and reports based on case studies in the engineering industry and retail trade, mostly in Sweden but to some extent also in other European countries. Quantitative as well as qualitative research methods have been used. We conducted the fieldwork during the late 1990s. We have also pursued a longitudinal study on temporary employment in the Swedish labour market.

Methodically we have used questionnaires, interviews with HR personnel and union representatives, locally as well as at central level. Interviews with representatives of employers' organizations have also been conducted. Agreements, negotiating protocols and relevant published material from employers' as well as employees' organizations have also been used. For further reading on methodological issues we refer to three reports published in Swedish and in English (Håkansson and Isidorsson 1997, 1998; Håkansson 2001).

\subsection{Dynamics of Company Strategies for Flexibility}

At the company level, several theoretical approaches have been used to try to explain the drive towards strategies for flexibility. One way of explaining these changes is institutional isomorphism, a concept put forward by Paul DiMaggio and Walter Powell. The theory explains the diffusion of different concepts of production and management strategies rather than the source of change. To understand the use of different strategies for capacity flexibility in firms and other organizations, and principally other concepts of production, we must analyse some institutional changes that have occurred during the past decades. We see these institutional changes in a larger cyclical process, thus adopting a structural analysis of the development of concepts of production. Before we describe contemporary developments in concepts of production and their significance for flexibility we will describe structural changes that influence this development.

During the last couple of decades, industrialised countries have witnessed a transition in working life whereby new concepts of production and a new work organization have been introduced. Well-known work in this field has been conducted by Horst Kern and Michael Schumann (1989:15-16, 23, 1990); Michael Piore and Charles Sabel (1984); Lennart Schön (2000); Christopher Freeman (1992:134); and Carlota Perez (1985). A common denominator is that the researchers classify the change as a complex change of the whole economy, although initially starting in manufacturing industry. Kern and Schumann, as well 
as Perez and Freeman, emphasise the role of computers and microelectronics as fundamental to present developments. Perez and Freeman, like Joseph Schumpeter, distinguish between inventions and innovations. The latter is an invention that is possible to exploit in a social and economic context.

Freeman separates four levels of innovations: 1) stepwise innovations that occur more or less continuously; 2) radical changes, for example new materials such as nylon, 3) new technological systems like clusters of innovation within petrochemicals and finally 4) techno-economic paradigms. The fourth level, changes of techno-economic paradigms, entail clusters of continuous and radical innovations and new technological systems. These paradigm shifts entail great leaps in improvements in productivity. Changes in techno-economic paradigms show a cyclical development, thus called structural cycles (Schön 2000: 19-34). These structural cycles consist of a crisis phase, a transformation phase, a rationalisation phase and eventually a new crisis phase. It is during the crisis phase that new cluster of continuous and radical innovations and new technological systems are introduced. Later in this transformation phase when the technology has been spread and the rationalization potential in this technology has been exhausted, one can see a focus on rationalisations through changes in the organization of work, for example the introduction of lean production concepts (Isidorsson 2001: 326-31, 340-41). The changes of techno-economic paradigms or structural cycles show great similarities with the so-called Kondratiev cycles, the 40-50 year long business cycles founded on empirical findings presented by the Russian economist in the 1920s. A new structural cycle is coupled with a cheap key factor. The previous two transitions to new structural cycles were accompanied by cheap steel and electricity at the turn of the 19th century and the next structural cycle was coupled with cheap oil products in the 1940s and 1950s. Cheap microelectronics play the same role for the present structural cycle as steel and oil did for the previous two. A main point with these structural cycles and the techno-economic paradigm shifts is their profound significance for the technological as well as the organizational system.

It is in this perspective that new concepts of production, new models of management and new work organization should be interpreted. If there is a rationalisation potential in introducing the new technology then it diffuses in the economy. In the present techno-economic paradigm the concept of lean production is important for understanding the development towards the use of different strategies for flexibility. Central to this production concept is efforts to reduce costs of production, implying just-in-time and elimination or reduction of stocks and buffers. Another characteristic of this production concept is the notion of customer satisfaction. Due to microelectronics it is also now easy to offer a large variety of products. Production for stock is becoming more expensive and uncertain. Microelectronics is also an important prerequisite for the timing of just-in- 
time production and the communication and logistics between a factory and its sub-contractors.

Companies that practise lean production are very exposed to changes in demand. Because of the lack of buffers and stocks, changes in demand must be absorbed within the work organization. This implies an ability to adjust the production volume, that is, capacity flexibility. A flexible production concept puts new demands on the staff; moderate changes in demand must be absorbed within the work organization. In periods of high demand the firm or organization must increase its production capacity. This can be done by any of the three strategies mentioned earlier: numerical flexibility, working time flexibility or functional flexibility. If numerical flexibility is used this involves hiring new personnel, which could be agency workers, temporarily employed or permanently employed, depending on the duration of the expected increase in demand. The choice of category of personnel depends on institutional factors such as employment legislation and collective agreements. If working time flexibility is used this entails increased working hours for personnel. The third strategy, functional flexibility, requires a flexible work organization where employees can vary the work tasks depending on the actual demand situation. In periods of high demand functional flexibility could mean that personnel concentrate on direct production, thus moving personnel from work tasks with less acute time-limits such as monthly administrative reports. In case of falling demand the strategy for flexibility has to be used the opposite way around. If numerical flexibility is used this implies reduction in personnel, initially by not prolonging fixed-term contracts or no longer using agency workers. Working time flexibility entails decreased working hours for the employees. In case of functional flexibility personnel have to move to areas with a higher demand or to move to indirect work tasks.

In manufacturing the traditional way of adjusting production to changes in demand has been the use of overtime or to hire or lay off employees. A major drawback with both hiring and laying off employees is that it takes at least a month before it comes into effect. A specific drawback with lay offs is that it also may disquiet among employees about employment security among employees, thus being counterproductive for the organization. A disadvantage with overtime is that it only functions in case of increased demand. Much depends on context. The high unemployment rate in Sweden in the mid 1990s lead to a very low rate of labour turnover in companies. In the 1980s, when labour turnover could be 25 per cent, it was possible to balance production volume and the number of employees with a hiring freeze. When one out of four of the employees left on their own initiative, the employer did not have to give notice, thus making it easy to reduce the staff merely by introducing a temporary freeze on employment. Furthermore, temporary layoffs are coming to an end in Sweden since the government has withdrawn its financial support of the insurance covering this (Håkansson and Isidorsson 1997). 
In the beginning of the 1990s there were massive reductions of employees with open-ended contracts, so called permanently employed. In the first half of the $1990 \mathrm{~s}$, the number of such contract fell from 3.6 million to 3.0 million or approximately 600,000 thus indicating that the expression permanently employed is quite misleading. The massive reductions of employees also meant that the previous high labour turnover decreased and the possibility of using a hiring freeze to achieve flexibility disappeared. During the second half of the 1990s, when the number of open-ended contracts on the Swedish labour market levelled out, the number of fixed-term contracts, also called temporarily employed, increased. The share of fixed-term contracts of all contracts increased from 10.1 per cent in 1990 to 15.9 per cent in 1999. This is equivalent to an increase of fixed-term contracts by roughly 50 per cent in eight years. Holmlund and Storrie (2002) argue that the share of fixed-term contracts correlates to the actual business cycle. The share increases in times of recession and decreases slowly in times of recovery. However, the share of fixed-term contracts was on a considerably higher level in the end of the 1990s and early 2000s than it was in the beginning of the 1990s. Indicating a shift in the use of temporarily employed workers on the Swedish labour market, we suggest that one major explanation for this is a need for firms and organizations to adapt to changes in demand. Also Holmlund and Storrie (2002) find this explanation plausible.

The requirement of flexibility has produced demands for changing the legal regulation of employment. In several countries in Europe, including Sweden, there has been a liberalisation of the regulation of fixed-term contracts (Vigneau et al. 1999). One Swedish example is the employer's absolute right to employ personnel on a temporary basis.

To conclude, the main driving force for flexibility is new productions concepts. However, the choice of strategy for flexibility is dependent on institutional contexts such as labour market legislation, collective agreements and the power balance between the labour market parties. In countries with relatively little security of employment, it is easy to use numerical flexibility with the 'hire and fire' strategy. The union is then more anxious to implement a strategy for flexibility that increases employment security for the permanent employees. In Sweden, with greater employment security and experience in new forms of work organization such as semi-autonomous work groups, unions seek solutions that combine flexibility and posibilities for upgrading employees' skills. The Swedish metalworker's union, for example, supports working time flexibility and functional flexibility.

\subsection{Strategies for Flexibility}

John Atkinson has created a theoretical model of The Flexible Firm, which to a large extent has dominated the theoretical discussion of flexibility (Atkinson 1984). Atkinson's model, which could be regarded as an ideal type, should be 
treated as an analytical tool for describing different types of flexibility and their effects on work organization. Atkinson distinguishes three strategies for flexibility: functional, numerical and financial. Later distancing was added as a fourth strategy (Atkinson and Meager 1986).

According to Atkinson, a workplace can achieve functional flexibility by alternating between different tasks or between indirect and direct production jobs. This kind of flexibility presupposes a core of multi-skilled workers. These workers have skills specific to the firm and are therefore not easily replaced. They have to be ready to alternate between different tasks and be willing to accept training and retraining. The more work tasks the employees can handle, the greater the potential for flexibility. The pay system rewards acquisition of new skills. These core workers have secure employment.

Numerical flexibility implies variation in the number of employees. The aim is to exactly match the number of employees to current demand. According to Atkinson a workplace can achieve numerical flexibility by contracting temporary employees, by hiring personnel from temporary work agencies, or by using subcontracting manufacturers and entrepreneurs. Numerical flexibility requires work tasks that can be carried out by unskilled workers or workers with skills that are not firm specific such as electricians, welders and data system programmers. These groups are easy to replace. They therefore become a peripheral group of workers, to be 'hired and fired' depending on the number of orders. The peripheral group of workers are not necessary unskilled workers, but their skills are general. This group consists of workers on fixed-term contracts, part-time and job-sharing. The most important distinction is not between white and blue-collar workers but rather between workers with firm-specific skills and general skills. The workers with firm-specific skills belong to the core and the workers with general skills belong to the periphery.

The third strategy, financial flexibility, reinforces functional and numerical flexibility. Different forms of pay systems, such as extra bonuses given to multiskilled workers, reinforce the possibility of using functional flexibility.

The fourth strategy, distancing, implies outsourcing and subcontracting of parts of the business. According to Atkinson and Meager, this is an alternative to flexibility rather than another form of flexibility (Atkinson and Meager 1986). The theoretical model of Atkinson and Meager is shown in Figure 6.1 below. 


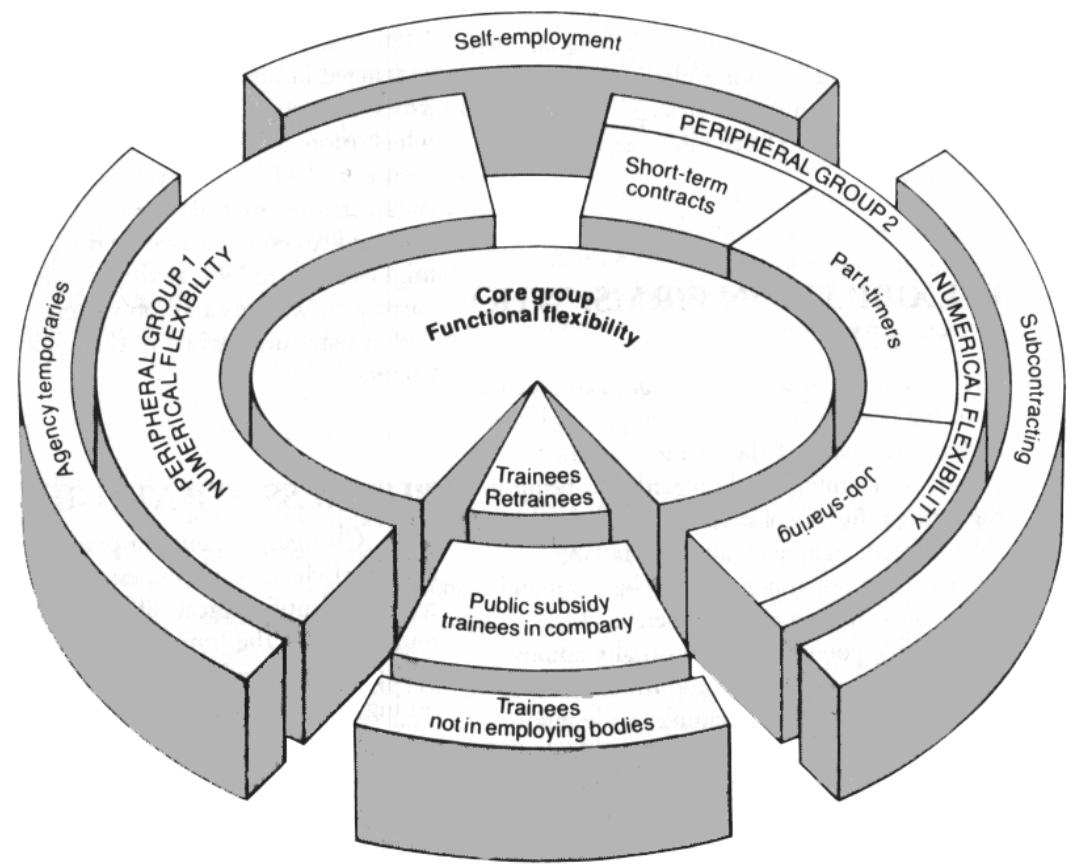

Source. Atkinson and Meager (1986: 4).

The figure shows the core group in the centre encircled by the peripheral group and an outer circle of agency temporaries, self-employment and subcontracting. The figure is somewhat modified since it first appeared in 1984, primarily by distinguishing trainees. In the core group training can be used as functional flexibility, i.e. in times of low demand personnel can shift to training/retraining. However public subsidy trainees in the first peripheral group cannot be used in a principally different way than other temporary employees. The most important feature is thus their employment status, not whether they are trainees.

Atkinson and Meager treat financial flexibility as an independent strategy but emphasise that it is a strategy aiming to reinforce numerical and functional flexibility (Atkinson and Meager 1986: 4). Notably financial flexibility or pay flexibility is not included in the figure above. In our terminology we have not treated financial flexibility as a strategy for flexibility since this form of flexibility cannot be used alone to achieve capacity flexibility.

Working time flexibility means variation in working and operating hours in a manner that corresponds to current demand. Atkinson and Meager include flexible working time in numerical flexibility (Atkinson and Meager 1986: 3-4). Our 
studies show that numerical flexibility and working time flexibility can be used separately under different conditions and that they generate different results for individuals, work organization and labour market. We therefore argue for treating flexible working time as a separate strategy. In our analysis the three strategies for flexibility are consequently numerical, functional and working time flexibility. Numerical flexibility is achieved by engaging external resources; working time flexibility and functional flexibility are internal strategies. The employees are used more effectively. All three strategies are inter-linked with work organization and competence levels of employees. The three strategies can be combined, but different combinations lead to different results.

Atkinson and Meager do not distinguish between different kinds of fixed-term contracts. In their model, all types of fixed-term contracts belong to the peripheral group at the workplace. The division into core and periphery, also called primary and secondary workers, signify a dual labour market. According to theories of the dual labour market the primary workers are well paid and have favourable possibilities to competence development and career while the secondary workers have worse employment conditions, are low paid and have limited possibilities for a career (Toft 1987). The different types of fixed-term contracts are mainly leave replacement, project, probationary, seasonal and on-call. We do not think that all types of fixed-term contracts can be classified as secondary work. This is in accordance with findings from Aronsson et al. (2000). Probationary workers and project workers have greater chances to develop and learn new tasks at work than other groups of temporary workers, greater even in comparison to permanent employees. Probationary and project workers also get more training and experience better opportunities to influence how to perform the work tasks compared to other temporaries. On-call workers and seasonal workers, on the other hand, have limited possibilities to influence their work. They get less training compared to other groups of temporary workers and they are more pessimistic about their chances to develop new skills at work. Atkinson's theoretical model does not take this aspect into account. In Atkinson's model all temporary employees belong to the periphery.

We also criticise Atkinson's model for assuming that all kinds of fixed-term contracts imply capacity flexibility. Probationary work and leave replacements are two types that do not aim at flexibility. The idea of probationary work is to ensure the fit of the person to a specific job and then employ the person on an open-ended contract. The aim of using leave replacement is to replace an absent employee, not to temporarily increase the staff. On the other hand seasonal workers and on call workers correspond directly to a temporary need for more personnel. In addition these groups can be used for the purpose of replacing absent employees. Project workers can be used both for capacity flexibility and specific projects for which it is not possible or desirable to use permanent employees. Due to varying working conditions and the different function of the fixed-term 
contract, we argue that it is important to distinguish between different types of fixed-term contracts when discussing numerical flexibility.

In Atkinson's model there is an assumption that functional flexibility implies multi-skilled workers. The flexibility is in this case achieved by work enlargement and work enrichment. In addition we argue that functional flexibility can be achieved in a more simple way, through a redistribution of employees working with different products but similar work tasks. Assuming different products do not have the same demand cycles; it is possible to move employees between similar work assignments in different departments. The car factory Opel in Rüsselsheim can serve as an example. The factory produces two car models, Omega and Vectra. Assuming that the different products do not have the same demand situation, it is possible to move employees between the two production lines. This may not change the work tasks of the employees. For example, the assembly of rear-view mirrors is the same on both models. This type of functional flexibility may not require work enlargement or multi-skilled workers.

We argue that the term functional flexibility should be used only when describing a strategy aiming at capacity flexibility, that is an adaptation to the current demand situation. Frequently, functional flexibility is used synonymously with work enlargement. For example, functional flexibility has been defined as the use of teams, job rotation, flattening of management structures and/or greater involvement of lower-level employees (Kalleberg 2001). These definitions of flexibility do not differ from the traditional definition of work enlargement and work enrichment in socio-technical research. We question this definition of functional flexibility because it does not necessary imply capacity flexibility. Work enlargement and work enrichment only serve as functional flexibility if the workers alter between production tasks, administration and planning according to demand.

\subsection{Prerequisites for Using Different Strategies for Flexibility}

Our research shows that the three strategies for capacity flexibility require different work organizational settings. The use of numerical flexibility requires work tasks with only brief introduction to the workplace. This does not necessarily mean that temporarily employed or agency workers are low skilled workers. Numerical flexibility requires standardised work tasks but the standardisation can be designed in different ways. The point is that the temporaries' skills are general and they are therefore easy to replace even if their skill levels are relatively high level. Findings in the Information and Communication Industry indicate that numerical flexibility is used in system development such as writing programme codes. This group is highly skilled; usually personnel in these positions have a university degree. However, programming is seen as the least qualified work in this group (Isidorsson 2002). 
Institutional settings also affect the use of numerical flexibility. One factor is the possibility of recruiting personnel. In times of high unemployment there is surplus labour available, workers are in weak power positions and therefore forced to accept employment conditions offered by the employer. The regulations of open-ended contracts influence the use of fixed-term contracts. Empirical findings suggest that strict regulation of open-ended contracts contributes to the use of fixed-term contracts (Holmlund and Storrie 2002). Countries with a high degree of regulation have a larger share of fixed-term contracts compared to countries with less regulation. Industrial Relations are in many ways similar in the four Nordic countries, Denmark, Finland, Norway and Sweden. However, the regulation of open-ended contracts is somewhat different. The regulation of open-ended contracts is fairly strict in Finland, Norway and Sweden. Denmark, with less regulation, diverges from the Nordic pattern in this respect. A conclusion is therefore that fixed-term contracts not are suitable as indicators of the level of numerical flexibility in a country; institutional settings must be taken into account in cross-national comparisons.

A company can achieve working time flexibility in different ways. Working time flexibility always implies longer working days or weeks in peak order time and consequently shorter working days or weeks in periods with low demand. Our research shows that there is a strong connection between the employees' work tasks and their conception of acceptable level of working hours. The work organization and tasks are the main restrictions affecting the maximum working hours. Employees having predefined and simple work tasks, such as working on the assembly line for example, are less willing to work longer than eight hours a day (Survey 1995, Survey 1996). By contrast, employees with more complex and independent work tasks are more willing to work longer days. The degree of complexity and independence in the work thus seems to determine how many hours the employees are willing to work (Håkansson and Isidorsson 1997, Åkerstedt 1996). To facilitate the use of working time flexibility it is important to enlarge or enrich the work tasks and increase the possibilities that workers can influence how and when to do the tasks.

When the workplace uses functional flexibility some basic prerequisites must be fulfilled. When alternating between different products, there has to be different patterns of demand for the different products. When shifting between different work tasks, there has to be different workloads for different work tasks. The latter kind of functional flexibility also entails multi-skilled personnel.

\subsection{Consequences of Using the Different Strategies for Flexibility}

The different strategies for flexibility lead to different consequences on an individual level, on a work-place level and on the labour market. In the following 
pages we will analyse consequences on these different levels. Some forty case studies, mostly in manufacturing and retail trade, are the basis of this analysis. All the companies studied had implemented at least one strategy for flexibility. Our aim was to find out what consequences followed from each strategy. In addition to interviews with managers and union representatives, we also conducted field observations on site in most of the companies. In each case we collected information on how flexibility was used, how the amount of flexibility was estimated and how the work organization was influenced by or adapted to the chosen strategy for flexibility. We used questionnaires to the employees in a few cases that made it possible to draw conclusions about the impact of capacity flexibility for the individual employee.

A longitudinal study of 1700 temporary employees in Sweden during a fouryear period supplements the analysis of consequences of numerical flexibility. The point of departure for this study was the theoretical discussion about the division into core and periphery at workplaces which use temporary employed. The longitudinal approach made it possible to answer the question to what degree temporaries got permanent jobs and to what degree they stay in temporary employment but with different employers. The latter would indicate a division in core and periphery on the labour market. The study is based on statistics on individuals from the Swedish labour force survey (LFS) and data from the Swedish National Labour Market Administration and The Swedish National Tax Authority.

To sum up, the use of different methods, that is case studies of workplaces, questionnaires to employees, official statistics and longitudinal data on individuals, makes it possible for us to draw conclusions at different levels.

\subsubsection{Consequences for Individuals}

Our research shows that all strategies for flexibility lead to increased work intensity for personnel, not by a higher work pace but through a rationalization of periods with low workload. With all strategies the idea is to minimize the slack. For the employees this means a constant full workload without periods of less intensive work. Companies using numerical flexibility strive to employ a minimum of personnel that, independent of business or demand cycle, have a full workload. In periods of demand above the minimum level, companies increase staff by hiring temporaries or by using agency workers. For the temporary personnel this means that they only work in periods of high workload. When a company uses working time flexibility the workload for the personnel is constant but the number or working hours can vary. In periods of decreased demand managers reduce working time and thereby operating hours. In periods of high demand the number of working hours is increased. Functional flexibility also intensifies the individual's workload. Employees are occupied with different tasks depending on demand. Functional flexibility admits competence development and other activities aiming 
at work enrichment and/or work enlargement. These activities, especially competence development aiming at work enrichment, can involve time for reflection and could therefore balance the increased intensity.

For the individuals, all strategies lead to increased uncertainty but different types of uncertainty for different strategies. With working time flexibility, the uncertainty involves when employees have to work. When a workplace uses functional flexibility, the uncertainty is where the employees will work or what they will work at. Finally, with numerical flexibility, the uncertainty for the temporarily employed is if they have any work. It is also important to bear in mind that the strategies for achieving flexibility today are used to adapt human resources to production and demand, not to adapt working life to individual needs as when "flexitime" was introduced in the 1970s. On the contrary, even when employees today can influence working conditions, flexibility is established under the employers' conditions to fit production needs.

All strategies also lead to increased employment security for employees with open-ended contracts. Reductions in demand are met by reduced working time, less use of temporary personnel or variation in work tasks, thus offering secure employment to employees on open-ended contracts. The use of numerical flexibility leads to fewer, but more secure open-ended contracts and more temporary, insecure contracts.

In a study of atypical employee's perception of job prospects, Furåker and Berglund (2001: 60) state that the ratio of temporary employed who agreed with the statement "my job is secure" was one fourth of that of permanently employed. One important dimension of insecurity is income. According to a study by Isaksson et al, employees on fixed-term contracts are less likely to bring about the desired level of employment than employees in temporary work agencies (Isaksson et al. 2001). In Sweden agency workers in general are employed on open-ended contracts. Their collective agreement entitles them to a guaranteed income of 75 to 85 per cent of their full time salary.

Several studies show that, in the private sector, insecurity in employment and related problems also affect health and well being (Aronsson et al. 2000, 2002; Benavides et al. 2000). In addition to insecurity in the private sector, we stress that people with certain types of fixed-term contracts are exposed to those simple, routine tasks that could easily be separated from other tasks.

In the discussion on temporary workers, there is a myth that employees desire fixed-term contracts (Bodin et al. 1996; Lundgren 1997). According to this myth, a fixed-term contract gives a form of independence which especially young people prefer. The temporaries are supposed to be 'free' to choose between different jobs, and to have the possibility of long holidays for travelling. According to a Swedish survey there is very strong preference for open-ended contracts. 87 per cent of all temporarily employed prefer an open-ended contract. This also holds true for young people (SOU 1999: 208-16). The preference for employment secu- 
rity is not a specific Swedish phenomenon. It applies to a majority of workers in Europe.

From the employer's perspective, it has been argued that fixed-term contracts benefit both employers and employees. They create flexibility for the employer and for the temporarily employed they provide a stepping-stone into the labour market. In our research we have examined this statement critically. We argue that the use of fixed-term contracts does not necessary imply flexibility. Some forms of fixed-term contracts, like probationary work and leave replacement, do not imply flexibility. We also argue that temporary employment as a stepping-stone to the labour market is only partially true. This is shown in our longitudinal study of 1,700 workers with fixed-term contract in Sweden. The following table shows what happens to the temporary employed during a two-year period. We distinguish different labour market status for employees who had fixed-term contract. The labour-market status indicates varying degree of occupation, from openended contract to long-term unemployment. Labour market status for temporaries during a two-year period is shown in table 6.1 at the top of next page.

Table 6.1. Labour-market status during a two-year period 1994-1996 for people who had a fixed-term contract 1994.

\begin{tabular}{lc}
\hline Labour-market status during a two-year period & Per cent \\
\hline Getting an open-ended contract & 38 \\
Alternating between different fixed-term contract & 20 \\
Alternating between fixed-term contract and unemployment & 37 \\
Long term unemployed & 1 \\
Out of the work force & 4 \\
\hline Total & 100 \\
$\mathrm{~N}$ & 1666 \\
\hline
\end{tabular}

Source: SCB, Statistics Sweden. AKU and ALDA. Authors' tabulation. Probability: $C^{2}{ }^{2}=0.001$

Our study shows that four out of ten employees with fixed-term contracts had an open-ended contract within a two-year period. However, just as many alternate between temporary work and unemployment. The transition from a fixed-term contract to an open-ended contract is dependent on the type of fixed-term contract. The differences between special types of fixed-term contracts are shown in Table 6.2. 
Table 6.2. Labour-market status during a two-year period 1994-1996 for employees who had different types of fixed-term contract 1994.Column percentages.

\begin{tabular}{|c|c|c|c|c|c|c|c|}
\hline Type of fixed-term contract 1994 & $\begin{array}{l}\text { Proba- } \\
\text { tionary }\end{array}$ & $\begin{array}{l}\text { Leave } \\
\text { replace- } \\
\text { ment }\end{array}$ & Project & On call & Seasonal & Holiday & Others \\
\hline \multicolumn{8}{|l|}{ Labour market status 1994-1996 } \\
\hline Open-ended contract & 76 & 40 & 42 & 31 & 29 & 20 & 29 \\
\hline $\begin{array}{l}\text { Alternating between different } \\
\text { fixed-term contract }\end{array}$ & 5 & 24 & 22 & 17 & 6 & 21 & 21 \\
\hline $\begin{array}{l}\text { Alternating between fixed-term } \\
\text { contract and unemployment }\end{array}$ & 13 & 32 & 34 & 44 & 62 & 46 & 46 \\
\hline Long term unemployed & 5 & 1 & 1 & 2 & 0 & 0 & 3 \\
\hline Out of the work force & 1 & 3 & 1 & 6 & 3 & 13 & 1 \\
\hline Total & 100 & 100 & 100 & 100 & 100 & 100 & 100 \\
\hline $\mathrm{N}$ & 114 & 622 & 287 & 268 & 96 & 135 & 144 \\
\hline
\end{tabular}

Source: SCB, Statistics Sweden. AKU and ALDA. Authors' tabulation.

Probability: $\mathrm{Chi}^{2}=0.001$

Within a two-year period, three out of four probationary workers had open-ended contracts. This seems to support the stepping stone hypothesis. The result is not remarkable though. The aim of a probationary contract is to find out whether the employee is suitable for an open-ended contract. However, this kind of contract does not imply any capacity flexibility at the workplace.

As stated above two of the groups are primarily used in order to achieve capacity flexibility: on-call workers and seasonal workers. The stepping stone hypothesis holds true for only 30 per cent of seasonal workers and on-call workers. These two groups are also most exposed to unemployment. Nearly two thirds (62 per cent) of workers on seasonal contracts shift between work and unemployment within a two-year period. For on call workers, this holds true for nearly half of them.

Holiday workers are the group with the fewest open-ended contracts after a two-year period. This group consist mainly of students, and the result is therefore not surprising. However, employees with holiday contracts not only alternate between holiday work and studies, they are also to a large extent unemployed.

Employees on leave replacement contracts and project contracts change to open-ended contracts to the same degree, 40 and 42 per cent. These groups have less risk of unemployment compared to the other types of contracts, with the exception of probationary work.

The type of fixed-term contract is not the only explanation of the labourmarket status these employees achieved in a two-year period. Other important variables are gender, age, education level and citizenship. However, for employees with different types of fixed-term contracts, the variations in the possibilities 
of getting an open-ended contract remain, even when the other variables are taken into account. The effects of all variables are shown in a logistic regression (see appendix on page 150). The function of the fixed-term contract seems to be important for the opportunity to acquire an open-ended contract. Using leave replacement as reference, employees working on probationary contract have better opportunities to achieve an open-ended contract while on-call workers, seasonal workers and project workers have fewer possibilities. This result holds true independent of gender, age, educational level etcetera. Accordingly, there is no evidence supporting the stepping stone hypothesis when the function of the temporary workers is capacity flexibility.

Our results indicate that there is a core-periphery dimension among the employees with fixed-term contracts as to the possibility to acquiring an open-ended contract. This dimension conflicts with the conventional division into coreperiphery in which the core consists of workers who have favourable work conditions. Workers on leave replacement contracts fit in the periphery as to work conditions but belong to the core regarding the possibility of achieving an openended contract. The opposite holds true for employees with project contracts.

\subsubsection{Consequences at Workplace Level}

All three strategies for flexibility imply rationalisation. Periods with low demand are linked to reduced staff, reduced working hours, or a redirection of job assignments to requested ones. However, the strategies lead to different consequences at the workplace level. Furthermore, one single strategy can result in different outcomes at the workplace level. Our study in the engineering industry shows that workplaces using numerical flexibility can either place the temporaries in special teams or integrate them into the ordinary teams. The former results in a segregation of employees into two groups: a core group of multi-skilled employees and a peripheral group of temporary workers doing the simple work tasks as described in Atkinson's model. This also includes a segregation in employee training and participation in the teams. Our study shows that when the temporaries are integrated into the ordinary teams, this results in a stagnation of competence and work development for the permanent employees in the team. The work tasks have to be at a simple level with short introduction time to facilitate the use of temporary workers. There is an absence of participation and employee training for all workers (Håkansson and Isidorsson 1997). In this case, the permanent employees can hardly be characterized as core workers. Our results underline the importance of taking work organization into consideration when analysing flexibility in workplaces. This is neglected in Atkinson's theoretical model The Flexible Firm.

Our study also shows that the use of numerical flexibility influences labour relations at the workplace level. For local unions one of the most important factors in making an agreement or a settlement with management has been employment 
security. However this holds true for those already employed. Local unions, but also management, see the negative aspects of giving notice to employees. From a local union perspective, dismissals create uncertainty among members/workers. Experience shows that employees, despite long service, cannot be sure of keeping their job in times of dismissals. Managers in companies investing in training are unwilling to loose these investments. In addition, giving notice to permanent staff is seen as creating a negative atmosphere that affects productivity. Using workers on fixed-term contracts or agency workers could avoid this. On the other hand our case studies show that social integration on the workplace is affected in a negative way by using numerical flexibility. From a union perspective there are several drawbacks to numerical flexibility by using agency workers. Who is going to represent the agency workers? They might not even be organized in the same union. Even if they are organized in the same union their loyalties are unclear. Is their prime loyalty to their temporary workplace or to the temporary work agency? For the unions, it is hard to organize agency workers. Daily union work among such members is almost impossible.

Changes in the balance of industrial relations are also revealed in other ways. We have witnessed examples where management have used their agency workers to weaken the local union's negotiating power. In one organization the permanent employees and the local union were dissatisfied with the behaviour of management. In order to achieve better working conditions the workers refused to work overtime. This was however countered by management by asking already employed temps to work more (Håkansson and Isidorsson 1997: 54-60). These results are supported by findings in a study by Sten E. Navrbjerg. According to his study the use of strategies for flexibility weakens union power. The main reason for this is differences in employment security (Navrbjerg 2001: 79).

A company using working time flexibility can respond to fluctuations in demand by adjusting working hours and by that also operating hours. In practice changes in working time are difficult to match perfectly to changes in demand. Our studies show that agreements allow for \pm 10 per cent variation in working hours. However, the potential for flexibility downwards is greater since it is possible to reduce working time to nil for limited periods of time. The agreements also include some kind of due notice. In our case studies the span was two days to four weeks (Håkansson and Isidorsson 1997). In times of high demand there is less need for recruitment. Instead management can increase operating hours by introducing longer working hours. In times of low demand they can reduce working hours for employees and thereby reducing the risk of dismissals. The company can keep a stable staff and turnover stays low. A stable work force also facilitates possibilities for training and developing the work organization. However, our research shows that companies using working time flexibility tend to see all working time as production time, thus neglecting time for training, competence development and activities aiming at improving routines. 
Functional flexibility also results in less labour turnover at the workplace level. One advantage with this kind of flexibility is that it works instantly and is therefore the fastest strategy in adapting to changes in demand. On the other hand, more complex forms of functional flexibility require personnel with a broader competence profile. If personnel do not have this, time must be allocated prior to the introduction of functional flexibility. This type of functional flexibility also permits developing the organization of work. In times of low demand, employees can be redirected to indirect work such as administration, planning and employee training or transferred to departments or sections with higher demand.

According to Navrbjerg, the use of functional flexibility may also challenge the union in another way. Core workers get favourable work conditions such as influence and responsibility. These workers are therefore committed to the employer and may not need the union to the same extent as do peripheral workers (Navrbjerg 2001:81). So both numerical and functional flexibility may weaken the union.

\subsubsection{Consequences at Labour Market Level}

On a macro level the use of working time flexibility as well as functional flexibility probably leads to a more stable labour market. In times of economic upswing, companies can increase the number of working hours or reorganize the work tasks. There is less need for new recruitment. In times of economic recession on the other hand, there is less need for layoffs. In case of flexible working hours, the employer reduces working hours. If the workplace uses functional flexibility, employees move to departments or sections with higher demand or turn to indirect work tasks such as training. Both strategies would reduce the need for companies to recruit staff. A lower turnover also makes it more difficult for newcomers to enter the labour market.

Numerical flexibility, on the other hand, leads to a higher turnover on the labour market and a reduction of open-ended contracts. Numerical flexibility makes it easier to get employment although not on a permanent basis. When discussing mobility on the labour market, the notion that the temporarily employed shop around like free agents between different jobs and employers is a myth. According to this myth, the mobility caused by fixed-term contracts is highly functional for the labour market. When one job is finished, another job at another employer starts, beneficial for employees as well as for employers. However, we have found that 50 per cent of the temporary employees are dependent on one sole employer (Håkansson 2001). When there is no more work in the company, the temporarily employed often becomes unemployed, he or she does not move to another company.

Previously we argued that it is important to distinguish between different types of fixed-term contracts. All types do not entail or aim at capacity flexibility 
at the workplace. Seasonal workers and on-call workers are most connected to capacity flexibility. Those types of fixed-term contract also involve a risk of long-term insecurity on the labour market. The use of numerical flexibility therefore leads to segregation between temporary employees and permanent employees.

For the labour movement the use of numerical flexibility means new challenges. Sweden has witnessed efforts by the unions trying to avoid agency workers becoming second-rate workers with second-rate payment and working conditions, so-called social dumping. To avoid social dumping all 18 unions within the LO and the Swedish Service Employers' Association have signed a national agreement. LO is the central organization for 18 affiliates that organize bluecollar workers within both the private and the public sectors. The Swedish Service Employers' Association organizes employers in the temporary work agency trade. The agreement is unique in so far as it is identical within all unions affiliated to LO. The agreement was drawn up with the assistance of LO, but signed by the 18 national unions. Since the early 1980s, centralised agreements on peak level have become unusual in Sweden. Since the early 1980s wage negotiations have been decentralised. The motive for LO to sign the temporary work agency agreement was twofold; besides avoiding social dumping the aim was to get all employees on the labour market within a collective agreement. A collective agreement means that all workers in a specific area have the same basic employment conditions. The main clause in the agreement states that agency workers are entitled to the same working conditions and the same payment as the ordinary personnel in the customer company. However the phrase 'with equivalent worktasks' is under dispute at several workplaces (LO 2000: $§ 5) .{ }^{23}$ For the employer's organization the agreement serves as recognition of the work agency trade on the Swedish labour market. (ALMEGA: 2000).

\subsection{Conclusions}

Prerequisites and consequences of different strategies can be summarised as in the following table:

\footnotetext{
${ }^{23}$ Interviews with ombudsman Bo Carlsson LO and ombudsman Håkan Löfgren LO 14 March 2002.
} 
Table 6.3. Prerequisites for and consequences of different strategies

\begin{tabular}{|l|l|l|l|}
\hline & $\begin{array}{l}\text { Working time flexibility } \\
\text { (Flexibility in working hours) }\end{array}$ & $\begin{array}{l}\text { Numerical flexibility } \\
\text { (Flexibility in the number of } \\
\text { employees) }\end{array}$ & $\begin{array}{l}\text { Functional flexibility } \\
\text { (Flexibility in work } \\
\text { organization) }\end{array}$ \\
\hline Prerequisites & $\begin{array}{l}\text { Facilitated by variation in work } \\
\text { tasks } \\
\text { Reduced working time }\end{array}$ & Short job introduction & $\begin{array}{l}\text { Different patterns of } \\
\text { demand for products or } \\
\text { work tasks }\end{array}$ \\
\hline $\begin{array}{l}\text { Consequences for } \\
\text { individuals }\end{array}$ & $\begin{array}{l}\text { Increased work intensity } \\
\text { Uncertainty as to when and } \\
\text { how long the employees have } \\
\text { to work }\end{array}$ & $\begin{array}{l}\text { Increased work intensity } \\
\text { Uncertainty for the temps as to } \\
\text { whether they have any work } \\
\text { Risk of long term insecurity }\end{array}$ & $\begin{array}{l}\text { Increased work intensity } \\
\text { Uncertainty as to where } \\
\text { the employees will work } \\
\text { or what they will work } \\
\text { with }\end{array}$ \\
\hline $\begin{array}{l}\text { Consequences at } \\
\text { workplace level }\end{array}$ & $\begin{array}{l}\text { Rationalisation of production } \\
\text { Less turnover }\end{array}$ & $\begin{array}{l}\text { Rationalisation of production } \\
\text { Segmentation in core and } \\
\text { periphery at the work-place } \\
\text { or } \\
\text { Stagnation in work develop- } \\
\text { ment }\end{array}$ & $\begin{array}{l}\text { Rationalisation of } \\
\text { production } \\
\text { Less turnover } \\
\text { Possibility to competence } \\
\text { development }\end{array}$ \\
\hline $\begin{array}{l}\text { Consequences at } \\
\text { labour market level }\end{array}$ & More stable labour market & $\begin{array}{l}\text { Segmentation into core and } \\
\text { periphery on the labour } \\
\text { market }\end{array}$ & More stable labour market \\
\hline
\end{tabular}

Management can use different strategies to achieve capacity flexibility. The theoretical model drawn up by Atkinson and Meager is very useful as an analytical tool even though we have made some critical remarks. Our main critique is that Atkinson's model neglects the importance of the work organization. The use of numerical flexibility does not necessarily lead to a division into a core of multiskilled workers and a periphery of low-skilled workers. Numerical flexibility can also be used in another way, by integrating the temporaries into ordinary teams. This results in work tasks with short introduction time for all employees in the team. The fusion of temporaries and permanent workers in the same team therefore prohibits the permanent employees from becoming core workers (in Atkinson's meaning of the term).

The use of strategies for flexibility affects labour market relations. This holds true especially for the use of numerical flexibility. At company level, both numerical and functional flexibility may weaken the union. The division into core and periphery creates two groups of workers with different employment security that in turn may weaken the union. In addition, the use of functional flexibility may reduce the core workers' need for a union. These workers get favourable work conditions by being core workers.

We stress that the analysis of capacity flexibility benefits from being extended to comprise not only the workplace level but also the labour market level and the individual level. The use of agency workers influences conditions for the union, locally as well as centrally. The local union works first of all for the workers em- 
ployed at the workplace. For agency workers the local union level is problematic, implying that the central union has become the most important level. The work conditions for agency workers are regulated in a central collective agreement.

At the individual level, all strategies lead to increased employment security for those already employed. In the case of numerical flexibility, this security is achieved at the expense of temporaries. One important result deriving from our research is that the use of numerical flexibility leads to a long-term insecurity for individuals working on contracts aiming at flexibility. The myth of temporary workers as free agents on the labour market has to be abandoned since our study shows that 50 per cent of the temporary employed are dependent on one sole employer. When the temporaries are not needed at one workplace, they often become unemployed. This means that the flexibility of the company is paid for by the temporary employees and indirectly by the unemployment insurance system.

\section{References}

Åkerstedt, Torbjörn (1996), 'Arbetstider, hälsa och säkerhet', in SOU 1996 no. 145, Appendix 12, Arbetstid; längd, förläggning och inflytande, Stockholm: Fritze.

ALMEGA (2000), 'Unikt bemanningsavtal ökar rörligheten på arbetsmarknaden', Press release, 20 April, ALMEGA Homepage: www.almega.se/caradoc/Pressmeddelande/ Unikt_bemanningsavtal_ökar_rör_A.htm.

Aronsson, Gunnar and Sara Göransson (1998), 'Tidsbegränsat anställda och arbetsmiljödialogen: En empirisk studie', Arbete och hälsa 1998 no. 3, Stockholm: Arbetslivsinstitutet.

Aronsson, Gunnar, Margareta Dallner and Tomas Lindh (2000), 'Flexibla inkomster och fasta utgifter - En studie av ekonomisk stress och hälsa bland korttidsanställda', Arbete och hälsa 2000 no. 20, Stockholm: Arbetslivsinstitutet.

Aronsson, Gunnar, Klas Gustafsson and Margareta Dallner (2000),

'Anställningsformer, arbetsmiljö och hälsa i ett centrum-periperiperspektiv', Arbete och hälsa 2000 no. 9, Stockholm: Arbetslivsinstitutet.

Aronsson, Gunnar, Klas Gustafsson and Margareta Dallner (2002), 'Work Environment and Health in Different Types of Temporary Jobs', European Journal of Work and Organizational Psychology, vol. 11, pp. 151-75.

Atkinson, John and Nigel Meager (1986), Changing Working Patterns: How Companies Achieve Flexibility to Meet New

Needs, London: National Economic Development Office.

Atkinson, John. (1984), 'Manpower Strategies for Flexible Organisations', Personnel Management, August.

Benavides, FG., J. Benach, A. Diez-Roux and C. Roman (2000), 'How Do Types of Employment Relate to Health Indicators? - Findings from the Second European Survey of Working Conditions', Journal of Epidemiology and Community Health no. 5.

Bodin, Mats, Christer Bredbacka and Eric Giertz (1996), I (o)takt med tiden. Om näringslivet av idag och dess kringapparat - av igår? Stockholm: SAF.

Carlsson, Bo, ombudsman LO, interview 14 March 2002 in Stockholm.

Freeman, Christopher (1992), The Economics of Hope: Essays on Technological Change, Economic Growth and the Environment, London: Pinter Publ.

Furåker, Bengt and Tomas Berglund (2001), 'Atypical Employment in Relation to Work and Organizational Commitment' in Bengt Furåker (ed.) Employment, Unemployment, Marginalization: Studies on Contemporary Labour Markets, Göteborg and Stockholm: Department of Sociology, Göteborg University; Almqvist \& Wiksell International, pp. 49-71.

Holmlund, Bertil and Donald Storrie (2002), 'Temporary Work in Turbulent Times: The Swedish Experience', The Economic Journal, 112 (June), F1-F25. 
Håkansson, Kristina and Tommy Isidorsson (1997), Flexibla tider: En studie av arbetstidsflexibilitet och andra flexibilitetsstrategier inom verkstadsindustrin. Stockholm and Göteborg: Svenska Metallindusriarbetsreförbundet; Göteborgs universitet, Internationella arbetslivsstudier.

Håkansson, Kristina and Tommy Isidorsson (1998), 'Flexibility and Competence', in Daniel Fleming, Pauli Kettunen, Henrik Søborg and Christer Thörnqvist (eds), Global Redefining of Working Life - A New Nordic Agenda for Competence and Participation? Copenhagen: Nordic Council of Ministers, Nord 1998:12, pp. 243-64.

Håkansson, Kristina (2001), Språngbräda eller segmentering? En longitudinell studie av tidsbegränsat anställda, Uppsala: Institutet för arbetsmarknadspolitisk utvärdering, 2001 no. 1.

Isaksson, Kerstin, Gunnar Aronsson, Katalin Bellaagh and Sara Göransson (2001), 'Att ofta byta arbetsplats. En jämförelse mellan uthyrda och korttidsanställda', Arbete och hälsa 2001 no. 7, Stockholm: Arbetslivsinstitutet.

Isidorsson, Tommy (2001), Striden om tiden: Arbetstidens utveckling $i$ Sverige under 100 år $i$ ett internationellt perspektiv, Göteborg: Avhandlingar från Historiska institutionen $\mathrm{i}$ Göteborg 30, Göteborgs universitet.

Isidorsson, Tommy (2002), Contingent Employment in the Information and Communication Technology Industry: A Swedish Case Study, Göteborg: Working Paper Series, Department for Work Science, Göteborg University.

Kalleberg, Arne (2001), 'Organizing Flexibility: The Flexible Firm in a New Century', British Journal of Industrial Relations, vol. 39, pp. 479-504.

Kern, Horst and Michael Schumann (1989), 'New Concepts of Production in West German Plants', in Peter J. Katzenstein (ed.), Industry and Politics in West Germany. Toward the Third Republic, New York: N.Y. Cornell U.P., pp. 87-110.

Kern, Horst and Michael Schumann (1990), Das Ende der Arbeitsteilung? Rationalisie rung in der industriellen Produktion: Bestandsaufnahme, Trendbestimmung, München: Beck.

LO (2001), 'Bemanningsavtalet - en enkel handbok', LO, Homepage: www.lo.se/bemanningsavtal /pdf/Handbok.pdf.

Löfgren, Håkan, ombudsman LO, interview 14 March 2002 in Stockholm.

Lundgren, Håkan (1997), Inställningen till olika kontraktsformer, Stockholm: SAF, Rapport från SAF Januari 1997.

Perez, Carlota (1985), 'Microelectronics, Long Waves and World Structural Change: New Perspective for Developing Countries', World Development, vol. 13, pp. 441-63.

Piore, Michael J. and Charles F. Sabel (1984), The Second Industrial Divide: Possibilities for Prosperity, New York: Basic Books.

SAF (1996), Arbete utan fast anställning: Om de förändrade relationerna på arbetsmarknaden, Stockholm: SAF.

SCB (Statistics Sweden), Labour Force Surveys 1994-1996.

Schön, Lennart (2000), En modern svensk ekonomisk historia: Tillväxt och omvandling under två sekel, Stockholm: SNS förlag.

SOU (1999), DELTA. Utredningen om arbetslöshetsersättning: Betänkande av Utredningen om arbetslöshetsersättningen och deltidsarbete m.m. Stockholm: Fritze, SOU 1999 no. 27.

Toft, Christian (1987), Labour Markets and Segmentation Theories, Aarhus: Studies in Labour market dynamics, Working paper 1987:5, Aarhus school of economics and business administration, Institute of Economics, Aarhus university.

UNICE. (2000) Press release Brussels, 3 May.

Vigneau, Christophe, Kerstin Ahlberg, Brian Bercusson and Niklas Bruun (1999), Fixedterm Work in the EU: A European Agreement Against Discrimination and Abuse, Stockholm: Arbetslivsinstitutet.

Womack, James P., Daniel T. Jones and Daniel Roos (1991), The Machine that Changed the World: The Story of Lean Production, New York: HarperPerennial. 


\section{Appendix}

Table 6.4. Relative effects on odds of getting an open-ended contract within a two-year period. Logistic regression.

\begin{tabular}{|c|c|c|}
\hline & Odds ratio & Level of significance \\
\hline \multicolumn{3}{|l|}{ Type of temporary contract } \\
\hline Leave replacement (reference) & 1.00 & \\
\hline Probationary work & 2.70 & $* * *$ \\
\hline Project work & 0.66 & $*$ \\
\hline Seasonal work & 0.42 & $* * *$ \\
\hline Holiday work & 0.28 & $* * *$ \\
\hline On call & 0.55 & $* * *$ \\
\hline Others & 0.43 & $* * *$ \\
\hline \multicolumn{3}{|l|}{ Sector } \\
\hline Industry (reference) & 1.00 & \\
\hline Hotel, restaurants, retail & 1.06 & $\mathrm{~ns}$ \\
\hline Health, care & 0.34 & $* * *$ \\
\hline Other sectors & 0.60 & $* *$ \\
\hline \multicolumn{3}{|l|}{ Socio-economic status } \\
\hline Higher white collar (reference) & 1.00 & \\
\hline Lower and middle white collar & 0.98 & $\mathrm{~ns}$ \\
\hline Blue collar & 0.96 & $\mathrm{~ns}$ \\
\hline \multicolumn{3}{|l|}{ Education } \\
\hline University (reference) & 1.00 & \\
\hline Upper secondary school & 0.58 & $* * *$ \\
\hline Comprehensive school & 0.64 & * \\
\hline \multicolumn{3}{|l|}{ Gender } \\
\hline Male (reference) & 1.00 & \\
\hline Female & 0.54 & $* * *$ \\
\hline \multicolumn{3}{|l|}{ Age } \\
\hline $16-24$ & 0.57 & $* * *$ \\
\hline 25-44 (reference) & 1.00 & \\
\hline $45-64$ & 0.63 & $*$ \\
\hline \multicolumn{3}{|l|}{ Citizenship } \\
\hline Swedish (reference) & 1.00 & \\
\hline Not Swedish & 0.64 & $*$ \\
\hline
\end{tabular}

$*=p<0.05, * *=p<0.01, * * *=p<0.001, n s=$ not significant at a 95 per cent level 


\title{
7. Decentralized Pay in the Danish Public Sector
}

\author{
Kirsten Bregn
}

\subsection{Introduction}

New Public Management has spread also to the Nordic countries. It could be argued that there is a special Nordic variant at the local level in the municipalities and counties, while the development in the state sector has been more in accordance with an Anglo-Saxon main stream (Klausen and Ståhlberg 1998: 197). In any case an important aspect of the development in Denmark is new pay systems, which have implicated nearly a revolution in the pay systems of the public sector (Bregn 1998a). Since 1997, we have seen a fundamental change take place. The payment systems have been changed from systems based on central and collective agreements to decentralized and individualized systems. Central goals of the new pay systems have been to improve efficiency and also to make public sector jobs more attractive. One of the most important aspects of the new pay system has been the introduction of pay supplements which are based on individual assessments.

The new public sector pay systems in Denmark have the following basic characteristics:

- supplements related to functions, qualifications and results can be added to basic pay

- the allocation of pay supplements is based on agreements between the employers and the employees' organization/the employees' representative.

- the amount and composition of the pay is open to the public according to the Danish law on right of access to documents in the public administration (Lov om offentlighed i forvaltningen).

It is the goal that the new pay system should result in better jobs and more motivated employees (Finansministeriet 2000a: 11). However, individual assessments based on subjective performance assessments could also be disadvantageous for the employees, as their income is partly dependent on assessments that do not necessarily mirror the performance of the employees. Thus from the employees' point of view there are a number of risks associated with individual subjective 
assessments. In the following, some causes of bias related to subjective assessments are considered. Various ways of restricting the possible arbitrariness in the assessments are discussed, especially those related to the system of agreements in the Danish public sector.

The perspective taken is primarily that of the employees. This differs from that offered in the publications of the public employer's organization, and from the perspective which dominates management literature. Murphy and Cleveland (1995) explicitly stress the potential conflict of interests between the employees that are assessed and the organization:

Our focus is here on the organization's perspective, and it is likely that the costs and benefits of performance appraisal to ratees will be quite different from those experienced by the organization. (1995: 325).

However, there is also a relation between the interests of the employees and public sector efficiency. If the assessments are not based on the goals of the institution, they will not increase efficiency in the public sector. If the subjective assessments result in negative effects on motivation and the work environment, they can negatively affect efficiency in the public sector (Marsden and French 1998: 35, 51; Marsden and Richardson 1994: 253, Marsden et al. 2001).

\subsection{The Change in the Danish Public Sector Pay System in Brief}

The collective bargaining round in 1997 introduced a new pay system at both central and local government levels. Basic pay is agreed through centralized collective agreements. In addition, supplements related to functions, qualifications and results can be obtained. These can be agreed both centrally and locally. In 1999, nearly all employees in both the municipalities and counties were permanently transferred to new pay systems. In 2002, the most recent round of bargaining, the number of groups that were transferred to the new pay systems were increased. During 2003 nearly 50 per cent of the employees in the state sector will be paid according to the new pay systems. This part will increase as newly employed members of organizations who have decided to transfer to the new system automatically are paid according to the new pay system.

Local agreements on pay supplements related to performance could be entered into by all employees in the public sector irrespective of whether they are on the old system or the new. Supplements can be based on both objective performance indicators that could be controlled by a third party and on subjective performance indicators that are not verifiable by a third party.

For employees on the new pay systems, supplements can also be given according to qualifications. Some qualifications, for example education and experience, are objective. However, the criteria could be more broadly defined to include personal qualifications i.e. responsibility, flexibility, stability, initiative, 
engagement and so on (Finansministeriet 1998: 47, Økonomistyrelsen 2000; Personalestyrelsen 2001b). This means that the difference between qualifications and performance is not clear as some of the criteria, which are related to qualifications, could also be seen as performance-related criteria.

In general the total amount of the pay supplements pursuant to the new pay systems is still rather limited. For employees on the new pay systems in the state sector 6.8 per cent of total pay was in 2001 based on supplements locally agreed (Personalestyrelsen 2001a: 59). It is, however, the intention of the public employers that the pay supplements negotiated locally should increase to 15-20 per cent of the total pay (Finansministeriet 1999b: 286; Hedegaard and Poulsen 1998: 22).

\subsection{Subjective Performance Appraisals - Some Sources of Error}

In contradiction to objective performance measures a third party can not verify subjective performance assessments and that leaves room for discretion. In general, the manager, who evaluates the employees, might have other interests than meeting the goals of the organization. Making the 'correct' assessments can be associated with costs if the assessments are negative and benefits can be obtained by making 'incorrect' assessments if the assessments are better than they should be. To give the managers incentives to follow the goals of the organization and not their own goals is a general challenge in relation to organizational design (Baker et al. 1988 613-15; Murphy and Cleveland 1995: 142, 213).

To give pay supplements could be seen as an element in a gift exchange (Akerlof 1982). By giving a pay supplement 'paying back' is expected. Thus Tirole (1986) has, based on sociological studies of the internal organization of the firm, explained behaviour in organizations as being based on a general norm of reciprocity by which favours are exchanged for favours.

At the individual level, the weighing of costs and benefits for the manager could mean that the employees who are expected to cause most trouble for the manager if they are dissatisfied receive better assessments. This could also mean that a manager would be inclined to reward popular employees at the expense of employees who have a better performance but who are less popular.

The manager who is working closest to the employees has better information about their performance. However, this manager would also have broader interests in relation to the assessments than upper level managers who do not have close relations to the employees. Even in a case in which assessments did not have any consequences it was found that the degree of contact had implications in terms of assessment bias. This was found in an experiment in which others' contribution to task completion should be rated in groups communicating either electronically or face-to-face. In the case of face-to-face communication, the lik- 
ing of individuals accounted for significant variance in ratings (Weisband and Atwater 1999: 636).

In-depth-interviews with 60 upper-level executives undertaken by Longenecker et al. (1987) showed that the managers' own aims and interests influenced the appraisals: 'Managers made it clear that they would not allow excessively accurate ratings to cause problems for themselves, and that they attempted to use the appraisal process to their own advantage' (ibid.: 191).

That the employees find that favouritism is prevalent and assessments are not fair are some of the general problems associated with assessments according to subjective evaluations (Lawler 1990, 87-88). Murphy and Cleveland (1995: 324) mentions that dissatisfaction with performance appraisal is the norm in most organizations, and there appears to be little human resource managers can do to improve the image of performance appraisal. Even if a successful system is developed, it is likely that enthusiasm for the system will soon wane, and in a few years the new system will look as bad as all of the ones that have come before it.

Prendergast and Topel (1993: 361) concluded that 'favoritism is extremely difficult to constrain' (Cf. also Prendergast 1999, 31; Lawler 1990, 72). Also in the empirical studies concerning performance-related pay in the public sector, it is a recurrent observation that the employees find that favouritism takes place and that assessments are not fair (Dowling and Richardson 1997: 356; Heery 1998: 87; Marsden and French 1998: 130, 136, 145; Marsden and Richardson 1994: 254; OECD 1993: 87; OECD 1997: 7). A considerable number of the employees in the British Inland Revenue found that performance-related pay had resulted in jealousy between staff and has helped to undermine staff morale (Marsden and French 1998: 31).

For the group of employees as a whole, a general tendency of 'leniency' (a general positive bias in the assessments), and a tendency of 'centrality' (to compress ratings) can be observed (Baker et al. 1988: 595; Heery 1998: 84-85; Kessler and Purcell 1992: 25-26; Kellough and Lu 1993: 51; Milkovich and Newman 1993: 314; Murphy 1992: 40ff; OECD 1993: 35-37; Prendergast 1999: 30, 607-8). These tendencies might also be understood in terms of reciprocity. However, there could also be other causes of compression as discussed below.

\subsection{Managers' Interest in 'Easy' Assessments and Discretion}

It could also be in the managers' interest to reduce the time spent in relation to assessments (Kessler and Purcell 1992: 26; Murphy 1992: 41). This could imply that differentiation between employees is restricted, especially when the decisions may have to be justified to dissatisfied employees. Employees who have been assessed positively are continuously assessed positively although their performance may have worsened, as it is too time consuming to reveal changes. In 
the same way employees who have earlier been evaluated as low performers could face difficulties in changing this assessment.

A study of the implementation of performance-related pay in local government in England (Heery 1998: 83) revealed widespread informality in the operation of the scheme. A number of the managers failed to carry out the interim appraisals kept appraisal interviews to a minimum and filled out the appraisal documents in a mechanical way.

A classical problem is that less visible, however important, activities are not noticed and therefore are not credited. For the employees, this means that they would have an incentive to allocate efforts to the activities that are observed and credited. In general, subjective assessment would give the employees an incentive to influence the assessment at the expense of productive activities (Milgrom 1988; Milgrom and Roberts 1988).

Even if the employees should be assessed according to specified criteria, it does not necessarily mean that the managers make the assessments in this way (Kessler and Purcell 1992: 26-27). An alternative is to make an overall assessment and afterwards to 'work backwards' (Heery 1998: 84). By administering a scheme based on specific criteria, in an informal way, the managers could increase their discretion. Longenecker et al. cite the following statement made by a manager: 'Occasionally an employee comes along who needs to be reminded who the boss is, and the appraisal is a real tangible and appropriate place for such a reminder.' (Longenecker et al. 1987: 189).

\subsection{Other Aspects Influencing the Assessments}

If pay is based on subjective assessments of the employees there is the risk that performance will be underreported to save wages (Prendergast 1999: 29). Marsden and Richardson (1994: 255, 257) report an example of this from the Inland Revenue. When the assessments were coupled with pay, the assessments were reduced compared to the earlier level.

Another cause of 'incorrect' evaluations can be that the assessments are manipulated to adjust the wages with the aim to attain labour in short supply. Assessments could then be influenced by the market rather than reflecting the performance of the individual employee.

Managers can also make the assessments in different ways. This means that the employees can be subject to arbitrariness dependent on the managers who make the assessments. Differences across an organization could, for example, occur if one part of an organization is dominated by managers which have developed relations with the employees over a long period of time, whilst other parts of the organization are dominated by new managers who generally make assessments that reflect actual performance (Lewis 1998). 


\subsection{Some Possible Ways of Reducing the Risk of Arbitrariness}

In the following, some possible ways of restricting favouritism and arbitrariness in the assessments are briefly discussed. Some general possibilities are presented, in particular those related to the fact that pay supplements are allocated within the system of agreements established in the Danish public sector.

\subsubsection{Publication of Pay Supplements and Reasons for Giving them}

If pay supplements could be kept secret from others than the employer and the employee, it is not necessary to legitimate differences in pay. More generally a discriminating monopsony with secret pay is economic advantageous for the employer (Mossin 1998). According to the Danish Law on right of access to documents (Lov om offentlighed i forvaltningen) it is not possible to keep the wage of the individual employee in the public sector secret. The size and composition of public sector employees' pay is subject to right of access to documents. However, the reasons for the pay supplements (e.g. the assessments behind a performance-related pay supplement) are not subject to the right of access to documents (Vogter 1998: 101).

Earlier, in the private sector, salaries and wages could be kept secret. However, a draft has been passed in June 2001 which implies that all employees have the right to inform anyone about his own wage (Lov om andring af lov om lige lon til maend og kvinder. (Lønoplysninger). Lov nr. 445 af 7. juni 2001). Although there is no public access to information this change means a convergent tendency towards the conditions of the private and public sector.

It seems as if men have been favoured by the new pay system, and that they in general have obtained a larger share of the amount paid as pay supplements (Alborg Kommune 2001; see also Fransson 2000; Ibsen and Christensen 2002). In general women's wages are still lower than men's. It was stipulated by the law mentioned above that all employers with at least ten employees on demand should be obliged to work out statistics showing wages differentiated in terms of sex and the criteria which are relevant for payment of the employees. The employees' representative could use the statistics, but it is otherwise confidential. This could have been an important means to promote equal pay for men and women. However the right wing government that came to power in the late 2001 has decided to postpone this statistics indefinitely.

If the pay supplements and the causes for giving them are published it could reduce the incentive to favouritism. Publication could also give information about the behaviour that is desired, thus providing an incentive for others to do likewise. A publication can also increase the value of the reward because a symbolic reward is added when others are informed about the reward. However, this symbolic element could also increase the distorting effects of assessments and supplements that are not considered fair. 
If reasons for giving pay supplements should reduce the room for favouritism and arbitrariness, the reasons should be specified. Often pay supplements in the Danish public sector are given based on 'a special effort' giving no concrete evidence (Mørk and Sørensen 2002).

\subsubsection{Performance-related Pay for Managers}

One way to give the manager an incentive to act in accordance with the organization's goals is to give the manager a pay supplement in relation to his ability to fulfil them. In the private sector, performance-related pay for managers are well known. In the public sector, performance contracts have been introduced (Finansministeriet 1999a: Ch. 1; Finansministeriet 2000c). Compared to a private organization it is, however, typically, more difficult to assess the performance because the basic goal is not reflected in a financial result. When performance is more difficult to assess it means that the costs associated with 'wrong' assessments are less visible.

In the contracts, which are entered with the directors of the Danish public sector organizations, the Ministry of Finance recommend that the management of the new pay systems i.e. the restriction on pay increases should be included in the contracts. This would give the managers an incentive to restrict pay increases under the new decentralized system (Finansministeriet 2000c).

\subsubsection{Quotas and Forced Distribution of Assessments}

The risk that performance is underestimated to reduce costs could be avoided if there is a quota for pay supplements. A consequence of this is, however, competition among the employees. If some of the employees choose to make a great deal of effort the outcome could be that the employees pressurise each other to work harder without getting a common reward. If the number of employees is rather small, the employees could collude and make agreements about their level of effort.

Forced distribution of the assessments which pay supplements are based on, setting a quota on the number that could be in the best group, the next best and so on, could be a way to avoid the tendency towards leniency and centrality mentioned above. However, it could also mean that cost considerations could not influence the assessments. Moreover, it could contribute to make the assessments in different parts of an organization homogeneous.

Forced distribution does, however, not ensure that the assessments are made more 'correctly'. On the contrary, a manager can be forced to make assessments that deviate from the 'correct' one. For example if many fulfil the demands necessary for the best assessments.

Forced distribution means a relative assessment of the employees and implies competition on the restricted assessments or competing on avoiding them. If the 
number of employees is restricted, a solution for the employees is also here collusion.

Relative assessments of the employees mean that the assessment of one employee depends on the performance of the others. In another unit, the employee could be assessed otherwise. This could be considered unfair. Moreover, it could also provide an incentive to employees to move to units where colleagues are perceived to be comparatively bad performers.

One possibility of reducing some of these problems is to regulate the distribution of assessments according to the performance of the unit as a whole. If the performance of the unit is improved, the number of employees that could obtain the best assessments is increased, too (Murphy 1992: 54-56). A precondition is, however, that it is possible to assess the performance of the unit, which is typically more difficult in the public sector than in the private sector.

\subsubsection{Various Assessors}

One possibility is to let more than one manager carry out the assessments of the same persons. This is, however, obviously associated with costs. Also the other assessors could, however, have other interests than making fair assessments. If the assessors believe that the assessments made by the majority are perceived to be the right assessments they would have an incentive to conform to the assessments which it is expected that others will make. The consequence is what is called yes men (Prendergast 1993). This does not promote dynamic. The assessors could also collude and co-ordinate their assessments to save time and costs associated with justifying variations in assessments (Tirole 1986).

Controlling managers' assessments by letting the employees assess each other could also be a possibility. The colleagues could have considerable information about the efforts of their colleagues. As a group the employees would have an interest in have the best assessments if the supplements were related to the level of the assessments. To avoid that the employees increase the wages by giving high assessments, it is necessary to limit the pool that could be paid out. The employees would, however, then be competing about the pool and have an interest in low assessments for their colleagues. Besides damaging the working environment it could also reduce efficiency in the organization.

As with managers' assessments, colleagues could be influenced of sympathies and antipathies. For the employees there would be an incentive to make coalitions supporting each other.

The assessments could also be confronted with self-assessments, which could be discussed at the appraisal interview. The bargaining power of the individual would, however, be decisive for the result. 


\subsection{Pay Supplements According to Individual Appraisal in the Danish Public Sector}

All pay supplements in the Danish public sector are given according to an agreement between the employer and the employees' representative or organization. An agreement can be made that the criteria as well as the individual pay supplements should be agreed. However, an agreement can also be made that the individual pay supplements should not be agreed. This is the case in the National Tax Tribunal. A performance related pay scheme prescribes that 69 per cent of a pool is distributed equally between all employees (however, graduated according to whether the employee is manager, professional or clerk), while 27 per cent is distributed according to an individual assessment of the employee according to criteria such as the number of finished cases, the difficulty of these, quality, efficiency, co-operation, initiative, flexibility, stability, service orientation and resource awareness (4 per cent is allocated to a staff club). The assessment of employees that are not managers is made by their managers after a consultation with the president of the organization. The employees' representatives are informed about the distribution (Landsskatteretten 2001).

In the Danish Competition Authority (Konkurrencestyrelsen) pay supplements related to qualification are also based on the managers' assessments. The employees are informed that the evaluation could be changed if the manager, the representative of the employees', and the board of managers agree to do so (Konkurrencestyrelsen 1998b).

Although the individual pay supplements are not negotiated, the employees' representatives could still have an indirect influence as an agreement can be cancelled - depending on the agreement concerning the period of validity - if it is realized that the management allocates pay supplements in a way which is not found to be acceptable. The possibility of control could, however, be limited, as it could be difficult to assess the managers' dispositions if one has not been involved.

To give the managers the right to allocate pay supplements according to their discretion is consistent with the aim of stronger manager roles, which is behind the pay reform (Ministry of Finance 1998).

For the employees' representative it can be an advantage to avoid the task of continuously assessing the colleagues in order to be able to participate in agreements on assessments and distribution of pay supplements to the colleagues (see also Navrbjerg et al. 2000). Also the subjective assessments made by the employees'representatives can suffer from many of the same biases as the mangers. At the same time as it is advantageous for the employees that the representative is taking part in agreements on the pay supplements according to subjective appraisals, it is also a large disadvantage as the representative is now participating 
in decisions about which of their colleagues who should have supplements and who not.

In larger workplaces, the employees' representative could also lack the information which makes it meaningful to bargain on the assessments of the employees. At the same time, the fact that the representative is not involved could create an informal room for the employees who could then contact the manager and bargain informally themselves. In particular, at academic workplaces it could be a desire for at least some of the employees to have this opportunity rather than being represented by a representative. It is remarkable that the committee for the largest organization for professionals 'The association of Danish lawyers and Economists' wants that it should be possible to agree on deviations from the general agreements that could open up for individual bargaining. It was suggested that this should be a demand in the next bargaining round (DJØF 2001). The chairman argued that it was in accordance with the demands of the day, with the needs of the employees and in accordance with more individualistic attitudes of demands of the younger generations. However, the representatives rejected the proposal among others because it would weaken the representatives and the association (Bøgelund 2001: 25). Newly research at local government levels showed that 60 per cent of the employees found that local supplements should be bargained by themselves (Madsen 2002:376).

For all employees in the public sector yearly meetings, employee development consultations, between the individual employees and the managers should be arranged. The public employers want that pay should also be discussed at these meetings. A study carried out in late 1999 found that pay was discussed at the development consultations in 18 per cent of the organizations in the state sector that were included in the study (Økonomistyrelsen 2000: 5.2). In the municipalities, the tendency is that the development consultation in the vast majority of cases included a talk about wage and the wage in the future (Kommunernes Landsforening 1999b: 126; Madsen 2002: 354). It could be said that it is in accordance with the basic ideas of the new pay systems that discussions of the further development of the employees' resources is also linked with discussions of the possibilities to be rewarded. The consequence can, however, be that the employees representatives are excluded form the process (KTO without printing year; AC 1997; Madse 2002). In the department of the Ministry of Finance, the representative has a very passive role. In reality the bargaining is taking place at the development consultations arranged between the individual employee and the manager (Hede 2001).

If the representative does not participate in the bargaining of the supplements, when the pool that is to be distributed and the way the pay supplements are given is fixed (this includes, for example, the question of permanent, temporary or oneoff pay supplements), the consequences are only related to the distribution among the employees. 
The situation is different if there is no pool, and supplements are given dependent on individual negotiations. If the representative is excluded from the process or is weakened in the bargaining process in such cases it would also have consequences for the total amount that the employees receive. This is because the individual employee will typically be weaker than the representative who is bargaining for all the employees. For example, the representative can threaten not to make agreements about pay supplements at all. This possibility makes no sense for individual employees.

If it is not possible to obtain an agreement, and an interest dispute occurs, the bargaining should - if one of the partners, the local management or the representative/the union wants - be continued with representatives from a higher level in the administration. In the state sector the bargaining could be carried on together with representatives from the ministry and the organization, and if there is still disagreement the bargaining can be carried on by the Ministry of Finance and the organization (Finansministeriet 2000d). In the municipalities and the counties bargaining could be continued together with rrepresentatives from The National Association og Local Authorities (Kommunernes Landsforening) or The Association of County Councils (Amtsrådsforeningen) and the organization. If there is still disagreement the bargaining can be carried on by Kommunernes Landsforening or Amtsrådsforeningen and the organization (KTO og de kommunale arbejdsgiverparter 1999: 9). By the bargaining rund in 2002 a further level was added, as it was decided that if it is still not possible to come to an agreement a final bargaining can take place in a committee with equal representation of the parties (Kommunernes Landsforening 2002).

\subsection{Conclusion}

A central aim of the pay reform in the public sector is to increase public sector efficiency and to make jobs more attractive. For the employees it can be positive to have the opportunity to influence their pay. Pay supplements based on subjective performance assessments also mean, however, that the employees are subjects of the risk of favouritism and biased assessments.

The fact that pay supplements in the public sector are based on agreements between the employer and the employees' representatives could - depending on the ability and integrity of the representative - reduce the discretionary room for the employe. There are, however, tendencies towards a development that reduces the role of the representative. The managers have an interest in being able to use pay supplements as incentives and with respect to this to couple the employee development consultations with discussions about pay supplements. For many employees, e.g. professionals, it could seem too be more appropriate to bargain for themselves rather than letting it over to the representative. In practise a system more similar to the system in the private sector could then be the effect for such 
employees. For managers in the public sector, an individual right to bargain on pay supplements was agreed at the bargaining round in 1999 (Finansministeriet 2000d).

The employers both in the state sector and local governments have claimed a 'simplification' and further decentralization increasing the part of wage formation determined at the local level (Finansministeriet 2001, KL 2001, Poulsen 2001). By the bargaining round in the state sector no structural changes took places and no part of the agreed wage increase should be paid out as locally agrreed supplements. This means that locally agreed supplements should be added to the agreed general increase in wages. However, at the bargaining round in 2002 at the local government levels the negotiations broke down. A major cause was the employees' organizations' resistance to accept the share of the increases in wages that should be negotiated locally which was wanted by the employers' organization. After the intervention of the conciliation officer a proposal was made meaning a modest increase in the part of the pay supplements agreed locally and no important structural changes in the pay systems. The amount of the agreed increase in wages that should be paid out as supplements locally agreed should be 0.25 per cent the first year, 1.22 per cent the second year and 0.40 per cent $i$ the third year. The ballot among the members of the organizations revealed a large resistance against the proposal although it was passed. Only 51.9 per cent elected for a 'yes'. In some organizations the resistance was very large. 94.5 per cent of the teachers, 73 per cent of the nurses and 75 per cent of the members of The Danish Association of Masters and PhDs refused the results of the compromise proposed by the conciliation officer. As the votes of the members of all organizations are counted together the proposal was, however, accepted. Part of the cause of the large resistance of the proposal was the amount of the increase. The result made it however also clear that a further decentralization of the wage formation with supplements according to subjective appraisals is not generally accepted as a way to make workplaces more attractive.

\section{Literature}

AC (2001), 'ACs forhandlingsoplæg ved aftale- og overenskomstforhandlingerne 2002'.

Akerlof, George (1982), 'Labor Contracts as Partial Gift Exchange', The Quarterly Journal of Economics, vol. 97, pp. 543-69.

Ålborg Kommune (2001). Lønpolitisk redegфrelse.

Baker, George P., Michael C. Jensen and Kevin Murphy (1988), 'Compensation and Incentives - Practice vs. Theory', The Journal of Finance, vol. 43, pp. 593-616,

Bregn, Kirsten (1998a), 'A Silent Revolution in Denmark's Public Sector Pay System', in

Daniel Fleming, Pauli Kettunen, Henrik Søborg and Christer Thörnqvist (eds), Global Redefining of Working Life - A New Nordic Agenda for Competence and Participation?, Copenhagen: Nordic Council of Ministers, pp. 293-319.

Bregn, Kirsten (1998b), 'Anvendelse af direkte $\varnothing$ konomiske incitamenter i den offentlige sektor - Resultatløn', in Kirsten Bregn (ed.) Omstilling i den offentlige sektor i et $\phi$ konomisk perspektiv, København: Jurist og Økonomforbundets Forlag, pp. 41-67.

Bregn, Kirsten (1999), 'Resultatrelateret løn nogle mulige hindringer for motivation og ef- 
fektivitet', Nordisk Administrativt Tidsskrift, vol. 80, pp. 339-353,

Bregn, Kirsten (2003 forthcoming), ‘Økonomiske incitamenter på det offentlige arbejdsmarked gennem nye lønformer' in Kirsten Bregn (ed.) Økonomiske incitamenter og markeder. København: Jurist og Økonomforbundets Forlag.

DJØF (2001), Overenskomstforhandlingerne 2002. Bestyrelsens forslag til krav.

Dowling, Bernard and Ray Richardson (1997), 'Evaluating Performance-related Pay for the Managers in the National Health Service', International Journal of Human Resource Management, 8, pp. 348-66.

Finansministeriet (1998), Ledelse, udvikling og $l \phi n$.

Finansministeriet (1999a), Resultatlon i staten.

Finansministeriet (1999b), Budgetredeg $\phi$ relse 99.

Finansministeriet (2000a), Motivation i staten - drivkraft til udvikling og fornyelse.

Finansministeriet (2000b), Nye veje - kladt på til løn og ledelse.

Finansministeriet (2000c), Skrivelse fra $\mathrm{Fi}$ nansministeriets departementchef til alle departementschefer. Resultatlønskontrakter for direktører, institutionschefer $m v$. for år 2001.

Finansministeriet (2000d), Vejledning om nye lonsystemer $i$ staten.

Finansministeriet (2001). Lønpolitik 01.

Finansministeriet and Centralorganisationernes Fællesudvalg (1998), Attraktive arbejdspladser $i$ staten.

Lov om andring af lov om lige lфn til maend og kvinder (Lønoplysninger) (2001), Lov nr. 445 af 7 . juni.

Fransson, Susanne (2000), Lönediskriminering: en arbetsrättslig studie av könsdiskriminerande löneskillnader och konflikten mellan kollektivavtal och lag, Uppsala: Iustus.

Hede, Anders (2001), 'Tog de deres egen medicin?', Samfundsøkonomen no. 5, pp. 37-44.

Hedegaard, Frank and Jan Struwe Poulsen, (1998), 'Lønstyring og økonomisk råderum i kommunernes nye lønsystem', Samfundsфkonomen, no. 4-5, pp. 19-23.

Heery, Edward (1998), 'A Return to Contract? Performance Related Pay in a Public Service', Work, Employment and Society, vol. 12, pp. 73-95.

Ibsen, Flemming and Jens Finn Christensen (2000), Løn som fortjent, København: Jurist- og Økonomforbundets Forlag.
Ibsen, Flemming and Jens Finn Christensen (2002), Ny løn mellem organisation og marked, København: Kommuneinformation.

Kessler, Ian. and John Purcell (1992), 'Performance Related Pay - Objectives and Application', Human Resource Management Journal, vol. 2, pp. 16-33.

Klausen, Kurt Klaudi og Krister Ståhlberg (1998), New Public Management i Norden: nye organisations- og ledelsesformer $i$ den decentrale velfardsstat, Odense: Odense Universitetsforlag.

Kommunernes Landsforening (1999a), Én samtale om udvikling og lon.

Kommunernes Landsforening (1999b), Løn- og personalepolitikken på spring til år 2000.

Kommunernes Landsforening (2000), En vej til bedre resultater - om lon og belønning.

Kommunernes Landsforening (2001), Mål og udfordringer på det kommunale overenskomstområde.

Kommunernes Landsforening et al. (1997), Aftale om resultatlon indgået mellem Kommunernes Landsforening, Amtsrådsforeningen, Kфbenhavns Kommune, Frederiksberg Kommune og Kommunale Tjenestemand og Overenskomstansatte.

Kommunernes Landsforening (2002). Maeglingsforslag. Generelle forhandlinger.

Konkurrencestyrelsen (1998a), Kvalifikationsvurdering, 15. september 1998.

Konkurrencestyrelsen (1998b), Kvalifikationsvurdering, 25. september 1998.

KTO (year unknown), TR's rolle i lфndannelsen.

KTO og de kommunale arbejdsgiverparter (1999), Aftale mellem KTO og de kommunale arbejdsgiverparter om ny londannelse.

Landsskatteretten (2001), Resultatlønsaftale.

Lewis, Philip (1998), 'Managing Performancerelated Pay Based on Evidence from the Financial Services Sector', Human Resource Management Journal, 8, pp. 66-77.

Longenecker, Clinton O., Henry P. Sims and Dennis A. Gioia (1987), 'Behind the Mask - The Politics of Employee Appraisal', The Academy of Management Executive, 1, pp. 183-193.

Madsen, Jørgen Steen (2002), Forhandlingssystemet - konflikt eller forlig, København: Kommuneinformation 2002.

Marsden, David and Ray Richardson (1994), 'Performing for Pay? The Effects of "Merit Pay' on Motivation in a Public Service', British Journal of Industrial Relations, vol. 32, pp. 243-261.

Marsden, David and Stephen French (1998), What a Performance - Performance Related Pay in the Public Services, London: Centre for Economic Performance. 
Marsden, David, Stephen French and Katsuyuki Kubo (2001), Does Performance Pay De-Motivate, and does it Matter? London: Centre for Economic Performance.

Milgrom, Paul R. (1988), 'Employment Contracts, Influence Activities, and Efficient Organization Design', Journal of Political Economy, vol. 86, pp. 42-60.

Milgrom, Paul and John Roberts (1988), 'An Economic Approach to Influence Activities in Organizations', American Journal of Sociology, vol. 94, Supplement, pp. 154-79.

Milkovich, George T. and Jerry M. Newman (1993), Compensation, Irwin: Homewood.

Milkovich, George T., A.K. Wigdor, et al. (1991), Pay for Performance - Evaluating Performance Appraisal and Merit Pay, Washington, D.C.: National Academy Press.

Ministry of Finance (1997), New pay systems in the Danish public sector.

Mossin, Axel (1998), 'De nye lønsystemer tidstypisk, men problematisk modernisering', Samfundsøkonomen, no. 4-5, 1998, pp. 40-7.

Murphy, Kevin J. (1992), 'Performance Measurement and Appraisal: Motivating Managers to Identify and Reward Performance', in W.J. Bruns (ed.) Performance, Measurement, Evaluation and Incentives, Boston, Mass.: Harvard Business School Press.

Murphy, Kevin R. and Jeanette N. Cleveland (1995), Understanding Performance Appraisal, Sage.

Mørk, Maja and Karen Holt Sørensen (2001), 'Den nye lønreform - an anvendelse af anvendelse og målsætninger', Speciale ved forvaltnigsuddannelsen, Roskilde Universitetscenter.

Navrbjerg, Steen E. et al.(2000), 'Nye udfordringer for lokale ledelses- og medarbejderrepræsentanter i den (amts)kommunale sek- tor', København: FAOS for Det Personalepolitiske Forum.

OECD (1993), Private Pay for Public WorkPerformance-related Pay for Public Sector Managers.

OECD (1997), 'Performance Pay Schemes for Public Sector Managers - An Evaluation of the Impacts', Public Management Occasional Papers no. 15.

Økonomistyrelsen (2000), Notat: Evaluering af lonreformen.

Pedersen, Dorthe et al. (2002), Løn mellem kollektiv og individ, København: Kommuneinformation.

Personalestyrelsen (2001a), Lønpolitik '01.

Personalestyrelsen (2001b), Evaluering af fors $\phi g$ med nye lonsystemer $i$ staten.

Poulsen, Jan Struwe (2001), 'Ny løn i kommunerne - erfaringer og perspektiver', Samfundsøkonomen, no. 5, pp. 10-16.

Prendergast, Canice (1993), "A Theory of "Yes Men", American Economic Review, vol. 83, pp. 757-70.

Prendergast, Canice (1999), 'The Provision of Incentives in Firms', Journal of Economic Literature, vol. 37, pp. 7-63.

Prendergast, Canice. and Robert Topel (1993), 'Discretion and Bias in Performance Evaluation', European Economic Review, vol. 37 , pp. $355-65$.

Tirole, Jean (1986), 'Hierarchies and Bureaucracies - On the Role of Collusion in Organizations', Journal of Law, Economics and Organization, vol. 2, pp. 181-214.

Vogter, John (1998), Offentlighedsloven med kommentarer, København: Jurist- og Økonomforbundets Forlag.

Weisband, Suzanne and Leanne Atwater (1999), 'Evaluating Self and Others in Electronic and Face-to-face Groups', Journal of Applied Psychology, vol. 84, pp. 632-39. 


\title{
8. From Centralized Self-regulation to Organized Decentralization: Occupational Health and Safety (OHS) in Sweden 1940-2002
}

\author{
Annette Thörnquist
}

\subsection{Introduction}

In November 2001, the Swedish government initiated a tripartite dialogue between the State and the main labour market parties with the purpose to encourage better health in working life. This was part of a comprehensive governmental 11point programme presented in the autumn Budget Bill, including measures for better work environment and more clearly defined responsibilities for the employers (Näringsdepartementet 2001). The aim of these talks, which were concluded in December 2002, was both to initiate a broad co-operation on the prevention of work-related bad health and to make measures for rehabilitation-of workers already on sick-leave. The background was the dramatic increase in long-term sickness absence since the late 1990s. The governmental reform programme included other means as well: for example, a reinforcement of the Labour Inspectorate, grants for the training of regional safety representatives and considerable grants for trials to reduce incidence of poor health in the public sector, which had the highest rate of work absence due to illness. According to the government, better health and safety in working life were crucial for future economic growth, employment and welfare. This was not only because of the huge public expenditures on sickness benefits, but also due to an increasing shortage of labour in many trades, partly as a result of the rapidly rising rate of long-term sick-leave, even among younger employees (SOU 2002, no. 5; Dagens Nyheter 13 November, 2001, 16 April, 2002; Nilsson 134-44).

The purpose of this chapter, however, is not to discuss the causes of or the solutions to the multifaceted problem of work-related bad health. Instead, it focuses the pattern of interaction between the labour market parties, and between them and the State, when it comes to handling issues related to the work environment. Occupational health and safety (OHS) was one of the main items in the 'Swedish model' for co-operative industrial relations during the model's heydays in the decades of great industrial progress after World War II. Yet, in the 
decades of great industrial progress after World War II. Yet, in the last decades when the classical Swedish model for industrial relations has been successively dismantled, so has the traditional model for treating OHS. Hence, this chapter analyses the change in OHS from a historical perspective up to the tripartite talks in 2002 within the wider context of changing industrial relations in general.

The Swedish and international scholarly debate concerning the move towards decentralization of industrial relations in the 1980s and 1990s has mainly dealt with deregulated wage formation, which of course is the most conspicuous effect (Traxler 1995; Pontusson and Swensson 1996; Thörnqvist 1999; Kjellberg 1998, 2000; Traxler et al. 2001; Elvander 2002). However, in a discussion of the general changes of the industrial relations system, it is also important to take into account the long-term development of other sides of working life, such as the work environment. An important reason why OHS has been rather neglected in the industrial relations discourse is that the issue has often been regarded as a special case, as a neutral item on the bipartite or tripartite agenda on which all involved parties shared the same interests. In this chapter, however, OHS is considered an integrated part of the industrial relations system, and thus also to a certain extent a question of differing attitudes, ideologies and interests.

To sum up, although OHS and wage setting have been covered by agreements of different character, and accordingly the handling of the issues mainly have been kept apart in practice, it is interesting to compare the long-term developments in these fields. The focus in this chapter is on the development of the peaklevel bipartite and tripartite co-operation in the area of OHS in the privatelyowned sector of the economy, and the associated development of the governmental OHS policy. OHS in the public sector have developed along similar lines. Yet, since the preconditions for the labour market parties' organizing and co-operation have partly been different, as have their relation to the government, this sector deserves a separate study and is therefore left out of this chapter's limited space.

\subsection{From Centralized Self-regulation towards Reinforced State-regulation}

The classical Swedish model of industrial relations has been characterized as a system of 'centralized self-regulation'. This refers to a system of central agreements concluded between strong and well-organized parties at confederate, national level, in combination with an active union presence and organized labourmanagement arrangements at workplace level. Moreover, the system implied the preference of self-regulation over state regulation (Kjellberg 1998; 2000). Another fundamental element of the Swedish industrial relations model was the main labour market parties' corporate representation on government authorities' boards and commissions. For example, they were represented on the Labour Market Board (Arbetsmarknadsstyrelsen AMS) established in 1948, and on the 
National Board of Occupational Safety and Health (Arbetarskyddsstyrelsen) that was set up in 1949, and from the mid-1950s onwards on the regional advisory councils within the Labour Inspectorate. Like the Swedish bargaining model, the system of tripartite co-operation had deep historical roots, instituted even before the introduction of the universal and equal right to vote in 1921 (Rothstein 1992: 98; se also Johansson and Magnusson 1998: 145). From about 1940 to 1980, the Swedish system of industrial relations moved from centralized self-regulation towards reinforced State regulation. The development in the field of OHS provides a good example.

Central agreements on co-operation (samarbetsavtal) and associated joint councils at the national level were cornerstones in the Swedish model of centralized self-regulation. The peak-level OHS agreement was the first of these cooperative arrangements that followed in the wake of the 1938 Saltsjöbaden General Agreement between the Swedish Employers' Confederation (SAF) and the Swedish Trade Union Confederation (LO). In the same year they commissioned a joint committee to plan the organization of industrial safety at local level. The concrete background was the increasing problem of industrial accidents that emerged during the inter-war period of rapid mechanisation and rationalisation. The work of the committee resulted in a central agreement in 1942 concerning the local organisation of OHS. At the same time the Joint Industrial Safety Council (Arbetarskyddsnämnden) was established as a central body for co-operation, information and propaganda between the LO and the SAF. ${ }^{24}$ The Council received a secretariat and started to work in practice in 1945. After some hesitation from the SAF, the parties agreed that the managing director should represent the LO, since that would increase the Council's creditability among the workers. Erik Thörnberg, union secretary at the Metal Workers' Union (Metall) was appointed managing director. Thörnberg stayed at the post until 1972, when Ingvar Söderström from the LO, succeeded him. Söderström on his part was the head of the Council until 1999, Hence, the leadership of the Joint Industrial Safety Council has been exceptionally stable, and accordingly the trade union movement had a (visible role in the organization (minutes from the Joint Industrial Safety Council, 9 May 1945; Ekström 1992: 8-10; interviews with Ingvar Söderström 2 May 2002 and Gideon Gerhardsson 15 November 2002).

There were also central agreements on co-operation on apprentice training (1944), on works councils (1946) and on time-and-motion studies (1948). Apart from the agreement on works councils, separate central bodies were established for co-operation on these issues as well (Johansson 1989). The central agreements consisted mainly of recommendations. An important exception, though, was that a ban on harassment of safety representatives should be inaugurated in binding collective agreements. In 1946 the parties in about 4,000 companies rep-

\footnotetext{
${ }^{24}$ The chairman of the Council, on the other hand, has traditionally been a SAF delegate.
} 
resenting more than 400,000 workers had adopted the principles in the OHS agreement (Lundh and Gunnarsson 1987: 73-6; Johansson and Magnusson 1998: 138-48).

The main idea behind the central arrangements on co-operation, initiated mainly by the employers, was a mutual interest in solving labour market problems voluntarily instead of through legislation. Concerning OHS, the LO would have preferred stricter collective agreements at industry level. Therefore, the LO and the Social Democratic Party (SAP) continued to pursue the issue also as a political question, and in the 1949 Workers' Protection Act (Arbetarskyddslagen) the main regulations on local work safety laid down in the central agreement were codified, including the principle of co-operation. In this way, safety representatives and joint safety committees were made mandatory in workplaces (SFS 1949, no. 1-4). The central OHS agreement aimed to create the same safety procedures in all companies. The agreement was revised and extended several times. In 1967, for example, an agreement concerning OHS services and a statement on training in OHS issues were included. During the following decades these fields of activities were greatly expanded and received separate agreements (Lundh and Gunnarsson 1987: 105-08; Hydén 1990: 206-10; Gerhardsson 1990).

The Joint Industrial Safety Council launched safety campaigns, conferences, and issued study material concerning OHS that was designed to provide a basic training for safety representatives and foremen, but also for managers and others involved in local safety organizations. The main pedagogical model used was the 'study circle', a non-hierarchal form of adult education that traditionally was used by many Swedish associations for promotion of voluntary adult education in a lot of areas. Thus, an important prerequisite for the successful development of mass-training in OHS were the Council's close co-operation with these organizations, especially with the Workers' Educational Association (Arbetarnas Bildningsförbund $\mathrm{ABF}$ ) and its associated publishing house the Correspondence School (Brevskolan), which was owned by the LO, the Social Democratic Party and the Swedish Co-operative Association (Kooperativa Förbundet (annual reports of the Joint Industrial Safety Council 1942-1960). Thus, training in OHS became integrated in the well-established national and local infra-structure of this traditionally strong popular movement. This integration significantly reinforced the system of centralized self-regulation in the field of OHS.

In 1976, a new and binding work environment agreement was concluded, preceded by a central agreement on training in 1974, which granted the safety representatives and the foremen the right to study during paid working time. These agreements also covered the Federation of Salaried Employees (PTK) that represented an increasing category of employees. In 1978, the PTK entered the Joint Industrial Safety Council as a second party representing the employees. Hence, these agreements meant further reinforcement of the system of entralized selfregulation, but simultaneously state regulation was considerably extended and 
reinforced through a vast revision of the Workers' Protection Act in 1973 and the new Work Environment Act in 1977, and also by other labour market legislation introduced in the 1970s (Hydén 1990; Tucker 1994; Martin 1995). The extensive labour legislation and the dismantling of the 1938 Saltsjöbaden Agreement by the 1976 Co-determination Act, led to the dismantling of the classical Swedish model of self-regulation. On the other hand, the new laws were semi-dispositive, framework laws, which among other things meant that they should be supplemented by agreements. In the 1970s and 1980s the labour market parties' participation on the governmental boards and in commissions of the OHS agencies and other working life agencies increased significantly as well. For example, the parties were involved in the exercise of public authority through their representation on the regional boards of the Labour Inspectorate and on the National Board for Occupational Safety and Health (Johansson and Magnusson 1998: 159-67; Arbetarskyddsstyrelsen 1999: 24-5; Johansson 2000; Elvander 2002). ${ }^{25}$

The background to the reinforced State regulation of the labour market was several alarming reports from the LO in the late 1960s and the first half of the 1970s on its members' discontent with their work environment. About 80 per cent of the asked LO members claimed that they in various ways and to various degrees suffered from work environmental problems, such as loud noise, chemical health risks, ergonomic problems, problems with cold, draught or heat and stress (for an overview see LO 1996: 15-18). Another important factor was the vast labour unrest that emerged in the late 1960s and early 1970s as a reaction to rapid technical development, rationalisation and structural transformation. Particularly the growing left-wing political movements regarded the 'Saltsjöbaden spirit', i.e. the policy of co-operation between labour and capital, as responsible for the social problems caused by the blind faith in large-scale, industrial development. In 1969-70, a three months long wildcat miners' strike occurred in the State-owned company LKAB in the ore-fields in northern Sweden. The strike was to a large extent provoked by dissatisfaction with the physical and the psycho-social environment. In the following years - like in many other countries as well - a broad and radical public opinion demanded improvements in the work environment (cf. Dwyer 1991: 78-80; Johansson and Magnusson 1998: 155-67).

According to Svante Nycander (2002) the key actor in the extended labour legislation in Sweden in the 1970s was not the LO, as has generally been argued in the scholarly debate, but the Social Democratic Party, supported by the Liberal Party (Folkpartiet) (Elvander 2002; cf. Nordfors 1985; Johansson and Magnusson 1998). The labour market reforms of the 1970s, especially the laws on job

${ }^{25}$ Through the revision of the Workers' Protection Act in 1973 the regional advisory councils of the Labour Inspectorate were reorganized into decising-making boards authorized to issue injunctions and prohibitions, and through the 1977 Work Environment Act the National Board of Occupational Safety and Health received the right to issue provisions that were legislatively binding to comply with. 
security and co-determination, and the plans put forward by the LO to establish so-called wage-earners' investment funds, lead to a political and ideological mobilization within the SAF. This was encouraged by the bourgeois government, which, after more than 40 years of Social Democratic governance, came to office in 1976 and remained till 1982 (Johansson 2000: chapter 4). In the late 1970s and the early 1980s the political climate changed and the negotiations became tougher. Yet there was a fair degree of political agreement on the new Work Environment Act that was passed in 1977. The previous working life reforms in the 1970s - especially the vast revision of the Workers' Protection Act in 1973 extended tripartite co-operation, and the public opinion on these issues all paved the way for the new Work Environment Act (Johansson and Magnusson 1998: 165-67).

\subsection{From 'Safety Pays' to 'Better Work Environment' (BAM)}

Over the decades the governmental OHS policy has changed, as has the policy pursued by the labour market parties. Along with the change, the area of OHS has been continuously redefined and widened. The different profiles of the Joint Industrial Safety Council's major campaigns and training programmes illustrates this development well. OHS in Sweden was for a long time focused on industrial accidents, even in the second half of the 20th century. Accidents still caused a lot of problems, even though the rate of accidents that caused disability or death decreased. As accidents caused serious disruptions in production, leading to high insurance costs and high labour turnover, employers could see clear economic advantages in the prevention of accidents. In addition, workplace accidents could to a comparatively large extent be reduced through organizational changes and disciplinary measures. Hence, for many employers, at least in larger firms, it became obvious that 'Safety Pays' (Arbetarskydd lönar sig). This was the name of the Joint Industrial Safety Council's first big campaign and correspondence course that started in 1954 as a basic education project for safety representatives, foremen and other involved in local safety organizations.

The prevention of occupational diseases, on the other hand, usually required more radical and costly investments. Also, as workers exposed to unhealthy work environment often get diseased years later, the question of responsibility could be rather complicated. Hence, the problem of work-related diseases was and still is an issue generally both more complex and fraught with conflict than occupational injuries, for the labour market parties as well as for the government or the parliament. The breakthrough for a wider interest in occupational diseases came in the 1960s, along with rising public demand for a better work environment and, more generally, on environmental issues.

Since the inter-war period, Swedish OHS policy was influenced by the American Safety Movement, which emerged in the USA in the early 20th century 
as a Tayloristic safety management strategy focused on the problem with accidents (Sund 1994). This strategy implied that workers' own ability and willingness to avoid accidents were crucial for achieving safety at work. Another influence was international research on the 'human factor' as the cause of accidents, particularly the theory of 'accident birds', i.e. that a small number of workers caused a great number of accidents (Hagbergh 1960). Thus, for a long time OHS focused on the creation of 'safe persons', rather than 'safe places' (cf. Gallagher 1997).

The Joint Industrial Safety Council's second big campaign and study material came in 1958, under the name 'Why does it happen?' (Varför händer det?). The campaign was influenced by industrial psychology and reflected a more analytical approach to the causes of accidents (Hagbergh 1960; Arbetarskyddsnämnden 1982: 33-35). Although issues related to workers' comfort and well-being figured in the Joint Industrial Safety Council's activities in the 1950s, local work on safety still focused on the problem with accidents. Nevertheless, unions concerned with occupational diseases, such as silicosis, had for a long time tried to put the problem on the agenda. In the 1950s the general shortage of labour made also employers more aware of the increasing problem with occupational diseases (Thörnquist 2001). In addition, the National Institute of Public Health, with a special department for occupational medicine and occupational hygiene, now contributed to a development of these disciplines, which had lagged behind in Sweden compared to several other earlier industrialized countries (Gerhardsson 1992). For the LO, the 1961 congress became a turning-point by broadening the definition of the field of workers' protection. The congress stated that the trade union movement should pay much more attention to technological developments and health risks related to rapid technological change and rationalization. After the congress, the LO employed a medical expert who among other things was engaged in the major surveys in the late 1960s and early 1970s on the members' experiences of work environment hazards. In addition, the LO and the SAF revised the central OHS agreement in 1967 from this broad perspective (Ekström 1992: 72; Johansson and Magnusson 1998: 155-56).

Due to the alarming reports from the LO investigations in the late 1960s on its members' and safety representatives' views of hazardous work environment, the LO and the Social Democratic Party presented a joint work environment programme. Fundamental to the programme was the principle that the work environment should get more adapted to workers' conditions and needs. Ergonomics, climate and social issues now received more attention. By that the programme marked a reorientation of the OHS policy towards a policy that in the first place aimed at the creation of 'safe places'. In all its essentials this programme was codified in the comprehensive revision of the Workers' Protection Act in 1973. This reorientation was also clearly reflected in the Joint Industrial Safety Council's new broad campaign and correspondence course 'Better Work Environment' 
(Bättre Arbetsmiljö, BAM) that started in 1974. The rapid technical and organizational changes in working life increased public awareness of work environmental problems, and the implementation of the new work environment reforms required a significant increase in information and mass education on OHS. This became the main task for the Joint Industrial Safety Council in co-operation with the associations for adult education. The BAM spread throughout the whole labour market, including the growing public sector, where the parties had established joint arenas for OHS co-operation and associated issues in the 1960s and 1970s. The BAM was perhaps the greatest adult education project that ever had been carried out in Sweden. It shaped a common labour market consciousness on OHS. The study material BAM, as well as the democratic pedagogical model for its implementation, (the 'study circle'), also attracted great international attention. $^{26}$ According to Ingvar Söderström, the members within the Federation of Salaried Employees (PTK) helped to instigate the socio-psychological issues that were later included in the BAM (Ekström 1992: 71-75; Ocsarsson 1997: 27-32). The preparation and implementation of the vast mass-training programme BAM was made possible by considerable grants from the State's Work Environment Fund (Arbetsmiljöfonden) that had been established in 1972 and was financed by payroll taxes. Its purpose was to fund research, training and development in the OHS area as well as in working life in general (Oscarsson 1997).

Hence, along with the broadening of the concept of work environment and the enlargement of the field covered by OHS, there was a move towards increased state regulation of these issues. In this process, as has been shown, centralized bipartite co-operation was also reinforced, and corporate co-operation between the labour market parties and the state on work environment issues increased at all levels in society. As will be stressed below, the most important SAF affiliates became more and more critical to all centralized and corporative arrangements over the 1980s.

\subsection{Towards Organized Decentralization}

Let us in this section once again return to the general changes in the Swedish industrial relations system during the post-war period. In what way has this system changed and what has been the prime mover in this development? In the early 1950 s the SAF and the LO begun to co-ordinate and centralize collective wage bargaining and already in the mid-1950s this practice was well established. The initiative came from the SAF. During the inflation boom due to the Korean War, the main interest was to curb wage-price spirals. Furthermore, centralization of wage bargaining reduced the risk for labour unrest, particularly important at a

\footnotetext{
${ }^{26}$ In co-operation with ILO, BAM has been translated into almost 40 languages, and it has been adapted to the various economic structures in the countries concerned.
} 
time of great demand for labour. For the LO, the centralized negotiation system made it easier to pursue the so-called 'solidaristic wage policy', aimed at levelling out the wage gaps between workers in different trades, and this policy also helped to speed up the process of rationalization and create better pre-conditions for general real wage increases. Accordingly, during the decades of great economic progress both parties gained from the system of centralized agreements (Kjellberg 2000: 182-84; Thörnqvist 1999; Elvander 2002).

However, in the early 1980s the employers association in the engineering industry (VI) began to call in question the centralized negotiation system, regarding it as less beneficial to industries exposed to international competition. The rising wage level, and the difficulties with controlling inflation within the framework of the central agreements, strengthened this conviction. In 1983, on the background of major labour unrest, the engineering employers and their counterpart, the Swedish Metal Workers' Union (Metall) settled an industry level agreement without awaiting the outcome of confederate level. A main reason was that both associations saw increased sectoral wage differentials as necessary in a time of rapid internationalization and radical changes in the organization of work. The engineering industry agreement was supposed to set the norm for the whole labour market. In the 1980s the SAF little by little changed its strategy on wage negotiations, following the international move towards decentralized labour relations. Some structural changes within the association contributed to this move. The SAF had become more heterogeneous, since many new employers within the private-owned service industries had been affiliated; thus the proportion of small companies had increased. The growing public sector, and the fact that salaried employees and civil servants had become increasingly important actors on the labour market also complicated the centralized negotiation system (Kjellberg 2000: 184-89).

In 1990, the SAF finally abandoned centralized wage bargaining and closed down its department for wage negotiations. According to Christer Thörnqvist (1999), the main rationale for the SAF's new and more aggressive policy was not the changes in the organization of work, such as the new concept of flexible production (cf. Pontusson and Swensson 1996), but ideological considerations. As mentioned, the labour market reforms in the 1970s, and the subsequent plans of the LO to establish so-called 'wage-earners' investment funds', had led to a political and ideological mobilization within the SAF (Thörnqvist 1999). In the early 1990s the growing international crisis lead to increased unemployment and a greater supply of labour. For this reason, as well, the centralized wage negotiations no longer attracted employers (se also Johansson and Magnusson 1998: 339-41).

Franz Traxler (1995) describes the decentralization of collective bargaining in countries such as Sweden, Denmark, Germany and Austria - where the main labour market parties traditionally have had a strong position - as 'organized 
decentralization', initiated and forced through mainly by strong employers' associations. 'Organized' in this case refers to the fact that these countries retained some important features of the old system, unlike the UK, USA and New Zealand, countries which, in the words of Traxler, instead experienced 'disorganized decentralization. According to Thörnqvist (1999: 82), trade unions still have much to gain from maintaining the framework of the old system in countries; therefore unions in countries that have undergone 'organized decentralisation' are better of than in countries with 'disorganized decentralization'.

In the 1990s, the Swedish government took several initiatives to co-ordinate wage negotiations, in order to stabilize wages and prices Anders Kjellberg (1998: 89-115, 2000: 189-98) characterizes these stabilization drives as 'state regulated centralization'. The first initiative was the so-called 'Rehnberg Agreements' (Rehnbergsavtalen) in 1991-1992, which comprised the whole labour market. The 'Industry Agreement' (Industriavtalet), concluded in 1997 and revised in 1999, was another highly important attempt to co-ordinate wage formation. The agreement was settled between eight trade unions and twelve employers' associations in the manufacturing sector and has been regarded as a revitalization of the traditional system of 'centralized self-regulation'. The agreement consists of two parts: first, procedures for wage negotiations; and second, a general policy document on industrial development concerning competition, skills and competence, research and development, taxes and energy policy. The initiative came from the trade unions in the engineering industry. In 1992 the blue- and white-collar unions in engineering had jointly established the Wage Bargaining Council (Förhandlingsrådet) to curb the employers' plan to completely decentralize bargaining. However, in the late 1990s, centralization was to some extent also in the employers' interest, since it promoted stable prices and wages, and impeded industrial conflicts without government intervention or imposition of regulating income policy. Other institutions connected to the Industry Agreement included an industrial committee, consisting of four independent economists, an economic council and 5-10 independent chairmen, who should assist at the negotiations to avoid conflicts (Kjellberg 2000: 196). In association with the Industrial Agreement the parties established a new 'unofficial' mediation institute to encourage such self-regulation. (Kjellberg: 2000: 189-98; Elvander 2002).

\subsection{Corresponding Developments in OHS}

Industrial relations in the field of OHS has taken the same direction in recent decades as industrial relations at large: from 'centralized self-regulation' towards 'organized decentralization'. Even in this area the initiative to decentralize came from the SAF. In the early 1990s, the SAF not only abandoned central wage bargaining but also annulled the central work environment agreements, including the arrangements on OHS services and training. The SAF also withdrew from the 
corporative representation in government OHS agencies. Ever since the 1970s, actually, employers had claimed the existing centralized and corporate OHS relations to be ineffective and directed by the LO and the Social Democratic Party. An important purpose of the SAF's withdrawal from the governmental boards and commissions was thus to undermine the power of the trade union movement (LO) and indirectly also the Social Democratic Party. The exceptions were the Labour Court and the Pension Insurance Funds (AP-fonderna). The SAF's new, offensive strategy in the 1990s has been to influence the government directly, by exerting an impact on the political agenda (cf. Kjellberg 1998: 94; Johansson 2000: 207, 220-21).

Furthermore, in 1993 the OHS services lost its government grant that had covered about one third of its costs. In practice this meant that the OHS services got privatized and scaled down. In 1989 the OHS services covered almost 80 per cent of all Swedish employees. The corresponding rate in 2000 was only about 50 per cent (Gerhardsson 1990; Remaeus and Westerholm 2000: 70-72). In addition, grants to the regional safety delegates for supporting small companies with no or weak safety organizations, were greatly reduced over the same period despite the large and increasing proportion of small companies the 1990s (Frick 1996). Moreover, the Labour Inspectorate, which had been reinforced through the 1991 Work Environment Act, was reorganized and scaled down again in 1995 as a result of the general downsizing within the public sector. In addition, since the early 1990s, the strategy of surveillance was changed: now the inspectors should focus on the workplaces with the heaviest problems (Arbetarskyddsstyrelsen 1999: 33-40; Remaeus and Westerholm 2000: 66). Hence, the dissolution of the central work environment agreements was followed by a downsizing of the Swedish public welfare system in this area, started by the bourgeois government in 1991, but continued by the Social Democratic Party when it came back into office in 1994. This also contributed to the general decentralization of industrial relations in the area of OHS.

Similar to developments within wage bargaining, the central work environment agreements, including OHS training and OHS services, have been replaced by arrangements at industry level in the 1990s. Here too, the employers' policy is to decentralize as much as possible to the local level. All sectors are not covered by these agreements and their contents vary from sector to sector, and the exact meaning must be specified at the local level. Åke Lindh, negotiator at the Department for Work Environment at Metall, has characterized them as 'undressed Christmas-trees'. According to Lindh, the employers are very reluctant to agree to work environment agreements at the industry level, claiming, among other things, that there is no conflict between the parties involved at this level. Yet Metall has concluded work environment agreements for the largest sectors involved: the engineering industry, the iron works, the forges and Samhall, which is a group of companies within different trades employing handicapped people. 
One bargaining areas in which Metall negotiate, but which is not covered by such agreements is automobiles and trucks (Bil och traktor), including car repair shops. The firms in this trade are often small with great work environmental problems, especially muscle-skeletal injuries and chemical hazards, such as isocyanides. Many workplaces lack local safety representatives as well. In the traditionally hazardous mining industry, where the workers are also affiliated to Metall, there exists no work environment agreement, but there is a permanent bipartite body working with OHS issues. Hence, OHS are still prioritised issues, and the parties have a silent agreement to stick to the main principles in the old central agreement. Within Metall, however, as in many other trade unions in the private as well as in the public sector the coverage of local work environment agreements is weak (interview with Åke Lindh 3 June, 2002).

As with wage bargaining, however, there has been trade union resistance against a too far-reaching decentralization; the trade unions have begun to coordinate the work environment agreements at the industrial level. Thus, in wake of the 'Industry Agreement' Metall co-ordinates negotiations on both wages and work environment with other LO affiliated unions in manufacturing as well as with the Swedish Association of Graduate Engineers (Civilingenjörsförbundet, $C F$ ) and the Swedish Association for Salaried Employees in Industry (Svenska Industritjänstemannaförbundet, SIF). Hence, the aim is also to integrate OHS in other bargaining issues (ibid).

\subsection{New Ways of Implementing OHS}

In the 1980s and 1990s the increasing internationalization of the Swedish economy contributed to the adoption of new strategies for implementing OHS. Moreover, this development has been related to the general decentralization of industrial relations. Despite the offensive governmental work environment policy in the 1970s and the increasing public awareness concerning work environment issues, work injuries still caused great problems in the 1980s. In particular, diseases due to ergonomic factors increased, and not least women were afflicted. New technology and new forms of work organization developed rapidly. The latter part of the 1970s and the early 1980s has been regarded as a time when the rewards of work environment reforms were reaped. At the same time, however, the Swedish economy underwent a structural crisis. A wave of shut downs occurred in some fundamental industries, such as the textile industry, ship building and the iron and steel industry, and in the year 1980 large-scale industrial conflict broke out covering almost all sectors of the Swedish economy. In addition, the change in the political climate made co-operation between the parties difficult. Despite the successful mass-training projects, the implementation of the reforms lagged behind in small firms. The big campaign 'the Good Work' (Det goda arbetet), launched by Metall in the mid-1980s, applied a holistic perspective on 
matters related to the organization of work, work environment, co-operation, job security and gender equality (LO 1991). Yet, it was often difficult to integrate OHS in other labour-management issues and in the organization of production; therefore this process became a driving force for the adaptation of new international management strategies for the implementation of OHS.

Since the mid-1980s there has been a trend in advanced industrial countries to handle work environmental issues through OHS management, among other things to better integrate OHS in production. Major disasters, such as those at the oil rig Alexander Kielland and on the Piper Alpha rig in the North Sea, as well as the growing nuclear power industry, contributed to an increasing rising interest in risk analysis and systematic safety management (Frick and Wren 2000; Walters and Langa Jensen 2000). Historically voluntary safety management originates in the so-called Safety Movement, but it has also been influenced by modern management strategies for quality control and for the safeguarding of the external environment. Like the ideology of decentralization, the concept of safety management is rooted in an 'American model' for organizing industrial relations. Since the late 1980s, however, there is an ongoing international trend to make OHS management mandatory. In 1989 EU issued a general directive (EEC 1989/391) to harmonize the implementation of OHS management within the associated countries. An important purpose was also to guarantee workers' independent participation in OHS.

In the second half of the 1980s, industries such as electronics and the pharmaceutical industry developed rapidly in Sweden. The economy became increasingly internationalized and business conditions improved considerably. However, as in the upward economic trend ten years later, the social costs for work injuries and long-term sick absence increased dramatically. The cost increase in the late 1980s was also partly an effect of an extension of the concept 'work-related disease' in the 1977 Industrial Injury Insurance Act. For these reasons the Social Democratic Party established the major governmental Work Environment Commission (Arbetsmiljökommisionen) in 1988. The outcome was a major revision of OHS legislation, in the 1991 Work Environment Act. The new legislation emphasized employers' responsibility for the work environment and the rights of employees to have a say on their working conditions, social as well as physical and organizational. The main change, however, was the regulation of 'internal control' that obliged employers to systematically plan, organize, implement and follow up OHS management. By this legislation and the subsequent provisions on internal control issued by the National Institute of Occupational Safety and Health in 1992 and 1996, Sweden complied with the main regulations in the EU directive (SOU 1990 no. 49; AFS 1991 no. 6; AFS 1996 no. 6; Nilsson 2003, 53-6).

The Swedish reforms were influenced by the successful Norwegian experience of safety management at oilrigs, termed 'internal control'. After the Alexan- 
der Kielland oilrig disaster in the North Sea in 1980, Norwegian offshore companies voluntarily established safety management measures, leading to considerable improvements in the work environment. In 1992 legislation made internal control mandatory for onshore occupations as well. Compared to the Swedish reform, Norwegian legislation on internal control is more comprehensive and covers other fields, such as the Pollution Control Act, The Fire and Explosion Prevention Acts and Electrical Installations and Electrical Equipment Act (Gaupset, 2000; Lindoe and Hansen 2000).

While it is difficult to compare the implementation of these reforms in different countries the Norwegian reform has been comparatively successfully implemented, especially within the private sector. However, in both countries, the implementation of internal control has been problematic in small companies that often have great work environmental problems. Such companies often lack safety representatives and cannot afford expensive courses, conferences and consultants. In the larger firms, international competition may be a driving force for the implementation of internal control, since management of the work environment, as well as the management of quality control and the external environment, tends to give competitive advantages on international markets. Yet, in Sweden, there has sometime been a tardy work to introduce the reform also in these firms. The introduction of internal control has been comparatively successful in the public sector, around 60 per cent has implemented the reform, compared to less than 30 per cent in the private sector (Arbetsmiljöverket, Rapport 2001, no. 12: 5-7, 56). This might have to do with the fact that the traditional Swedish way of handling OHS has not as deep roots in the public as in the private-owned sector; therefore the social partners in the public sector may have been more open-minded.

Generally for the Swedish labour market goes that there is a lack of knowledge among employers as well as among safety representatives, foremen and managers on how internal control should be implemented (Arbetsmiljöverket 2001: 46; Dagens Nyheter 13 Nov. 2001; Nilsson 2003: 57-60). In 2001, the Work Environment Authority (the former National Board of Occupational Safety and Health) decided to change the name 'internal control' to 'systematic work environment management' (systematiskt arbetsmiljöarbete). By underlining 'management' and 'work' instead of 'control' the idea was to more clearly emphasize the employers' responsibility for the work environment, and OHS should be integrated in all stages of the production process (AFS 2001, no. 1). One of the governments' main purposes with the tripartite talks in 2002 was to encourage OHS activities at workplace level for a successful implementation of the regulation of systematic work environment management (interview with Kenth Pettersson, 8 March 2002).

Frick $(2000,2002)$ argues that the reform on internal control marked a paradigmatic shift in Swedish work environment policy, since the State now interfered in how employers should organize the implementation of the legislation. Up 
till that time the law had prescribed who was responsible for the work environment and what should be done, but not in what way. This change can even be regarded as an interference in the employers' prerogative of control of the process of production.

To talk of a paradigmatic shift in this context might be a bit exaggerating. It is true that the law and provisions prescribed a detailed system of safety management, and in this meaning it was indeed an important structural change. The reform also gave employers more freedom of action. The reform entailed a reregulation of the system of governmental work environment control that meant a decentralization of responsibility for the control of the concrete working conditions to the employers. As in many other Northern European countries, the Swedish regulations in this field have become less detailed, moving from specification standards to performance standards. Rather than regulating technical conditions in detail, OHS inspectors were to ensure that there exists a system for OHS management in the companies in accordance with the provisions of internal control. Given that there exists a documented system for internal control in the way the regulations on internal control entailed, employers are still free to decide how these goals should be achieved in practice, i.e. to achieve the protective performance required. In this way, the regulations should not impede technological development. At the same time, the Swedish labour inspectors' traditional advisory role at the workplaces has decreased (cf. Remaeus and Westerholm 2000: 65). In addition, and highly interesting in the context of this chapter, the implementation of internal control implied an increased adaptation of the OSH agreements at firm level, which corresponded well with the employers' general interests in a-decentralisation of labour relations.

\subsection{The Development of a Joint Industrial Safety Council in the 1980s and 1990s}

The Joint Industrial Safety Council has survived as a remnant of the classical Saltsjöbaden arrangement, despite the fact that the central work environment agreements and the tripartite arrangements in this area were discontinued in the early 1990s. How then did the Council develop in the 1980s and 1990s given the general changes in the system of industrial relations?

Even before the central OHS agreements, including OHS service and training, were discontinued the Council declared that existing agreements should be more adapted to the various conditions and needs at industry and local level, thus increasing their creditability. Furthermore, informational and training materials should be more clearly specified to different industries and target groups. After the SAF had cancelled the central work environment agreements for good, the $\mathrm{SAF}$, the LO and the PTK issued a declaration of principle stating that the Joint Industrial Safety Council should continue its work. In a new policy Statement the 
Council emphasized that OHS, in accordance with the internal control reform, should be systematically integrated in the production process and more linked to the development of productivity, knowledge and skills in individual companies. This also presupposed decentralization and more flexible regulations in the agreements. Moreover, the relationship between a good work environment and profitability was strongly underlined (Söderström cited in Ekström 1992: 74-75; Arbetarskyddsnämnden 1990, 1993). In many ways the programme was in line with the policy pursued by SAF (cf. Lars-Gunnar Albåge cited in Ekström 1992: $45)$. Yet the Council never advocated termination of the central agreements.

No doubt the absence of central OHS agreements involved major changes for the work of the Joint Industrial Safety Council, especially the agreement on training, which had granted the safety representatives 40 hours annually for OHS studies. The era of huge mass-training projects in co-operation with the adult educational associations was over. Further, the deep economic crisis and mass unemployment made the labour market parties prioritise other issues over OHS. In addition the Work Environment Fund was dissolved in 1995 and the Joint Industrial Council and the adult educational associations lost most government grants for training projects. What had been the solid financial basis for the elaboration and implementation of the mass-training projects was thus removed. After that the study material provided was to be financed by those who ordered it, i.e. mainly the local labour market parties. ${ }^{27}$ Already in the 1980s, the Council began to offer more specified and company-based courses and conferences, and this trend continued in the 1990s. Companies could order courses individually tailored to their business area and organizational structure. External experts were also increasingly engaged in the Council's activities. Another trend in the 1990s was that managers at the intermediate level began to demand that training in OHS should be related to common interest regarding work organization and leadership (interviews with Henrik Lindahl, 6 Dec. 2001 and with Ingvar Söderström, 6 Mar. 2002). In many respects the implementation of OHS has developed along the same lines as company programmes for quality control, competence and diversity.

Yet a new version of 'Better Work Environment', BAM, was launched in 1997 and designed to be applicable to all employed in a workplace. It was still based on the idea of the study circle, but the social partners at the workplaces were free to jointly decide how it should be implemented (annual reports of the Joint Industrial Safety Council 1997-2001; interview with Ingvar Söderström, 6 Mar. 2002).

\footnotetext{
${ }^{27}$ The AFA Insurance (Arbetsmarknadens Försäkringsaktiebolag), a fund administrating insurance based on collective agreements contributes to the financing of some of the Joint Industrial Safety Council's/Prevent's projects (annual reports of the Joint Industrial Safety Council/Prevent 1995-2001). Owned jointly by the LO, the PTK and the SAF (and its successor), AFA is actually a remnant of the classic Swedish model as well, and AFA has co-operated with the Joint Industrial Safety Council since the late 1970s.
} 
Hence, in the 1990s the close contacts between the Joint Industrial Safety Council and the adult educational associations decreased dramatically and training in OHS was decentralized. Traditional industrial trade unions, such as Metall, still organize training activities through ABF; however, today only some 4,000 people are engaged in OHS training activities organized by ABF, in comparison with around 24,000 in the 1980s (interview with Olof Sand, 5 Mar. 2003).

An important structural labour market change over the last few decades is the increase of salaried employees, relatively as well as in absolute figures. In January 2000 the Council therefore changed its name to Prevent: Management and Labour Improving the Work Environment in order to adapt better to the fact that white-collar workers within the organization not readily identified themselves as 'workers', which the first element Arbetar-in the old name, the compound word Arbetarskyddsnämnden stated (interview with Ingvar Söderström 6 March 2002). Furthermore, since 1999 the strong personal link between the managing director and the labour movement no longer exists. The current director, Henrik Lindahl, had worked for a long time at the secretariat in a senior administrative post but he had no previous career in the labour movement. In this sense his appointment was a break with tradition (Arbetarskyddsnämnden 1999; ANS årsberättelse 1999).

In many ways the Joint Industrial Safety Council/Prevent has adapted its policy and activities to the general trend towards decentralized industrial relations and in some respects even advocated this trend, albeit within the framework of central OHS agreements. It is reasonable to assume, however, that the rapid development towards decentralization - reflected by the drop in mass-training projects and the development of more business-based models of education in OHS has accelerated, not only because the withdrawal of the government funding, but also due to the overall weakening of union power.

\subsection{The Future of the Swedish Model of OHS}

What will then happen to the Swedish way of dealing with OHS in the future? As regards tripartite co-operation, the labour market parties' representation on the boards of governmental work environment agencies has not been re-establish. Since the 1990s, the practice is that the parties are represented through advisory councils on the National Board of Occupational Safety and Health, and the Labour Market Board, AMS. They can give their views on the items on the agenda and be consulted before decisions are made. This is however far from the strong influence the labour market parties, especially the trade union movement, had on governmental boards and commissions in the 1970s and the early 1980s. The boards consist of individuals from the government and from different sectors and groups in society, for example the trade union movement and the business world, 
but the unions and the employers' associations do not nominate them (Arbetarskyddsstyrelsen 1999: 39; Kjellberg 1998: 94).

Concerning bipartite co-operation, the most obvious changes have been the abandoning of centralized work environment agreements in the private sector, and the privatization of the system of OHS services. For the LO, the discontinuance of centralized agreements and the dismantling of the tripartite arrangements meant that the department of work environment was greatly downsized. At the same time, the economic crisis and the problem of mass-unemployment overshadowed other labour market problems. Consequently, less support was given to OHS at the local level as well. At the LO congress in 1996 there was a reaction against this development and the congress became the start of a renewed activity in OHS, albeit with reduced resources. During the second part of the 1990s, there has also been a general rise in union commitment to work with environmental issues at industry level (LO 1996, 2000; interviews with Ingvar Söderström 24 Apr. 2002 and 2 May 2002 and with Carina Nilsson 11 Jun. 2002). Today, however, there are no indications of a reorganization of the central work environment agreements, simply due to employers' dislike of such arrangements. Even if employers are reluctant to make agreements also at industrial level, the parties' increasing co-ordination of wage agreements in the second half of the 1990s might also influence further co-ordination of the work environment agreements. As mentioned, some unions already co-ordinate their negotiations on work environment issues. This might revitalize the system of 'centralized self-regulation'. Moreover, in the final report from the tripartite talks in 2002, it was suggested that the 2004 bargaining rounds should include the item of better health in working life and that such steps should be evaluated in the 2006 bargaining rounds (Dagens Nyheter 17 Dec. 2002; Ett arbetsliv för alla, 2003).

The demand for revitalization was also urged by a 53 days long strike among electricians in the summer of 2003. The strike was a protest against the high work pace in the construction sector, why the Electricians' Union demanded 25 per cent wage increase for work under a high pressure during a period of 24 hours or more. Such a demand would have been unrealistic within the old centralised bargaining system, and it is exemplifies that decentralisation may be negative also for the employers, since it tends to lead to demand for compensation and thus inflation. Therefore, the Confederation of Swedish Enterprise forced the LO to find out another solution, why the LO proclaimed that the work environment should be prioritized in the industry-wide bargaining rounds in 2004 (Arbetaren 2003 no. 26).

Another initiative to centralized solutions of OHS problems worth mentioned, although it failed, was the fact that the Confederation of Swedish Enterprise invited the trade unions at the confederate level to discuss a health insurance system based on collective agreements for the first three months of a full-time sick leave. The background was discontent with the government's policy concerning 
the costs for the vast sick-leave. The LO agreed to such a dialogue, given that the PTK would participate as well. In return, however, the LO, want to discuss the future organisation of the OHS services, rehabilitation and training. According to the press, the LO counts on an inclusion of the OHS service in the collective agreements (LO-tidningen 5 Sep. 2003; Tidningen Arbetarskydd, 2003 no. 9). As it turned out, however, the PTK refused, mainly because OHS problems are to be discussed in the coming bargaining round. Thus the issue was removed from the agenda.

How, then, will management-labour co-operation develop at workplace level, which is the most important arena for the implementation of OHS? The institutional and legislative framework, the provisions on internal control and other regulations still promote the principles of the classic Swedish model of bipartite co-operation. Swedish employees have the legal right to participate in internal control and are required to do so (AFS 1992 no. 6, 1996 no. 6). Co-operation between the parties is also underwritten in the work environment agreements at industry level, as well as in the still existing central agreements between the parties in the public sector (including other related issues as well). In addition, the law prescribes that the local safety representatives and the unions should monitor the implementation of the reform of internal control.

The problem is rather how co-operation could be carried out in the context of the great structural changes in working life that have occurred in recent decades and the associated change in labour market power relations. The use of shortterm employment contracts, scaled down organizations, outsourcing, agency work and flexible working hours have made union activities at workplace level more difficult. Likewise, the move towards more individualized labour relations make employees less willing to complain about deficiencies in their work environment (Aronsson and Gustafsson 1999). A survey conducted by the LO in 1996 showed that about 30 per cent of the LO members considered themselves to be suffering from work-related injuries, mainly diseases, but only 58 per cent of them had reported their problems. This was also due to the fact that the burden of proof of the employees concerning work-related illness increased through a revision of the occupational injury insurance legislation in 1993 (LO 1996: 60-73). New LO studies indicate that these problems are still highly present, despite a growing commitment of many unions to address them. In addition, according to the LO, the ill-health in working life is a class related problem as well, since LO members are more afflicted by work injuries and musculoskeletal diseases than are salaried employees (LO 2000; LO 2002; Nilsson 2003; Dagens Nyheter 16 Apr. 2003).

A general decline in union activities in the 1990s, in particular within the private-owned sector of the service industries, has also weakened co-operation between the parties on industrial safety. Swedish trade union density is still among the highest in the world - about 80 per cent) - but since the late 1980s the level 
has been more fluctuating. A new trend in the 1990s was also that more employees affiliated directly to the unemployment funds, without first applying for membership in a union, which had been the standard procedure for almost a century (Kjellberg 2001: chapter 4 and 8). In the beginning of 2000 a report from the Work Environment Authority showed that almost four out of five work sites with five or more employees lacked local safety representatives. One year later the situation had improved a little, though, and over the past two years, the number of safety representatives has increased consederable (Arbetarskydd 2000 no. 5; Arbetarskydd 2001 no. 12, 2003 no. 4). Yet if the long-term trend decline in union activities at workplace level continues, unions may lose the initiative and the power to set the agenda and thus to define the real meaning of 'good work environment'. It should also be kept in mind that local union commitment has always been crucial for the success of the development of OHS in Sweden. Decentralization of industrial relations in OHS, as well as decentralization of the system for control of the implementation of the work environment act, has made it even more urgent to reinforce union commitment at workplace level.

Another problem is that OHS management originates in an American tradition rather than in the Swedish model of self-regulation. In the reform on internal control the law-maker has, purposely or not, tried to intermesh these different traditions. This mix of traditions and strategies, related to different systems of industrial relations, seems to have complicated co-operation between the parties, in particular in the private sector.

\subsection{Concluding Remarks}

As this chapter has shown, the developments of OHS has followed the general trend in industrial relations in the post-war period, that is, the shift from 'centralized self-regulation' to 'organized decentralization'. Which actor or actors has then gained from this development?

It was the SAF that abandoned centralized agreements, about wages as well as regarding the work environment in the early 1990s. Concerning the SAF's decision to quit centralized wage negotiations, the immediate cause was obvious in a time of increasing labour supply. Christer Thörnqvist has however underlined the ideological rationales behind the decision. It is reasonable to suppose that the main rationale underlying SAF's decision to abandon centralized work environment agreements, including those concerning OHS services and training, was also ideological. It is obvious that this decision was related to the decentralization of wage agreements. In addition, the discontinuing of the central work environment agreements accompanied the SAF's withdrawal from the corporate cooperation in the government agencies, a fact that strengthens this conclusion. As mentioned, the main motive for the SAF's withdrawal from the governmental boards therefore seems to have been that the SAF wanted to undermine political 
cooperation between the trade union movement and the Social Democratic Government on decision-making bodies.

For the unions, on the other hand, the central work environment agreements and the corporate representation in the government agencies were of great value, both real and symbolic and consequently, the dismantling of the corporate system was a setback for the whole trade union movement (interviews with Leif Kjellstrand 24 Apr. 2002, with Ingvar Söderström 2 May, 2002, and with Carina Nilsson 11 Jun. 2002).

A widespread opinion among the LO affiliated unions is that the cancellation of the central agreements concerning OHS services has strongly contributed to the growing problem with ill health in working life. Similarly, the lack of knowledge about work environmental issues is regarded as a consequence of the discontinuing of the central agreement on education in OHS (interviews with Henrik Lindahl 6 Dec. 2001, with Ingvar Söderström 2 May 2002, with Åke Lindh 3 May 2002 and with Carina Nilsson 11 Jun. 2002). In the revision of the Work Environment Act in 1999 and the subsequent revision of the provision of Internal Control/Systematic Work Environment Management the writing on this point has been adjusted to fulfil the EU directives concerning OHS, which means that the regulations are more imperative. However, this does still not mean that they are legislatively mandatory, which the LO advocates (AFS 2001:1). Today almost 30 per cent of the LO members lack of have insufficient OHS services, and this has also contributed to the LOs attempts to revitalize the centralised dialogue on OHS. In the past two years the LO and the ABF have made great efforts to encourage the study activities in general at the workplaces, and the State has also given grants for this purpose. Thus participation in the study activities has increased from about 10,000 to some 24,000 people. Although these efforts have not been specified to OHS training, it may have an effect on this field as well (interview with Olof Sand 5 Sep. 2003).

Given this background, one might argue that the tripartite talks carried out in 2002 were an attempt to restore centralized tripartite co-operation on work environment issues. Moreover, according to the final report, the tripartite talks aim to encourage bipartite co-operation by suggesting an integration of the work environment issues in the bargaining rounds at industry level. However, it should be kept in mind that the tripartite talks were initiated by the government. Despite the governmental involvement in the bargaining rounds in 1990, which lead to the successful co-operation codified in the Rhenberg Agreements, the labour market parties still guard the principle of self-regulation. They would not readily accept any shift towards centralization if they considered it to be against their interests, no matter if the government urged for it. This is in itself a vital residual feature of the classical Swedish model. Also, this initiative failed due to disunity between the parties, like other attempts in the late 1990s to carry out tripartite talks on job security had done. 
In mid-December 2002, shortly before the end of the tripartite talks, the Confederation of Swedish Enterprises decided to no longer take part in the cooperation. According to the Confederation, the main reason was that the prime interest for both the government and the unions was to increase the employer's economic responsibility for long-term sick-leave, which the Confederation regarded mainly as a vast abuse of the health insurance system (Dagens Nyheter 12 Dec. 2002). Thus the pattern of the early 1990s reappeared. Once again the employers' confederation abandoned tripartite cooperation, partly due to the possibilities implied in this system for a political cooperation between the Social Democratic government and the trade unions. In this case, however, the LO, as well as TCO, feared that an extended economic responsibility for the firms would only hit back at the employees (Dagens Nyheter 28 Jan. 2003). Despite this disunity, the government passed legislation in July 2003, stating that the companies should pay also the third week of an employee's full time sick-leave, on top of the two weeks that they already were obliged to pay for (Dagens Nyheter 11 Jun. 2003).

This chapter has argued that studies of the development of OHS can broaden the perspective in the scholarly discourse on the general changes in industrial relations, in this case the move towards decentralization. Having this broader perspective might better explain the long-term development of OHS as well. In the international debate on the international convergence versus divergence of industrial relations systems, Franz Traxler, Sabine Blaschke and Bernhard Kittel (2001) argues that in countries with a long corporatist tradition, such as Sweden, the system of industrial relations has developed towards what they label 'lean corporatism', rather than towards 'neo-liberalism', i.e. completely decentralized bargaining. ${ }^{28}$ With regard to the different characteristics of the agreements on wage formation and on other terms of employment such as the work environment, this term may also be useful to characterize the current Swedish OHS model. In many ways there has been an adaptation to market discipline and a clear move towards decentralization in this field. At the same time, both labour and capital, and the state, still have clear interests in organized labour relations.

As the initiative of the tripartite talks for better health in working life showed, there is a tendency towards a 'neo-corporative co-ordination' of the state's and the labour market parties handling of work environment problems. However, there is also a tendency towards a revitalization of centralized self-regulation in this field, mainly through coordination of the OHS agreements at the industrial level. The main rationale behind this move has been the great economic and social costs of long-term sick-leave, which the unions mainly regard to be a conse-

\footnotetext{
${ }^{28}$ 'Lean corporatism' is defined in the following way: 'market forces are so inserted into labour relations that their actors' sensitivity to monetary signals ... increases: all forms of coordinated bargaining strongly respond to monetary policy, in stark contrast to uncoordinated bargaining'. Moreover, lean corporatism creates a network-style labour market governance (Traxler et al. 2001: 300-01).
} 
quence of decentralization, privatization and downsizing in the OHS system in the 1990s, including training and company health service.

\section{References}

AFS (1992), no. 6 Internkontroll av arbetsmiljön, Stockholm: Arbetarskyddsstyrelsen.

AFS (1996), no. 6 Internkontroll av arbetsmiljön, Stockholm: Arbetarskyddsstyrelsen.

AFS (2001), no. 1 Systematiskt arbetsmiljöarbete, Stockholm: Arbetarskyddsverket.

Annual reports for the Joint Industrial Safety Council 1942-2000 and for Prevent 2001 (in mimeograph 1942-1949).

Aldrich, Mark (1997), Safety First: Technology, Labour, and Business in the Building of American Work Safety, 1870-1939, Baltimore, MD and London: Johns Hopkins University Press.

Arbetarskydd (2000) no. 5.

Arbetarskydd (2001) no. 12.Arbetarskydd (2003) no. 9.

Arbetarskyddsnämnden (1990), Program för 1990-talet, Stockholm: Arbetarskyddsnämnden.

Arbetarskyddsnämnden (1993), Uttalande antaget av Arbetarskyddsnämnden den 21 september 1993. SAF, LO och PTK. Om Arbetarskyddsnämndens uppgifter under 90-talet, Stockholm: Arbetarskyddsnämnden.

Arbetsmiljöverket (2001), Rapport no. 2001:12.

Aronsson, Gunnar and Klas Gustafsson (1999), “'Kritik eller tystnad - En studie av arbetsorganisations- och anställningsförhållandens betydelse för arbetsmiljökritik', Arbetsmarknad och Arbetsliv, vol. 5, pp. 189-206.

Crouch Colin and Franz Traxler (eds) (1995), Organized Industrial Relations in Europe: What Future? Avebury: Aldershot.

Dagens Nyheter, 13 November 2001.

Dagens Nyheter, 16 April, 2002.

Dagens Nyheter, 17 December 2002.

Dagens Nyheter, 11 June 2003.

Dagens Nyheter, 16 April 2003.

Dwyer, Tom (1991), Life and Death at Work: Industrial Accidents as a Case of Socially Produced Error, New York: Plenum Press.

EEC (1989), 'Council Directive 1989/391 EEC of 12 June 1989'.

Ekström, Örjan (1992), 50 år i samverkan: Arbetarskyddsnämnden 1942-1992, Stockholm: Arbetarskyddsnämnden.
Elvander, Nils (2002), 'Industriavtalet och Saltsjöbadsavtalet: En jämförelse', Arbetsmarknad och Arbetsliv no. 3, pp. 191-204.

Ett arbetsliv för alla (2003) Rapport från trepartssamtalen. Stockholm: Regeringskansliet.

Frick, Kaj (1996), De regionala skyddsombudens verksamhet, Stockholm: Arbetslivsinstitutet, Arbetslivsrapport 1996:22.

Frick, Kaj and John Wren (2000), 'Reviewing OHS Management Multiple Roots, diverse Perspectives and Ambiguous Outcomes', in Kaj Frick et al. (eds), Systematic OHS Management: Perspectives on an International Development, Oxford: Pergamon, pp 17-42.

Frick, Kaj (2002), 'Sweden: Occupational Health and Safety Management Strategies from 1970-2001', in David Walters. (ed.): Regulating Health and Safety Management in the European Union, Brussels: P.I.E. Peter Lang

Gallagher, Clair (1997), Health and Safety Management Systems: An Analysis of System Types and Effectiveness, Melbourne: National Key Centre in Industrial Relations, Melbourne Monash University.

Gaupset, Solveig (2000), 'The Norwegian Internal Control Reform - An Unrealised Potential?' in Kaj Frick et al. (eds), Systematic OHS Management: Perspectives on an International Development, Oxford: Pergamon, pp. 329-50.

Gerhardsson Gideon (1992), Arbetsgivare synar arbetsmiljön, Stockholm: SAF.

Gerhardsson, Gideon (1990), Svensk Företagshälsovård, Helsingfors: Niva.

Gustafsson, Rolf A. (1994), 'Traditionernas ok inom arbetsmiljöpreventionen', in U.-B. Strömberg (ed.), Kampen för folkhälsan, Prevention i historia och nutid, Borås: Natur och Kultur, pp. 263-319.

Hagbergh, Allan (1960), Olycksfall, individ och arbetsmiljö. Stockholm: Personaladministrativa rådet, Pa-rådets meddelande, nr. 23.

Hydén, Håkan (1990), 'Arbetsmiljö', in Niklas Bruun, Boel Flodgren, Marit Halvorsen, Håkan Hydén and Ruth Nielsen, Den nordiska modellen: Fackföreningarna och arbetsrätten $i$ Norden - nu och i framtiden, Malmö: Liber, pp. 175-258. 
Johansson Anders L. (1989), 'I Saltsjöbadsavtalets kölvatten', in Sten Edlund et al. (eds), Saltsjöbadsavtalet 50 år: Forskare och parter begrundar en epok 1938-1988, pp. 125-47, Stockholm: Arbetslivscentrum.

Johansson, Anders L. and Lars Magnusson (1998), LO andra halvseklet: Fackföreningsrörelsen och samhället, Stockholm: Atlas.

Johansson, Joakim (2000), SAF och den svenska modellen: En studie av uppbrottet från förvaltningskorporatismen 1982-91, Uppsala: Skrifter utgivna av Statsvetenskapliga förvaltningen i Uppsala, 142.

Kjellberg, Anders (1998), 'Sweden: Restoring the Model?', in Anthony Ferner and Richard Hyman (eds), Changing Industrial Relations in Europe, Oxford: Blackwell, pp. 74-117.

Kjellberg, Anders (2000), 'Arbetsgivarstrategier i Sverige under 100 år', in Carsten Strøby Jensen (ed.), Arbejdsgivare $i$ Norden: En sociologisk analyse av arbejdsgiverorganisering $i$ Norge, Sverge, Finland og Danmark, København: Nordisk Ministerråd, Nord 2000:25, pp. 155-284.

Kjellberg, Anders (2001), Fackliga organisationer och medlemmar i dagens Sverige, Andra reviderade upplagan, Lund: Arkiv.

Lindoe, Preben and Kåre Hansen (2000), 'Integrating Internal Control into the Management Systems', in Kaj Frick et al. (eds), Systematic OHS Management: Perspectives on an International Development, Oxford: Pergamon, pp. 437-55.

LO (1991), Vägar till välfärd $i$ arbetet: Slutrapport från LOs arbetsmiljöutredning, (LAMU), Stockholm: Landsorganisationen.

LO (1996), Färre och hårdare jobb? En enkätundersökning bland LOs medlemmar om arbetsmiljön, Stockholm: Landsorganisationen.

LO (2000), Arbetsskadorna ökar inom LOområdet: En bearbetning av den officiella arbetsskadestatistiken, Stockholm: Landsorganisationen.

LO (2002), Fler belastningssjukdomar, längre sjukskrivning: En larmrapport från $\mathrm{LO}$, Stockholm: Landsorganisationen.

LO-tidningen (2003), 5 September.

Martin, Andrew (1995), 'The Swedish Model: Demise or Reconfiguration?', in Richard Locke, Thomas Kochan and Michael Piore (eds), Employment Relations in a Changing World Economy, Cambridge, MA and London: MIT Press, pp. 263-96.

Metall (1999), Ett krafttag för arbetsmiljön halvera arbetsskadorna! En presentation av Metalls SCB-undersökningar om arbets- miljön, Stockholm: Sv. Metallindustriarbetareförbundet.

Nilsson, Carina (2003), Vem bryr sig? Om arbetsmiljöarbete under tre årtionden, Stockholm: Landsorganisationen.

Nycander, Svante (2002), Makten över arbetsmarknaden: Ett perspektiv på Sveriges 1900-tal, Stockholm: SNS.

Näringsdepartementet (2001), 'Faktablad om budgetpropositionen för 2002 som överlämnats till riksdagen de 20 september, 2001', Stockholm: Regeringskansliet, Näringsdepartementet.

Oscarsson, Bo (1997), 25 år för arbetslivets förnyelse: Forskning och utveckling på arbetslivets område, Stockholm: Rådet för Arbetslivsforskning.

Pontusson, Jonas and Peter Swenson (1996), 'Labor Market Production Strategies, and Wage Bargaining Institutions: The Swedish Employer Offensive in Comparative Perspective', Comparative Political Studies, vol. 29, pp. 223-50.

Prevent, Stockholm: Minutes of the Joint Industrial Safety Council's meetings, 9 May 1945 and 9 October 1945 (unpublished).

Records of the Joint Industrial Safety Council (unpublished).

Remaeus Bertil and Peter Westerholm (2000) 'Myndighetstillsyn och företagshälsovård', in Staffan Marklund (ed.), Arbetsliv och hälsa 2000, Stockholm: Arbetarskyddsstyrelsen and Arbetslivsinstitutet, pp. 59-77.

Rothstein, Bo (1992), Den korporativa staten: Intresseorganisationer och statsförvaltningen $i$ svensk politik, Stockholm: Norstedts.

SFS (1949) no. 1-4, 'Arbetarskyddslag'.

SOU (1990), no. 49, Arbete och hälsa: Betänkande av Arbetsmiljökommissionen, Stockholm: Arbetsmarknadsdepartementet.

SOU (2002), no. 5, En handlingsplan för ökad ohälsa i arbetslivet, Stockholm: Regeringskansliet, Näringsdepartementet.

Sund, Bill (1994), 'The Safety Movement and the Swedish Model', Scandinavian Journal of History, vol. 19, pp. 41-62.

Thörnquist, Annette (2001), 'The Silicosis Problem in the Swedish Iron and Steel Industry during the 20th Century', in Annette Thörnquist (ed.), Work Life, Work Environment and Work Safety in Transition: Historical and Sociological Perspectives on the Development in Sweden during the 20th Century, Stockholm: National Institute for Working Life: 'Arbetsliv i Omvandling/Work Life in Transition' 2001:9, pp. 70-101.

Thörnqvist, Christer (1999), 'The Decentralization of Industrial Relations: The Swedish 
Case in Comparative Perspective', Euro-

pean Journal of Industrial Relations, vol. 5, pp. 71-87.

Traxler, Franz (1995), 'Farwell to Labour Market Associations? Organized versus Disorganized Decentralization as a Map for Industrial Relations', in Colin Crouch and Franz Traxler (eds), Organized Industrial Relations in Europe: What Future? Aldershot: Avebury.

Traxler, Franz, Sabine Blaschke and Bernhard Kittel (2001), National Labour Relations in Internationalized Markets: A Comparative Study of Institutions, Change and Performance, Oxford: Oxford University Press.

Tucker, Eric (1994), 'Constructing the Conditions of Worker Participation in OHS Regu lation: Lesson from Sweden', in Wallace Clement and Rianne Mahon (eds), Swedish Social Democracy: A Model in Transition, Toronto: Canadian Scholars' Press, pp. 167-93.

Walters, David and Kaj Frick (2000), 'Worker Participation and the Management of OHS: Reinforceing or Conflicting Strategies?' in Kaj Frick et al. (eds), Systematic OHS Management: Perspectives on an International Development, Oxford: Pergamon, pp. 43-65.

Walters, David and Per Langa Jensen (2000), 'The Discourse and Purposes behind the Development of the EU Framework Directive 89/391', in Kaj Frick et al. (eds), Systematic OHS Management: Perspectives on an International Development, Oxford: Pergamon, pp. 87-98.

\section{Interviews}

Gideon Gerhardsson, professor emeritus in technical occupational medicine, former SAF delegate on the Joint Industrial Safety Council's board, 15 December 2002.

Leif Kjellstrand, former LO delegate at the Joint Industrial Safety Council's board, Stockholm, 24 April 2002.

Henrik Lindahl, managing director at the Prevent, 6 December 2001; 6 December 2002.

Åke Lindh, work environment secretary at Metall, Stockholm, 3 June 2002.

Carina Nilsson, investigator at the Dept. of Work Environment, LO, 11 June, 2002.

Kenth Pettersson, general director for the Swedish Work Environment Authority (Arbetsmiljöverket), Stockholm, 8 March 2002.

Olof Sand, secretary at the Workers' Educational Association (Arbetarnas Bildningsförbund ABF), Stockholm, 5 March 2003.

Ingvar Söderström, former managing director at the Joint Industrial Safety Council (Arbetarskyddsnämnden, Prevent), Stockholm, 6 Mars, 24 April and 2 May 2002. 



\title{
9. Gender-specific Strategies for Industrial Action: The Swedish Case in Historical Perspective
}

\author{
Susanne Fransson and Christer Thörnqvist
}

\subsection{Introduction}

From a trade union perspective, a pre-condition for successful bargaining has always been the possibility to take powerful industrial action, with the strike as the most important means. ${ }^{29}$ One result of the transformation of Nordic Industrial Relations and the growing importance of multinational HRM strategies in the last decades has been the challenge to traditional methods of collective action and thus patterns of industrial conflict have changed. This chapter discusses one, often forgotten, aspect of these changes: the differences between men and women.

Primarily, the debate on collective action emanates from a few classic studies: Shorter and Tilly (1974), Tilly et al. (1975), Clegg (1976) and Crouch and Pizzorno (1978). All these studies emphasize strikes as the workers' strongest means for bringing pressure to bear in negotiations with the employer. Yet, mention is seldom made of the fact that irrespective of time or country, strikes have been a weapon mainly used by male-dominated trade unions within male-dominated occupations. Strikes for instance, have always been more frequent among miners, longshoremen and metal workers than among workers in food processing or garment, or in service occupations (Thörnqvist 1994: 157-68).

Obviously, gender differences alone do not explain differing strike patterns or other forms of labour market militancy. Features such as pay setting systems, organization of work, labour processes and trade union traditions are highly important to understand occupational differences. Yet, gender differences remains even after all other factors are taken into account, which motivates the subject for this study. Also, there are tendencies that the wage-gap between men and women is today slightly widening, or at least no longer narrowing after half a century of

\footnotetext{
${ }^{29}$ This chapter is written as a part of a more extensive study of gendered bargaining and conflict patterns and wage discrimination, financed by the Swedish Council for Working Life and Social Research (FAS). Besides the help from our colleagues in the Nordfram network, we would especially like to thank Linda Lane, Göteborg University, for valuable comments on previous drafts.
} 
slow equalization (Statistics Sweden 2001: 256), which calls for new strategies from a 'female' trade union perspective.

In the mid-1970s, Clegg (1976) observed a close association between collective bargaining structure and overall patterns of industrial conflict. For instance: the risk of strikes - official as well as wildcats - is higher the more decentralized a bargaining system is; yet, the number of wildcat strikes can be reduced by elaborated and efficient dispute procedures (Clegg 1976: 76 and 82). The conclusion still holds, however, later studies have shown that the relation between collective bargaining and industrial conflict is more complex than Clegg suggested. Particularly important in our case is that the outcome of the relation between collective bargaining and industrial conflict differs widely between the four main Nordic countries, among which Norway and Denmark are the two poles. Norway has experienced an exceptional industrial peace, even during the rebellious 1970s, while unofficial strikes in the Danish private sector have become an integral and largely accepted part of the bargaining system, unaffected by businesscycle related economic factors (Stokke and Thörnqvist 2001).

Therefore, we shall limit our investigation in this chapter to a case study of Sweden. It would take us too far to try to cover all the five Nordic countries. However, we do not limit our study to any particular sector of the Swedish economy; on the contrary, a starting-point is that gender differences in conflict patterns and bargaining strategies exist both between and within different industries.

Moreover, in most Western countries labour disputes are regarded as disputes of interest, irrespective if the dispute is a minor clash of opinion between an employer and his employees in shop-floor negotiation over wage setting, or if it is a strike involving thousands of workers. In all the Nordic countries, industrial relations are heavily legislated, or 'juridified', such that disputes of interest are transformed into disputes of rights (Bruun 1990: 18-19). Hence, knowledge of labour legislation is necessary to understand old and new collective strategies. Of particular importance is how the status of the most important means for labour market regulation, the collective agreement has changed. Sweden has the highest overall union density in the world; the vast majority of Swedish employees are covered by collective agreements. There is no actual difference between men and women; in the end of the 1990s, 52 per cent of all union members were women (Kjellberg 1999: 66-67 ${ }^{30}$ ).

Still, collective bargaining has developed within an industrial relations system dominated by men and male dominated organizations; accordingly, new agreements are always settled within the frames of the existing industrial relations system. Thus, in the words of Bercusson and Dickens (1996), neither collective bargaining nor the collective agreement is gender neutral.

\footnotetext{
${ }^{30}$ Women's organization rate is slightly higher in the public and slightly lower in the private sector than men's.
} 
Yet, this is a previously unexplored field of research and we do not claim to cover all sectors of the labour market or all aspects of labour legislation equally well. Our findings should rather be seen as a point of departure for further, more detailed analyses.

One hypothesis, or rather guideline for the study is that reasons why employed females are less strike-prone than males must have deep historical roots; otherwise, the differences would not be so sharp. Hence, we discuss both the first attempts to organize women in the labour market and - rather thoroughly - some strikes organized and carried through by only women. In both cases, the aim is to illustrate differences between 'standard' or 'male' ways of organizing union activities and carry out strikes. Second, we focus on the early and mid-1990s, since this period was a rather sharp turning point in the history of the Swedish model. Two events are highlighted especially: the decentralization of collective bargaining and the individualisation of labour market legislation. Since both events affected 'ordinary' trade union policies and strategies, our hypothesis is that the 'female' strategies must also have been affected. Moreover, parts of the new legislation were explicitly aimed to equalise relations between the sexes, which strengthens our hypothesis.

Accordingly, the outline of this chapter is largely chronological. The following section deals with the first attempts to organize women workers at the turn of the previous century and other 'female' strategies till the end of the Second World War. Section 3 discusses some remarkable women's strikes in the otherwise so quiet heyday of the Swedish model. Section 4 analyses the evolution of new collective strategies among women workers in the 1990s, particularly in the health care sector. Section 5 presents some theoretical aspects on the development as well as the most important issues for the future.

\subsection{Organizing Women: Some Historical Aspects on Organizational Power and Strategies up to the Second World War}

\subsubsection{Women's organizations}

Workers have traditionally tried to achieve collective rights through trade union organization. Yet, there have historically been great organizational differences between men and women. The most important difference was that women, for several reasons, did not associate themselves with trade unions to the same extent as men. Still, there were several unions only open for women in the early 1900s. Östberg (1997: 200) found 62 such organizations, aimed at defending female workers' rights versus employers. The reasons behind the rise of female unions were that many women found it difficult to be heard within the existing unions. 
This pattern was particularly clear in governmental services (Nilsson 1996; Waldemarson 1996).

The first Swedish union for women was founded in 1886 by gloveseamstresses in Lund in southern Sweden; the first women's unions chiefly appeared in textile and clothing, where the relative number of female workers was very high. In 1902, those organizations formed the Women's Union (Kvinnornas fackförbund): a confederation covering the whole textile and clothing sector. However, men initiated the Women's Union. Since women generally worked for much lower wages than men did, the intention of the organization was to reduce wage competition between the sexes. That was also the main reason why the Women's Union was accepted as a member of the Swedish Confederation of Trade Unions (LO) in 1904. Already six years later though, the Women's Union was split up and ever since then the LO has promoted mixed organizations including both female and male members.

Almost simultaneously, though, purely female occupational organizations were founded in the public sector. The public sector appointment system strictly separated men and women into different positions; thus women found an organization of their own much more powerful than belonging to a union run by the interests of another (male) profession. Moreover, women did not feel welcome in the male-dominated unions; some of the public sector unions even openly declared that membership was reserved for men (Nilsson 1996: 152 and 182).

Despite the LO's policy to avoid separate unions for men and women, a large number of female occupational organizations with union ambitions still existed in the private sectors between the wars. In Stockholm alone, there were about fifty such organizations, organizing as diverse groups as female office workers, sales clerks, restaurant staff, domestic servants and dentists. Many of these organizations cannot be labelled as trade unions in the traditional sense. Yet, their purpose was to attain collective rights through collective actions, even though employers did not recognise the organizations as negotiating partners and even though they were not as militant as the 'male' unions (Östberg 1997).

If women's organizations were recognised as neither negotiating partners nor militant, one must ask what power resources and strategies they really had. In both the private and the public sector, a key feature was co-operation rather than confrontation in contacts with employers as well as with other worker organizations. Women built networks. The goal was also to negotiate with each employer separately and on individual basis. By increasing the members' skills and educational level, these organizations believed they could improve their members' employment conditions and wages in negotiations with employers (Waldermarsson 1996: 213).

However, a main flaw in this strategy was that it was best suited for a highly 'gender-typed' labour market; that is, industries, businesses and enterprises where there were distinctly demarcated occupational groups dominated by 
women. Swedish unions are however industry associations, not occupational ones like for instance in the UK. The more the unions within the LO and the Swedish Confederation of Professional Employees (TCO) amalgamated into larger unions, the harder it became to maintain women's separate organizations. As affiliates of an industry association, a women's union had to accept all employees in the industry as eligible for membership, not only workers with specific occupations (Nilsson 1996: 226-27; Östberg 1997: 140 and 157) Accordingly, women's unions disappeared with the continuous amalgamation during the interwar period.

\subsubsection{Competition or Loyalty?}

As mentioned, women competed with male workers in the labour market through their lower wages, which made them both dangerous and unpopular in the trade union movement, especially in periods of increasing unemployment. In Denmark, low-wage competition was an explicitly stated means for women's unions such as Kvindeligt arbejdsforbund (KAD). For instance, Kvindeligt arbejdsforbund opposed the introduction of the ILO's convention no. 100, a principle of equal pay for equal work between men and women (Olsen 1984: 237).

It is not likely that low-wage competition as a consciously used means for women's organizations was particularly wide spread in Sweden. Still, the threat was very real to the traditional unions. Separate wage scales for men and women were introduced in the Swedish engineering industry in the 1920s. For more than a decade, the employers' association, VF (Verkstadsföreningen), had pressed for separate wage rates but the union Metall, had resisted in order to avoid negative competition for jobs between men and women. When Metall finally agreed on separate wages for women, the main argument was that since women themselves accepted lower wages and were willing to work for wages below those prescribed by the collective agreement, maintaining equal wages would just hinder settling of agreements (Larsson 2001: 149).

It is in situations such as these that we find the origin of women's more defensive labour market strategies. While men could actively press for higher wages or other forms of better terms, women had, both individually and collectively, to fight for the rights to work at all, and for the right to keep their job if they married. As in most European countries, this difference became obvious right after the Second World War. Women had filled in for men in the sectors of the economy which were of high importance for the mobilization - not to the same extent as in the belligerent nations, but no doubt the Swedish economy would have suffered seriously without the new female labour in manufacturing. When the war was over, the women were supposed to go back to homemaking, or rather to return to menial jobs, in order to make room for men. Normally the women made no fuss about leaving their better-paid manufacturing jobs in the war industry; 
they did it in solidarity with their husbands, brothers and sons, who where the ordinary breadwinners.

Actually, several of them had entered the labour market in loyalty with their country. In a successful newsreel drive during the war, the Swedish government introduced the character 'Mrs. Loyalty' (Fru Lojal). Mrs. Loyalty was every married woman without juveniles who, beside her tasks as a homemaker, took place in the war industry during the state of alert. Mrs. Loyalty did this - as her name hints - not for her own purposes but in a rather altruistic manner for the benefit of the country in a very specific historical situation. Accordingly, it was only natural that she did not get the same pay or gained the same rights or working conditions as an ordinary, male worker: after all, her position was only temporary. It was also natural that Mrs. Loyalty should not compete with the returning men after the war, despite the expanding labour market (Overud 2000).

Yet, neither the 'entering' nor the 'returning' should be exaggerated. In fact, after the war, women returned to lower-paid, menial jobs; they did not leave the labour market. The percentage of women working (outside the agrarian sector) varied between 30 and 35 per cent during the whole period 1930-1950. The number of married women in the labour market even increased after the war, from some 10 per cent in 1945 to about 15 per cent in 1950. In addition, the sharp rise came in 1960, when the number of women in the labour market increased from under 40 to some 55 per cent in only two years (Lundh 2002: 206-9).

Despite the return to menial jobs or homemaking, many women had made new organizational experiences, useful for the future. One experience was that women did not count as men, even when they did the same job and even when they where in practice the family's breadwinner, as they many times were during the war. They had also learned that the better-paid jobs were for men, not for women. Some trade unions, such as the largest public sector union for municipality workers (Kommunal) even refused to affiliate women, since they were considered 'temporary employees' and supposed to leave their jobs as soon as the war was over (cf. Lane 1995).

\subsection{Women on Strike}

True, the women's organizations disappeared from the labour market during the palmy days of the Swedish model and the solidaristic wage policy; yet, the different strategies between men and women remained. The most obvious case is the strike pattern: both legal and wildcat strikes were more sparser in 'female' occupations and unions dominated by women (Thörnqvist 1994: 175-78). Moreover, strikes in traditionally male occupations chiefly had an offensive character; they were short wildcats in the manufacturing industries, usually in connection with plant-level negotiations, aiming at gaining as much as possible from the 
wage-drift. During the Fordist era, the threat to stop an assembly line was always dangerous to the firm, which thus gave the workers a strong position in wage negotiations. One goal with the Swedish model was to equalize wage differences between occupational groups in different industries. Therefore, and actually a bit paradoxically, there was always a great possibility to gain from wage-drift in the local negotiations in the profitable export industries, such as the male-dominated engineering industry. Accordingly, the use of wildcat strikes in connection with firm-level negotiations were always more tempting in those industries than in declining industries such as the female-dominated garment industry. In other words, the typically male strike took place among the groups of workers who had the most to profit from the Swedish model (ibid. 295-99).

Before we go on to discuss the connection between men and women's strike patterns and the Swedish industrial relations system and work organization, it should be emphasised that gender differences are likely to be partly international. Hence, the differences cannot be solely explained in a national context, that is, by the greater opportunities for wage-drift male occupational groups received within the Swedish model. Already in the 1950s, Knowles (1952: 210) noticed that while for instance skilled, male car workers could be very strike-prone, grievance among young unskilled women in the clothing industry rather appeared in increasing labour turnover. Even though Knowles discusses the UK half a century ago, his statement is well representative of today's Sweden or at least Sweden in the 1980s. Probably the situation was the same half a century before Knowles's study too (cf. Cederqvist 1980: 116-22). As hinted above though, not many studies have addressed the issue more seriously. However, the few existing investigations, dealing with for instance the UK, Norway and Finland, all seem to arrive at the conclusion that differences between men and women are rather due to structural factors than explicitly to gender. Women very often worked in industries where neither men nor women were particularly active in trade unions and in sectors where there was little hope of wage-drift (cf. Julkunen and Rantalaiho 1993). Not strangely, men and women with similar occupations seem to act in the same way. A thorough study of strike-proneness in British manufacturing in the late 1970s found no significant evidence of differences between workplaces with a high number of female workers and workplaces with only few women employed (Edwards 1981: 143).

\subsubsection{Some Remarkable - but Unsuccessful - Women's Strikes}

Even though 'female' strikes are rare, there are of course examples in most countries of women's strikes that attracted attention and were widely publicized at the time of occurrence. Sweden is no exception, and the rest of this section shall discuss some of the most important Swedish strikes with only women as participants. These strikes, however, were mainly defensive; they aimed at maintaining something rather than getting higher pay or achieving better working conditions. 
One of the most noticed industrial conflicts during the conflict torn 1970s took place among female cleaners. More correctly, the conflict consisted of five nearly simultaneous and closely connected wildcat strikes, directed against the same cleaning company, ASAB, in five different places in the end of 1974. In total, some 350 women participated and the reason for the strikes was a shift from wages by the hour to work by contract, which in practice lowered the cleaners' pay.

The outcome of the strikes differed depending upon the municipalities in which they took place. In two of the cases, it is pointless to speak in terms of success or failure, since the actions had the character of short sympathetic strikes. Both the strikes ended in the Labour Court, and most of the participants paid fines for violating the peace obligation. (A ban on strikes is always incorporated in a collective agreement.) At the time, however, the penalty of 200 Swedish Kronor per striker was barely more than symbolic.

In two other cases, at the company Domnarvets Jernverk in Borlänge in central Sweden and in the ore-fields in the very north, the strikers came out relatively successful: the company agreed on wage raises to compensate for the new work form. In addition, the strike in the ore-fields ended with penalties in the Labour Court for many of the participants, but that does not change the fact that the result was rather satisfactory to the strikers.

The fifth wildcat however, which took place at a hotel in Skövde in western Sweden, ended in disaster for most of the participants. Already from the beginning of the conflict, the company took a very harsh attitude and two spokesmen for the strikers were fired after only one day's strike. In the eyes of the employer, the two women were 'strike-leaders', which justified the dismissals. There after, the strike took a different turn: the aim was now to get the company to re-engage the two 'strike-leaders'. After 17 days of continuous strike and a legally binding request of the Labour Court to return to work, the rest of the cleaners - in all eight women, were also fired. A case was brought to the Labour Court, which declared the dismissal of the 'strike-leaders' illegal, and sentenced the company to pay damages and retroactive wage to the two women. Yet, the court had no objections to the dismissal of the rest of the cleaners. Even if circumstances such as the lowering of the real wages and firing of the 'strike-leaders' in some way could make the illegal action excusable, these circumstances had lost all its importance because of the length of the strike, the court argued (AD 1975 no. 31).

In February 1975, while the cleaners were still on trial in the Labour Court, 38 sewers - all of them women - in Gällivare in the very north of Sweden took illegal action against the introduction of a new piecework system. Even this conflict was rather widely publicised in the daily newspapers. Already from the start, the positions between the workers and the company were locked; the strikers refused to go back to work and the employer refused to negotiate as long as they did not. Still, the strikers could maintain the strike despite the lack of income, much due 
to economic assistance from outside. Among other things, they received 20,000 Swedish Kronor from 'the miners' strike fund', a fund created after the great miners' strike five years earlier, on purpose to support wildcat strikes. After two months of strike though, the company presented the strikers with an ultimatum: if they did not immediately return to work, the employer would consider the matter as if the workers had voluntarily given notice to quit and thus hire new workers. 16 employees obeyed the employer's request, while the remaining 22 continued the strike. Yet, since the strike now had lost most of its power, even these 22 workers gave in a few weeks later. The company refused to let them return to work and the case was never tried in the Labour Court (Thörnqvist 1994: 12526).

Ten years after these two conflicts, one of the involved companies, Domnarvets Jernverk in Borlänge, was again involved in a wildcat strike, a strike that had many similarities with the previous one. The strikers were cleaners, women, hired by $\mathrm{ASAB}$, and the reason for the strike was a change in the work organization. Yet, while the first strike at Domnarvets Jernverk was rather successful from a striker's point of view, the strike in 1985 ended after six weeks with dismissals of 14 workers. After an investigation by the Labour Court - which took over a year - the court declared the dismissals illegal and the cleaners could return to their old work. The reason was, according to the court, that the strikers intended to go back to work when they heard that the company considered firing them, but they were refused entrance to the workplace, even though they had not yet formally given notice of dismissals (Thörnqvist 1998: 53-54).

Of course, it is not possible to generalize out of the few cases presented here. However, they do have some things in common that taken together makes it clear that conflicts are not examples worthy of imitation. All of the strikers were women; all the strikes were largely defensive; and they all ended with the firing of some of the participants (even though the cleaners at Domnarvets Jernverk a year later got their jobs back). Moreover, the conflicts stress the role of tradition, both for militancy and for success. In an interview for a documentary book on the 1974 ASAB conflict, one of the cleaners explained that one reason the strike was so much worse in Skövde than in the ore-fields was the lack of support from other groups of workers. The cleaners in the ore-fields had a great deal of support from the miners, maybe not with money, but with advises and moral support (Johansson and Grahm 1975: 130). The authors developed this further and noticed that the workers at Domnarvets Jernverk had very clearly taken sides for the cleaners' strike, among other things by refusing to work in areas which were not 'cleaned enough to be safe'. In Skövde though, the strikers were left on their own (ibid. 147). The importance of help from 'male' groups of workers with more militant traditions is also highlighted by the sewers' strike. True, the sewers lost the conflict, but they held out more than two months, much thanks to the financial assistance from the 'miners' strike fund'. Even if workers in the clothing 
industry have little experience of industrial conflict, the women in Gällivare lived in an area with long militant traditions. In April 1975, when the cleaners' and sewers' conflicts in the ore-fields were almost over, another, very short, wildcat strike for higher wages broke out, involving nine female shop cleaners in the same area. For a local newspaper, one of the women explained that all the strikers were married to miners, thus they 'knew what a strike meant' (NorrbottensKuriren, 22 April 1975).

Two other wildcat strikes among women, both in 1978, might shed even more light on the issue. One of the strikes, in a food industry company located outside Kristianstad in southern Sweden, run parallel with a strike among men in the same occupation and the same area, and with almost the same demands. Hence the strike turned out very successful: the strikers could return to work already after five hours, after the company's CEO had promised to adjust both wages and piecework rates in line with the strikers' wishes. The other strike, among 18 sewers in Kramfors in northern Sweden, makes a glaring contrast to the one outside Kristianstad: the strikers were given notice of dismissal after only four hours of strike. Seemingly, the notice was never carried into effect, though (Thörnqvist 1994: 176-77).

To sum up, the outlook on the most important women's strikes in Sweden after the Second World War supports our hypothesis: a successful wildcat strike from a female workers' perspective should preferably take place in 'male' industries with long traditions of militancy, where possibilities for wage-drift are high and where even a short stoppage can force the employer to make concessions. It also seems as if wildcat strikes in manufacturing actually had a positive impact on real wages for blue-collar workers at large in the conflict-ridden 1970s and 1980s (Thörnqvist 2001: 166-69).

When it comes to legal strikes, it is more difficult to determine their impact, since the parties usually arrive at a solution without open conflicts. Furthermore, in the public sector where the number of female employees is high, possibilities to take legal industrial action have been more restricted. Public employees did not gain the right to strike or take other forms of actions until 1965. Thus, they have had little chance to develop any militant traditions. Although the threat of collective quitting has for long been a means of voicing discontent, particularly in the health care sector. On the other hand, wildcat strikes have been more frequent than official sanctioned ones in the public sector and the 'male' occupational groups have been the most strike-prone. Neither should the need for support from outside the sector be neglected in the case of legal public sector strikes. We find an illuminating case if we leave our focus on Sweden for a moment and look at Finland. The industrial relations systems in the two countries are closely related enough to make findings from Finland interesting even from a Swedish viewpoint. One of the largest strikes in Finnish post-war history took place in the public health care sector in spring 1983. Doctors and trained nurses (with the excep- 
tion of midwives) did not take part, but all the sector's lower paid and/or less skilled occupational groups such as midwives, nurse's assistants, dental nurses and janitors, in total 20,200 individuals 97 percent of whom were women did. The action was officially legal, but since the entire health care sector struck, the strike was declared by the Finnish Parliament to be highly dangerous to the Finnish society. Despite this, the strikers managed to gain a satisfactory collective agreement. According to strikers and contemporary commentators, the outcome to a large extent was the result of the strong support the strike had in public opinion; if the public at large had not found the strikers demands fair and justified, it would have been impossible to maintain the strike (Alasilta-Hagman and Pitko 1984).

\subsection{The 1990s: The Dismantling of the Swedish Model Demands New Strategies}

Although a relatively small number of negotiations end in open conflicts, the threat of strikes, actions short of strikes or of collective quitting are still the employees' most important power resources. If typically female groups of workers have not been able to successfully use them, one must ask what means they have used instead and how they will change in the future.

This section focuses on the late 1980s and early 1990s as a historical turning point. As discussed above, due to wage-drift the solidaristic wage policy primarily benefited male workers during the golden era of the Swedish model. At the same time, the solidaristic wage policy guaranteed that the wage gap did not expand too much between different occupational groups, at least not between groups of blue-collar workers.

In other words, typically female unions could accept the dominance of the male groups in the export industries because due to the centralized system they still got a fair share. In the same way as women had been 'loyal' to the Swedish nation during the Second World War, they now had to stay 'loyal' to the Swedish model, at least those that could not return to a life as fulltime housewives. On some occasions, as in the 1952 bargaining rounds, the peak-level agreement between the Swedish Employers' Confederation (SAF; today the Confederation of Swedish Enterprise, SN) and the Swedish Trade Union Confederation (LO) even prescribed higher overall wage raises for women than for male workers in order to reduce the wage gap between the sexes. Female groups could also benefit from the principle of 'equal pay for equal work', a principle that was a cornerstone of the solidaristic wage policy. A prominent expression of this policy was the abolishing of the special wage rates for women in the mid-1960s (Fransson 2000: 145-47). The wage gap between men and women narrowed during the first postwar decades in the export oriented male-dominated engineering industry as well as in the low-paid female-dominated textile and garment industries (Svensson 
1996; Sund 2002). In the engineering industry, which is normally the leading and normative industry in the national industry-wide bargaining rounds, the wage gap shrank from 31 per cent in 1950 to 11 per cent in 1990. Even so, the narrowing of the wage gap seems to have been a result of change in the structure of labour supply and demand rather than the solidaristic wage policy adapted by LO. (Svensson 1996). The number of women in the labour market increased sharply in the early 1960s. Many of the new jobs for women grew within the relatively low-paid public sector, which held back the overall narrowing of the wage gap between the sexes in this sector. The rise in the female labour market participation rate was exceptional also in an international context. In Western Europe, only Denmark and the UK showed comparable increases in the proportion of women working in the 1960s and 1970s (Carpenter and Jefferys 2000: 86-87).

From the mid-1980s onwards, however, the wage equalizing trend was reversed until the introduction of the Industry Agreement in $1997 .^{31}$ In February 1990, the SAF Board of Directors announced its decision to discontinue participation in peak-level bargaining with its union counterparts. The aim was to decentralize - even individualize wage setting, but also to decentralize industrial relations at large, and with that dismantling the whole Swedish model (cf. SAF 1990). The system was never completely decentralized as the SAF had hoped, primarily due to the stabilization drive during the deep recession in the early 1990s and to union resistance and co-ordination of the industry-wide bargaining rounds. Yet, the system was challenged, and today the strategy of 'loyalty' with the Swedish model has been at stake for almost two decades. Already in 1983 the Swedish Engineering Employers' Association (VF) settled an industry-wide agreement with the Metal Workers' Union (Metall) without awaiting a peak-level agreement between their central confederations: the SAF and the LO. A few years later, at the 1986 LO Congress, the President of Metall, Leif Blomberg, accused the public sector unions of pressing irresponsible wage claims that threatened the entire economy. Instead of traditional wage solidarity, in the words of Blomberg, it was self-evident that wages should be much higher in the ('male') profitable export industries than in the ('female') unproductive public sector. Subsequently, and partly as a result of Blomberg's attack, LO policy changed in a less favourable way towards the public sector (Swenson 1992: 52-54).

\subsubsection{Developing New Strategies by the Use of Legislation}

Together with the SAF's attempts to decentralize and individualize industrial relations, Swedish labour market legislation has also become more individual-

\footnotetext{
${ }^{31}$ The Industry Agreement or, more correctly, the 'Agreement on industrial development and wage formation', is an agreement signed by all SAF (SN) affiliated employers' associations and their trade union counterparts within the competition-exposed sector. In practice, the signing of the Industry Agreement signalled that the SAF had given up the struggle for decentralization of collective bargaining, provided that the export industry should remain wage leading (Elvander 2002).
} 
ized. Since collective bargaining and the collective agreement has always been a cornerstone in Swedish industrial relations, an interesting question is whether trade unions have been able to adapt to the individualization of labour market rights. The 1995 bargaining rounds actualized the issue, when - largely female groups in the health care sector attempted to turn the new legislation into their own favour. The core of the new strategy was to rely on the ban on discriminatory wage setting due to sex, a section inaugurated in the law of equality (that is, equality between men and women). ${ }^{32}$ Strictly juridical the content of the ban is very much in line with the traditional solidaristic wage policy. A major difference is that while the main intention of the solidaristic wage policy was to equalize wage gaps between industries and companies, the purpose of the ban on discriminatory wage setting due to sex is to achieve justice between male and female employees in the same firm.

In 1995, the Swedish Association of Health Professionals (Vårdförbundet) explicitly stated that its female members, in particular nurses, were discriminated as compared to men in health care with comparable tasks and experience. All salaries in the health care sector, Vårdförbundet argued, should be based on individual qualifications, which would favour the union's female members who in general had a high degree of formal competence (Fransson 2001). Moreover, due to solidaristic wage policy the wage gap between trained and assistant nurses was very small, ${ }^{33}$ evoking demands from trained nurses that their salaries should be upgraded in accordance with their skills (Olsson 1996: 37 and 63). In other words, Vårdförbundet claimed a general raise in pay for all its members and in addition, trained nurses demanded individual pay raise in line with their high competence level.

The demands resulted in a seven weeks long official strike. The conflict was complicated by the discrepancy between the peak-level negotiators and the members on how 'a general raise' should be interpreted. Many members believed that the claim was a general rise of 5,000 Swedish Kronor a month settled by the union at peak level, which no doubt would have been politically impossible. Accordingly, despite the fact that the outcome was rather good compared to what other occupational groups had gained from the bargaining rounds the result after seven weeks of continuous strike was a great disappointment for many nurses. The union leadership had failed to make clear that most of the upgrading should take place at local level, after local and individual negotiations (ibid.: 43).

In conclusion, Vårdförbundet tried to combine the use of legislation - the prohibition of discriminatory wage setting due to sex - with the individualization of salary negotiations in the public sector, which gave more room for pay according

\footnotetext{
${ }^{32}$ Previous bans on wage discrimination have been registered in Swedish labour law since 1980 and EC law since 1957.

${ }_{33}$ Assistant nurses are not organized by Vårdförbundet, but by the Swedish Municipal Workers’ Union (Kommunal), which is affiliated to the LO. Vårdförbundet do also organize laboratory technicians, whose wage-struggle has never reached much public attention, though.
} 
to individual competence. Further, this combination legitimized the nurses' claims in the eyes of the public opinion. When settling a collective agreement, it is the stronger party that reaps most benefits from the final formulation. By relying on labour market legislation, Vårdförbundet turned the focus from strength to rights; the nurses deserved higher salaries because it was not fair - either from a legal or a moral point of view - that they should be less paid than men of comparable skills, responsibility and work experience.

This appeal to 'fairness' was found reasonable by media and the public at large, but not by Vårdförbundet's bargaining counterpart nor the appointed mediators (ibid.: 121 and 144). Several of Vårdförbundet's members also took individual initiatives to press for higher salaries, but in each case without results. One example is when, during the strike, 200 nurses in intensive care collectively reported their employer - the city of Stockholm - to the authorized governmental body, the Office of the Equal Opportunities Ombudsman (JämO), for wage discrimination. The nurses' report lead to a process in the Labour Court. However, the case was not heard until 2001 (AD 2001 no. 76).

In a parallel case, a midwife in Örebro in central Sweden brought her employer to the Labour Court. The midwife claimed that her job was in allimportant aspects equal to the job of a male so-called clinical engineer with a considerably higher salary; thus, she argued, she was discriminated due to her sex. The Court's tried the case in 1996. However, the decision was that it was not proven that the midwife's work tasks were comparable to the clinical engineer's and accordingly it was not proven that she was discriminated. A majority of the Court's members made very high demands for evidence that the two jobs were actually equal. (AD 1996 no. 41). Despite the lack of success, the case was very important for the advantageous outcome of the local negotiations that ran parallel with the trial.

Furthermore, in 2001 the same midwife's - together with another midwife's work tasks were once again compared to those of a clinical engineer. This time, the Court found the tasks equal; but left it to the employer to justify the pay differences between the employees. To prove that differences in salary was not due to sex discrimination the employer made three main arguments: first, the employer claimed, the clinical engineer had higher market value; second, the two employees' salaries were regulated by two different collective agreements; and third, the man was older. Accordingly, the pay discrepancy was not discriminating (AD 2001 no. 13).

Even if the Labour Court may be criticized for making too low demands on the employer's evidence, the verdict was a leap forwards from a midwife's point of view. The Labour Court had established that a midwife's job was in principle equal to a clinical engineer, which was a very useful argument for salary negotiations to come. In another case in 2001, the Labour Court also found an intensive care nurse's work tasks equal to a clinical engineer. The pay discrepancy between 
the two was not found discriminating due to different market positions (AD 2001 no. 76).

To conclude, the combination of legal and individual means was certainly a new strategy. Individual strategies, based on legislation, showed in accordance with trade union strategies and demands to revaluate women's work tasks. The decentralization of collective bargaining had gone further in the public sector than in the private, and the rounds in 1995 speeded up the process (Elvander 1997). Accordingly, it was female employees in health care and nursing who showed most interest in new forms of pay setting in the following years. They saw a chance to upgrade their positions' status and with that to achieve better salaries (Fürst 1997: 327-30). It is interesting that this was a collective strategy; individualization of pay setting should promote salary raises generally for women in health care and nursing. The intention of individualizing and decentralizing pay setting was of course the opposite: to achieve wider wage spread and greater wage flexibility (cf. Bregn 1998: 306; Pontusson and Swenson 1996).

The collective agreement has never been systematically used as a means to achieve equality between the sexes (Dahlberg 1996). Furthermore, only very few cases regarding sex discrimination in working life, such as discriminatory wage setting, have been brought before the Labour Court. The Swedish Labour Court draw heavily on old preparatory works when interpreting the law against discrimination, despite several new clauses in the law of equality and the introduction of EC law from 1995 onwards. The Labour Court usually argues that the labour market parties' 'overall values' should decide the wage setting guidelines even at firm level; thus the company seldom has to prove that wage discrepancies between male and female employees are discriminating. The Labour Court has found it easy to accept the employers' argument that the male employees at large have a higher market value; male workers will find other firms which pay better if they do not get higher remuneration than their female colleagues (Fransson 2000: 378-81).

Hence, in practice it has shown to be difficult - in fact almost impossible - for women to gain from the combined strategy of individualization and legislation. Yet, the labour market parties have attempted to equalize opportunities for men and women to achieve the same pay for comparable work tasks. One means has been systematic job evaluation, developed by the parties in the public sector. However, the attempt led to conflicts between male and female occupational groups and as a result systematic job evaluation has only been sparsely used (ibid.: 417).

Furthermore, there have been 'gendered' conflicts within some unions in the 1990s. For instance, the Municipal Workers' Union (Kommunal) lost male members after the 1995 bargaining rounds when many firemen showed their dissatisfaction by leaving the union. 
Despite the difficulties for female workers to gain from the reformed legislation, many important issues - such as the principle of equal pay for equal work have no doubt been juridified. The introduction of the ban on discriminatory wage setting between men and women is in fact the most powerful government intervention ever in any Nordic industrial relations system (Fransson 2000: 28687). If the ban in coming years is shown to be more than just a paper tiger, it will most likely have an impact on the conflict pattern. For instance, is it possible to strike against discriminatory wages if the wage setting is already legally declared 'fair'? As many times previously in Nordic labour market legislation systems, a matter of interest has been turned into a matter of right, which in this case provides less room for collective and individual negotiations and which stresses the need for new strategies to be able to benefit from the new clauses.

However, even though the Nordic labour markets are highly juridified in international comparison, juridifying wage setting is actually an adaptation to EC law. Another, more famous, Nordic characteristic is the collective agreements' strong legal status; the normal government policy in Sweden has ever since the late 1930s been to leave wage setting in the main to the labour market parties. When unions such as Vårdförbundet attempt to use the new legislation as a strategic means they are in fact challenging the fundamental ideas of this free bargaining model. On the other hand, Vårdförbundet is aware of the problem and has made clear that it has no intention to systematically push issues to the Labour Court. According to the union's President Eva Fernvall (2001: 6), challenging and changing existing gender-discriminating values in the collective agreements is not promoted by turning pay discrepancies into a Court issue.

Nevertheless, it is clear that union activity is of great importance for the Labour Court's decisions in single cases regarding wage discrimination. If a union does not actively stress these items in firm-level negotiations, it is very unlikely that the Labour Court should judge a case against the employer (Fransson 2000: 380). Thus far, very few cases of wage discrimination have been brought to court; trade unions have not used collective agreements as a means for equality between the sexes.

\subsection{Concluding Discussion}

The aim of this chapter was to present evidence for different 'male' and 'female' industrial conflict patterns and bargaining strategies. The results are however provide no final answers, rather they should be understood as analytical and theoretical starting-points for further studies of a previously neglected field of research.

Our examples are too sparse to explain gender differences in labour market strategies/behaviour at large; since the labour division between the sexes has been and still is strongly marked, strictly occupational differences must first be 
more thoroughly researched. At the end of this section, we shall also point out a few trends in working life that might affect the gender differences in the near future.

We do believe however, that we have rather strong evidence of some important historical trends and turning-points, which must be seriously considered to understand why trade unions dominated by women or other organized groups of women have acted and act differently, regardless of which sector of the labour market we discuss.

Table 1 at the top of the next page briefly summarizes the main historical labour market strategies used by unions and other labour market organizations with a high proportion of women. The table includes both 'actual' strategies, that is, means consciously used to achieve certain goals, which usually are better bargaining outcomes, and 'possible' strategies, that is, forms of collective action that are not systematically used to bring pressure to bear on an employer, but which might open a strong collective potential under certain circumstances.

Table 9.1. Ways for women and organizations dominated by women to gain labour market influence: A historical overview.

\begin{tabular}{|l|l|}
\hline Period & Means \\
\hline Before the 1950s. & $\begin{array}{l}\text { Special trade unions for women; individual struggle for the right } \\
\text { to work and equal pay within the ordinary unions and political } \\
\text { organizations. }\end{array}$ \\
\hline $\begin{array}{l}\text { About the mid-1950s } \\
\text { to the late 1980s. }\end{array}$ & $\begin{array}{l}\text { Acceptance of the 'male' export industry as wage leading: the solidaristic } \\
\text { wage policy guaranteed that also women's occupations got real wage in- } \\
\text { creases during the heydays of the Swedish model. }\end{array}$ \\
\hline From about 1990 & $\begin{array}{l}\text { Use of new legislation, which is becoming more important than the } \\
\text { collective agreement when the industrial relations system decentralizes. } \\
\text { 'Collective individualisation': stressing individual qualifications, } \\
\text { that is, a high degree of formal competence, to increase salaries for } \\
\text { an occupational group at large. } \\
\text { Combining 1) and 2). }\end{array}$ \\
\hline
\end{tabular}

Women have always had a weaker position in the labour market than men had. Accordingly, unions dominated by women have been weaker than 'male' ones. Historically the demand for male workers has been great in the important competition-exposed export industries, while women have mainly been found in domestic market oriented industries or the public sector. Still, during the golden era of the Swedish model the solidaristic wage policy was a guarantee for continuous pay rises, even in the backward sectors of the economy. In return, the unions in sectors dominated by women had to offer 'loyalty' with the system. One of the 
purposes of the centralized bargaining system was to avoid wage-price spirals resulting from high pay raises in the profitable export industries. Thus, even workers in the lower paid industries had to accept the negotiating framework set by the export industries, since higher collective wage-claims in any single sector could risk the whole system.

When SAF's decentralization efforts were started in 1990, the 'loyalty' strategy was no longer possible to maintain. Even though the decentralization process was never taken as far as the SAF originally called for, the entire industrial relations system was in a state of flux. In fact, the system has been continuously challenged since the 1983 agreement between the Engineering Employers' Association and the Metal Workers' Union. Moreover, the 'female' public sector unions could no longer rely on solidarity from the unions in the private sector, a fact that complicated the situation in the late 1980s and early 1990s even further.

It is in this historical context we must view two of the most interesting new collective means in the 1990s, both of them actually radical breaks with the traditional thinking dominated by the solidaristic wage policy. The first one is to rely on legislation rather than collective bargaining in remuneration issues; the other is to use individual wage claims as a collective means, partly because of the new pay negotiating structure.

Despite the introduction of new labour market laws in the 1970s, such as the 1974 Employment Security Act (LAS) and the 1976 Codetermination Act (MBL), the core of the Swedish model has always been the collective agreement. Thus, the systematic use of the legislation against wage discrimination to increase women's salaries in the health sector no doubt is a new means. It was systematic in the sense that important unions sanctioned it, yet no union has of yet attempted to systematically take cases before the Labour Court.

The new strategy is not only a result of a transformation of the collective bargaining system; the shift was also facilitated by some general changes in the labour market legislation. Much like the other Nordic countries, Swedish labour law has moved towards a system where individual rights in working life is provided in laws on discrimination rather than in clauses in collective agreements. Since 1999, there are four such laws in the Swedish legislation (NumhauserHenning 2000). ${ }^{34}$

Furthermore, even if the strategy is new, the idea of it actually dates back to the late 1970s and early 1980s. Nordic students of law lively discussed possibilities to use legislation as a means for social change 'from below'; in other words, to rely on legislation not just as protection for people with small economic and societal power resources, but also as a means for single individuals, groups of individuals, alternative movements or a political opposition to achieve goals in

\footnotetext{
${ }^{34}$ It is interesting that it was the unions that supported this development, while the SAF opposed it. To achieve a flexible labour market, the SAF argued, it was necessary to deregulate all aspects of working life. Hence no new laws should be registered, not even to guarantee individual rights (Government Bill 1997/98 no. 177).
} 
the face of resistance (cf. Hydén 1982). By the early or mid-1980s the debate had already faded away. However, in light of the latest labour market development there is no doubt that the debate left an impression.

The evidence presented in this chapter shows that relying on legislation is not enough to achieve goals such as pay increases. Yet, in combination with other strategies it is an interesting means. One such strategy might be "collective individualism'. If, for instance, a single nurse claims that her work should be remunerated equal to a man with a comparable job, it is an individual strategy, but if a group of women simultaneously put the same claim, and if a union sanctions the claim, it is a collective strategy. Of course such a strategy is dependent on the use of legislation; otherwise there would be no norm of 'comparable jobs' to refer to and rely on. Yet, the few examples we have seen thus far show that it is very difficult in practice to combine the two strategies.

However, how gender-specific the new strategies will be is also a matter of change in work organization. As discussed in this chapter, many of the differences between men and women's conflict strategies depend on their different jobs; strike-prone men work in export-oriented industries while quiet women are found in menial service jobs and caring. It is not likely that the service industries - with the exception for highly qualified services such as IT, will receive the same market status as the export industries. The question is what will happen with the bargaining and conflict strategies if the work organizations converge. Traditionally, men - since they worked in manufacturing - produced goods or services and seldom had to meet the customer and found it easy to fight over wage-drift by threatening to stop the production. Women, on the other hand, met their customers or patients' face-to-face everyday; they were supposed to care for them and thus could not fight for wage-drift nor go on strike. Today, however, the trend, or at least the discursive trend is that people in services and caring 'produce' service or care, while workers in manufacturing must care for each individual customer due to 'customized production'. Moreover, occupations in manufacturing as a proportion of the total economy has been for decreasing decades; accordingly, today most men work in some form of service jobs.

A comparison of Australia, Japan and the USA show that front-line work that is, employees with direct contact with the customers, in the service sector have become more Fordist, despite claims of the opposite in the lean production influenced discourse. The comparison concluded that front-line work did not converge, on the contrary both national differences and discrepancies between different kinds of customer-oriented jobs remained (Frenkel et al. 1999). What is interesting from our point of view is that studies such as these of work organization support the diminishing demarcations between manufacturing and service occupations, but contrary to claims usually made by neo-liberals they do not arrive at some form of lean production or just-in-time-concept as the only answer. (cf. Traxler et al. 2001). The trends described also open up for new conflict pat- 
terns, were the differences between 'male' and 'female' occupations will either disappear or just be a matter of trade union traditions.

Convergence in work organization cannot explain whether differences between male longshoremen and female garment workers will remain or disappear; but from our perspective, it is an interesting issue for the future. Will it be easier for women to use the ban on wage discrimination due to sex as a collective strategy if more jobs converge?

This far, it is too early to talk of 'strategies', what we have seen is rather tactical solutions in specific situations. Yet, both the use of legislation as a means 'from below' and 'collective individualism' may easily develop into organized trade union strategies.

\section{References}

AD (1975) Arbetsdomstolens domar, no. 31. AD (1996) Arbetsdomstolens domar, no. 41. AD (2001) Arbetsdomstolens domar, no. 13. AD (2001) Arbetsdomstolens domar, no. 76. Alasilta-Hagman, Lea and Sinikka Pitko (1984) Naiset lakossa: Laupeudentyöstä palkkataisteluun, Helsinki: Tammi.

Bercusson, Brian and Linda Dickens (1996), Equal Opportunities and Collective Bargaining in Europe, 1: Defining the Issues, Loughlinstown, Dublin and Luxembourg: European Foundation for the Improvement of Living and Working Conditions and Office for Official Publications of the European Communities.

Bregn, Kirsten (1998), 'A Silent Revolution in Denmark's Public Sector Pay System', in Daniel Fleming, Pauli Kettunen, Henrik Søborg and Christer Thörnqvist (eds), Global Redifining of Working Life - A New Nordic Agenda for Competence and Participation? Copenhagen: Nordic Council of Ministers, pp. 293-319.

Bruun, Niklas (1990), 'Den nordiska modellen för facklig verksamhet', in Niklas Bruun, Boel Flodgren, Marit Halvorsen, Håkan Hydén and Ruth Nielsen (eds), Den nordiska modellen: Fackföreningarna och arbetsrätten i Norden - nu och i framtiden, Malmö: Liber, pp. 15-59.

Carpenter, Mick and Steve Jefferys (2000), Management, Work and Welfare in Western Europe: A Historical and Contemporary Analysis, Cheltenham and Northampton, MA: Edward Elgar.

Cederqvist, Jane (1980), Arbetare i strejk: Studier rörande arbetarnas politiska mobilisering under industrialismens genombrott: Stockholm 1850-1909,
Stockholm: Stockholmsmonografier No. 41. Clegg, Hugh A. (1976), Trade Unionism under Collective Bargaining: A Theory Based on Comparisons of Six Countries, Oxford: Blackwell.

Crouch, Colin and Alessandro Pizzorno (eds) (1978), The Resurgence of Class Conflict in Western Europe Since 1968, London: Macmillan.

Dahlberg, Anita (1996), 'Jämställdhet och kollektivavtal i EU: Studie av förhållandena i Sverige', Europeiska fonden för förbättring av levnads- och arbetsvillkoren, Working paper WP/96/59/SV.

Edwards, P.K. (1981), 'The Strike-proneness of British Manufacturing Establishments', British Journal of Industrial Relations, vol. 19, pp. 135-48.

Elvander, Nils (1997), 'The Swedish Bargaining System in the Melting Pot', in Nils Elvander and Bertil Holmlund, The Swedish Bargaining System in the Melting Pot: Institutions, Norms and Outcomes in the 1990s, Solna: Arbetslivsinstitutet, pp. 5-89.

Elvander, Nils (2002), 'The New Swedish Regime for Collective Bargaining and Conflict Resolution: A Comparative Perspective', European Journal of Industrial Relations, vol. 8, pp. 197-216.

Fernvall, Eva (2001), 'Ansvaret vilar på parterna', Lag \& Avtal, no. 2, p. 6.

Fransson, Susanne (2000), Lönediskriminering: En arbetsrättslig studie av könsdiskriminerande löneskillnader och konflikten mellan kollektivavtal och lag, Uppsala: Iustus.

Fransson, Susanne (2001), 'Collective and Individual Strategies - Women's and Men's Wages', in Kevät Nousiainen, Åsa Gunnarsson, Karin Lundström and Johanna Niemi- 
Kiesiläinen (eds), The Responsible Selves, Aldershot: Ashgate, pp. 195-221.

Frenkel, Stephen J., Marek Korczynski, Karen A. Shire and May Tam (1999), On the Front Line: Organization of Work in the Information Economy, Ithaca and London: Cornell University Press.

Fürst, Gunilla (1997), 'När kvinnor utvecklar nya lönemodeller', in Ledare, makt och kön: SOU, no. 135, pp. 327-46.

Government Bill (1997/98) no. 177.

Hydén, Håkan (ed.) (1982), Rätten som instrument för social förändring: $\mathrm{Om}$ legalstrategier, Lund: Liber.

Johansson, Klas and Jessika Grahm (1975), Vi är ju ändå bara städerskor, Göteborg: Barrikaden.

Julkunen, Raija and Liisa Rantalaiho (1993), 'Women on Strike - Nonexistent or Silenced?', in Pauli Kettunen (ed.), Strike and Social Change, Turku: Turku Provincial Museum Publication Series 7 , pp. 97-114.

Kjellberg, Anders (1999), 'Fagorganisering i Norge og Sverige i et internasjonalt perspektiv', in Arbejderhistorie 1999: Arbok for Arbeiderbevegelsens Arkiv og Bibliotek, Oslo: Arbeiderbevegelsens Arkiv og Bibliotek, pp. 57-83.

Knowles, K.G.J.C. (1952), Strikes: A Study in Industrial Conflict, Oxford: Blackwell.

Lane, Linda (1995), 'Unsuitable Work for Women? Women Employed as Trolley Conductors in Gothenburg, Sweden during World War II', Göteborg: BA thesis, Department of Economic History, Göteborg University.

Larsson, Lars-Evert (2001), 'Women's Wages within the Swedish Engineering Industry: A Historical Perspective', in Steve Jefferys, Frederik Mispelblom Beyer and Christer Thörnqvist (eds), European Working Lives: Continuities and Change in Management and Industrial Relations in France, Scandinavia and the U.K., Cheltenham and Northampton, MA: Edward Elgar, pp. 147-56.

Lundh, Christer (2002), Spelets regler: Institutioner och lönebildning på den svenska arbetsmarknaden 1850-2000, Stockholm: SNS.

Nilsson, Bengt (1996), Kvinnor i statens tjänst - Från biträden till tjänstemän: En aktörsinriktad undersökning av kvinnliga statstjänstemäns organisering, strategier och kamp under 1900-talets första hälft, Stockholm: Almqvist \& Wiksell International.
Norrbottens-Kuriren (1975), 22 April. Numhauser-Henning, Ann (ed.) (2000), Perspektiv på likabehandling och diskriminering: Antologi, Lund: Juristförlaget.

Olsen, Anne (1984), 'Kvindeligt Arbejderforbund - Mellem kvindekrav og partikrav', in Anne Margrete Berg, Lis Frost and Anne Olsen (eds) Kvindfolk: En danmarkshistorie fra 1600 til 1980, bind 2: 1900-1980, København: Gyldendal, pp. 227-42.

Olsson; Åke (1996), Nu eller aldrig! Om kvinnors kamp för rättvis lön, Stockholm: Federativ.

Östberg, Kjell (1997), Efter rösträtten: Kvinnornas utrymme efter det demokratiska genombrottet, Eslöv: Bruno Östlings bokförl. Symposion.

Overud, Johanna (2000), 'I beredskap med Fru Lojal: Husmodern i nationens tjänst 19391945', Arbetarhistoria, no. 3-4 (95-96), pp. 18-25.

Pontusson, Jonas and Peter Swenson (1996), 'Labor Markets, Production Strategies, and Wage Bargaining Institutions: The Swedish Employer Offensive in Comparative Perspective', Comparative Political Studies, vol. 29, pp. 223-50.

SAF (1990), Marknad och mångfald - SAFs program för 90-talet, Stockholm: SAF.

SAF-tidningen 1990 no. 33.

Shorter, Edward and Charles Tilly (1974), Strikes in France, 1830-1968, London: Cambridge University Press.

Statistics Sweden (2001), Lönestatistisk årsbok 2000 [Statistical Yearbook of Salaries and Wages 2000], Örebro: SCB.

Stokke, Torgeir Aarvaag and Christer Thörnqvist (2001), 'Strikes and Collective Bargaining in the Nordic Countries', European Journal of Industrial Relations, vol. 7, pp. 245-67.

Svensson, Lars (1996), 'Politics or Market Forces? The Determinants of the Relative Wage Movements of Female Industrial Workers in Sweden, 1960-1990', Scandinavian Economic History Review, vol. 44, pp. 161-82.

Swenson, Peter (1992), 'Union Politics, the Welfare State, and Intraclass Conflict in Sweden and Germany', in Miriam Golden and Jonas Pontusson (eds) Bargaining for Change: Union Politics in North America and Europe, Ithaca, N.Y. and London: Cornell University Press, pp. 45-76.

Sund, Bill (2002), 'Kvinnolön och institutionell makt: Lönefrågans institutioner och drivkrafter i ett historiskt och industriellt perspektiv (1940-1960)', in Josephine Askegård, Kjersti Bosdotter and Klaus 
Misgeld (eds), Kvinnor tar plats: Arbetsmarknad och industriarbete på 1900-talet, Stockholm: Arbetarrörelsens arkiv och bibliotek, pp. 101-17.

Thörnqvist, Christer (1994), Arbetarna lämnar fabriken: Strejkrörelser i Sverige under efterkrigstiden, deras bakgrund, förlopp och följder, Göteborg: Avhandlingar från historiska institutionen i Göteborg 9.

Thörnqvist, Christer (1998), 'Hur trivialiteter blir ideologi: Vilda strejker i Arbetsdomstolen under 20 år', Arkiv för studier $i$ arbetarrörelsens historia, no. 72 , pp. 39-63.

Thörnqvist, Christer (2001), 'What Do Strikes Strike? The Impact of Strikes and Lockouts in Sweden 1975-1990', in Steve Jefferys, Frederik Mispelblom Beyer and Christer Thörnqvist (eds), European Working Lives: Continuities and Change in Management and Industrial Relations in France, Scandinavia and the U.K., Cheltenham and Northampton, MA: Edward Elgar, pp. 157-71.

Tilly, Charles, Louise Tilly and Richard Tilly (1975), The Rebellious Century, 1830-1930, Cambridge, MA: Harvard University Press.

Traxler, Franz, Sabine Blaschke and Bernhard Kittel (2001), National Labour Relations in Internationalised Markets: A Comparative Study of Institutions, Change, and Performance, Oxford: Oxford University Press.

Waldemarson, Ylva (1996), 'Kön, klass och statens finanser - En historia om statligt arbetsgivarskap och statsanställda kvinnor 1870-1925', in Lasse Kvarnström, Ylwa Waldemarson and Klas Åmark (eds), I statens tjänst: Statlig arbetsgivarpolitik och fackliga strategier 1870-1930, Lund: Arkiv, pp. 111-243. 


\title{
10. Research and Politics - The NordFram Group 1989-2003
}

\author{
Bernt Schiller
}

There have been three research projects about the future of the Nordic model of industrial relations (NordFram). Nord stands for nordisk (Nordic) and Fram for framtid (future). The first project lasted from 1989 until February 1994. The final report (Schiller et al. 1993) synthesises all the results in different areas of the project. The report on the second NordFram project was published in December 1998 (Fleming et al. 1998) and the report on the third and last project is published here (in 2003).

The background to the first NordFram project is twofold. The first is related to the researchers' previous studies in industrial democracy in the Nordic countries. Probably, these previous studies can tell us something of the common values that underpin the project. These values, that underpinned research into industrial and economic democracy, have receded into the background while industrial relations generally have moved from questions of industrial and economic democracy to questions of how employees (not necessarily trade unions) in cooperation with employers could best develop their qualifications in order to make companies more globally competitive.

The second circumstance of importance is the return of the question of European integration to the centre of the political debate in the Nordic countries. In the mid-1980s, the challenge of European economic integration led to an increased co-operation in the North. Under pressure to become more attached to the Continent, the Nordic countries, as many times before, sought support and further co-operation among themselves.

The Nordic Council, meeting in Reykjavik in 1985, called for increased Nordic economic co-operation in general. The question of strengthening the position of employees in Nordic transnational companies was on the agenda. A committee of Nordic civil servants, representatives of business and labour was appointed. The committee proposed to give the employees in companies with operations in more than one Nordic country the right to meet for discussions among themselves and, for the purpose of acquiring more information, the right to meet with group management also. The employers' dissented to this proposal. Even the basic fact as to whether such corporate group consultation already existed was a 
matter of dispute between the Nordic employers' organizations and the confederations of labour. Our group already existed at this time and, perhaps because all the Nordic countries were represented in the group, it was called upon to investigate these factual conditions.

The very rapid development in European integration challenged the research group to broaden its mandate. The civil servants on the Nordic Council of Ministers' committee for working life and labour relations agreed to include in the terms of reference the general effect of internationalization on Nordic labour relations. This was quite logical, considering that Nordic company groups often had subsidiaries, not only in other Nordic countries and in Europe but worldwide. Widening the purpose of the project corresponded well to the goals of a Swedish research project on the effects of internationalization on Swedish labour market relations. The Swedish Work Environment Fund funded this project, which was based in Gothenburg. The congruence of the research goals made it possible to integrate the two projects and pool resources. This model, using additional national funding, has also been applied in the following NordFram projects. The reports from the first project were published when the question of membership in the European Union was at its height in 1994. They were given much attention by the Nordic Council of Ministers and presented at a large conference in Copenhagen.

At that time, the political tendency towards closer Nordic co-operation had already vanished. As often before the ties to the stronger European powers had proved to be stronger than Nordic cohesion. Sweden, Norway and Finland had negotiated separately with the European Union in order to acquire membership on as good terms as possible. Later, the energies of national elites were spent on trying to convince their reluctant people of the blessing of membership. After the referenda, in which Norway voted no, Nordic co-operation seemed to be relegated to Norway and the Nordic islands of the North Atlantic.

During the debate, those opposed to membership of the EU pointed to Nordic co-operation as an alternative to European integration. Our central question in the NordFram assignment became: How would the Nordic model of labour relations be influenced when, and if, they were confronted with the continental traditions that dominated EU? This question was politically loaded. Even the existence of a special Nordic model had been denied in public debate and by some researchers. In the reference group attached to the NordFram project the representative of the Swedish Employers' Confederation (SAF), in particular, denied the existence of a Nordic model. Our results, however, supplied good arguments, not only for the existence of a Nordic model of labour relations, but also viewed optimistically its future survival within the EU. We also presented evidence for the presence of special Nordic traditions of labour relations inside Nordic corporate groups.

It was felt that there was a strong need for this research to be continued. The feeling among the researchers was that we had just begun to penetrate a complex 
issue of immense importance which reached far beyond the more narrow issue related to the consequences of Nordic membership of the European Union. The wider context of internationalized production processes and their effects on participation and democratic communication in the workplace shifted the focus to concepts such as competence and qualifications and their importance in global competition. In this context, supra-national regulation of capital-labour relations was expected to be only a minor palliative to the overall requirement of efficiency. The challenge to Nordic industrial relations had not diminished. There was no absolute line between research and politics in the strive to protect or change existing Nordic labour relations. The task was as expressed in the last sentence of my introduction to our common report in 1994:

Research must critically penetrate history and the present in search for knowledge and self-awareness which might supply the small Nordic communities with tools to elaborate the distinctive features, which we admittedly cherish, and which so far have characterised both Nordic employers and employees (Schiller et al. 1993: vi).

Unlike the first project, the second project of the NordFram research group was not related to European integration. It was instead the perceived threat of globalization, which made it worthwhile to highlight those perspectives of the first project in which the focus was on the consequences of global organization of companies and their production. In the national discourses, both on employee influence and company efficiency, 'competence' tended to be regarded as an important asset in competitiveness, perhaps the most important in competition between national and regional economies. In addition, people who opposed the tendencies of social exclusion and marginalization, inherent in global deregulation of national protective rules, saw this as nearly the only way to defend the interests of labour. Our research was based on the assumption that there existed a special Nordic tradition of voluntary tripartite co-operation. The studies that had just been concluded had strengthened expectations of finding a special Nordic competitive advantage in competence development by co-operation and participation.

As in the first project concerning the Nordic model as a concept, theoretical studies were conducted on the concepts of competence and qualification. It became more and more obvious that the discourse of the Nordic model and the new challenges related to globalisation were central to the project. National identities and models are articulated under outside pressure. They are a form of reflexive thinking, comparing 'us' to others, and serve to help adapt to the primary demands of global market forces. Thus, the general premise of the project became that national strategies for competence development and national models of industrial relations, at least temporarily and superficially, help in adapting to global demands for competitiveness.

The underlying conditions in the globalization discourse consist of the undeniable spread and increase of foreign direct investments (FDI) by the multina- 
tionals made possible by the deregulation of the national economies of the West. The ideological superstructure is the theory of market economics. The development of social conditions in the industrialised world that make the ideas of deregulated markets acceptable, could be studied most clearly in the social democratic parties in the Nordic countries. Their leadership has become part of the national social élite. This development could best be described with the help of the central-periphery models in use during the 1970s. The model has both a geographical and social dimension. The urban social élite is the centre and the rural areas in the north of Scandinavia are the periphery. A map of voting on membership in the EU is a good illustration. North of a line Helsinki-Stockholm-Oslo there were solid No majorities and South of that line Yes majorities.

The social democratic parties, still to a large extent trade union parties, have certainly experienced the rift between the centre and the periphery. White- and blue-collar unions of export-oriented engineering industries tend to accept the implications of market ideas more readily than unions in lower paid domestic industries and services. In addition to this split in the labour movement, the individualism related to the market economy ideology weakens the collectivism of the trade union idea.

The fact that Sweden and Finland joined the EU is reflected in the continuation of studies of co-operation in transnational corporations. The question is no longer whether the Nordic model of labour relations will be threatened by EU directives but rather to what extent these directives will offer protection to Nordic labour interests and traditions of co-operation within Nordic corporate groups. Many researchers attach great importance to the 1994 Directive on European Works Councils (EWC). In my opinion, however, they underestimate the obvious influence of the principle of subsidiarity in the procedures, laid down in the text, of how to establish an EWC. It gives the directive a formal weakness favouring the dominance of the influence of employers.

In the third NordFram project, research has gone deeper into the functioning of Nordic Work Councils, especially Danish and, comparing the results with European investigations. Employers seem to adopt a more positive attitude when they have experience of the Work Councils. Many TNCs seems to find them useful instruments for developing their company groups' human resource management (HRM) strategy. This is natural when there already exists a tradition for cooperation, as is the case in several Nordic groups. Nevertheless, the third report stresses that the formal quality of the company's EWC agreement and the provision of the necessary material resources are important but not sufficient to make an EWC function in the long run. The trade union experience is more mixed. Generally speaking, the unions from the home country of the TNC have more influence than unions from subsidiaries. Such unions also enjoy the advantage of recourse to national structures of representation and could communicate with management in their mother tongue. Not unexpectedly, language and cultural 
problems are main problems for international labour co-operation. Another problem is that the EU directive is tailored to the manufacturing industry. It is poorly suited to service companies with a large number of small work places with many part-time employees.

The perspectives, theoretical and empirical, applied in the second and third projects demonstrate how the research is also influenced by the discourse on globalization and its consequences. How this discourse is generated and the power it exerts on working-life issues becomes an important question. The discourse not only deals with competitiveness, competence and innovation and the phenomenon of increasing reflexivity but is also part of the same phenomenon. The actors on the global scene are above all the transnational corporations. Perhaps the roots of the global discourse are to be found in the way these corporations develop and change. In the first project we viewed the transnational corporations, in spite of the increase in foreign direct investments, as still mainly nationally based. We thought that, generally, research and development resources would remain in the parent country. In hindsight this seems doubtful. The globalization of investment and trade leads to increased technological specialisation; a sort of 'hybridisation' might be the best way to describe this economic dynamism. In regard to labour relations, the Nordic transnationals studied in Malaysia and Singapore in the first project did not reveal specific Nordic traditions, except for the self-perceptions of some Nordic managers. Adaptation to local conditions, dominated by the 'big' American and Japanese companies, was the rule.

A later study of Danish groups in South East Asia reveals that their staff, down to middle management and technicians, could well have standards of knowledge and qualifications that are comparable to those of the staff of headquarters in Denmark. However, participation and increased influence does not follow from this. National industrial relations systems and local workplace traditions offer little resistance to the policies of the transnationals. Formal management-labour relations, but only inside the company are encouraged by, for example, the regimes of Malaysia and Singapore.

In the Nordic countries, the trade unions' freedom of manoeuvre is mainly defined by national industrial relations systems. To reverse this situation and to counter corporate groups' global HRM strategies, the unions need to turn back to the transnational actions and the ideology of solidarity of the First International of 1864. This, however, presupposes trade union systems of developed international communication and identification. Although, organized labour strives for regulation, through ILO conventions and EU directives, there is a stronger interest in using national frameworks of protection against globalization. The perspective of convergence of policies dealt with in the third NordFram project is more valid for the HRM systems used by the TNCs in order to streamline the quality of production and services. As a consequence of this convergence, labour, regarded as an investment in human capital, demands social responsibility in the behaviour 
of the TNC. This is something the major Japanese corporations have long applied. The globalization of media that exposes some TNCs to the wrath of consumers world-wide, may contribute to social responsibility in Western TNCs.

The scope of analysis in the particular studies of NordFram 2 and 3 was more limited. Instead of trying to find definitive answers to the overall question of the relation between competitive advantage, competence and participation in the Nordic countries, the researchers confined themselves to some more limited problems of working life raised by globalization. The change of agenda in the public discussion on working life is indeed illustrated by the move away from the subjects of industrial and economic democracy in the previous research. Studies were carried out on global strategies for human resource management, demands for labour flexibility regarding working time, salaries and employment conditions.

In the Danish public sector, payment systems were found to have changed from central and collective agreements to decentralized and individual systems. The Introduction of supplements to pay, based on individual assessment, has become an important feature. Generally, these new tendencies, accepted by many employees, work in the direction of reducing the collective influence of unions.

In Sweden too, from about 1990, the industrial relations system has become more decentralized. The wage policy based on solidarity up until the 1970s meant that the strong unions in the export industries were held back in favour of weaker unions in domestic industries and services that had many female employees. Since this solidarity has gone, trade unions dominated by women have begun to use new legislation against wage discrimination and to take employers to the labour court. Swedish labour law, as in the other Nordic countries, has moved towards a system whereby individual rights are provided for in legislation against discrimination rather than in collective agreements.

Studies were also carried out on the effects of the tendency towards more flexible working time. It was found that flexibility in the number of employees, numerical flexibility, does not always lead to a division into a core of multiskilled workers and a periphery of low-skilled workers. However, the long-term effect is insecurity for individuals working on contracts that seek to be flexible. To think that temporary workers wander from employer to employer is an illusion. Generally, they are heavily dependent on one employer. However, the split into two categories of employees with different degree of job security affects the cohesion of the workforce and makes union action more difficult.

Finally, there are some possibly interesting general features on the organization of work within the project. We have spent the limited resources available primarily on seminars for discussion of common concepts and theories. Some special money has from time to time been earmarked for in-depth analysis of concepts such as the Nordic model, competence and qualification, diversity and convergence. One person has carried the burden of trying to coordinate the indi- 
vidual (and individualist) researchers. To achieve that, there have been regular telephone conferences that had to be timed to three time zones round the globe.

Viewing the content of the three reports, my impression is that the first project was more integrated than the two following. This was probably due to the way the terms of reference of the task given by the Nordic Council of Ministers. The two following projects have been more ordinary research projects with a considerable freedom to apply common concepts and theories to the individual interests of the researcher.

The researchers not only represent all the Nordic countries; they also represent several different disciplines including a philosopher together with historians and social scientists from Bergen with a special interest in industrial structure as well as work place organization. Conceptual studies of the Nordic model as well as sociological studies of competence and qualification have been carried out in Iceland. Historians and students of law in Gothenburg and Helsinki, but also social scientists in Roskilde, have studied labour market regulation through collective agreements and legislation, both in the Nordic countries and internationally. A special team of lawyers has compared Nordic legislation with that of the European Union, Germany and France. The project has had a multidisciplinary, but also an interdisciplinary character.

Looking at the long list of researchers, who over the years have taken part in NordFram and remembering all the people at trade unions, employers organizations and other institutions, who in one way or another have been in contact with the project, it is possible that the project itself has contributed to Nordic cohesion and network building. At the same time, the project has generated a great number of contacts in Western Europe, North America and South East Asia.

\section{References}

Fleming, Daniel, Pauli Kettunen, Henrik Søborg and Christer Thörnqvist (eds), Global Redefining of Working Life - A New Nordic Agenda for Competence and Participation? Nordic Council of Ministers, Nord 1998:12
Schiller, Bernt, Knut Venneslan, Hans-Jakob Ågotnes, Niklas Bruun, Ruth Nielsen and Dennis Töllborg, The Future of the Nordic Model of LabourRelations, Copenhagen: Nordic Council of Ministers, Nord 1993:36. 



\section{Contributors}

\author{
Monica Andersson \\ Ph.D student at the Department of \\ Work Science, Göteborg University \\ and former HRM practitioner at \\ Volvo and SCA. \\ (monica.andersson@av.gu.se)
}

Kirsten Bregn

Associate Professor, Ph.D. Dept. of Social Sciences, Roskilde University. (bregn@ruc.dk)

Daniel Fleming

Associate Professor. International Development Studies, Roskilde University. (fleming@ruc.dk)

Susanne Fransson

Doctor of Laws. Senior researcher and lecturer, University College

Trollhättan-Uddevalla

(Susanne.Fransson@htu.se)

\section{Kristina Håkansson}

$\mathrm{Ph} . D$. Senior researcher and lecturer in work science and sociology,

Department of Work Science,

Göteborg University.

(kristina.hakansson@av.gu.se)

\section{Jan Heiret}

Dr. Philos. Associate Professor, Dept. of History, University of Bergen. (jan.heiret@rokkan.uib.no)
Tommy Isidorsson

Ph.D. Senior researcher, Department of Work Science, Göteborg University (Tommy.Isidorsson@av.gu.se)

\section{Herman Knudsen}

Senior lecturer at the Department of Social Development and Planning, Aalborg University (hk@plan.auc.dk)

Bernt Schiller

Professor of History, Department of Work Science, Göteborg University (bernt.schiller@aiv.gu.se)

\section{Henrik Søborg}

Associate Professor. International Development Studies, Roskilde University (henriks@ ruc.dk)

\section{Annette Thörnquist}

Assistant Professor, National Institute of Working Life, Uppsala

(annette.thornquist@

arbetslivsinstitutet.se)

Christer Thörnqvist

$\mathrm{Ph}$.D. Senior researcher and lecturer, Department of Work Science, Göteborg University and University College Trollhättan-Uddevalla. christer.thornqvist@av.gu.se 
Obtain your Nord and TemaNord reports from:

\begin{tabular}{|c|c|c|}
\hline BELGIUM \& LUXEMBOURG & FRANCE & ROMANIA \\
\hline Jean de Lannoy & Librairie LAVOISIER & Euromedia s.r.l. \\
\hline Avenue du Roi, 202, 1190 Brussels & 14 , rue de Provigny & Str Dionisie Lupu nr 65, 70184 Bucuresti \\
\hline \multirow{2}{*}{$\begin{array}{l}\text { Tel +32 (0)2 } 5385169 \text { Fax +32 (0)2 } 5380841 \\
\text { jean.de.lannoy@euronet.be }\end{array}$} & 94236 Cachan Cedex & Tel + 4016140664 Fax + 4013129646 \\
\hline & $\begin{array}{l}\text { Tel +33 (1) } 47406700 \text { Fax +33 (1) } 47406702 \\
\text { group @lavoisier.fr }\end{array}$ & SWEDEN \\
\hline CANADA & www.lavoisier.fr & Fritzes \\
\hline Renouf Publishing Company Ltd & & Kundtservice, 10647 Stockholm \\
\hline 5369 Canotek Road, Ottawa, Ontario K1J 9J3 & GERMANY & Tel +46 (0)8 $6909190 \mathrm{Fax}+46(0) 86909191$ \\
\hline Tel + $1(613) 7452665$ & UNO-Verlag GmbH & order.fritzes@nj.se \\
\hline $\mathrm{Fax}+1(613) 7457660$ & Am Hofgarten 10, 53113 Bonn & www.fritzes.se \\
\hline order.dept@renoufbooks.com & Tel +49 (0)228949020 & \\
\hline www.renoufbooks.com & $\begin{array}{l}\text { Fax }+49(0) 2289490222 \\
\text { info@uno-verlag.de }\end{array}$ & $\begin{array}{l}\text { THE NETHERLANDS } \\
\text { De Lindeboom Internationale Publikaties b.v. }\end{array}$ \\
\hline $\begin{array}{l}\text { CHINA } \\
\text { CNPIEC }\end{array}$ & www.uno-verlag.de & $\begin{array}{l}\text { Postbus 202, } 7480 \text { AE Haaksbergen } \\
\text { Tel +31 (053) } 5740004\end{array}$ \\
\hline Europe Division 16 Gongti East Road & HUNGARY & Fax +31 (053) 5729296 \\
\hline P.O. Box 88, Beijing & Euro Info Service & books@delindeboom.com \\
\hline Tel +86105066 688-8 Fax +86 105063101 & $\begin{array}{l}\text { PO Box 1039, } 1245 \text { Budapest } \\
\text { Tel +36 (1) } 3292487 \text { Fax +36 (1) } 3492053\end{array}$ & www.delindeboom.com \\
\hline DENMARK & euroinfo@euroinfo.hu & UNITED KINGDOM \\
\hline Svensk-Norsk Bogimport A/S & & The Stationery Office \\
\hline Esplanaden 8 B, 1263 København K & ICELAND & P.O. Box 276, London SW8 5DT \\
\hline Tel +45 331426 66 Fax +45 33143588 & Mál og Menning & Tel +44 $8706005522 \mathrm{Fax}+448706005533$ \\
\hline snb@bog.dk & Laugavegi 18, 101 Reykjavik & customer.services@tso.co.uk \\
\hline www.snbog.dk & $\begin{array}{l}\text { Tel +354 (9)515 } 2500 \text { Fax +354 (9)515 } 2505 \\
\text { verslun@ mm.is }\end{array}$ & www.tso.co.uk/bookshop \\
\hline ESTLAND & & USA \\
\hline Astro Raamatud AS & LATVIA & Bernan \\
\hline Pärnu mnt 142, 11317 Tallinn & Jana Rozes Gramàtnica & 4611-F Assembly Drive \\
\hline Tel +3726548485 Fax +3726548475 & Kr. Barona iela 5, 1011 Riga & Lanham MD 20706-4391 \\
\hline book@astro.ee & Tel +371 (0)2 $284288 \mathrm{Fax}+3717370922$ & $\begin{array}{l}\text { Tel +1 (301) } 4597666 \mathrm{Fax}+1 \text { (301) } 4590056 \\
\text { query@bernan.com }\end{array}$ \\
\hline FAROE ISLANDS & LITHUANIA & www.bernan.com \\
\hline H.N. Jacobsens Bókahandil & Penki Kontinentai & \\
\hline Postboks 55, 110 Tórshavn & A. Stulginskio 5, 2001 Vilnius & ÅLAND \\
\hline \multirow[t]{2}{*}{$\begin{array}{l}\text { Tel +298 } 311036 \text { Fax +298 } 317873 \\
\text { hnj-bokh@post.olivant.fo }\end{array}$} & $\begin{array}{l}\text { Tel +370 (5) } 2664540 \text { Fax +370 (5) } 2664565 \\
\text { books@ @ ci.lt }\end{array}$ & $\begin{array}{l}\text { Lisco bok- och pappershandel } \\
\text { Skarpansvägen } 25, \text { Box } 8\end{array}$ \\
\hline & www.books.It & 22101 Mariehamn \\
\hline \multirow{7}{*}{$\begin{array}{l}\text { FINLAND } \\
\text { Akademiska Bokhandeln } \\
\text { PB 128, Centralgatan 1,00101 Helsingfors } \\
\text { Tel +358 } 912141 \\
\text { akatilaus@ akateeminen.com } \\
\text { www.akateeminen.com }\end{array}$} & & Tel +358 (0)1817177 Fax +358 (0)1819771 \\
\hline & NORWAY & info@lisco.fi \\
\hline & Akademika A/S & \\
\hline & Postboks 84 Blindern, 0314 Oslo & \\
\hline & Tel +4722853030 Fax +4722853080 & \\
\hline & bloken@sio.uio.no & \\
\hline & www.akademika.no & \\
\hline
\end{tabular}

